\title{
On the relationship between molecular weight and anticoagulant activity of heparins : in vitro and ex vivo studies
}

Citation for published version (APA):

Bendetowicz, A. V. (1992). On the relationship between molecular weight and anticoagulant activity of heparins : in vitro and ex vivo studies. [Doctoral Thesis, Maastricht University]. Rijksuniversiteit Limburg. https://doi.org/10.26481/dis.19920327ab

Document status and date:

Published: 01/01/1992

DOI:

10.26481/dis.19920327ab

Document Version:

Publisher's PDF, also known as Version of record

Please check the document version of this publication:

- A submitted manuscript is the version of the article upon submission and before peer-review. There can be important differences between the submitted version and the official published version of record.

People interested in the research are advised to contact the author for the final version of the publication, or visit the DOI to the publisher's website.

- The final author version and the galley proof are versions of the publication after peer review.

- The final published version features the final layout of the paper including the volume, issue and page numbers.

Link to publication

\footnotetext{
General rights rights.

- You may freely distribute the URL identifying the publication in the public portal. please follow below link for the End User Agreement:

www.umlib.nl/taverne-license

Take down policy

If you believe that this document breaches copyright please contact us at:

repository@maastrichtuniversity.nl

providing details and we will investigate your claim.
}

Copyright and moral rights for the publications made accessible in the public portal are retained by the authors and/or other copyright owners and it is a condition of accessing publications that users recognise and abide by the legal requirements associated with these

- Users may download and print one copy of any publication from the public portal for the purpose of private study or research.

- You may not further distribute the material or use it for any profit-making activity or commercial gain

If the publication is distributed under the terms of Article $25 \mathrm{fa}$ of the Dutch Copyright Act, indicated by the "Taverne" license above, 
On the Relationship Between Molecular Weight and Anticoagulant Activity of Heparins

In Vitro and Ex Vivo Studies 
Cover Illustration by:

Paul Logister (with many thanks to Gustavo Epelman)

CIP-DATA KONINKLIJKE BIBLIOTHEEK, DEN HAAG

Bendetowicz, Ana Victoria

On the relationship between molecular weight and

anticoagulant activity of heparins : in vitro and ex vivo

studies / Ana Victoria Bendetowicz; [ill. by the

author].- Maastricht : Datawyse. - Ill.

Thesis Maastricht. With ref. - With summary in Spanish

and Dutch.

ISBN 90-5291-081-2

NUGI 743

Subject headings: heparins / blood coagulation 


\title{
On the Relationship Between Molecular Weight and Anticoagulant Activity of Heparins \\ In Vitro and Ex Vivo Studies
}

\author{
Proefschrift
}

ter verkrijging van de graad van doctor aan de

Rijksuniversiteit Limburg te Maastricht, op gezag van de Rector Magnificus, Prof. Mr. M.J. Cohen, volgens het besluit van het College van Dekanen, in het openbaar

te verdedigen op vrijdag, 27 maart 1992 om 16.00 uur

door

Ana Victoria Bendetowicz

geboren te Córdoba, Argentinië 
Promotor: $\quad$ Prof. Dr. H.C. Hemker

Co-promotor: Dr. S. Béguin

Beoordelingscommissie:

Prof. Dr. P.J. Brombacher, voorzitter (Rijksuniversiteit Limburg)

Prof. Dr. J.W. ten Cate (Universiteit van Amsterdam)

Prof. Dr. O.C.K.M. Penn (Rijksuniversiteit Limburg)

Prof. Dr. M. Samama (Université P. et M. Curie, Paris VI)

Prof. Dr. H.A.J. Struijker Boudier (Rijksuniversiteit Limburg)

The cost of this disseration was supported by Rhône-Poulenc Rorer. 


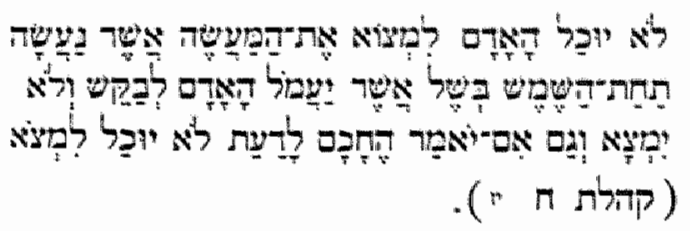

Man cannot guess the events that occur... even

if a sage should think to discover them, he would not be able to guess them. (Ecclesiastes 8,17 ) 



\section{CONTENTS}

$\begin{array}{lr}\text { Abbreviations: } & 8\end{array}$

Chapter 1: General Introduction 9

Chapter 2: On the Relationship Between Molecular Weight and Anticoagulant Activity of a Low Molecular Weight Heparin (enoxaparin). Accepted in Thrombosis and Haemostasis.

Chapter 3: The Heparin-Dependent Modulation of Factor X Activation in Plasma. Abstract in Thrombosis and Haemostasis 65 (6): 1312; 1991.

Chapter 4: The Determination of the Levels of Unfractionated Heparin and Low Molecular Weight Heparins in Plasma. Their Effect on Thrombin Mediated Feedback Reactions in vivo. Preliminary Results on Samples After Subcutaneous Injection. Haemostasis vol. 21, $N^{\circ}$ 4: 258-272; 1991.

Chapter 5: The Effect of Subcutaneous Injection of Unfractionated and Low Molecular Weight Heparin on Thrombin Generation in Platelet Poor Plasma. A Study in Human Volunteers.

Chapter 6: The Effect of Subcutaneous Injection of Unfractionated and Low Molecular Weight Heparin on Thrombin Generation in Platelet Rich Plasma. A Study in Human Volunteers.

Chapter 7: General Discussion

Summary and Conclusions

Resumen y Conclusiones

Samenvatting en Conclusies

Acknowledgments 


\section{ABBREVATIONS}

$\alpha_{2}$ M: $\alpha_{2}$-Macroglobulin

ACLM: Above Critical Chainlength of 18 Saccharides Material Anti-IIa: Antithrombin Activity

Anti-Xa: Antifactor Xa activity

AT III: Antithrombin III

APTT: Activated Partial Thromboplastin Time

BCLM: Below Critical Chainlength of 18 Saccharides Material

HAM: AT III- High Affinity Material

HCo II: Heparin Cofactor II

$\mathrm{kg}$ b.w.: $\mathrm{kg}$ of Body Weight

LA: AT III-Low Affinity Fraction

LMWH: Low Molecular Weight Heparin(s)

PF 4: Platelet Factor 4

PPP: Platelet Poor Plasma

PRP: Platelet Rich Plasma

RVV: Russell's Viper Venom

SA: Specific Activity

s.c.: Subcutaneous

SIU: Standard-Independent Unit

TF: Tissue Factor

TFPI: Tissue Factor Pathway Inhibitor

UFH: Unfractionated Heparin 


\section{GENERAL INTRODUCTION}

In this chapter we give a short overview of the history of the discovery of heparin, its biosynthesis and its modulator role in coagulation. We will end the general introduction with a description of the experimental chapters of this thesis.

\section{HEPARIN: ALMOST A CENTURY OF EXPERIENCE}

At the end of the XIX ${ }^{\text {th }}$ century, the first steps were taken to recognize the elements of blood coagulation: Hammersten described fibrinogen in 1877 (1), and Pekelharing isolated "prothrombin" in 1894 (2). The well known coagulation scheme of Morawitz (3) is based on his findings and those of Alexander Schmidt (4).

Also, the existence of anticoagulant substances was admitted: Pavlov in 1887 described that an aqueous tissue extract showed anticoagulant activity (5).

In 1911 Howell published his "Theory of blood coagulation". The message was that "activation does not occur in circulating blood because an inhibitory substance (antiprothrombin) is present in amounts sufficient to prevent the reaction;... the presence of thromboplastic substance neutralizes the action of the inhibitory substance, and permits the calcium to react with the prothrombin to form thrombin".

In 1916, Jay Mc Lean, a student at Howell's laboratory, was launched on a study of procoagulant substances from the brain. He extended his work to tissues such as liver, and heart. He noticed that the "thromboplastic activity" of a non-aqueous liver extract (named heparphosphatides) decreased upon storage. In addition, he observed: "various batches retard slightly the coagulation" (6). Howell identified this substance, "heparin", with the "circulating antiprothrombin" of his theory. Anyhow, "heparin" was obtained "by extracting the dried tissue with ether", being therefore a (phospho)lipidic entity which lacks a relationship with what we know today as heparin. Indeed, some phospholipids possess anticoagulant activity (7).

Despite a wrong premise, Howell had an insight with respect to the possible future use as an anticoagulant of the "new substance" discovered at his laboratory (8). Later, in 1922 the same Howell described under the same name "heparin" a different anticoagulant material prepared from dog liver by aqueous extraction and subsequent acetone precipitation which might have contained real heparin (9). A detailed review of these events 
was given by Verstraete (10).

Jacques in 1978 (11) and in 1987 (12), pointed out the difficulties entailed by Howell's "antiprothrombin" concept, and its monopoly position in the american clotting physiology during the first part of this century. Most of the medical schools in America followed this false theory for years, and the publication of several works that did not verify Howell's theory, was seriously delayed. Baylis, in 1915 (13), and Reed in 1925 (14) suggested that heparin could be used in the prevention of thrombosis, as well as in the prevention of thrombus growth.

Heparin obtained its name from its origin in liver (15). Charles and Scott demonstrated that heparin was present in various other organs (1618). In 1933 they found that heparin contains nitrogen. They could not demonstrate the presence of uronic acid, probably because quantitative tests were not available, and a qualitative test (naphthoresorcin) gave a negative result. They studied various tissue extractions and established that beef lung was an adequate source. From lung they prepared a large amount to allow clinical use.

In 1935, Jorpes (19) demonstrated that the metachromatic staining of mast cells discovered by Ehrlich in 1877 was due to the storage of heparin. $\mathrm{He}$ also reported that heparin contains glucosamine, and that the molar ratio to uronic acid was $1: 1$. He suggested that the key to the problem about heparin structure was the analysis of the ash: Indeed, this analysis allowed to demonstrate that heparin contains sulfate. A detailed review of the chemical characterization of heparin in the 1930's was given by Rodén and Feingold in 1985 (20).

The earlier heparin preparations were studied in thrombosis models in dogs (21). This material was also used in transfused patients, but the side effects were rather important (22). In 1936, a more purified heparin was administrated intravenously by Hedenious and Willander to themselves (23). They determined that the amount of heparin necessary for the anticoagulation of a human being was $100 \mathrm{mg}$ (1).

This was what we call now the "pre-industrial" stage of heparin. Later, a pharmaceutical company showed interest in the project and started to produce heparin on a larger scale (10).

In 1939 it was demonstrated that heparin can only be effective if a plasma component is present (24). This component, antithrombin III, was isolated and purified from plasma in 1968 by Abildgaard (25).

Heparin is one of the most common drugs used in the prevention of thrombosis. In the 1970 's, several investigations contributed to the knowledge of the structure-activity relationship of heparin. It has been possible to obtain well characterized fragments and fractions of heparin. In 1976 Johnson et al (26), showed that a low molecular weight heparin (LMWH) produced by gel filtration, when given subcutaneously to man 
produced higher blood levels (anti-Xa clotting assay) than was achieved with standard heparin. This observation, together with favourable results on thrombosis prevention in animals obtained with this material, lead to the hypothesis that heparins owe their antithrombotic activity to their anti-factor $\mathrm{Xa}$ activity (27). In addition, it has been suggested that heparins with high antithrombin activity would favorize the risk of bleeding (28). Because LMWH have lower effect on the APTT than unfractionated heparin, it was hoped that LMWH might have reduced bleeding risk. These conceptions were at the origin of the industrial production of low molecular weight heparins.

\section{BIOSYNTHESIS AND STRUCTURE OF HEPARIN}

Heparin is synthetized as a proteoglycan in the mast cells of connective tissue (29). Those cells are widely distributed throughout the organism, and they tend to be localized in close contact with capillary walls. Formation of the polysaccharide. Heparin is formed around a polypeptidic core. This, (MW 17,000 D) contains a region that is constituted by serine and glycine residues. The formation of the polysaccharidic chain is supposed to start after the xylosilation of the serine residues (30). The next step is the transfer, to the first xylose, of additional sugars from UDP-sugar precursors, to elongate the chain (30). Among these, units of glucuronic acid (GlcA) and N-acetyl-glucosamine (GlnNac), are added to the non reducing extremity of this nascent polysaccharide. The sequence hexuronic acid-glucosamine is a consequence of the substrate specificity of the biosynthetic glycosyltransferases (31 and references therein). The polysaccharide chains formed have a MW between 60,000 and 100,000 D. Subsequently, the proteoglycan passes through several distinct groups of membrane-bound enzymes, which are arranged in complexes or "stations". In a sequencial order, the chains are subject to $\mathrm{N}$-deacetilation of the $\mathrm{N}$-acetylglucosamine residues, $N$-sulfation of the resulting free amino groups, conversion of the D-GlcA to L-Iduronic acid (L-IdoA) by epimerization at C-5, and O-sulfation at $\mathrm{C}-2$ of IdoA and at $\mathrm{C}-6$ of GicN units (figure 1). The modification of an individual proteoglycan precursor molecule is a rapid process which is completed within less than one minute (31, 32 and references therein).

The sites where these reactions take place, are determined by the substrate specificity of the relevant enzymatic systems. This enzymatic process is not complete, and in addition to these major reactions, a number of minor reactions (O-sulfation) will occur (30). Finally, within the hours after the biosynthesis, the polysaccharide chain is degraded by an endoglycosidase (endo-B-glucuronidase), to fragments with MW between 

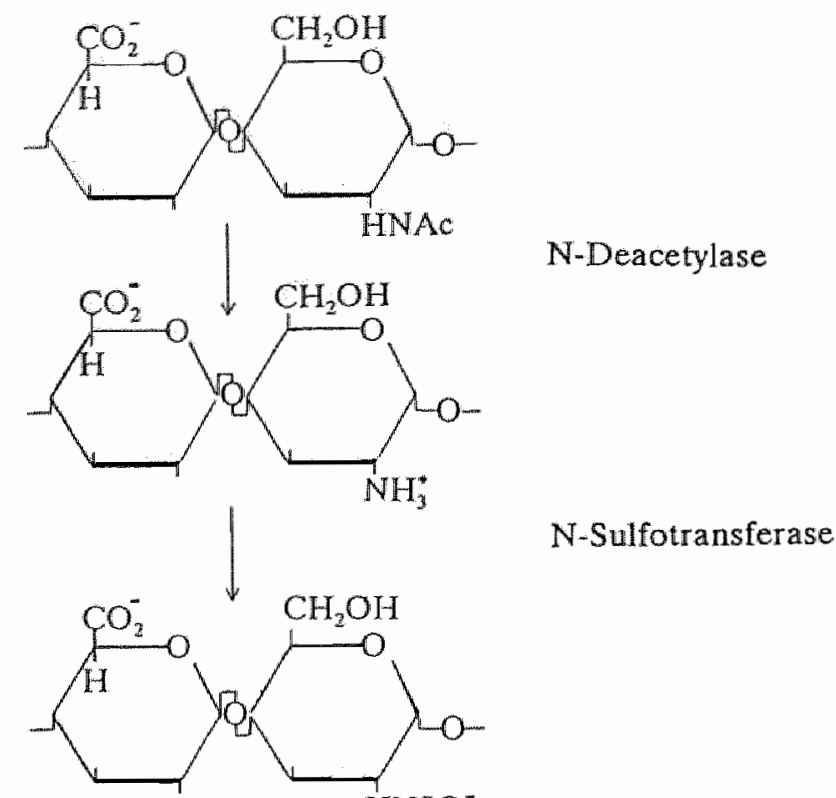

Hexuronosyl-C5-epimerase

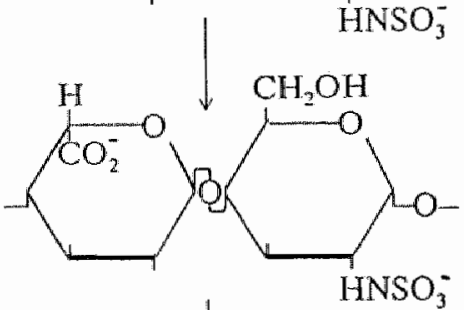

O-Sulfotransferase
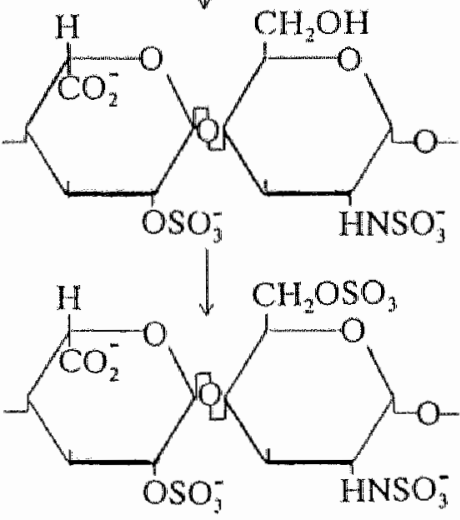

O-Sulfotransferase

Figure 1

Sequence of Polymer Modification Reactions Involved in the Biosynthesis of Heparin. From ref. 30 . 
5,000 and 30,000 D. Since cleavable glycosidic bonds are unevenly distributed along the polysaccharide chains, the resulting product is a pool of chains of different length (33).

Heparins used for therapeutic aims are sequences of glycosaminoglycans, and contain a wide variation of regular combinations of uronic acid (D-glucuronic or L-iduronic) and $\mathrm{N}$-sulfated or $\mathrm{N}$-acetylated glucosamine (34).

The post-transductional modification reactions, generate non repetitive-irregular regions. This explains why heparins are very heterogeneous molecules. These irregular regions, by interaction with macromolecules, are the mediators of the biological functions of glycosaminoglycans $(32,35)$. Mechanistic constraints imposed during the biosynthesis favor certain combinations of neighboring monosaccharide units and thus limit the heterogeneity of heparin (32). These non-variable regions inserted between the variable regions provide the structural basis for the interaction of heparin with AT III (30). The best known example is the interaction of AT III with a specific pentasaccharide region (figure 2) $(29,30,36-38)$.

Due to the sequential, step-wise characteristics of the polymer modification, such a pentasaccharide sequence is distributed along the polysaccharide in a highly non-random way, in minor proportion of the chains $(30,32,39,40)$.

Investigations done by the group of $\mathrm{J}$. Choay permitted to produce the pentasaccharide by organic synthesis (41; figure 2). The 3-O-sulfate, and the 6-O-sulfate groups contained in the $\mathrm{N}$-acetyl-glucosamine unit of the pentasaccharide are essential for its binding with AT III (42-44).

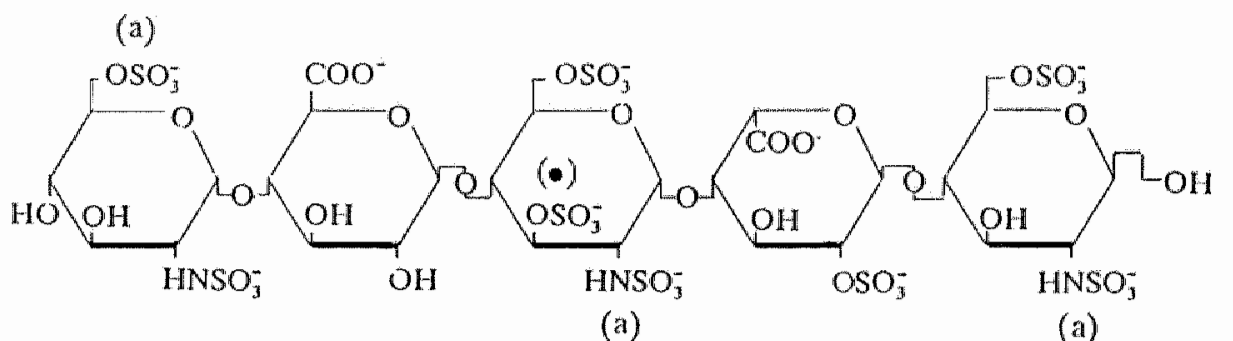

Figure 2.

Structure of the AT III Binding Region on Heparin. The group 3-O-sulfate, indicated with (๑), is unique to the antithrombin-binding region of the heparin molecule. In addition, the three sulfate groups indicated by (a) have been proven to be essential to the high-affinity binding of AT III. Adapted from refs. 31 and 41. 


\section{PROPERTIES OF HEPARIN}

The essential property of heparin, to be discussed extensively later, is the enhancement of the AT III dependent inactivation of clotting proteases. Heparin is a linear anionic polyelectrolyte. It carries considerable electronegative charge. This characteristic permits to heparin to form aspecific complexes with positively charged regions of proteins. Heparins complex with inorganic ions, alkylamines, alkaloids, biogenic amines, quaternary ammonium drugs. In vivo, it increases the negative electric potential of the vascular wall, mobilizes eosinophyls, activates macrophages; produces lymphocytosis, increases migration of B lymphocytes but inhibits $T$ and $B$ lymphocytes. Heparin also stimulates the activity of lipoprotein lipase, lecithinase, diamine oxidase, acid ribonuclease and Bglycerophosphatase in circulation. In addition, marked protective actions are observed (in animals) against toxic drugs (curare, digitalis, others). The modulatory effect of heparin on sensitivity reactions has also been described (complement, antigen-antibody reactions, glomerulonephritis). For a review see Jacques $(45,46)$. Heparin is also known to play a role, at least in vitro, in the regulation of plasminogenolysis mediated by pro-urokinase (45-53).

\section{HEPARIN FRACTIONS AND FRAGMENTS}

Fractions of heparin are obtained from the polysaccharide by solvent extraction or molecular filtration. Fragments are produced by chemical cleavage of the crude heparin before physical separation. The methods to prepare low molecular weight heparins (LMWH) differ from one pharmaceutical firm to another. A comparison of various methods used for the preparation of LMWH, and the MW of the final product is shown in table 1. Ideally, the structure of LMWH is the same as in the original polysaccharide. However, cleavage may occasionaly occur at the level of the active site for antithrombin ( 33 and refs. therein). Cleavage of heparin with radical-catalyzed depolymerization with $\mathrm{H}_{2} \mathrm{O}_{2}$ results in the production of fragments with a continuous distribution of the molecular weights. This is not the case when fragmentation is done with $\mathrm{HNO}_{2}$ or heparinase.

Most heparins are strongly polydisperse, hence there is a substantial difference between the weight average molecular weight (the $\mathrm{MW}$ with equal mass of material above and below), and the number average molecular weight (the MW with equal number of molecules above and below). Only if a heparin fraction is monodisperse (as, i.e. those used in chapter 2), the number-average and the weight-average will coincide. Best is to be 
informed about the molecular distribution in a heparin preparation, i.e. from HPLC measurements.

Table 1. Characteristics of Some Low Molecular Weight Heparins

\begin{tabular}{|c|c|c|c|}
\hline LMWH & MW & $\begin{array}{l}\text { Mo } \\
1 \% \\
250\end{array}$ & $\begin{array}{l}\text { Distr. Method for the Preparation } \\
500\end{array}$ \\
\hline CY $222 *$ & 3400 & 68 & Exhaustive nitrous acid depolymerization. \\
\hline PK 10169 (enoxaparin) $^{* *}$ & 4500 & 86 & $\begin{array}{l}\text { Benzylation followed by alkalline } \\
\text { depolymerization. }\end{array}$ \\
\hline NOVO LMWH* & 4800 & 61 & Enzymatic depolynnerization (heparinase). \\
\hline CY 216 (Fraxiparin) ${ }^{*}$ & 5500 & 85 & $\begin{array}{l}\text { Ethanol precipitation/fractionation, } \\
\text { depolymerization. }\end{array}$ \\
\hline Sandoz (LMWH/DHE)* & 6300 & 86 & Isoamylnitrate depolymerization. \\
\hline KABI 265 (Fragmin)* & 6400 & 73 & Nitrous acid depolymerization. \\
\hline OP $2123^{*}$ & 6500 & 62 & Peroxidative depolymerization. \\
\hline
\end{tabular}

* Data obtained from refs. 53 and 54 .

* Data obtained from the manufacturer

MW: Weight Average molecular weight:

2500-7500: Indicates the percentage of molecular species that are comprised in this range.

\section{A Concise Review of BLood CoAgulation}

Blood coagulation is a complex process regulated by simultaneous positive and negative feedback reactions (See figure 3 ).

The Initation. The association of Tissue Factor (TF) and factor VII(a), in the presence of $\mathrm{Ca}^{++}$ions, forms a complex that can activate factor $\mathrm{X}$ (55-57). The details of the conversion of factor $\mathrm{X}$ on $\mathrm{Xa}$, can be found in refs. 58,59 .

Although the complex TF/VII is able to activate factor X (55-57, and references therein), it is probably a rather inefficient activator $(55,60)$. The first traces of factor $\mathrm{Xa}$ that are generated initiate a positive activation loop: Factor VII is converted into $\mathrm{f}$ VIIa, which, complexed with TF, is a much more potent activator of factor $X$ (figure 3 ). This is the main mechanism of factor VII activation, but it can also be activated by the contact factors (61). The TF/VII(a) complex can also activate factor IX $(62,63)$. Factor IX can be activated by factor XIa originating from the contact activation mechanism (64). In view of the doubtful role of contact 
activation in physiological clotting, we will not discuss it further. Factor IXa in the presence of phospholipid, $\mathrm{Ca}^{++}$ions and factor VIII(a) (tenase complex) can in its turn, activate factor $\mathrm{X}$. The formed factor $\mathrm{Xa}$ also complexed to phospholipid, $\mathrm{Ca}^{++}$ions, and factor Va (prothrombinase complex), is the physiological activator of prothrombin (65-67). For a review on prothrombin conversion, see refs. 68-72.

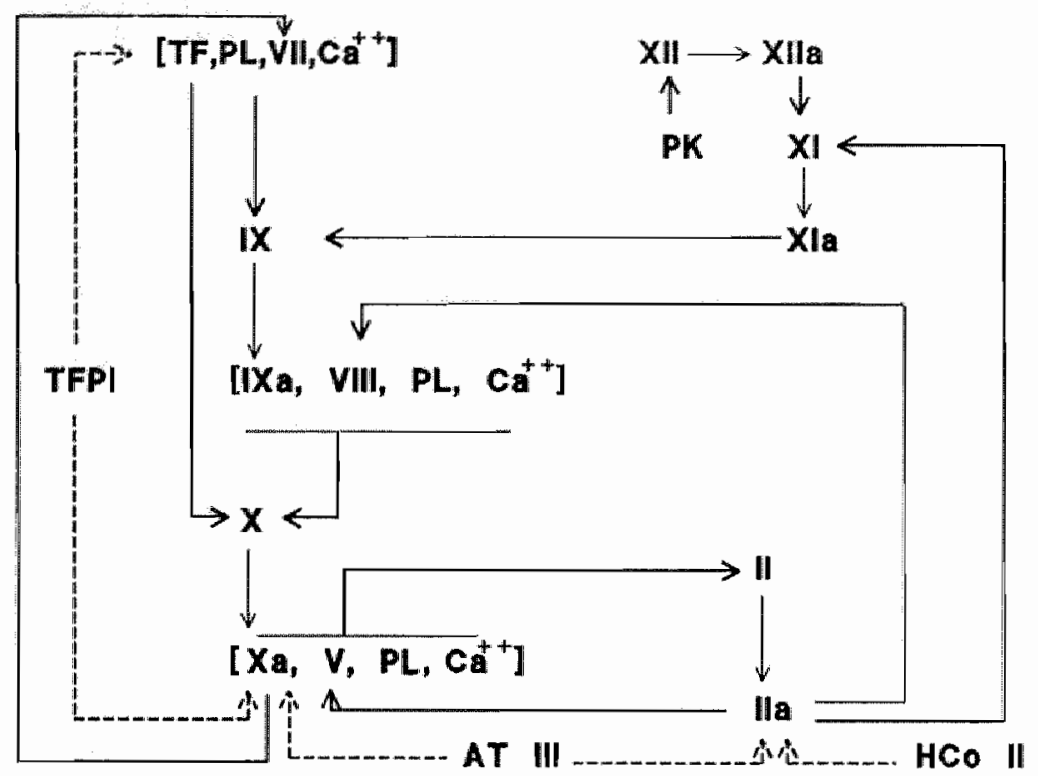

\section{Figure 3}

The Main Feedback Reactions of Blood Coagulation. Thick arrows: activation; thin arrows: conversion. Dashed arrows: inhibition. TF: Tissue Factor; PL: Phospholipid. For other abbreviations please refer to the text.

Thrombin, a pivotal enzyme in blood coagulation. As soon as the first traces of thrombin are formed, at least two positive feedback reactions take place. The inactive forms of factors $\mathrm{V}$ and VIII, are converted into their respective activated forms (73-76), and platelets are induced to produce procoagulant phospholipids at their outside by the so called flip flop reaction (77). The activated factors $V$ and VIII, are able to accelerate the massive thrombin formation (see figure 3 ).

Recently, it has been demonstrated that, in purified systems, factor XI can be activated by thrombin (78). This mechanism has not yet been demonstrated to be operative in plasma. 
The inhibition. The negative feedback of factor $X a$. The first traces of factor Xa, apart from activating factor VII, also initiate an inhibitory phenomenon. In the presence of factor VII, $\mathrm{Ca}^{++}$and tissue factor (TF) they bind to the Tissue Factor Pathway Inhibitor (TFPI), which inhibits the activity of [TF/VIIa] (79-84 and refs. therein).

The negative feedback of thrombin: Traces of thrombin trigger the activation of the protein $C$. Protein $C$ together with protein $S$ system, inactivates the clotting factors, Va and VIIIa $(85,86)$.

In plasma, factors $\mathrm{Xa}$ and IIa, among other activated serine proteases, are inactivated by AT III in a progessive manner (figure 3). Investigations done in our laboratory (87), showed that, in clotting plasma, AT III is responsible for $64 \%$ of the inhibition of thrombin. Its importance can be deduced from the fact that deficits of $50 \%$ on AT III cause a very high risk of thrombosis. $\alpha_{2}$-Macroglobuline and the other inhibitors (Heparin Cofactor II, $\alpha_{1}$ Protease Inhibitor $-\alpha_{1}$ PI-, etc), contribute with 23 and $13 \%$ respectively (figure 4 ).

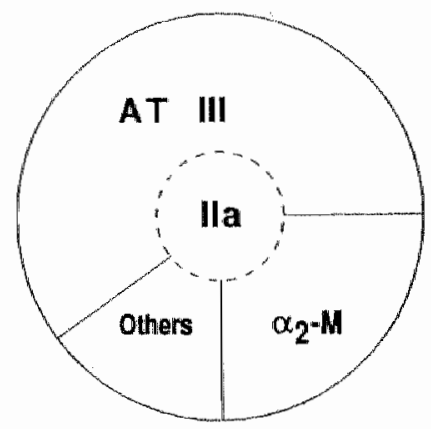

\section{Figure 4}

Inhibition of Thrombin: The Contribution of Various Mhibitors. AT III is the responsible for the inhibition of the $64 \%$ of thrombin that is formed. $\alpha_{2}$-macroglobuline and the others (Heparin Cofactor II, $\alpha_{1}$ protease inhibitor, etce), contribut the remaining 23 and $13 \%$ respectively.

Jesty suggested a classification of the inhibitors according to the nature of the inhibition and the behavior of the complex inhibitor-activator towards small substrates (88): AT III and $\alpha_{1}$ PI belong to the group of "inactivating inhibitors". $\alpha_{2} \mathrm{M}$ is a "non-activating" inhibitor because with proteases, it forms a complex that retains activity towards small substrates, although it loses its activity against macromolecular ones. This characteristic of the complex $\left[\alpha_{2} \mathrm{M}\right.$-serine protease] is supported by several investigations (8893). 


\section{The Catalysis of the INHIBITION of THE COAGULATION PRocess BY HEPARINS}

We will shortly give an overview of heparin and blood coagulation inhibitors, excluding AT III. Then we will focus on the AT III mediated activity of heparins.

Heparin potentiates the inhibition of thrombin by the Heparin Cofactor II (HC II; 94); but only at heparin concentrations that exceed the therapeutic range $(94,95)$. Among other glycosaminoglycans, the interaction of $\mathrm{HC}$ III with dermatan sulfate is very well documented.

From a study of Broze and coworkers (96) we know that in purified systems heparin potentiates the antithromboplastin activity of TFPI. Abildgaard (97-99), has shown that (LMW)heparin injected intravenously and/or subcutaneously into normal volunteers or into cancer patients increases the levels of TFPI, probably by releasing TFPI from the vessel wall. Untill now, it is unknown whether or not this is an important pathway for the down-regulation of the coagulation system.

The interaction between heparin and AT III is very well documented. Several investigations have been done to define the structural features that are necessary for the interaction of AT III-heparin with proteases (100-111). Two regions of the NH-terminal part of AT III are implicated in the heparin binding site. The integrity of a number of well defined aminoacids of the AT III molecule is required (105, 108, 110-112).

Exclusively those heparin molecules that possess the specific pentasaccharide sequence are able to induce a conformational change in the molecule of AT III. This conformational change exposes the active site of the inhibitor to the protease $(29,109-111)$. The conformational change leads to an increased affinity of AT III for factor Xa $(113,114)$. In contrast, the conformational change itself, is insufficient to catalyze thrombin inhibition. Accessory sequences than that necessary to inactivate factor Xa are required $(115,116)$. Heparin dissociates from the AT IIIprotease complex, and is available for a new interaction $(113,117)$.

\section{Heparin with High and Low Affinity for AT III}

Heparin preparations consist of polysaccharides that bind AT III (High Affinity Heparins) and that do not bind AT III (Low Affinity Heparins, LA). This is due to the post-transductional modification of the mature polysaccharide (section II of this chapter). Only one third of the heparin chains contains the pentasaccharide region $(118,119)$. The other two thirds lack anticoagulant activity per-se. Nevertheless, some investigators showed 
that LA fractions potentiate the antithrombotic activity of high affinity fractions (120-122). Several investigations showed that only very high concentrations of heparin are able to prevent the activation of prothrombin mediated by factor $\mathrm{Xa}$ in the absence of AT III, in a purified system, and in an AT III depleted plasma (123-125).

\section{The Molecular Weight of Heparin and the Catalysis of the Inhibition of Factors IIa and Xa.}

\section{a) In vitro Studies}

Heparin loses its capability to catalyze the AT III-thrombin reaction below a molecular weight of $5,400(116,120,121,126,127)$. Lane and coworkers demonstrate that the minimal chainlength required for the inhibition of thrombin is 18 saccharides (116), whereas the anti-factor Xa activity was present over the whole range of MW they studied.

Inhibition of the Feedback Reactions. Evidence that the main action of heparin is the inhibition of the feedback of factor V and VIII mediated by thrombin was provided by Josso et al (128), Hemker et al (87), Béguin et al (129), and Ofosu et al $(130,131)$. The importance of the inhibition of factor $\mathrm{Xa}$ at least in vitro (in plasma and in purified systems), has been questioned $(129,130,132)$. The inhibition of factor IXa by AT III has been shown to increase considerably in the presence of unfractionated heparin (133-135). We have preliminary evidence that LMWH are less effective in this respect. On the other hand, the activation of factor IX by the contact system is not inhibited by heparin (133). Investigations done in our laboratory $(91,129$, $136,137)$, permited us to distinguish between the inhibition of thrombin and the inhibition of its activator complex, prothrombinase. As a result of these studies, a classification of heparins was proposed: Heparins that inhibit prothrombin conversion were named "P" heparins, after the syn" thetic pentasaccharide, that is the model molecule of this class. Heparins that catalyze primarily thrombin inhibition have been named " $S$ " heparins, after Standard heparin $(87,129,137)$. It has also been shown that the synthetic pentasaccharide inhibits thrombin generation $(87,136,138,139)$.

Schoen et al (140), showed that in purified systems, the efficiency of heparins to catalyze the inhibition of factor $\mathrm{Xa}$, and of prothrombinase in purifed systems, increases with increasing MW. In the same study, it was observed that, $\mathrm{Ca}^{++}$ions stimulate the AT III dependent inhibition of human factor Xa. In two independent investigations, we have shown that a minimal MW of 5,400 is required to allow thrombin inhibition $(141,142)$. 


\section{b) Ex-vivo Studies}

Using Wessler's experimental model of thrombosis in rabbits, Holmer et al (143) demonstrated that intravenously injected heparin fragments possessing mainly anti-factor $X a$ require a minimum of $4000 \mathrm{D}$ to be effective thrombosis inhibitors.

It has been shown that after subcutaneous injection, as measured with classic methods $(27,144-145)$ the anti-factor Xa activity of (LMWH) heparins persists longer than the antithrombin activity does (146-148). Also a higher bioavailability of LMWH compared to unfractionated heparin has been demonstrated $(146,147,149)$. It has been suggested that the antifactor Xa activity could be a marker of (LMW)heparin concentration in blood (27), and that the antithrombotic effect of heparins might be due to their antifactor Xa activity, while bleeding is due to the anti-factor IIa activity (28). On the other hand, other investigators have found that for equivalent antithrombotic doses, LMWH showed similar hemorrhagic effects as UH (150, 151). Holmer et al (143), and Mätzsch et al (152) have shown that neither anti-factor Xa nor APTT is ideal for monitoring LMWH treatement.

Very recently, Samama et al (153) presented results of a study on more than 500 patients undergoing gynecologic surgery. They measured the anti-factor $\mathrm{Xa}$ activity and the prothrombin consumption in whole blood. The two values correlated well, suggesting that factor Xa inhibition leads to inhibition of prothrombin conversion.

Although in vitro the importance of the inhibition of thrombin is critical for the overall inhibition of coagulation, in clinical practice the antifactor Xa activity of LMWH appears to be a usefull parameter. It remains to be investigated whether this is because it is a usefull label of some relevant property of heparin, or because it is itself, in vivo, the relevant property.

The processes of absorption, distribution, and elimination of a drug should preferably be studied through the determination of drug levels in plasma. Pharmacological effects are certainly better predicted by the drug concentration in plasma than by the administrated dose (154). A test that measures the levels of active (LMW) heparin (i.e., in $\mu \mathrm{g} / \mathrm{ml}$ ), is not yet available. Until now, we have to make do with the observed effect of heparins on more or less complicated biological tests.

\section{c) The in vitro and ex vivo Neutralization of Heparins}

From current studies it is known that PF4 neutralizes completely the antithrombin and antifactor $\mathrm{Xa}$ activities of unfractionated heparin in plasma $(116,127,155-157$ and refs. therein). This protein stored in 
platelets, can only partly neutralize the antifactor Xa activity of $\mathrm{LMWH}$ $(116,127,155-157$ and refs. therein). This has been recently verified with experiments carried out in purified systems (127), using concentrations of PF4 that are equivalent to the concentration of PF4 released after the aggregation of a normal concentration of platelets.

Michalski et al (156) found that ex vivo (protamine and) platelet factor 4 neutralized only about half of the antifactor Xa activity of a LMWH fraction. Lane and coworkers (116) demonstrated in a set of experiments performed in vitro, that the antithrombin and the antifactor Xa activities of heparin fragments of $\geq 18$ saccharides units are completely neutralized by PF4, while decreasing MW, the refractivity for the neutralization increases. Denton et al (155) showed that an octa-decasaccharide possessing exclusively anti-factor Xa activity is only partly neutralized by platelet factor $4(\sim 50 \%)$. In patiens undergoing surgery with extracorporeal circulation, a study of Massonnet-Castel et al showed that the antifactor Xa of LMWH is also partly neutralized with protamine sulfate (158).In this study, there was no clear correlation between bleeding and anti-factor $\mathrm{Xa}$ or anti-IIa activities (158). Recently, Hirsh et al (159) measured bleeding tendency in rabbits, after the injection of a LMWH. The bleeding stopped after injection of a heparin-neutralizing agent (protamine sulfate), although incomplete neutralization of the anti-factor $\mathrm{Xa}$ activity was obtained.

It is known from the literature that in vitro, $\mathrm{UH}$ and enoxaparin are able to induce a prolongation of the lag phase of thrombin generation in platelet rich plasma (PRP; 160, 161). It is also known that only LMWHs are able to induce a decrease on the levels of thrombin generated in the presence of platelets $(160,161)$. It is not yet known if this essential difference between UH and a LMWH in PRP is due to a) the higher molar concentrations obtained with LMWH, allowing some active molecules to escape neutralization, and/or b) the relative insensitivity of LMWH to PF 4 (160).

\section{THE PRESENT INVESTIGATION}

The aim of the present investigation is to study the relationship between molecular weight and anticoagulant activity of heparins in human plasma, in vitro and ex vivo.

Chapter 2. From the literature, it appears that the inhibition of factor Xa requires only AT III high affinity material (HAM), while the inhibition of thrombin depends upon heparin chains above the critical chainlength of 18 saccharide units $(5,400 \quad$ D) -ACLM- of heparin. In this chapter, we investigated the relationship between the mollecular weight and the 
inhibitory activity of heparin on thrombin generation and prothrombin conversion in plasma. To this end, we studied a series of eight fractions of a LMWH with very narrow molecular distribution. We determined: the amount of HAM and of ACLM, as well as the amount of material below the critical chainlength of 18 saccharides (BCLM). We investigated the relative importance of the ACLM content for the specific antithrombin activity. In addition we compared the inhibition of prothrombinase by ACLM and BCLM, and its relative importance compared to thrombin inhibition.

Chapter 3. Much is known about the direct anti-factor $\mathrm{Xa}$ activity in plasma. It remains unknown whether heparin and LMWH impair factor Xa generation. Therefore, in this chapter we investigated the effect of unfractionated heparin (UH) and three of its derivatives (a LMWH, a synthetic pentasaccharide and a fraction without affinity for AT III) on the thromboplastin mediated-factor $\mathrm{X}$ activation in normal plasma, and in TFPIdepleted plasma. We compared these systems to the generation and inactivation of Russel's Viper Venom-induced factor $\mathrm{X}$ activation in plasma, and also to thromboplastin-induced factor $\mathrm{X}$ activation in a buffer system. In addition, we determined the decay constant of exogenous and endogenous factor $\mathrm{Xa}$, in the presence and in the absence of thromboplastin. Factor Xa generation curves were analyzed according to a model that assumed Michaelis- Menten kinetics of the activator, and pseudo first order kinetics of the respective inhibitions of factor $\mathrm{Xa}$ and [thromboplastin /factor VII(a)].

Chapter 4. In this chapter we propose a new way to measure the concentration of the active-circulating species of heparin in plasma, and we tested this approach in a very limited scale, in three volunteers.

To this aim we have first characterized the heparins injected. Two main parameters were obtained:

a) HAM, ACLM and BCLM content

b) The Specific antifactor $\mathrm{Xa}$ and antithrombin activities.

We define a Standard Independent Unit (SIU), as the amount of heparin that, when added to $1 \mathrm{ml}$ of plasma that contains $1 \mu \mathrm{M}$ AT III, increases the decay constant of a coagulation protease (i.e. $\mathrm{f} \mathrm{Xa}$ or IIa) by one inverse minute. In plasma from three healthy volunteers that received unfractionated heparin or either one of two LMWHs, we determined the SIU of factor Xa and IIa. From these data, and the specific activities of the heparins obtained from the in vitro experiments, we calculated the timecourse of the ACLM and the BCLM levels.

In order to relate the concentrations found, to the biological effects, we have measured thrombin and factor Xa generation, after triggering the coagulation with thromboplastin. In platelet rich plasma (PRP), we also measured thrombin generation. 
The apparent feasibility of this approach, encouraged us to initiate a study in a larger number of volunteers.

Chapter 5. The results obtained in chapter 4 did not allow us to distinguish whether or not increasing levels of circulating heparin produce a dose-dependent effect on the inhibition of the generation of activated proteases (Xa or IIa). The first question that could be broached with the techniques developed in the previous chapter, was whether or not there exist fundamental differences between the s.c. injection of a low dose of a LMWH, and UH. The second question was the dose-dependency of the effects brought about by the LMWH. To this end, we studied in twelve volunteers, the effect of two different doses of a LMWH (enoxaparin, 40 $\mathrm{mg}$ and $1 \mathrm{mg} / \mathrm{kg} \mathrm{bw}$ ), and of $5000 \mathrm{IU}$ unfractionated heparin after s.c. injection. First we determined the course of the levels of ACLM and BCLM, which allowed us to investigate the pattern of elimination of the respective circulating ACLM and BCLM. Then, we measured the generation of thrombin, factor Xa, and prothrombinase.

Chapter 6. This chapter was designed to study the effect of s.c. injection of UH and two doses of enoxaparin, on the generation of thrombin in PRP. Our aim was to determine whether or not an essential difference exists between UH and enoxaparin after exposure to platelet neutralizing activities obtained after the platelet release reaction, induced by endogenous thrombin. To distinguish whether an inhibition of thrombin generation in PRP was due to the ACLM, or to the BCLM fraction of the respective heparins, we also measured the decay constant of thrombin and factor $\mathrm{Xa}$ in serum obtained after thrombin generation in PRP. 


\section{APPENDIX}

\section{The Clotting Factors and InhibItors Relenant to the PRESENT INVESTIGATION}

\section{1) PROPERTIES OF FACTORS II AND $X$}

Both of them, as members of the family of Vitamin-K dependent or Gla-protein family, possess $\gamma$-carboxyglutamic acid (Gla) residues (162164). These Gla residues are of crucial importance for the association of gla-proteins to phospholipid membranes (165). This interaction is probably achieved through the formation of calcium ion bridges between the glaresidues of the protein, and negatively charged phospholipids. These proteins also participate in interactions that, although dependent on the gla-domain and $\mathrm{Ca}^{++}$ions, are independent of phospholipid binding (i.e., the activation of factor Xa mediated by Russel's Viper Venom; 166).

FACTOR $X$ (Stuart-Prower factor). Its concentration in plasma is $\sim 160 \mathrm{nM}$ (167). Factor $X$ is a two chain glycoprotein of MW 55,000 D. The heavy chain contains the carbohydrate residues, and the active site serine. The light chain possesses the gla residues. Activation is brought about by cleavage of the heavy chain, which releases a small peptide (the activation peptide). Thus factor $\mathrm{X}$ is converted to $\alpha$-factor $\mathrm{Xa}(\mathrm{MW} \sim 50000)$ by the complex [IXa/VIIIa/Ca ${ }^{++} /$phospholipid], as well as by the TF/VIIa complex. This product can autocatalytically be converted to a lower molecular weight form, the B-factor Xa (MW 45000 D), after loosing a peptide of $\sim 5000$ $D$. Factor $\mathrm{Xa}$ is also able to convert factor $\mathrm{X}$ autocatalytically into $\mathrm{B}$-factor $X$ and $B$-factor $X a$, but this is apparently a minor pathway (59).

PROTHROMBIN (factor II). Its concentration in plasma is $\sim 1.8 \mu \mathrm{M}$ (168). Prothrombin is a single chain glycoprotein of $\mathrm{MW} 72,000 \mathrm{D}$. Upon factor $\mathrm{Xa} / \mathrm{Va} /$ phospholipid- mediated activation into thrombin, two pathways can occur: Patwhay A, and Patwhay B (170). Pathway A, occurs when cleavage mediated by factor Xa takes place at the $\mathrm{Arg}^{274}-\mathrm{Thr}^{275}$ peptide bond: Prethrombin 2 is formed as intermediate of thrombin formation (170). In addition, a large activation peptide (MW 36,000) containing, a.o., the Gla domain (fragment 1.2) is released (69). Fragment 1.2 activation fragment has been found to regulate the activation of prothrombin in purified systems (72). It contains a $\mathrm{Arg}^{155}-\mathrm{Ser}^{156}$ which is susceptible to feedback cleavage of thrombin (170). Also, it neutralizes heparin (72). The role of fragment 1.2 during in vivo prothrombin activation has not yet been established (72). In the other pathway for prothrombin activation (pathway $\mathrm{B})$, cleavage mediated by factor $\mathrm{Xa}$ occurs at the $\mathrm{Arg}^{323}-\mathrm{Ile}^{324}$ bond, and results in the formation of meizothrombin as intermediate. Meizothrombin 
formation has been very recently demonstrated to be regulated by thrombin mediated feedback activation (170).

\section{II) PROPERTIES OF ANTITHROMBIN III AND THE TISSUE FACTOR PATHWAY INHIBITOR}

Antithrombin III. This antiprotease has a MW of 58,000 (100). The concentration of AT III in human plasma is about $2.5 \mu \mathrm{M}$. It is a member of the serpin (serine protease inhibitor) superfamily. Like all other members of this family, it offers its cognate protease a higli-affinity substrate that resists complete cleavage $(110)$. The interaction terminates in an acylenzyme intermediate, in which the catalytic serine residue of the enzyme remains covalently bound to a carboxyl-terminal arginyll residue of the large fragment of the cleaved AT III molecule (107). The complex is subsequentely removed from circulation and catabolyzed.

Tissue Factor Pathway Inhibitor (TFPI). The TFPI concentration in plasma is $2.6 \mathrm{nM}$ ( 81 and refs. therein). In plasma, TFPI exists mainly in two molecular forms: One was reported as $\sim 42$ to $43 \mathrm{kD}$, and the other as $\sim 35$ to $36 \mathrm{kD}(83)$. TFPI is present in vivo in at least three different pools (169): sequestered in platelets, partitioned among the plasma lipoproteins (81-84), and released into plasma by heparin (97-99, 169). About $50 \%$ TFPI is asociated with VLDL, $44 \%$ with HDL, and $6 \%$ is not associated with lipoproteins (83). A heparin-releasable form has been very recently identified (169). It has been hypothesized that this form could be associated with vascular endothelial cell-glycosaminoglycans (169). In vitro, TFPI inhibits activated factor Xa directly $(79,82,96)$. TFPI could also contribute to a significant inhibition of factor Xa in vivo (169).

In the presence of factor $\mathrm{Xa}$, TFPI is a potent inhibitor of TF/VIIa activity $(79,82,96)$. A quaternary complex is formed between TF/VIla, factor $\mathrm{Xa}$ and TFPI. The TF/VIIa inhibition mediated by TFPI also requires the presence of $\mathrm{Ca}^{++}$ions. The interaction between factor $\mathrm{Xa}$ and TFPI, as well as the inhibition of TF/VIIa requires gla-residues (96). Heparin enhances the rate of inhibition of factor $\mathrm{Xa}$, whille $\mathrm{Ca}^{++}$and phospholipid decrease it.

\section{$\underline{\text { References }}$}

1) Hammersten, $O$. Zurlehre von der faserstoffgerimnung. Soc der Wiss. Uppsala, 211-273: 1877 .

2) Peckelharing, C.A.: Untersuchungen Über das fibrinferment. Verhandeling der Koninklijke Akademie van Weternschappen te Amsterdam. Tweede sectie-deel 1, $\mathrm{n}^{\circ}$ 3; 1892 .

3) Morawitz P. Die Chimie der blutgerinnung. Ergbnis der Physiol. 4: 307-422; 1905. 
4) Schmidt A: Ueber den faserstoff und die ursache seiner gerimnung. Arch. Anat. Physiol. Wissensch Medizin, 28:545, 1861.

5) Pavlow, I.P.: In biokhimiva sventyvaniya krovi (biochemistry of blood coagulation) Y. Bellik, Kiev, 1957. [English translation of excerpts] Reprinted OTS Washington, february 1959. U.S. Joint publications research service. L-507-N.59-13, 089.

6) Mc Lean, J.: The discovery of heparin. Circulation 19:75-78; 1959.

7) Kahn, M." Bourgain, R.: A propos du rốle ünhibiteur d"un lipoïde du type phosphoinositide sur la conversion de la prothrombine en thrombine. Arch. Int. Pharmacodyn. $149 ; 1,2 ; 284-289 ; 1964$.

8) Howell W.H. The coagulation of blood. Harvey lect. 12, 272-323; 1916-1917.

9) Howell, W.H.: Heparin an anticoagulant. Am. J. Physiol. 63: 434-435, 1922-3.

10) Verstraete, M.: Heparin and thrombosis: A seventy year long story. Haemostasis (suppl. 1):4-11:1990.

11) Jacques, L.B.: Addendum: The discovery of heparin. Sem. in Thrombosis and Haemostasis 4: 4 (spring): $350-353 ; 1978$.

12) Jacques, L.B.: The Howell theory of blood coagulation: A record of the pernicious effect of a false theory. Canadian Bulletin of Medical History 5 (2): 143$165 ; 1988$.

13) Baylis, W.M.: Principles of general physiology. 1st edition. Longman and Green, NY: $703 ; 1915$.

14) Reed, C.I.: The intravascular use of heparin. Am. J. Physiol. Biol. 74: 79-81; 1925.

15) Mc Lean, J.: The thromboplastic action of cephalin. Am. J. Physiol. 41: 250-57: 1959.

16) Charles, A.F.; Scott, D.A.: Studies on heparin I and II. The preparation of heparin. J. Biol. Chem. 102: 425-435; 1933.

17) Scott, D.A.; Charles, A.F.: Studies on heparin III. The purification of heparin. J. Biol. Chem. 102: 437-448; 1933.

18) Charles, A.F.; Scotti, D.A.: Preparation of heparin from beef lung. Trans. R. Soc. Canada; 28: 55-59; 1934 .

19) Jorpes, E.: The chemistry of heparin. Biochem. J. 29: 1817-1824; 1935.

20) Rodén, L.; Feingoid, D.: A vintage year for Jorpes, Crafoord, and heparin. TIBS, 407-409: 1985.

21) Murray, D.W.G.; Jaques, L.B. and Best, C.H. Heparin and vascular occlusion. Can Med. Assoc. J. 35:621-635; 1936. 
22) Mason, E.C.: A note on the use of heparin in blood transfusion. J. Lab. Clin. Med. $10: 203 ; 1924$.

23) Hedenius, P.; Wilander, O.: The influence of intravenous injections of heparin in man on the time of coagulation. Acta Med. Scand 88:443: 1936.

24) Brinkhous. K.M; Smith, H.W; Warner, E.D.; Seegers, W.H.: The inhibition of blood clotting: An unidentified substance which acts in conjunction with heparin to prevent the conversion of prothrombin to thrombin. Am. $\mathbf{J}$. Physiol 125: 683-687: 1939.

25) Abildgaard, U.; Highly purified antithrombin III with heparin cofactor activity prepared by disc electrophoresis. Scan. J. Clin. Lab. Invest. 21: 89-91; 1968.

26) Johnson, E.A.; Kirkwood, T.B.L.; Stirling, Y.; Perez-Requejo, J.L.; Ingram, G.I.C.; Bangham, D.R.; Brozovic, M.: Four heparin prepartions: anti-Xa potentiating effect of heparin after subcutaneous injection. Thromb. Haemostasis 35: 586-591: 1976.

27) Yin, E.T.; Wessler, S.; Stoll, P.J.: Biological properties of the naturally occuring inhibitor to activated factor X. J. Biol. Clem. 246: 3703-3711; 1971.

28) Cade, J.F.; Buchanan, M.R.; Boneu, B.; Ockelford, P.A.; Carter, C.J.; Cerskus, A.L.; Hirsh, J.: A comparison of the antithrombotic and hemorrhagic

effects of low molecular weight heparin fractions. Thromb Res. $35,613-625 ; 1984$.

29) Lindhal, U.: Approaches to the synthesis of heparin. Haemostasis 20 (suppl. 1): 146-153; 1990 .

30) Lindhal, U.; Kushe, M; Lidholt, K.; Oscarsson, L.G.: Biosythesis of heparin and heparan sulfate. In: Annals of the New York Academy of Sciences. Heparin and related polysaccharides: Structure and activites. 556 , pp $36-50 ; 1989$.

31) Forsee, W.T.; Rodén, L.: Biosynthesis of heparin. Transfer of N-acetylglucosamine to heparan sulfate oligosaccharides. I. Biol Chem. 256:7240.7247; 1981.

32) Lindahl, U.; Feingold, D.S.; Rodén, L; Biosynthesis of heparin. TIBS; 221-225; $\underline{1986}$.

33) Jacobson, K.G. and Lindahl, U.: Degradation of heparin proteoglycan in cultured mouse mastocytoma cells. Biochem. J. 246: 409-415; 1987.

34) Casu, B: Heparin Structure. Haemostasis 20 (suppl. 1): 62-73; 1990.

35) Riesenfeld, J.; Höök, M.; Lindahl, U: Biosynthesis of Heparin. J. Biol. Chem. 255: $922-928 ; 1980$.

36) Hopwood, J.; Hook, M.; Linker, A.; Lindahl, U.: Anticoagulant activity of heparin: Isolation of antithrombin-binding sites. FEBS letters. 69; 1: 51-54; 1976.

37) Thunberg, L.; Backstrom, G; Grundberg, H.; Riesenfeld, J; Lindahl, U.: The molecular size of the antithrombin-binding sequence in heparin. FEBS letters. 117; 1: 203-206; 1980. 
38) Thunberg, L.; Backstrom, G.; Lindahl, U.: Further characterization of the antithrombin-binding sequence in heparin. Carbohydr. Res. 100:393-410; 1982.

39) Radoff, S.; Danishefsky, I.: Location on heparin of the oligosaccharide section essential for anticoagulant activity. J. Biol. Chem. 259; 1: 166-172; 1984.

40) Jacobsson, K.G. Lindahl, U, and Horner, A.A.: Location of antithrombinbinding regiens in rat skin heparin proteoglycans. Biochem. J. 240: 625-632; 1986 .

41) Choay, J.; Lormeau, J.C.; Sinaij, P.; Casu, B.; Gatti, G.: Structure-activity relationship in heparin: A synthetic pentasaccharide with high affinity for antithrombin III and eliciting high anti-factor Xa activity. Biochem. Biophys. Res. Comm. 116: 492-499:1983.

42) Jacobsson, I.; Höök, M.; Pettersson, I.; Lindahl, U.; Larm, O.; Wisen, E.; von Figura, K.: Identification of $\mathrm{N}$-sulfated disaccharide units in heparin like polysaccharides. Biochem. J. 179: 77-87; 1979.

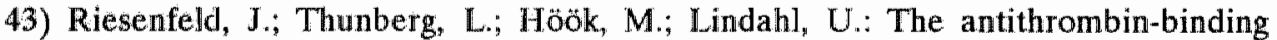
sequence of heparin. Location of $\mathrm{N}$-sulfate groups. J. Biol. Chem. 256; 5: 389-2394: 1981.

44) Atha, D.H.; Lormeau, J.C.; Petitou, M.; Rosenberg, R.D.; Choay, J.: Contribution of 3-O- and 6-O-sulfated glucosamine residues in the heparin-induced conformational change in antithrombin III. Biochemistry 26, 6454-6461; 1987.

45) Jacques, L. B.: Heparins - Anionic polyelectrolyte drugs. Pharmacological Reviews. 31, 2: 99-167: 1980.

46) Jacques, L. B.: Heparin: A unique misunderstood drug. TIBS 289-291; 1982.

47) Giuliani, R.; Swarcer, E.; Bendetowicz, A.V.: Heparina y Heparinoides. In: Manual de Hemostasia y Trombosis pp 82-86; 1989. Eds: Kordich, L.C.: Sanchez Avalos, J.C.; Vidal, O.; Campos Guerra, $C_{n}$ : Imprenta de la Federación Bioquímica de la Prov. de Buenos Aires.

48) Dosne, A.M.; Bendetowicz, A.V.; Kher, A.; Samama, M.: Marked potentiation of the plasminogenolytic activity of prourokinase by unfractionated heparin and a low molecular-weight heparin. Thromb. Res. 51: 627-630; 1988.

49) Lourenço, D.M.; Dosne, A.M.; Kher, A.; Samama, M. Effect of standard heparin and an molecular weight heparin on thrombolytic and fibrinolytic activity of single chain-urokinase plasminogen activator in vitro. Thrombos and Haemostas. 62; 3 : 223-926: 1989.

50) Hirsh, J ; Ofosu, F.A.; Levine, M.: The development of low molecular weight heparins for clinical use. Thrombosis and Haemostasis. pp 325-349; 1987. Ed: Verstraete, $\mathbf{M}_{\text {; }}$ Vermylen, $\mathbf{J}$,: Lijnen, H.R. and Arnout, J.: I.S.T.H. and Leuven University Press.

51) Edelberg, J.M. and Pizzo, S.: Kinetic Analysis of the effects of heparin and lipoproteins on tissue plasminogen activator mediated plasminogen activation. 
Biochemistry 29: 5906-5911: 1990.

52) Linblad, B.; Borgstrom, A.; Wakefield, T.W.: Whitehouse, W.M.; Stanley, M.C." Protamine reversal of anticoagulation achieved with a low molecular weight heparin. The effects on eicosanoids, clotting and complement factors Thromb. Res. 48.3140 , 1987.

53) Fareed, J.; Walenga, J.M.; Hoppensteadt, D.; Racanelli, A.; Coyne, E: Chemical and biological heterogeneity in low molecular weight heparins: Implications for clinical use and standarisation. Sem. Thromb. Haemost. 15, 4: 440-463; 1989.

54) Fareed, J.; Wallenga, J.M.; Hoppensteadt, D.; Huan, X.; Nonn, R.: Biochemical and pharmacological inequivalence of low molecular weight heparins. N.Y.Acad. Sci. 556: $333-353 ; 1989$.

55) Rao, L.V.M.; Rapaport, S.I. Bajaj, S.P.: Activation of human factor VII in the initiation of tissue factor-dependent coagulation. Blood 68; 3; 685-691; 1986 .

56) Rao K.V.M.; Rapaport, S.I.: Studies of a mechanism inhibiting the initiation of the extrinsic pathway of coagulation. Blood 69; 645-651; 1987.

57) Nemerson, Y.: Tissue factor and haemostasis. Blood 71: 1-8; 1988.

58) Fuijikawa. K.; Legaz, M.E; Davie, E.W.: Bovine factor Xa (Stuart Factor). Mechanism of activation by a protein from Russell's viper venom. Biochemistry; 11 : 4892-4889; 1972.

59) Jesty, J.; Spencer, A.K.; Nemerson, Y.: The mechanism of activation of factor X. Kinetic control of alternative pahtways leading to the formation of activated factor X. J. Biol. Chem. 249:5614-5622; 1974.

60) Wildgoose, P.; Berkner, K.L.; Kisiel, W.: Synthesis, Purification, and Characterization of an $\mathrm{Arg}_{152} \rightarrow$ Glu site-directed mutant of recombinant human blood clotting factor VII. Biochemistry; 29:3413-3420; 1990.

61) Altman. R.; Hemker, H.C: Contact activation in the extrinsic blood clotting systems. Thromb. Diathes. Haemorr.; 18, 525-531; 1967.

62) Josso, F.; Prou-Wartelle, O.: Interaction of tissue factor and factor VII at the earliest phase of coagulation. Thromb. Diath. Haemorr. Suppl. 17; 35-44: 1965.

63) Josso, F.; Béguin, S.: The possible role of factor VII in the intrinsic system. In: Human Blood Coagulation. Biochemistry, Clinical Investigation and Therapy: 1969. Eds: Hemker, H.C.; Loeliger, E.A. and Veltkamp, J.J. Leiden Univ. Press.

64) Ratnoff, O.D.; Davie, E.W.; Mallett, D.C.: Studies on the action of Hageman factor: Evidence that activated Hageman factor in turn activates plasma thromboplastin antecedent. I. Clin. Invest. 40:803-819; 1961.

65) Newcomb, T.F; Hoshida, M.: Factor V and thrombin. Scand. J. Clin. Lab. Invest. (suppl 84); 17: 61-69; 1965.

66) Vehar, G.A.; Davie, E.W.: Preparation and properties of bovine factor VIII 
(antihemophilic factor). Biochemistry: 19:401-410; 1980 .

67) Pieters, J.; Lindhout, T.; Hemker, H.C.: In situ generated thrombin is the only enzyme that effectively activates factor VIII and factor $\mathrm{V}$ in thromboplastin activated plasma Blood 1021-1024: 1989.

68) Suttie, J.W.; Jackson, C.M.: Prothrombin structure, activation and biosynthesis. Physiol. Rev. 57: 1-59; 1977.

69) Stenn, K.S.; Blout, E.R.: Mechanism of bovine prothrombin activation by an insoluble preparation of bovine factor Xa (thrombokinase). Biochemistry 11: 4502$4515 ; 1972$.

70) Esnouf, M.P.; Jobin, F.: Lipids in prothrombin conversion. Thromb. Diath. Haemorrh, 17: 103-110; 1965 .

71) Esmon, C.T.; Owen, W.G.; Jackson, C.M.: A plausible mechanism for prothrombin activation by factor $\mathrm{Xa}$, factor Va, phospholipids, and calcium ions. $\underline{\mathrm{J} \text {. Biol. }}$ Chem. 249: 8045-8047: 1974 .

72) Govers-Riemslag, J.W.P.; Speijer, H.; Zwaal, R.F.A.; Rosing, J.: The effects of prothrombin fragment 1 and fragment 1.2 on prothrombin activation. Thromb. Res. 38: $375-388 ; 1985$.

73) Biggs, R.; Mc Farlane, R.G.; Denson, K.W.E.; Ash, B.J.: Thrombin and the interaction of factor VIII and IX. Br. J. Haematol.; 11: 276-295, 1965.

74) Suzuki, K.; Dahlback, B.; Stenflo, J.: Thrombin catalyzed activation of human coagulation factor V. J. Biol. Chem. 257: 6556-6564, 1982.

75) Vehar, G.A.; Davie, E.W. Preparation and properties of bovine factor VIII (antihemophilic factor). Biochemistry; 19: 401-410; 1980.

76) Newcomb, T.F.; Hoshida, M.: Factor $V$ and thrombin. Scand. J. Clin. Lab. Invest. (suppl 84): 17:61-69:1965.

77) Bevers, E.M.; Comfurius, P.; Van Rijn, J.L.M.L; Hemker, H.C. Zwaal, R.F.A.: Generation of prothrombin converting activity and the exposure of phosphatidylserine at the outer surface of platelets. Eur. J. Biochem. 122; 429-436; 1982.

78) Naito, K.; Fujikawa, K.: Activation of human blood coagulation factor XI independent of factor XII (factor XI is activated by thrombin and factor XIa in the presence of negatively charged surfaces). J. Biol. Chem. 256: 7353-7358; 1991 .

79) Hubbard, A.R.; Jennings, C.A.: Inhibition of factor $X a$ and lipoproteins. Thromb. Res. 46: 527-537; 1987.

80) Rao, L.V.M.; Rapaport, S.I.: Studies of a mechanism inhibiting the initiation of the extrinsic pathway of coagulation. Blood 69:645-651; 1989.

81) Rappaport, S.I.: Inhibition of factor VIla/tissue factor-induced blood coagulation: 
With particular emphasis upon a factor Xa dependent inhibitory mechanism. Blood 73, 2: 359-365; 1989 .

82) Warn-Cramer, B.J.; Maki, S.L.; Zivelin, A.; Rapaport, S.I: Partial purification and characterization of extrinsic pathway inhibitor (the factor Xa-dependent plasma inhibitor of factor VIla/tissue factor). Thromb. Res 48-11: 1987.

83) Novotny, W.F; Girard, T.J.; Miletich, J.P.; Broze, G.J.: Purification and Characterization of the Lipoprotein-associated Coagulation Inhibitor from human plasma. J. Biol. Chem. 31: 18832-18837; 1989.

84) Girard, T.J.; Warren, L.A.; Novotny, W.F.; Likert, K. M.; Brown, S.G.; Miletich, J.P.; Broze, G.J.: Functional significance of the Kunitz-type inhibitory domains of lipoprotein-associated coagulation inhibitor. Nature: $338 ; 518-520 ; 1989$.

85) Marlar, R.A.; Kleiss, A.J.; Griffin, J.H.: Human protein C inactivation of factor $\mathrm{V}$ and VIII in plasma by activated molecule. Ann. N.Y. Acad. Soi., 370: 303-310; 1981.

86) Suzuki, K; Stenflo, J.; Dahlbäck, B.; Teodorsson, B.: Inactivation of human coagulation factor $\mathrm{V}$ by activated protein $\mathrm{C}$. J. Biol. Chem. 258: 1914-1920; 1983.

87) Hemker, H.C.: The mode of action of heparin in plasma. Thrombosis and Haemostasis; pp 17-36; 1987. Ed: Verstraete, M.; Vermylen, J; Lijnen, H.R. and Arnout, J.: I.S.T.H. and Leuven University Press.

88) Jesty, $\mathrm{J}$ : The kinetics of the inhibition of $\alpha$-thrombin in human plasma. $\mathrm{J}_{\text {. Biol. }}$ Chem. 261: 10313-10318; 1986.

89) Feldman, S.R.; Gonias, S.L.; Pizzo, S.V.: Model of $\alpha_{2}$-macroglobulin structure and function. Proc. Natl. Acad. Sci.; 82: 5700-5704; 1985.

90) Jesty, J.: Measurement of the kinetics of imhibition of activated coagulation factor $X$ in human plasma: The effect of plasma and inhibitor concentration. Analytical Biochemistry; 152, 402-411; 1986.

91) Hemker, H.C; Willems, G.M. and Béguin, S. A computer assisted method to obtain the prothrombin activation velocity in whole plasma independent of thrombin decay processes. Thrombosis and Haemostasis 56, 9-17; 1986.

92) Sottrup-Jensen, L.; Stepanik T.M.; Kristensen, T.; Wierzbjcki, D.M.; Jones, C.M.; Lonblad, P.B.; Magnusson, S.; Petersen, T.E.: Primary structure of human a${ }_{2}$ macroglobulin. The complete structure. II. Biol. Chem. 259, 13: 8318-8327; 1984.

93) Starkey, Ph.M; $\alpha_{2}$-macroglobulin: A review. In: The Physiological inhibitors of coagulation and fibrinolysis; pp 221-226; 1979. Eds: Collen, D.; Wiman, B.; Verstraete, $M$.

94) Tollefsen, D.M.; Majerus, D.W.; Blank, M.K.: Heparin Cofactor II. Purification and properties of a heparin-dependent inhibitor of thrombin in human plasma. $\mathbb{J}$. Biol. Chem. 257, 5; 2162-2169; 1982.

95) Tollefsen, D.M.; Pestka, C.A.; Monafo, W.J.: Activation of heparin cofactor II by 
dermatan sulfate. D. Biol. Chem. 258: 6713-6716:1983.

96) Broze, G.J. Warren, L.A. Novotny, W.F.; Higuchi, D.A.; Girard, J.J; Miletich, J.P: The lipoprotein-aissociated coagulation inhibitor that inhibits the factor VIItissue factor complex also inhibits factor Xa: Insight into its possible mechanism of action. Blood 71 : $335-343 ; 1988$.

97) Sandset P, Abildgaard, U; Larsen, A.L: Heparin induces release of extrinsic coagulation pathway inhibitor (EPI). Thromb. Res. 50: 803-813; 1988.

98) Lindahl, A.K, Abildgaard, U.; Stokke, G.: Release of extrinsic pathway inhibitor after heparin injection: Increased response in cancer patiens. Thromb. Res. 59: 651656:1990.

99) Lindahl, A.K; Abildgard, U.; Larsen, M.L.; Aamodt, L.M.; Nordfang, O.; Beck, T.C.: Extrinsic pathway inhibitor (EPI) and the post-heparin anticoagulant effect in tissue thromboplastin induced coagulation. Thromb. Res. Suppl XIV; 39-48; 1991.

100) Rosenberg, R.D.; Damus, P.S.: The purification and mechanism of action of human antithrombin-heparin cofactor. I. Biol. Chem. 248: 6490-6505; 1973.

101) Jordan, R. Beeler, D.; Rosenberg, R.D.: Fractionation of low molecular weifht heparin species and their interaction with antithrombin. J. Biol. Chem. 254: 29022913; 1979 .

102) Griffith, M.: Kinetic analysis of the heparin-enhanced antithrombin III/thrombin reaction. J. Biol. Chem. 254: 12044-12049; 1979.

103) Holmer, F.; Soderström, G.; Andersson, L.O.; Studies on the mechanism of the rate-enhancing effect of heparin on the thrombin-antithrombin II reaction. Eur. J. Biochem. 93: 1-5; 1979 .

104) Jordan, R.E.: Oosta, G.M.; Gardner, W.T.; Rosenberg, R.D.: The kinetics of hemostatic enzyme-antithrombin interaction in the presence of low molecular weight heparin. J. Biol Chem; 255:21: 10081-10090; 1980.

105) Blackburn, M.N.; Sibley, C.C.: The heparin binding site of antithrombin III. J. Biol. Chen. 255: 824-826; 1980.

106) Griffith, M.J.: Heparin Catalyzed inhibitor/protease reactions: kinetic evidence for a common mechanism of action of heparin. Proc. Natl. Acad. Sci. 80: 5460-5464: 1983.

107) Griffith, M.J.: Kinetics of the heparin-enhanced antithrombin III/thrombin reaction. Evidence for a template model for the mechanism of action of heparin. $\mathbf{J}_{\text {. }}$ Biol. Chem, 257; 13; 7360-7365; 1982.

108) Lindhal, U.; Thunberg, L.; Bäckstrom, J.; Riesenfeld, J.; Nordling, K. Björk, I.: Extension and structural variability of the antithrombin-binding sequence in heparin. J. Biol Chem. 259: 12368-12376; 1984.

109) Peterson, C.B.; Blackburn, M.N.: Antithrombin conformation and the catalytic 
role of heparin. I. Does cleavage by thrombin induce structural changes in the heparin binding region of antithrombin? J. Biol. Chem. 262: 7552-7558; 1987.

110) Carrel, R.W.; Christey, P.B.; Boswell, D.R.: Serpins: antithrombin and other inhibitors of coagulation and fibrinolysis. Evidence from amino acid sequences. In: Thrombosis and Haemostasis pp 1-15; 1987. Ed: Verstraete M, Vermylen J, Lijnen HR and Arnout J. I.S.T.H and Leuven University Press.

111) Sun, X.J.; Chang, J.Y.; Heparin binding domain of human antithrombin III initerferred from the sequential reduction of its three disulfide linkages. An efficient method for structural analysis of partially reduced proteins. J. Biol. Chem. 264: $11288-11293 ; 1989$.

112) Liu, C.S.; Chang, J.Y. The heparin binding site of human antithrombin III. Selective chemical madification at Lys ${ }^{114}$, Lys $^{125}$, and Lys ${ }^{287}$, impairs its heparin cofactor activity. J. Bioll. Chem. 262; 36: 17356-17361; 1987.

113) Craig, P.A.; Olson, S.T.; Shore, J.D.: Transient kinetics of heparin-catalyzed protease inactivation by antithrombin III. Characterization of assembly, product formation, and heparin dissociation steps in the factor $X$ reaction. $\mathbb{H}$. Biol. Chem. 263: $5442-5461: 1989$.

114) Shore, J.D.; Olson, S.T.; Craig, P.A.; Choay, J.; Björk, I.: Kinetics of heparin action. Ann. N.Y. Acad. Sci. 556: 75-80; 1989.

115) Andersson, L.O.; Barrowcliffe, T.W.; Holmer, E.; Johnson, E.A.; Sodenstrom, $G_{\text {: }}$ Molecular weight dependency of the heparin potentiated inhibition of thrombin and activated factor $X$. Effect of heparin neutralization in plasma. Thromb. Res. 15: $531-541,1979$.

116) Lane, D.A; Denton, J.; Flynn, A.; Thunberg, L.; Lindahl, U.: Anticoagulant activites of heparin oligosaccharides and their neutralization by platelet factor 4 . Biochem. J.; 218: 725-732; 1984.

117) Olson, S.T.; Shore, J.D.: Transient kinetics of heparin-catalyzed protease inactivation by antithrombin III. The reaction step limiting heparin turnover in thrombin neutralization. J.Biol. Chem. 261: 13151-13159; 1986.

118) Lam, L.H.; Silbert, J.E.; Rosenberg, R.D.: The separation of active and inactive froms of heparin. Biochem. Biopllys. Res. Commun.: 69: 570-577; 1976.

119) Höök, M.; Bjork, I.; Hopwood, J.; Lindahl, U.: Anticoagulant activity of heparin; Separation of high-activity and low activity heparin species by affinity chromatography on immobilized antithrombin. FEBS Letters 66: 90-93; 1976.

120) Barrowcliffe, T.W.; Merton, R.E.; Havercroft, S.J.; Thunberg, L.; Lindhal, U.: Effect of heparin oligosaccharides with high affinity for antithrombin III in experimental venous thrombosis. Thromb. Res. 34: 125-133; 1984.

121) Thomas, D,P.; Merton, R.E.; Barowcliffe, T.W,; Thunberg, L.; Lindahl,U.: Effects of heparin oligosaccharides with high affinity for antithrombin III in experimental venous thrombosis. Thrombos. Haemostas.; $47: 244-248$; 1982. 
122) Barrowcliffe, T.W.; Merton, R.E.; Havercroft, S.J.; Thunberg, L. Lindahl, U. and Thomas, D.P.: Low affinity heparin potentiates the action of high-affinity heparin oligosaccharides. Thromb. Res. $34: 125-133 ; 1984$.

123) Ofosil; F.A.; Blajchman, M.; Modi, G.; Cerskus, A.L.; Hirsh, J.: Activation of factor $X$ and prothrombin in antithrombin III depleted plasama. Thromb. Res. 23: $331-45 ; 1982$

124) Walker, F.I.; Esmon, C.T.: Interaction Between heparin and Factor Xa. Inhibition of prothrombin activation. Biochem. Biophys. Acta; $585: 504-515 ; 1979$.

125) Baruch, D.; Lindhout, T.; Wagenvoord, R.; Hemker, H.C.: Inhibition of thrombin-catalyzed reactions in blood coagulation and platelet activation by heparin fractions in the absence of antithrombin III. Haemostasis 16: 71-81; 1986 .

126) Thunberg; L; Lindahl, $U_{\text {.: }}$ On the molecular weight dependence of the anticoagulant activity of heparin. Biochem. J.4 181:241-243; 1979.

127) Schoen, P.; Lindhout, T.; Franssen, J.; Hemker, H.C.: Low Molecular weight heparin-catalyzed inactivation of factor Xa and thrombin by antithrombin III. Effect of platelet factor 4. Thromb. Haemostas. 66 (4): 435-441; 1991.

128) Hurlet-Birk Jensen, A; Béguin, S.; Josso, F.: Factor V and VIII activation "in vivo" during bleeding. Evidende of thrombin formation at the early stage of hemostasis. Pathol. Biol. 24: 6-10; 1976.

129) Bếguin, $S_{\text {; }}$ Lindhout, $T_{\text {; }}$ Hemker, H. C.: The mode of action of heparin in plasma. Thromb. Haemostas.; 60: 457-462; 1988.

130) Ofosu, F. A.; Sie, P.; Modi, G.J.; Fernandez, F.; Buchanan, M.; Blajchman, M.A.; Boneu, B. and Hirsh, J.: The inhibition of thrombin-dependent positivefeedback reactions is critical to the expression of the anticoagulant effect of heparin. Biochem. J. 243, 579-588; 1987.

131) Ofosu, F.A.; Blajchman, M.A.; Modi, G.J.; Smith, L.M.; Buchanan, M.R.; Hirsh, Ja: The importance of thrombin inhibition for the expression of the anticoagulant activites of heparin, dermatan sulfate, low molecular weight heparin and pentosan polysulfate. Br. J. Haematol:; 60: 695-704; 1985.

132) Pieters, Ji.; Lindhout, $T$.: The Limited importance of factor Xa inhibition to the anticoagulant property of heparin in thromboplastin activated plasma. Blood 72 : $2048-2052 ; 1988$.

133) Mc Nelly, T.B.; Griffith, M.J.: The anticoagulant mechanism of action of heparin in contact-activated plasma: Inhibition of factor $X$ activation. Blood 65: $1226-1231 ; 1985$.

134) Pieters, J.; Willems, G.; Hemker, H.C.; Lindhout, T.: Inhibition of factor IXa and factor $\mathrm{Xa}$ by antithrombin III/heparin during factor $\mathrm{X}$ activation. $\mathrm{J}$. Biol. Chem. 263: $15313-15318 ; 1988$.

135) Beguin, S; Dol. F. Hemker, H.C: Factor IXa inhibition contributes to the 
heparin effect. Thrombosis and Haemostasis 66: 306-309; 1991.

136) Béguin, S.; Choay, J.; Hemker, H.C.: The action of a synthetic pentasaccharide on thrombin generation in whole plasma. Thromb. Haemostas; 61: 397-401; 1989.

137) Hemker, H.C.; Béguin; S.: Mode of action of Unfractionated and Low Molecular Weight Heparin on the Generation of Thrombin in Plasma. Haemostasis 20 (suppl. 1). 81-92; 1990.

138) Walenga, J.M.; Bara, L.; Petitou, M.; Samama, M.; Fareed, J. and Choay, J.: The inhibition of the generation of thrombin and the antithrombotic effect of a pentasaccharide with sole anti-factor Xa activity. Thromb. Res. 51, 23-33, 1988.

139) Bendetowicz, A.V.; Bara, L.; Samama, M.: The inhibition of intrinsic prothrombinase and its generation by heparin and four derivatives in prothrombin poor plasma. Thromb. Res. ; 58: 445-454; 1990.

140) Schoen, P.; Lindhout. T.; Willems, G.; Hemker, H.C.: Antithrombin III-dependent anti-prothrombinase activity of heparin and heparin fragments. I. Biol. Chem. 264: $10002-10007 ; 1989$.

141) Bendetowicz, A.V.; Pacaud, E.; Béguin, S.; Uzan, A.; Hemker, H.C.: On the relationship between molecular mass and anticoagulant activity in a low molecular weight heparin (enoxaparin). To be published in: Thromb. Haemostas.; 1991.

142) Béguin, S.; Wielders, S.; Lormeau, J.C.; Hemker, H.C.: The mode of action of CY 216 and CY 222 in plasma. To be published in: Thromb. Haemostas.; 1991.

143) Holmer, E.; Mattsson, C.; Nilsson, S.: Anticoagulant and antithrombotic effects of heparin and low molecular weight heparin fragments in rabbits. Thromb. Res. 25: 475-485; 1982.

144) Teien, A.N.; Lie, M.: Evaluation of amidolytic heparin assay method. Increased sensitivity by adding purified antithrombin III. Thromb. Res. 10; 399-410; 1977 .

145) Bara, L., Combe-Tamzali, S.; Conard, J.; Horellou, M.H.; Samama, M.: Modifications biologiques induites par trois héparines de bas poids moléculaire: PK 10169, Kabi 2165 et CY 216, comparées à l'héparine non fractionnée, injectées par voie sous-coutanée chez le volontaire sain, et en chirurgie générale chez le sujet âgé en médecine. J. Mal. Vasc.; 12: 78-84; 1987.

146) Bara, L; Billaud, E; Kher, A.; Samama, M.: Increased anti-Xa bioavailability for a low molecular weight heparin (PK 10169) compared with unfractionated heparin. Sem. Thromb. Haemostas. 11, 3: 316-317; 1985.

147) Bara, L; Billaud, E.; Gramond, G.; Kher, A.; Samama, M.: Comparative pharmacokinetics of a low molecular weight heparin (PK10169) and unfractionated heparin after intravenous and subcutaneous administration. Thromb. Res. 39: 631636; 1985 .

148) Palm, M.; Wu, H.; Mattsson Ch.; Ansari, A.: Pharmacokinetic properties of size-homogeneous heparin oligosaccharides. Thromb. Res. 59: 799-806; 1990. 
149) Bratt, G.; Törnebohm, E.; Widlund, L.; Lockner, D. Low molecular weight heparin (Kabi 2165, Fragmin): Pharmacokinetics after intravenous administration in human volunteers. Thromb. Res. $42 ; 613-620: 1986$.

150) Pangrazzi, J.; Abbadini, M.; Zameta, M.; Naggi, A.; Torri, G.; Casu, B.; Donati, M.B.: Antithrombotic and bleeding effects of a low molecular weight heparin fraction. Biochem. Pharmacol. 34, 3305-3308; 1985 .

151) Diness, Y.; Nielson, J.L; Pedersen, P.C.; Wolfbrandt, K.H.; Ostergaard, P.B.: A comparison of the antithrombotic and hemorrhagic effects of low molecular weight heparin (PHN-1) and conventional heparin. Thromb. Haemostas. 55: 410-414, 1986.

152) Mätzsch, T.; Bergqvist. D.; Fredin, H.; Hedner, U.; Ostergaard, P.: Influence of a low molecular weight heparin on the inhibition of factor $X a$ and thrombin in hip surgery. Thromb. Res. 56: 559-564: 1989.

153) Samama, M.M.; Combe, S; Horellou, M.H.; Augras, D.; Truc, J.B.; Conard, J.; Girard, P.: Bara, L.; Poitout, Ph.: Anti Xa activity and prothrombinase inhibition in patients treated with two different doses of enoxaparin in gynecologic surgery. Thromb. Res Suppl XIV: 29-37, 1991.

154) Ambrosioni, E;; Strocchi, E.: Pharmacokinetics of heparin and low molecular weight heparins. Haemostasis 20: 94-97; 1990.

155 ) Denton, J.; Lane, D.J.; Thunberg, L.; Slater, A.M.; Lindhal. U.: Binding of platelet factor 4 to heparin oligosaccharides. Biochem. J.; $209: 455-460 ; 1983$.

156) Michalski, R.; Lane, D.A.; Pepper, D.S.; Kakkar, V.V.: Neutralization of heparin in plasma by platelet factor 4 and protamine sulphate. British. J. of Haematol. 38: 561-561; 1978.

157) Doutremepuich, C.; Bonini, F.; Toulemonde, F.; Bertrand, H.; Bayrou, B.; Quilichini, R.: In vivo neutralization of low molecular weight heparin fraction $\mathrm{CY}$ 216 by protamine. Seminars in Thrombosis and Hemostasis 11, 3: 318-322; 1985 .

158) Massonnet-Castel. S.; Pelissier, E.; Bara, $\mathbb{L}$.; Terrier, E.; Abry B.; Guibourt, J.; Swanson, B.; Carpentier, A." Samama, M.: Partial reveral of low molecular wight heparin (PK 10169) anti-Xa activity by protamine sulfate: In vitro and in vivo study during cardiac surgery with extracorporeal circulation. Haemostasis 16: 139-146: 1986.

159) Hirsh, J.; Buchanan, M.R.; Comparative effects of heparin and LMW heparin on hemostasis. Thromb. Res. Suppl. XIV; 11-17; 1991.

160) Béguin, S.; Lindhout, T.; Hemker H.C.: The effect of trace amounts of tissue factor on thrombin generation in platelet rich plasma; its inhibition by heparin. Thromb. Haemostas. 61:25-29:1989.

161) Béguin, S.; Hemker, H.C. Mode of action of enoxaparin in plasma. Acta Chir. Scand. Suppl. 556:51-56; 1990 .

162) Hemker, H.C.; Veltkamp, J.J.; Hensen, A.; Loeliger, E.A.: Nature of 
prothrombin biosynthesis: preprothrombinaemia in vitamin k-deficiency. Nature 200: 589-590; 1963.

163) Josso, F.; Lavergene, J.M.; Gouault, M.; Prou-Wartelle, O.; Soulier, J.P.: Différents états moléculaires du facteur II (prothrombine). Leur étude

à l'aide de la staphylocoagulase et d'anticorps anti-facteur II. Thromb. Diath. Haemorrh. 20: 88-98; 1968 .

164) Stenflo, J.: A new vitamin K-dependent protein. Purification from bovine plasma and preliminary characterization. J. Biol. Chem. 251: 355-363; 1976.

165) Nelsestuen, G.L.: Role of -carboxyglutamic acid. An unusual protein transition required for the calcium-dependent binding of prothrombin to phospholipid. $\underline{\mathbf{J} \text {. Biol. }}$ Chem. 251; 5: 5648-5656; 1976 .

166) Morita, $T$. in: Suttie (ed): Vitamin-K metabolism and vitamin-K dependent proteins; pp 124-128; 1979 (Univ. of Park Press, Baltimore).

167) Fujikawa, K; Legaz, M.E.; Davie, E.W.: Bovine factor $X_{1}$ (Stuart Factor). Mechanism of activation by a protein from Russell's Viper venom. Biochemistry. 11; 26: 4892-4899: 1972 .

168) Rouvier, J.; Collen, D., Swart, A.C.W.; Verstraete, M.: Prothrombin Metabolism in healthy subjects and in two patients with congenital hypoprothrombinemia. In: Prothrombin and related coagulation factors; 1975. Eds: Hemker, H.C.; Veltkamp, J.J. Leiden Univ. Press.

169) Novotny, W.F.; Palmier, M.; Wun T.C.; Broze, G.J.; Miletich, J.P. Purification and properties of heparin-releasable lipoprotein-associated coagulation inhibitor. Blood 78 (2): 394-400; 1991. 


\section{ON THE RELATIONSHIP BETWEEN MOLECULAR WEIGHT AND Anticoagulant ACTIVITy of a Low Molecular Weight HEPARIN (ENOXAPARIN)*}

\section{SUMMARY}

A low molecular weight heparin (enoxaparin, mean molecular weight - 4.400) was separated by gel chromatography into eight different fractions with a narrow distribution around the following mean molecular weights: $1800,2400,2900,4200,6200,8600,9800$ and 11000 . We compared the effect of enoxaparin on the generation of thrombin in plasma, to that of the eight fractions.

We determined: a) the $\%$ of material with high affinity to antithrombin III (HAM) and the \% of HAM above the critical chainlength necessary to allow thrombin inhibition (ACLM) b) the specific catalytic activity on the decay of endogenous thrombin and c) the inhibition of over-all thrombin formation in the extrinsic and the intrinsic pathway. From $b$ and $c$ we calculated the inhibition of prothrombin conversion in these pathways.

We found that a) there is a gradual increase of HAM with increasing molecular weight; b) the specific catalytic activity for the inactivation of thrombin does not vary significantly between the fractions when expressed in terms of ACLM. c) the potency to inhibit prothrombin conversion does not vary significantly between the fractions when expressed in terms of HAM.

Our observations support previous conclusions that the active heparin species come in two classes, the P-type and the S-type: The P-type has no anti-thrombin activity and an alledgedly invariable anti-prothrombinase activity when expressed in molar units $\left(\mathrm{IC}_{2 s}=\sim 0.1 \mu \mathrm{M}\right)$. The S-type has a higher anti-prothrombinase activity than the P-type has. Yet, at concentrations that give comparable overall inhibition of thrombin generation, the antiprothrombinase activity of the S-type contributes little to this inhibition because it is mainly determined by the anti-thrombin activity.

\section{INTRODUCTION}

Prevention of appearance of free thrombin at a site where the blood coagulation mechanism is triggered is putatively the main mechanism by which antithrombotic pharmaceuticals exert their action (1). Heparins act.

\footnotetext{
*Based on: Bendetowicz, A.V.; Pacaud, E.; Béguin, S.; Uzan, A ; Hemker, H.C. Accepted in: Thrombosis and Haemostasis.
} 
by catalysing the inactivation of clotting factors by AT III, heparin cofactor II being stimulated only at concentrations that are not usually attained in clinical practise. Consequently only those molecules that bind to AT III, i.e. the high affinity material (HAM), is capable to affect blood coagulation in a patient. Heparins loose their capacity to catalyse the AT III dependent inhibition of thrombin with decreasing molecular weight (2-6). Barrowcliffe et al (5), and Thomas et al (6) have shown that heparin fragments with a chainlength of 10-18 monosaccharide units have a high anti-factor $\mathrm{Xa}$ activity, and that a length of 20-22 saccharides is minimally required for an anti-thrombin activity. Lane and coworkers (4) studied a heparin series of 8 to $>18$ monosaccharides and concluded that 18 units is the smallest chainlength that allows for the potentiation of the inactivation of thrombin, whereas the activity against factor Xa was high in all fragments. From this it follows that all the HAM in a heparin has anti factor Xa activity, whereas antithrombin activity is only expressed in HAM above the critical chainlength of 18 monosaccharides (ACLM). It therefore seemed logical to think that low molecular weight heparins should owe their antithrombotic action at least in part to their anti-factor $\mathrm{Xa}$ activity.

From there it was a small step to surmise that LMWHs with a high ratio of antifactor $\mathrm{Xa-}$ to antithrombin activity could make better antithrombotic drugs than conventional, unfractionated heparins (7).

It has however been shown that the inhibitory action of a heparin measured on isolated factors do not necessarily directly reflect its activities in the complex medium of plasma (8-11). In order to study the effects of heparins under the conditions prevailing in clotting plasma, a method has been developed in our laboratory that allows the calculation of the conversion rate of prothrombin, independent of the simultaneous breakdown of the thrombin generated (8). By this approach it could be shown that:

1) Unfractionated heparin (UHH) acts mainly by enhancing the decay of thrombin, and its effect on the inhibition of prothrombinase in the extrinsic pathway is of minor importance (12).

2) The synthetic pentasaccharide (PS) that represents the AT IIIbinding site of heparin (13), and that does not catalyse direct inhibition of thrombin (14), unlike UH does inhibit prothrombinase via its action on inhibition of free factor Xa $(14,15)$.

3) Most low molecular weight heparins (LMWHs) act rather like standard heparin, in that they have a minor influence on the prothrombinase activity in plasma, even though their potency to inhibit factor $\mathrm{Xa}$ is high in proportion to their anti-thrombin activity (16).

One of the LMWH preparations that we studied, PK 10169 or enoxaparin, caused a relatively high inhibition of prothrombin conversion. This has previously been explained as being caused by a high proportion of pentasaccharide like material (17). This study was undertaken to establish 
what material in enoxaparin is responsible for its over-all action on blood coagulation. To this end, eight fractions with largely different average molecular weight (MW), and a narrow MW distribution around the peak have been prepared. We studied the anti-thrombin and antiprothrombinase properties as a function of the HAM and the ACLM content of these fractions.

\section{MATERIALS AND METHODS}

\section{Materials}

Reagents. Three batches of the low molecular weight heparin enoxaparin (88.145.02; 89.009.01; 89.037.01) were supplied by Rhône-Poulenc Rorer: They were prepared from heparin by chemical $\beta$-elimination. Three runs were performed with different batches of heparin. The average molecular weights (Mw) of the three batches of enoxaparin were around 4400,4500 , and 4500 respectively. Their anti factor Xa activities $(18,19)$ were 115,120 and $108.5 \mathrm{IU} / \mathrm{mg}$. Their activity in the European pharmacopoeia method (i.e. an activated partial thromboplastin time in sheep plasma) was $56.3,66$, and $57 \mathrm{IU} / \mathrm{mg}$ respectively. From one of these batches (88.145.02), eight fractions with narrow MW were obtained (see methods).

The chromogenic substrate for thrombin H.D-Phe-Pip-Arg-pNA (S2238), was obtained from Kabi, Sweden. Kaolin (Kaolin léger) was provided by B.L.B. Laboratoires du Bois de Boulogne (Puteaux, France). Buffer A: $50 \mathrm{mM}$ Tris- $\mathrm{HCl}, 100 \mathrm{mM} \mathrm{NaCl}, 0.5 \mathrm{mg} / \mathrm{ml}$ human serum albumin, $\mathrm{pH}$ 7.35. Buffer B: $50 \mathrm{mM}$ Tris- $\mathrm{HCl}, 100 \mathrm{mM} \mathrm{NaCl}, 0.5 \mathrm{mg} / \mathrm{ml}$ human serum albumin, $20 \mathrm{mM}$ EDTA at $\mathrm{pH} 7.90$.

Plasma. Blood from ten healthy donors was collected on $0.13 \mathrm{M}$ trisodium citrate; nine parts of blood to one part of citrate solution. A first and a second centrifugation were done at $15{ }^{\circ} \mathrm{C}$, during 15 minutes at $3000 \mathrm{x} \mathrm{g}$, and a third centrifugation was done at $4{ }^{\circ} \mathrm{C}$, for 1 hour at $23,000 \times \mathrm{g}$. The platelet free plasma thus obtained was stored at $-80^{\circ} \mathrm{C}$. It was checked that the clotting factors and the antiproteases were in the normal range. Defibrinated plasma was obtained by mixing an aliquot of plasma with 1:50 volume of a reptilase solution, letting a clot form for 5 min at $37^{\circ} \mathrm{C}$, and keeping the clotted plasma at $4^{\circ} \mathrm{C}$ for 10 minutes. The fibrin formed was discarded by winding it on a small plastic spatula. As it was previously shown, the concentration of factors II, VII, VIII, IX, X, XI and XII does not change significantly by the reptilase treatment (8).

Proteins. Reptilase was obtained from Boehringer Mannheim (Mannheim, 
W. Germany) and dissolved according to the instructions of the manufacturer. Soybean Trypsin Inhibitor, (batch $\mathrm{N}^{\circ} 43 \mathrm{~F} 8000$ ) was obtained from Sigma (St. Louis, USA). Staphylocoagulase was obtained from Laboratoires Stago (Asnières, France) and reconstituted according to the instructions of the manufacturer. Semipurified human AT III was a kind gift of Prof $\mathrm{H}$. Goudemand (Lille). Purified AT III was obtained by polyethylene glycol precipitation of barium citrate-adsorbed plasma and affinity chromatography on a heparin-sepharose column (20). The AT III was subsequentely freed of remaining heparin by ion exchange chromatography (21). Its activity was assessed by titration with active site titrated factor Xa (22). Human brain thromboplastin was prepared acording to Owren and Aas (23). Before use it was diluted with buffer A containing $0.1 \mathrm{M} \mathrm{Ca}^{++}$so as to clot a mixture of $30 \mu \mathrm{l}$ of thromboplastin, $30 \mu \mathrm{l}$ of buffer $\mathrm{A}$ and $120 \mu \mathrm{l}$ of plasma in $70-80$ seconds.

\section{Methods}

\section{Heparin fractionation}

From one of the enoxaparin batches (88.145.02) eight fractions with narrow molecular weight distribution were obtained by Large Scale Gel Permeation Chromatography on ACA 202 and ACA 54. The mobile phase was $0.33 \mathrm{M} \mathrm{NaCl}$. The average molecular weight of enoxaparin and the fractions (N6 to N36) was determined by High Performance Size Exclusion Chromatography (HPSEC) coupled with Laser Light Scattering. In addition, we estimate the average number of disaccharidic units per chain by ${ }^{13} \mathrm{C}$ NMR analysis (24). The narrow elution profiles and the ratio of weight average to number average molecular weights of close to unity indicated a limited degree of polydispersity. HPSEC was performed on an system that consists of a Gilson 302 pump, a RID 6 A differential refractometer (Shimadzu) and an SF UV detector (Kratos). Aqueous solutions of enoxaparin at $10 \mathrm{mg} / \mathrm{ml}$ were analysed on a two column system (TSK G $3000 \mathrm{SW}-30 \times 0.75 \mathrm{~cm}$ and Lichrosorb 100 diol $25 \times 0.75 \mathrm{~cm}$ ). The mobile phase $(0.3 \mathrm{M}$ phosphate buffer, $\mathrm{pH} 7$ ) was used at flow rate 0.75 $\mathrm{ml} / \mathrm{mn}$. Due to the narrow molecular weight distribution fractions, they were used to calibrate the chromatographic system applied subsequentley for the determination of the MW of enoxaparin.

\section{Fluorescence Measurements.}

The molar concentrations of the HAM in each isolated fraction were determined by a stoichiometric titration of AT III $(0.5 \mu \mathrm{M})$ in buffer (Tris $\mathrm{HCl} 50 \mathrm{mM}, \mathrm{NaCl} 0.1 \mathrm{M}, \mathrm{pH} 7.5$ ) as described in ref. 25. Briefly, the binding of a heparin fraction to Antithrombin III results in an increase of the tryptophan fluorescence of the protein (excitation at $285 \mathrm{~nm}$, emission 
at $345 \mathrm{~nm}$; ref. 26), upon addition of increasing amounts of heparin. The fluorescence of AT III increases proportionally with the heparin concentration until the equivalence point has been reached. The fluorescence increase is calculated as $\left(F-F_{0}\right) / F_{m}-F_{o}$, were $F$ is the fluorescence intensity of the sample containing heparin, $F_{o}$ that of the control solution without heparin, and $F_{m}$ is the fluorescence obtained at the saturation concentrations. The fluorescence increase can subsequentely be plotted as a function of the heparin concentration (in $\mu \mathrm{g} / \mathrm{ml}$ ).

The concentration of the heparin fraction at the inflection point (in $\mu \mathrm{g} / \mathrm{ml}$ ), contains the number of binding sites present in the AT III added (i.e. $0.5 \mu \mathrm{M}$ ). The AT III itself has been titrated with synthetic pentasaccharide that is assumed to contain $100 \%$ of high affinity material. In this way it is possible to obtain the molar concentration of binding sites per $\mathrm{mg}$ of heparin.

Knowing the MW of the heparin we can then calculate the percentage of high affinity molecules in the heparin prepartion. The titration was followed on a SLM Aminco SPF-500 C spectrofluorometer.

\section{Rate constants of inactivation of endogenous thrombin.}

Defibrinated plasma $(120 \mu \mathrm{l})$ is mixed with buffer A $(14 \mu \mathrm{l})$, and prewarmed for 5 minutes at $37^{\circ} \mathrm{C}$. Thrombin generation is started by the addition of $30 \mu \mathrm{l}$ of thromboplastin dilution. Two minutes after the peak activity of thrombin, $6 \mu \mathrm{l}$ of a $10 \mathrm{mg} / \mathrm{ml}$ Soybean Trypsin Inhibitor (SBTI) solution (8), is added together with $10 \mu \mathrm{l}$ of buffer that contains the heparin to be tested. At suitable intervals after this addition $10 \mu \mathrm{l}$ aliquots of the incubation mixture are transferred to cuvettes containing $0.2 \mathrm{mM} \mathrm{S}$ 2238 in $490 \mu \mathrm{l}$ of buffer B to measure residual thrombin activity. After 120 seconds, the reaction in the cuvette is stopped by adding $300 \mu 1$ of concentrated acetic acid. The pseudo-first order rate constant of inhibition of thrombin generated in plasma is calculated by fitting the data to

$C_{t}=C_{R}+C_{0} e^{-k t}$,

where $C_{t}$ is the thrombin activity at time $t, C_{R}$ is the steady end-level activity, $\mathrm{C}_{\mathrm{o}}+\mathrm{C}_{\mathrm{R}}$ is the amidolytic activity at the time of SBTI addition. The observed decay constant is the sum of two constants, $k=k_{1}+k_{2} ; k_{1}$ is the AT III-dependent decay constant of inhibition of thrombin, $k_{2}$ is the decay constant of inhibition of thrombin by $\alpha_{2}$-macroglobulin $\left(\alpha_{2}-\mathrm{M}\right)$. The ratio of $k_{1}$ to $k_{2}$ is determined as the ratio of the amounts of thrombin complexed with AT III and $\alpha_{2}-\mathrm{M}$ as described previously (8). From their sum and their ratio the constants are calculated. $k_{1}$ in all instances is lineary dependent upon the heparin concentration, so the second order rate constants of thrombin inhibition could be obtained from the pseudo-first 
order rate constants by calculating the increase of $k_{1}$ per $\mu g$ of heparin. $k_{2}$ appeared not to be dependent on the amount of heparin added.

\section{Thrombin Generation in Plasma}

$240 \mu 1$ of defibrinated plasma is supplemented with $60 \mu 1$ of buffer $A$, containing heparin at the desired concentration and incubated for $5 \mathrm{~min}$ at $37^{\circ} \mathrm{C}$. At zero time, thrombin generation is started by the addition of $60 \mu \mathrm{l}$ of a solution containing $100 \mathrm{mM}$ of $\mathrm{CaCl}_{2}$, and a trigger of coagulation. For the extrinsic system this is human brain thromboplastin, as described in the previous section. For the intrinsic system, $1 \mu \mathrm{M}$ phospholipid and $0.025 \mathrm{mg}$ kaolin (final concentration). At intervals, a $10 \mu \mathrm{l}$ aliquot of the mixture is sampled into a disposable plastic cuvette containing buffer and chromogenic substrate, as described above. The optical density is measured at $405 \mathrm{~nm}$. The amidolytic activities in the plasma samples are calculated from the O.D., and expressed as the equivalent concentration of thrombin (in $\mathrm{nM}$ ), according to a reference curve obtained with active site titrated purified human $\alpha$ thrombin. From the curves of amidolytic activity the thrombin concentrations were obtained as previously described (8).

\section{Prothrombinase Activity in Plasma}

The generation of prothrombinase activity is calculated from the amidolytic activity curve of thrombin generation as described previously (8). Briefly, the observed amidolytic activity is the sum of thrombin activity and the partial activity of $\alpha_{2} \mathrm{M}$-thrombin complex. The rate of thrombin generation at any moment is the sum of two processes: a) The conversion of prothrombin into thrombin by prothrombinase and b) the decay of thrombin by the action of plasma protease inhibitors. The rate of inhibition of thrombin at any time can be calculated from the concentration of thrombin at that moment and the pseudo-first order rate constant of thrombin inhibition by antithrombin III $\left(k_{1}\right)$ and $\alpha_{2}$-macroglobulin $\left(k_{2}\right)$. The rate of prothrombin activation (prothrombinase activity) then can be calculated from the observed rate of generation of amidolytic activity and the rate of thrombin inhibition.

\section{RESULTS}

\section{Physicochemical properties and AT III affinity of the fractions}

Table 1 summarises the data obtained from the physicochemical characterisation of the fractions. The ratio of near unity of the weight average to the number average molecular weight demonstrates the narrow distribution of the MW of these fractions.

Also in table 1 one finds the chainlength as calculated from the 
HPLC data on basis of a mean MW of 300 per monosaccharide unit, as well as the chainlength obtained from the NMR data. From these two parameters, and knowing that theoretically the chainlength has to be an even integral number, we estimated the most probable number of monosaccharide units for the major part of the material $\left(\mathrm{N}_{\mathrm{est}}\right.$ in table 1). We also calculated the amount of material with a MW $>5,400$ from HPLC profiles.

The titration of AT III with the heparins permitted to calculate the active concentration of heparin at the equivalence point. Subsequentely the percentages of material with high affinity for AT III (HAM) found in the different fractions were obtained (table 2). Figures 1 and 2 show the stoichiometrical titration of AT III with enoxaparin and its fractions. As can be seen from figure 3 , the percentage of HAM seems to increase linearly with the mean size of the heparin molecule.

Table 1. Properties of the Enoxaparin Fractions

\begin{tabular}{lllllll}
\hline Heparin & \multicolumn{3}{c}{ HPLC* } & \multicolumn{3}{l}{ NMR $^{* * *}$} \\
& MW & W/N & N & N & S/Cx & N $_{\text {es1 }}$ \\
\hline N6 & 1860 & 1.03 & 6.2 & 7 & 2.4 & 6 \\
N8 & 2400 & 1.02 & 8.0 & 9 & 2.4 & 8 \\
N10 & 2900 & 1.02 & 9.7 & 10.8 & 2.2 & 10 \\
N14 & 4200 & 1.01 & 14.0 & 14.5 & 2.2 & 14 \\
N20 & 6200 & 1.01 & 20.7 & 20.8 & 2.0 & 20 \\
N28 & 8600 & 1.01 & 28.7 & - & - & 28 \\
N32 & 9800 & 1.03 & 32.7 & - & - & 32 \\
N36 & 11000 & 1.05 & 36.6 & - & - & 36 \\
\hline
\end{tabular}

"HPLC: data from high performance liquid chromatograpliy;

**NMR: data from nuclear magnetic resonance; MW: weight average molecular weight $\mathrm{W} / \mathrm{N}$ : ratio of weight and number average molecular weight; $\mathrm{N}$ : number of monosaccharide units. S/Cx gives the ratio sulfate/carboxyl.

$\mathrm{N}_{\mathrm{est}}$ gives the estimated number of monosaccharides of the main component of the fraction assessed from the experimental data, and knowing it to be an even integral number. 
Table 2. AT III Binding Material of the Enoxaparin Fractions

\begin{tabular}{llllc}
\hline Heparin & $\begin{array}{l}\text { I. P* } \\
\mu \mathrm{g} / \mathrm{ml}\end{array}$ & $\begin{array}{l}\text { Binding Sites** } \\
\mu \mathrm{M} \text { AT/mg hep }\end{array}$ & $\begin{array}{c}\text { HAM }^{*} \\
\% \text { of total }\end{array}$ & $\begin{array}{c}\text { ACLM }^{* *} \\
\% \text { of HAM }\end{array}$ \\
\hline N6 & 114 & 8.8 & 1 & $<3$ \\
N8 & 36 & 30 & 6 & $<3$ \\
N10 & 31 & 32 & 9 & 3 \\
N14 & 21 & 48 & 20 & 10 \\
N20 & 10 & 50 & 30 & 67 \\
N28 & 9 & 55 & 50 & $>95$ \\
N32 & 8 & 62 & 61 & $>95$ \\
N36 & 10 & 52 & 57 & $>95$ \\
enox & 16 & 31 & 14 & 61 \\
\hline
\end{tabular}

*I.P. (inflection point): concentration of heparin at the equivalence point.

* Binding sites: Concentration of AT III that binds $1 \mathrm{mg}$ heparin.

-HAM: percentage of AT III- high affinity material contained in each molecular specic.

*ACLM: percentage with a MW >5.4kD.

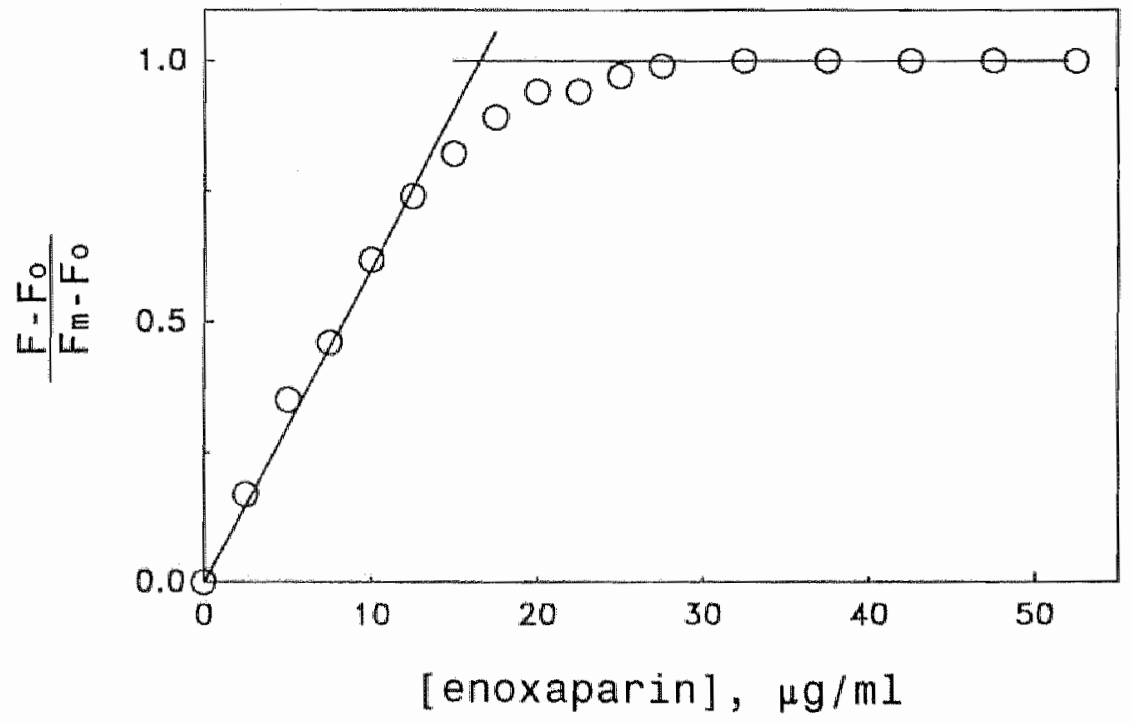

\section{Figure 1}

The Fluorometric Titration of AT III with Enoxaparin. The titration was done in the presence of $0.5 \mu \mathrm{M}$ AT III. The fluorescence increase is calculated as $\left(\mathrm{F}-\mathrm{F}_{\mathrm{o}}\right) / \mathrm{F}_{\mathrm{m}}-\mathrm{F}_{\text {, }}$ where $F$ is the fluorescence intensity of the sample containing heparin, $F_{0}$ that of the control solution without heparin, and $F_{m}$ is the fluorescence obtained at the saturation concentrations. For more experimental details see Methods section. At the equivalence point the concentration of enoxaparin was $16 \mu \mathrm{g} / \mathrm{ml}$. 

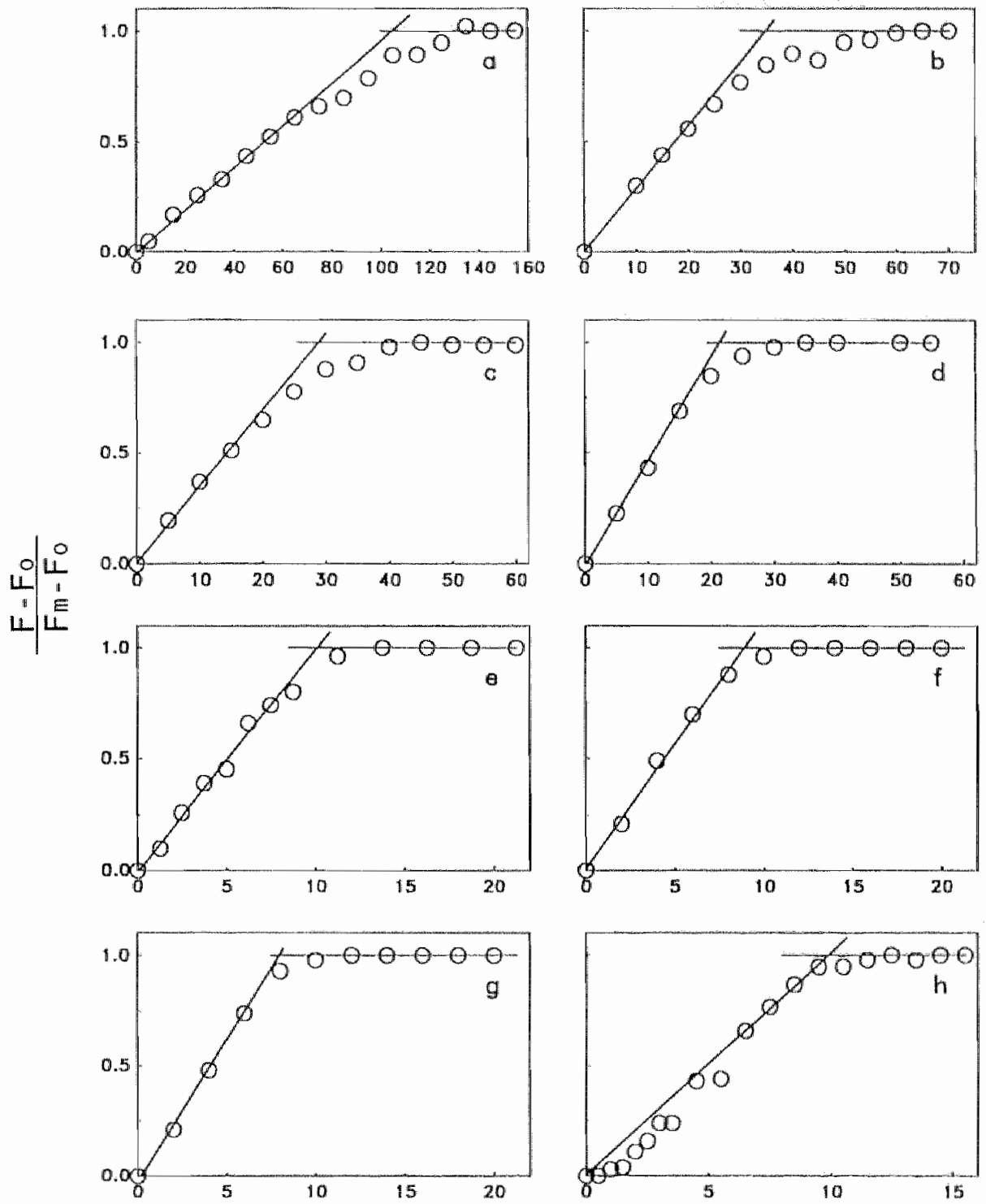

[Fraction], $\mu \mathrm{g} / \mathrm{ml}$

Figure 2

The Fluorometric Titration of AT III with the Fractions of Enoxaparin. Experimental conditions are the same as in figure 1. The concentration of the enoxaparin fractions at the inflexion point were: $114,36,31,21,10,9,8,10 \mu \mathrm{g} / \mathrm{ml}$ for N6 to N36 respectively. a: N6; b: N8; c: N10; d: N14; e: N20 f: N28; g: N32; h:N36. 


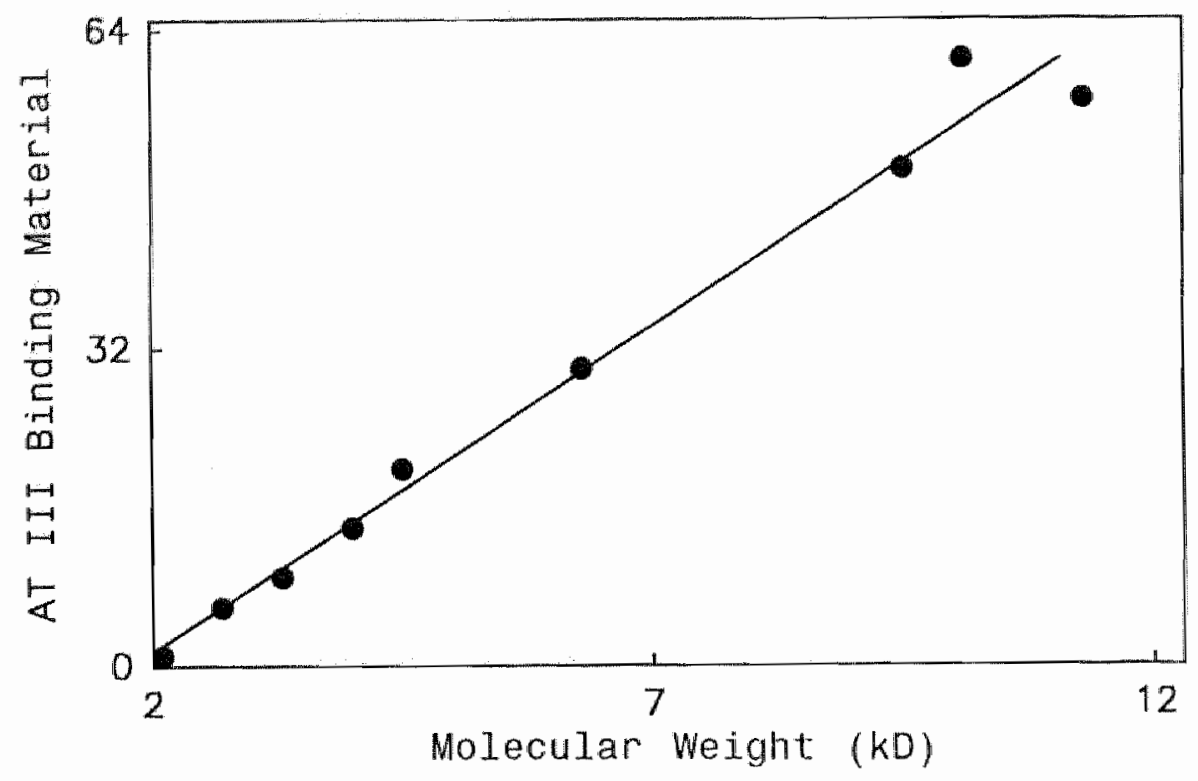

\section{Figure 3}

The Percentage of Heparin Material with High Affinity to AT III as a Function of Molecular Weight. The percentage of HAM was obtained from the fluorometric titration of AT III (table 2), and the molecular weight from the data shown in table 1.

determined the specific activity of the heparins (table 3 ). We define the specific activity of a heparin with respect to thrombin as the increase of the decay constant of thrombin in plasma per $\mu \mathrm{g} / \mathrm{ml}$ of heparin (it can also be expressed per nanomole in those preparations of well defined molecular weight). Reasoning that the activity is caused by molecules with a high affinity to AT III and above the critical chainlength of 18 monosaccharide units, we calculated the specific activities of both the HAM and the ACLM in the fractions. The specific activity of enoxaparin is $1.050 \mathrm{~min}^{-1} \mu \mathrm{g}^{-1} \mathrm{.ml}$ (mean of three batches), which is close to the value of $1.110 \mathrm{~min}^{-1} \cdot \mathrm{\mu g}^{-1} \cdot \mathrm{ml}$ ) calculated from previous data (17). This amounts to $7.500 \mathrm{~min}^{-1}$ per $\mu \mathrm{g} / \mathrm{ml}$ of HAM, and $31.2 \mathrm{~min}^{-1}$ per $\mu \mathrm{g} / \mathrm{ml}$ of ACLM. 
Table 3. Specific Antithrombin Activities*

\begin{tabular}{lllll}
\hline Heparin & total & HAM $^{*}$ ACLM & $\begin{array}{l}\text { ACLM } \\
\text { (nM) }\end{array}$ \\
\hline Enox & 1.05 & 7.5 & 31.2 & - \\
N6 & 0 & 0 & 0 & - \\
N8 & 0 & 0 & 0 & - \\
N10 & 0 & 0 & 0 & - \\
N14 & 0.07 & 0.35 & 3.5 & - \\
N20 & 3.30 & 11 & 16.3 & 2.63 \\
N28 & 6.14 & 12.3 & 12.3 & 1.34 \\
N32 & 6.69 & 10.8 & 10.8 & 1.10 \\
N36 & 9.62 & 16.9 & 16.9 & 1.35
\end{tabular}

*The activities are expressed in $\min ^{-1} \cdot(\mu \mathrm{g} / \mathrm{ml})^{-1}$ except for the last column that is in ( $\min ^{-1}$ $\left.\mathrm{nM}^{\cdot 1}\right)$

\section{The over-all inhibition of the thrombin peak}

The inhibitory activity of the heparins on the formation of free thrombin in clotting plasma is an over-all effect that can be due to both an increased

decay of thrombin and a decreased prothrombin conversion. We can determine in how far the over-all inhibition is to be attributed to inhibition of prothrombin conversion because, from the thrombin generation curve and the decay constant of endogenous thrombin, we can calculate the velocity of prothrombin conversion (ref. 8; figures 5 and 6 ). This calculation is based on the observed thrombin activities. When thrombin concentrations are lower than the $20 \%$ of the control value, it is difficult to estimate prothrombinase with the required accuracy. Half total inhibition of prothrombin conversion often occurs at $>80 \%$ inhibition of the thrombin peak. We therefore determined the concentration of heparin necessary to obtain $25 \%$ inhibition of the prothrombinase activity, and compared it to the heparin concentration that causes $25 \%$ inhibition of the thrombin peak $\left(\mathrm{IC}_{25}\right.$, table 4). This was done both in the extrinsic, and the intrinsic system (figure 7). The results were again expressed in terms of HAM. We did not calculate the results in terms of ACLM, since prothrombinase inhibition is not necessarily confined to heparin molecules longer than the critical chainllength.

It was systematically observed that the heparins did not cause a prolongation of the lag-phase in the extrinsic system but all fractions studied prolong the lag-phase in the intrinsic pathway (see figures 5, 6 and 8). 

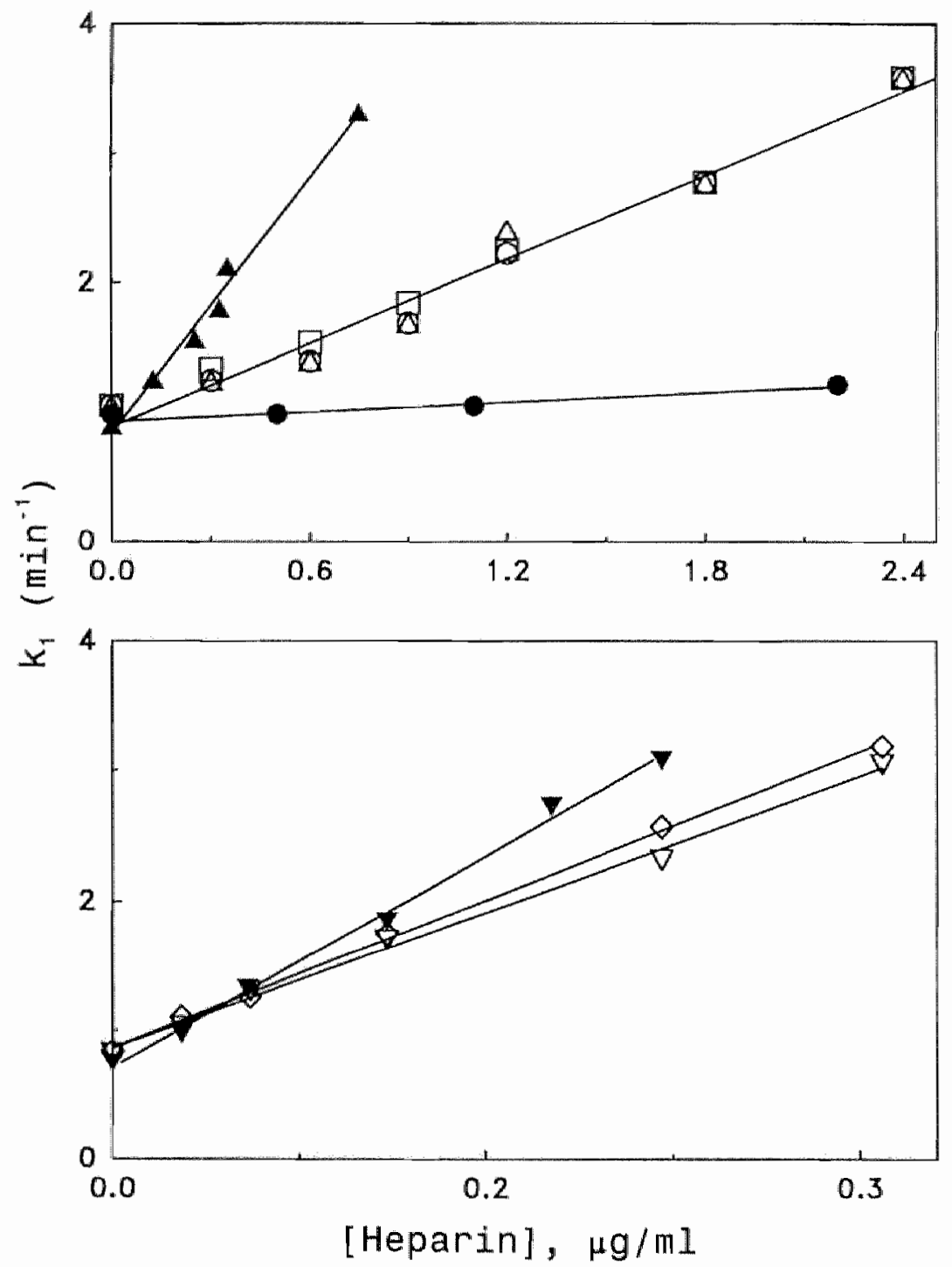

\section{Figure 4}

The Decay Constant of Endogenous Thrombin in Normal Plasma as a Function of the Heparin Concentration. Upper frame: Open symbols: Enoxaparin three batches.

N14; $\triangle-\Delta$ N20. Lower frame: $\Delta-\Delta N 28 ; \diamond-\diamond N 32 ; \nabla-\nabla N 36$ 

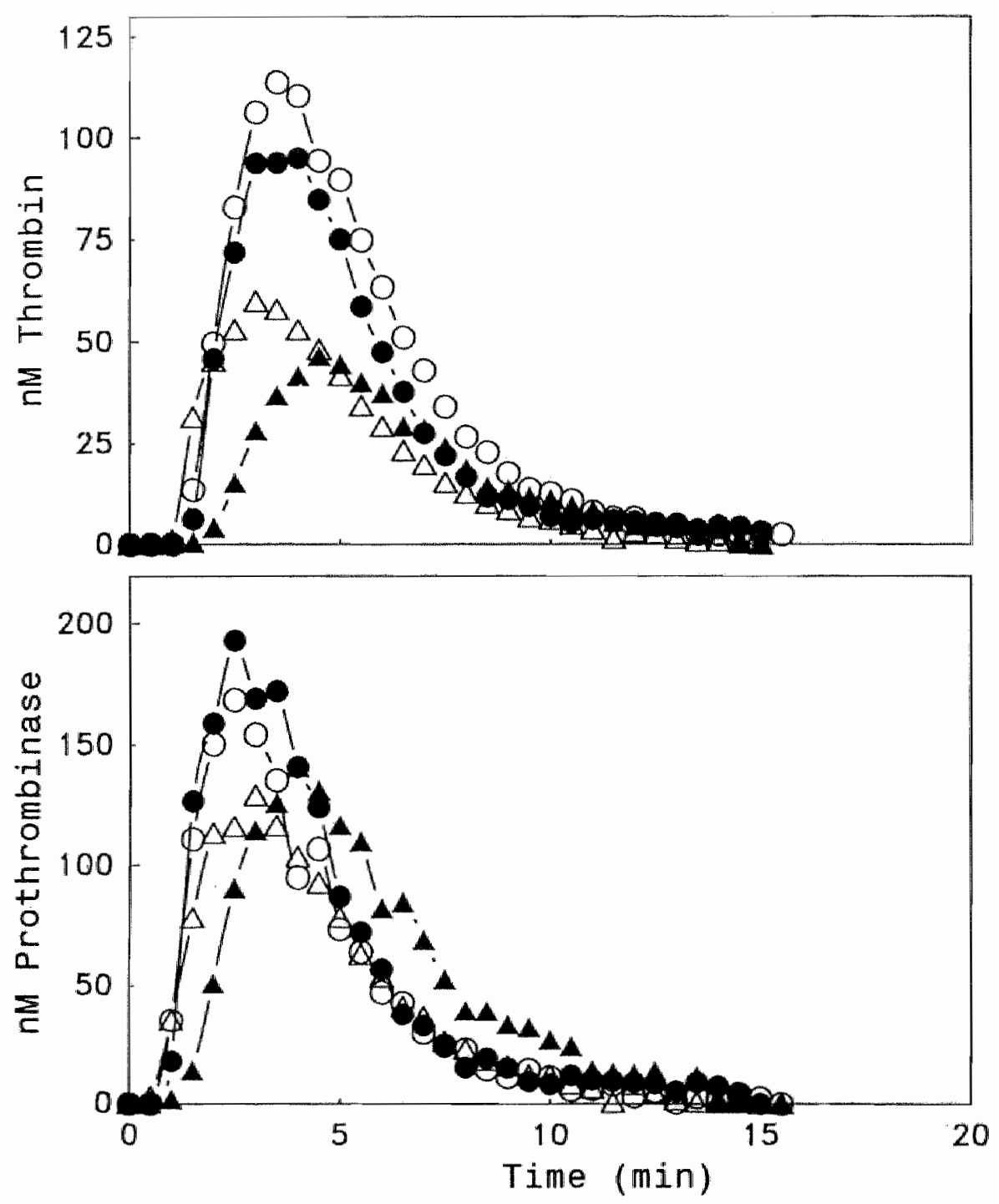

Figure 5

Exirinsic Thrombin and Prothrombinase Generation and Inhibition. Activation of coagulation was started after the addition of $17 \mathrm{mM} \mathrm{CaCl}_{2}$ (final concentration) and thromboplastin. For further experimental conditions see methods. $\mathrm{O}-\mathrm{O}$ Control; - $0.6 \mu \mathrm{g} / \mathrm{ml} ; \Delta-\Delta 0.9 \mu \mathrm{g} / \mathrm{ml} ; \wedge-\wedge 1.8 \mu \mathrm{g} / \mathrm{ml}$ enoxaparin. 

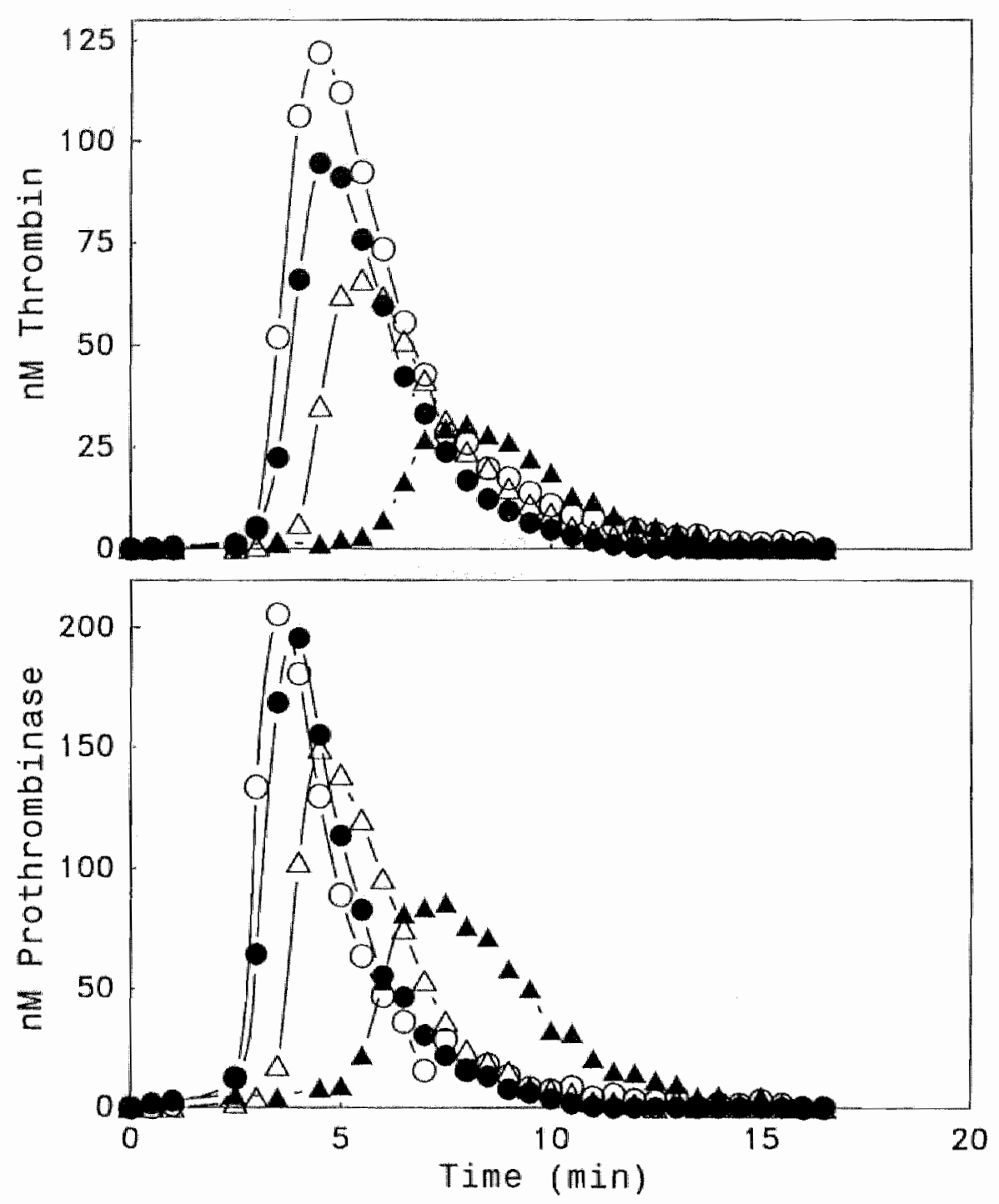

\section{Figure 6}

Intrinsic Thrombin and Prothombinase Generation and Inhibirion. Activation was started after the addition of $1 \mu \mathrm{M}$ PS:PS $(80: 20)+0.025 \mu \mathrm{g} / \mathrm{ml}$ kaolin. For further experimental conditions see methods. $\mathrm{O}-\mathrm{O}$ Control; $-0.6 \mu \mathrm{g} / \mathrm{ml} ; \Delta-\Delta 0.9 \mu \mathrm{g} / \mathrm{ml}$; 4-4 $1.8 \mu \mathrm{g} / \mathrm{ml}$ enoxaparin. 
Table 4. Concentrations that Cause $25 \%$ of Inhibition

A1) Weight basis (ng/ml), Extrinsic System

\begin{tabular}{lccccc}
\hline Heparin & \multicolumn{3}{c}{ Thrombin } & \multicolumn{2}{c}{$\begin{array}{c}\text { Prothrombinase } \\
\text { all }\end{array}$} \\
& all & HAM & ACLM & HAM \\
\hline Enoxaparin & 450 & 63 & $(26)$ & 750 & 105 \\
N6 & 15800 & 158 & - & 15800 & 158 \\
N8 & 4500 & 270 & - & 4500 & 270 \\
N10 & 3400 & 306 & - & 3400 & 306 \\
N14 & 2200 & 440 & 52 & 2600 & 520 \\
N20 & 200 & 60 & 40 & - & - \\
N28 & 70 & 35 & 35 & 170 & 85 \\
N32 & 80 & 50 & 50 & 210 & 130 \\
N36 & 90 & 51 & 51 & 340 & 194 \\
& & & & & \\
\hline
\end{tabular}

\section{Table 4}

A2) Weight Basis (ng/ml) Intrinsic System

\begin{tabular}{|c|c|c|c|c|c|}
\hline \multirow{2}{*}{ Heparin } & \multirow[b]{2}{*}{ all } & \multicolumn{2}{|c|}{ Thrombin } & \multicolumn{2}{|c|}{ Prothrombinase } \\
\hline & & HAM & ACLM & all & HAM \\
\hline Enoxaparin & 550 & 77 & $(32)$ & 750 & 105 \\
\hline N6 & 15800 & 158 & - & 15800 & 158 \\
\hline N8 & 4400 & 264 & - & 4400 & 264 \\
\hline N10 & 3800 & 342 & - & 3800 & 342 \\
\hline N14 & 1600 & 320 & 32 & 1600 & 320 \\
\hline $\mathrm{N} 20$ & 250 & 75 & 50 & - & - \\
\hline $\mathrm{N} 28$ & 50 & 25 & 25 & 75 & 37 \\
\hline N32 & 80 & 50 & 50 & 160 & 99 \\
\hline N36 & 60 & 34 & 34 & 130 & 74 \\
\hline
\end{tabular}


Chapter 2.

Table 4. Concentrations that Cause $25 \%$ of Inhibition BI) Molar Basis (nM) Extrinsic System

\begin{tabular}{lrrrrr}
\hline Heparin & \multicolumn{3}{c}{ Thrombin } & \multicolumn{2}{c}{$\begin{array}{l}\text { Prothrombinase } \\
\end{array}$} \\
& all & HAM & ACLM & all & HAM \\
\hline N6 & 8780 & 88 & - & 8780 & 88 \\
N8 & 1875 & 112 & - & 1875 & 112 \\
N10 & 1170 & 106 & - & 1170 & 106 \\
N14 & 524 & 123 & 12 & 619 & 123 \\
N20 & 32 & 10 & 7 & - & - \\
N28 & 8 & 4 & 4 & 18 & 9 \\
N32 & 8 & 5 & 5 & 21 & 13 \\
N36 & 8 & 5 & 5 & 27 & 16 \\
\hline
\end{tabular}

\section{Table 4}

B2) Molar Basis (nM), Intrinsic System

\begin{tabular}{lrrrrr}
\hline Heparin & \multicolumn{3}{c}{ Thrombin } & \multicolumn{2}{c}{$\begin{array}{c}\text { Prothrombinase } \\
\end{array}$} \\
& all & HAM & ACLM & all & HAM \\
\hline & & & & & \\
N6 & 8780 & 88 & - & 8780 & 88 \\
N8 & 1830 & 110 & - & 1830 & 110 \\
N10 & 1310 & 118 & - & 1310 & 118 \\
N14 & 380 & 76 & 7.6 & 380 & 76 \\
N20 & 40 & 12 & 8 & - & - \\
N28 & 6 & 3 & 2.7 & 8 & 4 \\
N32 & 8 & 5 & 5.1 & 16 & 10 \\
N36 & 5 & 3 & 2.7 & 10 & 6 \\
\hline
\end{tabular}




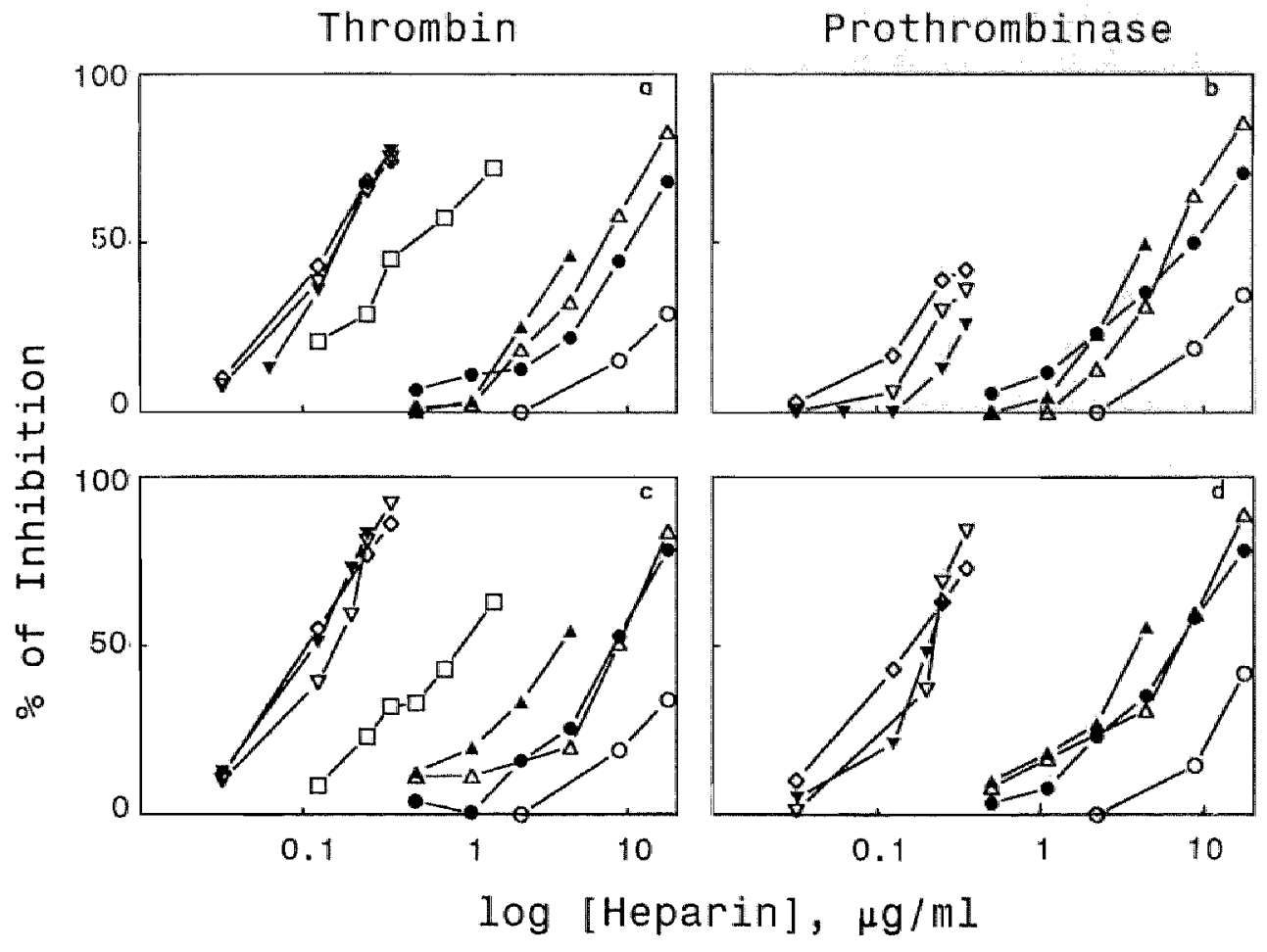

\section{Figure 7}

The Inhibition of Thrombin and Prothrombinase as a Function of Heparin Concentration. $a$ and $b$ : extrinsic; $c$ and $d$ : intrinsic $0.0 N 6,-N 8, \Delta-\Delta N 10$, $\Delta-\Delta \mathrm{N} 14, \square-\square \mathrm{N} 20, \diamond 0 \mathrm{~N} 28, \nabla-\nabla \mathrm{N} 32, \mathbf{\gamma}-\mathbf{\nabla} \mathrm{N} 36$. 

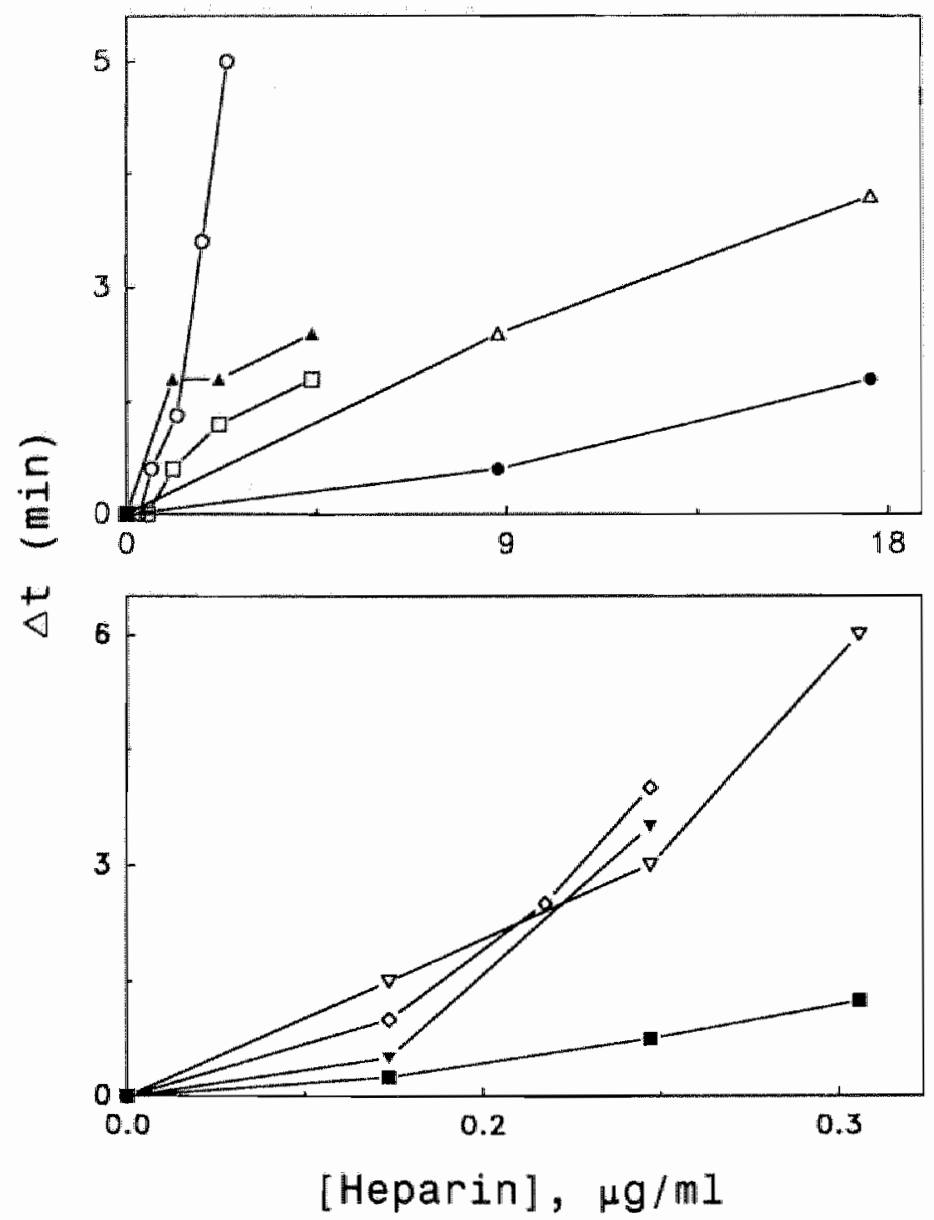

Figure 8

The Lag Phase of Intrinsic Thrombin Generation as a Function of Heparin Concentration. Upper frame: $\mathrm{O}-\mathrm{O}$ enoxaparin; - N6; $\triangle-\Delta \mathrm{N} 8 ; \Delta-\Delta \mathrm{N} 10 ; \mathrm{E}-\mathrm{N} 14$ Lower frame: $\quad-\mathbf{n} 20 ; \nabla-\nabla N 28 ; \quad \nabla-\nabla N 32 ; 0-0 \mathrm{~N} 36$.

\section{Discussion}

Heparins need a chainlength of 18 saccharides or more in order to catalyse thrombin breakdown but the anti-factor $\mathrm{Xa}$ activity requires only a pentasaccharide sequence (13). It is often suggested that the smaller a heparin is, the more it exhibits a specific anti-factor Xa activity (2-6). In the usually highly disperse LMWH preparations this can mean either of two 
things. First, is it possible that in heparin preparations with low mean molecular weight, the proportion of molecules with uniquely anti-factor Xa properties is high. Second, there might be a gradual change of properties with the chainlength i.e. the heparins become proportionally more efficient with increasing chainlength. There are no quantitative data available from the literature on the variation of the catalytic activity with the chainlength under circumstances comparable to those where heparins excert their therapeutic action, i.e. in plasma in the presence of $\mathrm{Ca}^{++}$ions (27-29), although it has been well documented that the effect of $\mathrm{Ca}^{++}$is important.

In this study, it was our aim to determine the effect of heparin chainlength on thrombin breakdown and prothrombin conversion under circumstances comparable to those in which heparins exhibit their therapeutic action, i.e. in clotting plasma. To this end we prepared a series of subfractions of the LMWH enoxaparin. These fractions appear to have a narrow molecular weight distribution, the ratio of weight average - and number average molecular weight is near unity and the chainlength obtained by dividing the molecular weight through the mean molecular weight of one monosaccharide unit (300) gives a figure near to the number obtained from NMR measurements. We therefore think that the fractions are reasonably homogeneous with respect to their chainlength.

They remain heterogeneous as to chemical composition. This already follows from the observation that the relative amount of a heparin preparation that binds to AT III decreases with decreasing molecular weight. This is a logical consequence of the LMWH preparations being obtained by random fragmentation of conventional heparin. With an increasing number of cleavages the mean molecular weight of the resulting product drops, but also the probability increases that the high affinity pentasaccharide region is severed so that the remaining molecule looses its HAM character. This automatically implies that the MW distribution of the HAM fraction within a LMWH cannot be the same as that of the total fraction. It must be shifted to the higher MW ranges. This again implies that it must be possible that isolation of a narrow zone of higher MW material from a LMWH will cause a relative gain of affinity material.

\section{The specific antithrombin activity}

To judge the effect of molecular weight on activity, one should express the activities on basis of the amounts of active material present, i.e. in terms of high affinity material (HAM) or, when anti-thrombin activities are concerned in terms of high affinity material above the critical chainlength of 18 monosaccharide units (ACLM). In an independent investigation (30), we compared the specific activites of an ultralow, low, and middle molecular weight fraction of the LMWH CY 216, and the isolated high affinity material obtained from them. We could show that the 
specific activity of the isolated high afinity material is indistinguishable from that of the original materials when corrected for the non-affine material.

The specific anti-thrombin activity was defined as the increase of the pseudo first order decay constant of endogenous thrombin in normal plasma brought about by $1 \mu \mathrm{g} / \mathrm{ml}$ of heparin. Alternatively, with heparin preparations of well defined molecular weight, the specific activity per nanomole. If the specific activity were constant with unit weight this would mean that the catalytic activity of a heparin molecule increases proportionally with its length, if it would be constant per molar unit this would indicate that being longer than 18 monosaccharide units is a necessary and sufficient condition for a heparin molecule to express full antithrombin activity.

Table 3 gives the specific activities found. It is confirmed that only the fractions with a chainlength $>18$ saccharide units possess anti-thrombin activity. The heparins without significant anti-thrombin activity (fractions N6 - N14), we call P-type heparins, the others, S-type heparins (16). Within the S- type group, no significant systematic variation of the specific activity can be observed with the chainlength, neither when expressed on a weight, or on a molar basis. The data do not allow to distinguish between these two possibilities. A larger series of heparins with well defined chainlengths between 20 and 40 monosaccharide units will have to be available to settle that question.

The specific activity of the active material in the parent enoxaparin, $31.2 \mathrm{~min}^{-1} /(\mu \mathrm{g} / \mathrm{ml})$, seems to be higher than that in each of its fractions. This probably is an artifact of calculation, due to the fact that the MW distribution of the unfractionated material is not the same as that of the HAM that it contains. The specific activities in table 3 have been obtained on basis of an ACLM content that is calculated by multiplying the $\%$ of HAM and the \% of ACLM. This is probably approximately correct for preparations with a narrow $\mathrm{MW}$ distribution such as the heparin fractions. In a polydisperse preparation like enoxaparin it will lead to an underestimation of the ACLM fraction, because there will be more HAM in the higher MW part of the preparation (fig. 3).

\section{The inhibition of prothrombin conversion}

The inhibition of extrinsic prothrombinase directly reflects the inactivation of factor $\mathrm{Xa}$. The inhibition of the intrinsic prothrombinase is a combined effect on factor $\mathrm{Xa}$ inactivation and factor $\mathrm{X}$ activation (see below). The IC 25 values for extrinsic prothrombinase inhibition, even when corrected for the non-affine material present, are lower for the S type heparins than for the P type materials. This is already clear when expressed on a weight basis and it is even more evident when they are expressed in 
molar units (table 4). This shows that in plasma, in the presence of $\mathrm{Ca}^{++}$, the medium molecular weight heparin species are more potent inhibitors than the ultra-low species are, as was also observed in a purified system $(31,32)$. Within the S or the P group no systematic shift of the activity with the molecular weight can be observed. It is rather as if the difference that brings about the anti-thrombin activity also increases the antiprothrombinase (i.e. anti-factor Xa )activity.

Table 4 suggest that the effect of the higher molecular weight species $(\geq N 20)$ in enoxaparin on intrinsic prothrombinase activity is more important than on the extrinsic one. This can be explained by their antithrombin activity, that entails an inhibition of Factor VIII activation, thus delaying the appearance of prothrombinase $(12,16,34-36)$. This not only causes a prolongation of the lag-phase (figure 8 ) but also might prevent factor IXa from being protected by factor VIIIa, so that it is inactivated by AT III-heparin and less prothrombinase is formed. This mechanism has been shown to be operative with unfractionated heparin (37).

\section{The inhibition of the thrombin peak}

The inhibition of the thrombin peak is the combined effect of inhibition of prothrombin conversion and enhancement of thrombin breakdown. Within the $\mathrm{P}$ group the IC 25 for thrombin inhibition is equal to that of prothrombinase inhibition, which is a logical consequence of their acting through inhibition of prothrombin conversion only. The value scatters around $100 \mathrm{nM}$ (table 4).

In the $\mathrm{S}$ group the concentration necessary to inhibit for $25 \%$ the thrombin peak is $2-4$ times lower than that required to obtain a similar inhibition of prothrombinase. This indicates that the main effect of the $S$ type heparins is on thrombin breakdown and that their anti-factor Xa activity, although definitely present, does not contribute much to the overall inhibition of the thrombin peak.

Comparison of the $\mathrm{IC}_{25}$ values of the parent enoxaparin and the fractions N6 - N36 shows that the molecular species $<6,000$ are hardly active in any form of thrombin inhibition. Because of the limited amount of material with $\mathrm{MW}>9,000$ in enoxaparin, we must conclude that the main active species must be thought to have a chainlength of between 20 and 30 saccharide units.

Our findings pertain to the question of the importance for a $\mathrm{LMWH}$ to have anti-factor Xa activity. Ever since Yin (38) suggested that to obtain. adequate anticoagulation, inhibition of factor $\mathrm{Xa}$ maight be a more efficient way than inhibiting thrombin, this idea has persisted in the literature (7). In fact, because factor $\mathrm{Xa}$ is only one of the three components of the prothrombin activating enzyme $(39,40)$, and because under the conditions in clotting plasma it is not the rate limiting component (16), inhibition of 
factor $\mathrm{Xa}$ is an inefficient way of inhibiting thrombin generation $(12,14$, $40)$.

It follows from our results that a considerable amount of the activity of enoxaparin, like that of unfractionated heparin, is due to its antithrombin properties. It is likely to be irrelevant for the antithrombotic activity wether the generation of thrombin is inhibited or its inactivation enhanced. This seems to be in accordance with results obtained in experimental thrombosis in animals ( 1 and references therein). The fact that both oral anticoagulation and heparin treatment are effective antithrombotic strategies, although acting by completely different mechanisms, points in that direction. Probably the clinical efficacy of a LMWH is determined by a favourable compromise between inhibitory properties, that become more pronounced with higher MW, and pharmacokinetical properties such as half-life time and bioavailability, that are better for smaller molecules.

\section{ACKNOWLEDGMENTS}

We thank the "Broeders van de Beijaard" for their generous donations of normal plasma. We are indebted to $M$. Vuilghorne for performing the ${ }^{13} \mathrm{C}$ NMR studies. The fruitful discussions with Theo Lindhout are gratefully acknowledged.

\section{References}

1) Chesebro, J.H.; Zoldheyi, P.; Badimon, L.; Fuster, V.: Role of thrombin in arteria] thrombogenesis: Implication for therapy. Thrombos. Haemostas. 66: 1-4;1991.

2) Thunberg, L.; Lindahl, U.; Tengblad, A.; Laurent, T.C.; Jackson, C.M.: On the molecular-weight-dependence of the anticoagulant activity of heparin. Biochem $J_{\text {. }}$ 181: $241-243 ; 1979$.

3) Andersson, L.O; Barrowcliffe, T.W.; Holmer, E.; Johnson, E.A.; Södenström, G.: Molecular weight dependency of the heparin potentiated inhibition of thrombin and activated factor $X$. Effect of heparin neutralization in plasma. Thromb. Res. 15: 531541: 1979 .

4) Lane, D.A., Denton, J.; Flynn, A.M., Thunberg, L.; Lindahl, U.: Anticoagulant activities of heparin oligosaccharides and their neutralization by platelet factor 4 . Biochem J. 218: 725-732; 1984.

5) Barrowcliffe, T.W.; Merton, R.E.; Havercroft, S.J.; Thunberg, L.; Lindhal, U.; Thomas, D.P.: Auticoagulant activities of heparin oligosaccharides. Thromb. Res. 34: 125-133; 1984. 
6) Thomas, D.P.; Merton, R.E.; Barrowcliffe, T.W. Thunberg, L.; Lindhal, U.: Effects of heparin oligosaccharides with high affinity for antithrombin III in experimental venous thrombosis. Thrombos. Haemostas. 47: 244-248, 1982.

7) Bratt, G.; Törnebohm, E.; Lockner, D.; Bergström, K.; A human pharmacological study comparing convetional heparin and a low moleuclar heparin fragment. Thrombos. Haemostas. 53; 208-211; 1985.

8) Hemker, H.C.; Willems, G.M.; Béguin, S.: A computer assisted method to obtain the prothrombin activation velocity in whole plasma independent of thrombin decay processes. Thrombos. Haemostas. 56: 9-17; 1986.

9) Jesty, J.: Analysis of the generation and inhibition of activated coagulation factor $\mathrm{X}$ in pure systems and in human plasma. $\mathrm{J}$. Biol. Chem.: 261: 8695-702; 1986.

10) Jesty J. The kinetics of inhibition of $\alpha$-thrombin in human plasma. J. Biol. Chem. 261:10313-18; 1986 .

11) Bendetowicz, A.V.; Bara, L.; Samama, M.: The inhibition of intrinsic prothrombinase and its generation by heparin and four derivatives in prothrombin poor plasma. Thromb. Res. 58: 445-454; 1989.

12) Béguin, S.; Lindhout, T.; Hemker, H.C.: The mode of action of heparin in plasma. Thromb. Haemostas. 60: 457-462; 1988 .

13) Choay, J.; Petitou, M.; Lormeau, J.C.; Sinay, P.; Casu, B.; Gatti, G.: Structureactivity relationship in heparin: A synthetic pentasaccharide with high affinity for antithrombin III and eliciting high anti-factor Xa activity. Biochem. Biophys. Res. Commun. 116: 492-99; 1983.

14) Béguin, S.; Choay, J.; Hemker, H.C.: The action of a synthetic pentasaccharide on thrombin generation in whole plasma. Thromb. Haemostas. 61: 397-401; 1989.

15) Wallenga, J.M.; Bara, L.; Petitou, M.; Fareed, J.; Samama, M.; Choay, J.: "The inhibition of the generation of thrombin and the antihrombotic effect of a pentasaccharide with sole anti-factor Xa activity. Thromb. Res. $51: 23-33 ; 1988$.

16) Hemker, H.C.: The mode of action of heparin in plasma. Thrombosis and Haemostasis; pp 17-36, Brussels. Verstraete M, Vermylen J, Lijnen H R. Arnout J (eds). Leuven University Press; 1987.

17) Béguin, S.; Mardiguian, J.; Lindhout, T.; Hemker, H.C.: The mode of action of low molecular weight heparin preparation (PK 10169) and two of its major components on thrombin generation in plasma. Thromb. Haemostas. $61: 30-34: 1989$.

18) Teien, A.N.; Lie, M.: Evaluation of an amidolytic heparin assay method: Increased sensitivity by adding purified antithrombin III. Thromb. Res, 10:399-410; 1977. 
19) Bara, L.; Combe-Tamzali, S.; Conard, J.; Horellou, M.H.; Samama, M.: Modifications biologiques induntes par trois héparines de bas poids moléculaire: PK. 10169, Kabi 2165 et CY 216, comparées à l'hêparine non fractionnée, injectées par voíe sous-coutanée chez le volontaire sain en chirargie générale et chez le sujet âgé en médecine. I. Mal. Vascul. 12: 78-84; 1987.

20) Thaler, E; Schmer, G.: A simple two-step isolation procedure for human and bowine antithrombin I//II (heparin cofactor): a comparison of two methods. Br. J. Haematol $31.233243 ; 1975$.

21) Miller-Andersson, M.; Borg, H.; Anderssion, L.O.: Purification of antithrombin III by affinity chromatography. Thromb. Res. 5: 439-452; 1974.

22) Smith, R. L. Titration of activated bovine factor $X$ J. Biol. Chem. 248: 24182423; 1973 .

23) Owren, P.A. Aas, K.: The control of dicumarol therapy and the quantitative determination of prothrombin and proconvertin. Scand. J. Clin. Lab. Invest. 3: 201218; 1951 .

24) Casu, B.; Oreste, P.; Torri, G.; Zopetti, G.; Choay, J.; Lormeau, J.C.; Petitou, M.: The structure of heparin oligosaccharide fragments with hgih anti-(factor Xa) activity containing the minimal antithrombin III binding sequence. Biochemistry 197:599-609; 1981.

25) Schoen, P.; Wielders, $S_{\text {; }}$ Petitou, M; Lindhout, T.: The effect of sulfation on the anticoagulant and antithrombin III-binding properties of a heparin fraction with low affinity for antithrombin III. Thromb. Res. 57: 415-423; 1990.

26) Nordenman, B.; Danielsson, A.; Björk, I.: The binding of low affinity and high affinity heparin to antithrombin. Fluorescence Studies. Europ. J. Biochemistry. 90, 16. 1978.

27) O'Neall-Speight, $M_{\text {; }}$; Griffith; M.J.: Calcium inhibits the heparin-catalyzed antithrombin $1 \mathrm{II} / \mathrm{thrombin}$ reaction by decreasing the apparent binding afinity of heparin for thrombin. Arch. Biochem. Biophys. 225 (2): 958-963; 1983.

28) Barrowcliffe, T.W.; Shirle Le, Y.: The effect of calcium chloride on anti-Xa activity of heparin and its molecular weight fractions. Thrombos. Haemostas. 62 (3): 950-954: 1989 .

29) Schoen, P.; Lindhout, T.; Franssen, J.; Hemker, H.C.: Low molecular weight heparin-catalyzed inactivation of factor Xa and thrombin by antithrombin III. Effect of platelet factor 4. Thromb. Haemostas. 66 (4): 435-441; 1991 .

30) Béguin, S.; Wielders, S.; Lormeau, J.C.; Hemker, H.C.: The mode of action of CY 216 and CY 222 in plasma. To be published in: Thrombosis and Haemostasis. 1991. 
31) Ellis, V.; Scully, M.F.; Kakkar, V.V.: The relative molecular mass dependence of the anti-factor Xa properties of heparin. Biochem. J. 238:329-333; 1986.

32) Barrowcliffe, T.W.; Havercroft, S.J.; Kemball-Cook, G.; Lindhal, U.: The effect of $\mathrm{Ca}^{+2}$, phospholipid and factor $\mathrm{V}$ on the anti-(factor $\mathrm{Xa}$ ) activity of heparin and its high-affinity oligosaccharides. Biochem. J. 243: 31-37: 1987.

33) Danielsson, A." Raub, E.; Lindahl, U.; Björk, I.: Role of ternary complexes, in which heparin binds both antithrombin and proteinase, in the accelaration of the reactions between antithrombin and thrombin or factor Xa. J. Biol Chem. 261: 15467-15473; 1986.

34) Ofosu, F.A.; Sie, P.; Modi, G.J.; Fernandez, F.; Buchanan, M.R.; Blajchman, M.A.; Boneu, B.; Hirsh, J.: The inhibition of thrombin-dependent positive feedback reactions is critical to the expression of the anticoagulant effect of heparin. Biochem. J. 243: 579-588; 1987 .

35) Ofosu, F.A.; Smith, L.M.; Anvari, N.; Blajchman, M.A.: An approach to assigning in vitro potency to unfractionated heparin and low molecular weight heparins based on the inhibition of prothrombin activation and catalysis of thrombin inhibition. Thromb. Haemost. 60: 193-198; 1988.

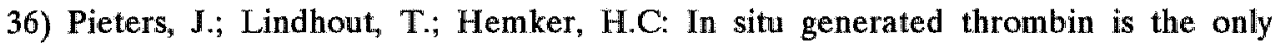
enzyme that effectively activates factor VIII and factor V in thromboplastin activated plasma. Blood 74 (3), 1021-1024; 1989.

37) Béguin; S.; Dol, F.; Hemker, H.C.: Factor IXa inhibition contributes to the heparin effect. Thromb. Haemost. 66: 306-309; 1991.

38) Yin, E.T.; Wessler, S.; Stoll, P.J.: Biological properties of the naturally occuring inhibitor to activated factor X. I. Biol. Chem. 246: 3703-3711: 1971.

39) Hemker, H.C.; Esnouf, M.P; Hemker, P.W; Swart, A.C.W; Macfarlane, R.G.: Formation of prothrombin converting activity. Nature 215:246-251; 1968.

40) Rosing, J.; Tans, G,; Govers-Riemslag, J.W.P.; Zwaal, R.A.F; Hemker, H.C.: The role of phospholipid and factor $\mathrm{Va}$ in the prothrombinase complex. $\mathrm{J}$. Biol. Chem. 249: 7798-7807; 1980.

41) Pieters, J.; Lindhout, T.: The limited importance of factor Xa inhibition to the anticoagulant property of heparin in thromboplastin-activated plasma. Blood $72(6)$; 2048-2052; 1988 . 



\section{The Heparin-Dependent Modulation of Factor X activation in Plasma*}

\section{SUMMARY}

Unfractionated heparin, a low molecular weight heparin (enoxaparin), an ultralow molecular weight heparin (pentasaccharide), and a fraction devoided of high affinity for antithrombin III (AT III), were examined on their ability to affect factor $\mathrm{Xa}$ generation in thromboplastin activated plasma. Factor Xa generation curves were analyzed according to a 3 parameter model that comprised Michaelis-Menten kinetics of factor Xa generation, pseudo first order kinetics of the inhibition of factor Xa and pseudo first order kinetics of neutralization of the factor $X$ converting activity of the thromboplastin/factor VIIa (TF/VIIa) complex. The half-life times of factor Xa activity and the activity of the TF/VIIa complex in whole plasma were 1.78 and 1.2 min respectively. All heparins, except the low affinity heparin decreased the half-life time of factor $\mathrm{Xa}$, causing a diminished factor $X a$ generation. Only unfractionated heparin and enoxaparin had an additional effect. They shortened, in a dose-dependent manner, the half-life time of the factor $X$ converting activity of the TF/VIIa complex. This effect of the two heparin preparations, however, was not the result of a heparin enhanced inactivation of the protease factor VIIa by AT III, but solely a stimulatory effect of these heparins on the neutralization of the TF/VIIa complex by a plasma Kunitz-type inhibitor, Tissue Factor Pathway Inhibitor.

\section{INTRODUCTION}

Thromboplastin-mediated factor Xa generation in plasma is a complex process regulated by positive and negative feedback reactions (for a review see ref 1). The initiation step is the formation of a complex between tissue factor (TF) and the plasma protein factor VII. This complex converts the first traces of factor $\mathrm{X}$ into the serine protease activated factor $\mathrm{X}$ (factor Xa). Then, factor Xa activates tissue factor-bound factor VII into the active two-chain form by proteolytic cleavage $(2,3)$. This is schematized in figure 1. Using a recombinant mutant of factor VII, it has recently been demonstrated that human factor VII, has indeed no intrinsic proteolytic

\footnotetext{
* Abstract published: Bendetowicz, A. V; Lindhout, T.* Hemker, H.C. Thrombosis and
} Haemostasis 65 (6): 1312; 1991 . 
activity toward factor $X(4)$, indicating that cleavage of factor VII seems to be essential for its activity. Besides the importance of this reciprocal activity of factor Xa, factor $\mathrm{Xa}$ also exerts a tight negative control over its own generation. Morrison and Jesty (5) could demonstrate that when plasma was preincubated with factor $\mathrm{Xa}$, the levels of factor $\mathrm{Xa}$ produced upon the addition of thromboplastin, were lower than in plasma without such a preincubation.

Hubbard and Jennings $(6,7)$ observed that the inhibition of thromboplastin requires an unknown plasma component, factor $\mathrm{Xa}$, and factor VII(a). This interaction has been shown to be calcium dependent (3, 7). The explanation for the observations made came from the work of Rapaport's group (3). These investigators could identify a plasma protein which on a factor Xa- mediated action destroyed the activity of the tissue factor/factor VIIa complex. The molecular mechanism of the action of this recently called Tissue Factor Pathway Inhibitor (TFPI) was elucidated by the groups of Rapaport $(1,2,3)$ and Broze $(8,9)$. These investigators observed that a quaternary complex is formed between TF/VIIa, factor Xa and TFPI.

\section{$[T F, P L, C a ̈, V I I] \longrightarrow[T F, P L, C a ̈, V I l a] \longrightarrow[T F, P L, C a ̈, V I l a]$ inactive}

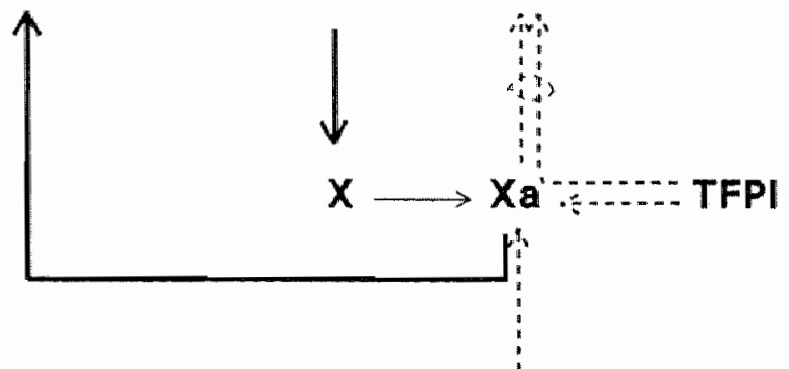

AT III

\section{Figure 1}

The Regulation of factor $X$ activation. Solid lines: Activation. Dotted lines: inhibition. Thick lines indicate reinforcement of the activation. TF: Tissue Factor; PL: Phospholipid; AT III: Antithrombin III. TFPI: Tissue Factor Pathway Inhibitor.

The group of Broze (9) has also reported that in the presence of AT III, heparin is able to prevent the inhibition of the tissue factor/factor VIla by factor Xa/TFPI in buffer system. This phenomenom is likely due to the rapid inactivation of factor $\mathrm{Xa}$ by $\mathrm{AT}$ III in the presence of heparin, thereby preventing the participation of factor Xa with TFPI in the inhibition of the $\mathrm{TF} / \mathrm{VIIa} / \mathrm{Ca}^{++} /$complex.

Although our understanding in respect to this regulatory system has increased dramatically, it remains to be established to what extent heparins 
are able to interfere with factor Xa generation in thromboplastin-activated plasma, apart from their direct action on the inactivation of factor Xa by AT III. We have therefore investigated the effects of unfractionated heparin (UFH), a low molecular weight heparin (LMWH, enoxaparin), an ultra-LMWH (synthetic pentasaccharide heparin) eliciting high affinity for AT III, and a heparin fraction with low affinity for AT III on factor Xa generation in thromboplastin-activated plasma.

\section{MATERIALS AND METHODS}

\section{Materials}

Reagents. Fatty acid-free human serum albumin (HSA) was a product of Sigma, St Louis, USA. The chromogenic substrates Bz-Ile-Glu- (piperidyl)-Gly-Arg-p-nitroanilide (S-2337) and H-DPhe-Pip-Arg-p-nitroanilide (S-2238), were purchased from AB Kabi Diagnostica, Stockholm, Sweden. The $4^{\text {th }}$ International Standard for Heparin (UFH; $180 \mathrm{U} / \mathrm{mg}$ ) was a kind gift of Dr. T.W. Barrowcliffe (National Institute for Biological Standards and Control, Potters Bar, UK). The LMWH enoxaparin (115 anti-Xa IU/mg) was obtained from Rhône-Poulenc Rorer, Vitry s/Seine, France. The ultralow molecular weight synthetic pentasaccharide heparin ( 800 anti-Xa IU/mg), and the AT III-low affinity fraction (LA; obtained from unfractionated heparin by affinity chromatography on AT III- sepharose) were a kind gift from. Institute Choay, Paris, France.

Proteins. Human factor Xa was prepared from human factor X, and quantitated as previously decribed $(10-12)$. Bovine factors $\mathrm{V}$ and II were purified and quantitated according to references 13 and 14 , respectively. Recombinant desulphato-hirudin (CGP39393) was a kind gift of Dr. R.B. Wallis, Ciba Geigy, Horsham, UK. Human brain thromboplastin was prepared according to Owren and Aas as previously described (15). It was verified that a mixture containing $80 \%$ citrated plasma, $20 \mathrm{mM} \mathrm{CaCl}_{2}$ and $1 / 30$ diluted thromboplastin clots in fourty seconds. Human AT III was prepared according to Thaler and Schmer (16), and subsequentely freed of heparin (17). The factor $X$ converting protein of the Russell's Viper venom (RVV-X) was purified according to ref. 18. The rabbit anti-human TFPI IgG was a gift of Dr. O. Nordfang, Novo Nordisk A/S, Gentofte, Denmark.

Plasma. Blood from healthy donors was collected on $0.13 \mathrm{M}$ trisodium citrate; nine parts of blood to one part of citrate solution. The blood was then centrifugated twice at room temperature for $15 \mathrm{~min}$ at $3,000 \times \mathrm{g}$. A third centrifugation was done at $4{ }^{\circ} \mathrm{C}$ for one hour at $23,000 \times$ $\mathrm{g}$. The obtained platelet free plasma was stored at $-80^{\circ} \mathrm{C}$. 
TFPI Neutralized Plasma. Normal plasma was incubated with a $1 / 200$ dilution of the anti-TFPI IgG (final concentration $0.4 \mu \mathrm{g} / \mathrm{ml}$ ) during $15 \mathrm{~min}$ at $37^{\circ} \mathrm{C}$. The neutralized plasma was stored at $-80^{\circ} \mathrm{C}$.

\section{Methods}

Factor Xa bioassay. Factor Xa was assayed in plasma samples, dilluted 1:200 in an ice-cold Tris buffer ( $50 \mathrm{mM}$ Tris- $\mathrm{HCl}, 175 \mathrm{mM} \mathrm{NaCl}, 0.5 \mathrm{mg} \mathrm{HSA} / \mathrm{ml}$, $\mathrm{pH}$ 7.9), using a bioassay as previously described (19) with minor modification to run the assay on an automated system (Beckman Biomek 2000 system). Briefly, $20 \mu \mathrm{l}$ sample was transfered to a well on a micro titer plate containing $60 \mu \mathrm{l}$ reaction mixture $(0.6 \mathrm{nM}$ factor $\mathrm{Va}, 50 \mu \mathrm{M}$ phospholipid and $5 \mathrm{mM} \mathrm{CaCl}$ in Tris buffer). After 4 min of incubation at room temperature, $20 \mu \mathrm{l}$ of a $10 \mu \mathrm{M}$ prothrombin solution was added. The reaction was stopped after two minutes by the addition of $100 \mu 1$ of Tris buffer containing $20 \mathrm{mM}$ EDTA. The chromogenic substrate for thrombin (S-2238) was added $(50 \mu \mathrm{l}$ of a $2.2 \mathrm{mM}$ solution). The reaction was stopped with $100 \mu \mathrm{l}$ of a $50 \%(\mathrm{v} / \mathrm{v})$ acetic acid after five minutes. The optical density (OD) of the reaction mixture was read at wavelenght of $405 \mathrm{~nm}$ versus a reference wavelenght of $540 \mathrm{~nm}$. A standard solution of human factor Xa $(1.4 \mathrm{nM})$ was run in parallel to calculate the molar concentration of factor $\mathrm{Xa}$ in the samples.

Factor Xa amidolytic assay. Sample of $10 \mu \mathrm{l}$ was added to a cuvette containing $490 \mu \mathrm{l}$ of a solution containing S-2337 $(0.22 \mathrm{mM})$, polybrene ( 2 $\mu \mathrm{g} / \mathrm{ml}$ ) and $20 \mathrm{mM}$ EDTA in Tris buffer. The concentration of factor Xa was calculated from the increase of $O D$ in time using a dual wavelength spectrophotometer (ID-RL, Maastricht, The Netherlands), with wavelenght of 405 and $546 \mathrm{~nm}$ for sample and reference respectively.

Eactor Xa Generation. a) Buffer system/thromboplastin. Human factor X (125 $\mathrm{nM}$ ) was incubated for $5 \mathrm{~min}$ at $37^{\circ} \mathrm{C}$ with human factor VII (10 nM) and AT III $(0.5 \mu \mathrm{M})$ in HSA buffer. Factor Xa generation was started by the addition of human brain thromboplastin $(1 / 30 \mathrm{v} / \mathrm{v}$ final concentration) and $\mathrm{CaCl}_{2}$ (final concentration $3 \mathrm{mM}$ ). Factor $\mathrm{Xa}$ activity was measured using the amidolytic assay. b) Plasma/RVV-X. Citrated plasma $(128 \mu 1)$ was supplemented with Tris buffer with or without heparin $(10 \mu 1)$, and $3 \mu l$ of $r$-hirudin (final concentration $2 \mu \mathrm{M}$ ), and incubated at $37{ }^{\circ} \mathrm{C}$ for $5 \mathrm{~min}$ while stirring. Factor $X a$ generation was initiated by the addition of $6.4 \mu 1$ of $0.5 \mathrm{M} \mathrm{CaCl}_{2}$, and $12.5 \mu \mathrm{l} \mathrm{RVV-X}$ (final concentration $3 \mu \mathrm{g} / \mathrm{ml}$ ). Timed samples were removed and assayed for factor $\mathrm{Xa}$ activity either by the amidolytic or bioassay. At factor Xa concentrations higher than $10 \mathrm{nM}$ in 
the undiluted sample, the amidolytic assay was used. c) Plasmal thromboplastin. Citrated plasma $(135 \mu 1)$ was supplemented with $4 \mu$ l of HSA buffer, with or without heparin, and $3 \mu$ ll of r-hirudin (final concentration $2 \mu \mathrm{M}$ ), and incubated at $37^{\circ} \mathrm{C}$ while stirring. Factor Xa generation was initiated by the addition of $11 \mu \mathrm{l}$ of a solution containing 0.5 $\mathrm{M} \mathrm{CaCl}$ and human brain thromboplastin (final concentrations $4 \mathrm{mM}$ free $\mathrm{Ca}^{++}$and $3.3 \mathrm{vol} \%$ thromboplastin). Timed samples $(5 \mu \mathrm{l})$ were removed and assayed for factor $\mathrm{Xa}$ activity using the bioassay.

Neutralization of Factor Xa Activity in Plasma. Purified human factor Xa (30 $\mathrm{nM}$ ) was added to plasma, in the presence of $4 \mathrm{mM}$ free $\mathrm{Ca}^{++}$and $2 \mu \mathrm{M}$ r-hirudin at $37^{\circ} \mathrm{C}$. Upon this addition the plasma dilution was $20 \%$. Samples were removed at timed intervals and assayed for residual factor $\mathrm{Xa}$ activity using the amidolytic assay. The pseudo first order rate constant of factor $\mathrm{Xa}$ inhibition in plasma was obtained from the slope of a semilogarithmic plot of the residual factor $\mathrm{Xa}$ activity versus time. The reported errors are the $95 \%$ of confidence limits.

Analysis of Factor Xa Generation Curves. A mathematical model that assumes Michaelis-Menten kinetics of factor $\mathrm{X}$ activation in plasma and first order kinetics of inhibition of the activator (TF/VIIa) and that of the product (factor Xa), was fitted to the experimental data. It was further assumed that:

$[\mathrm{X}]_{\mathrm{t}}=[\mathrm{X}]_{\mathrm{o}}-[\mathrm{Xa}]-[\mathrm{Xa} . \mathrm{I}]$

where $[X]_{1}$ is the concentration of factor $X$ at time $t,[X]_{0}$ is the concentration of factor $X$ at time zero, $[X a]$ is the concentration of free factor $\mathrm{Xa}$ at time $\mathrm{t}$, and $[\mathrm{Xa} . \mathrm{I}]$ is the concentration of the factor Xa-inhibitor complex at time $t$. Our second assumption was that the activator of factor $\mathrm{X}$ is the thromboplastin/activated factor VII (TF/VIIa) complex. The factor $\mathrm{Xa}$ generation curves in plasma can then be described by the following set of differential equations

$\mathrm{d}[\mathrm{TF} / \mathrm{VIIa}] / \mathrm{dt}=-\mathrm{k}_{\mathrm{TF} / \mathrm{NII} a}[\mathrm{TF} / \mathrm{VIIa}]$

$\mathrm{d}[\mathrm{Xa} \cdot \mathrm{I}] / \mathrm{dt}=\mathrm{k}_{\mathrm{Xa}}[\mathrm{Xa}]$

$\mathrm{d}[\mathrm{Xa}] / \mathrm{dt}=\left(\left(\mathrm{V}_{\max } / \mathrm{K}_{\mathrm{M}}\right)[\mathrm{X}]\right)-\mathrm{k}_{\mathrm{Xa}}[\mathrm{Xa}]$

where $k_{\mathrm{Tr} / \mathrm{vla}}$ and $\mathrm{k}_{\mathrm{Xa}}$ are the pseudo first order rate constants of inhibition of the activator complex TF/VIIa and factor $\mathrm{Xa}$, respectively. The initial conditions are: $[\mathrm{TF} / \mathrm{VII}]_{\infty}$, and both $[\mathrm{Xa}]_{o}$ and $[\mathrm{Xa} . \mathrm{I}]_{\mathrm{o}}$, equal zero at $\mathrm{t}=0$. 
The values for $V_{\max } / K_{M}$, $k_{\text {TP } / \text { III }}$, and $k_{\mathrm{Xa}}$ were estimated by a least squares fit of the numerical solution (20) of Equations 1 through 3 to the experimental determined factor $\mathrm{Xa}$ generation curve, using an iterative Gauss-Newton algorithm (21).

The reported errors represent the $95 \%$ confidence interval of the parameters as estimated by linearization of the nonlinear equation at the obtained parameter values (22).

\section{RESULTS}

\section{Validation of the Model in a Buffer System}

Varying amounts of factor $X$ were incubated with thromboplastin and factor VII. The factor $\mathrm{Xa}$ generation curves are shown in Fig. 2. After fitting the model as described in Material and Methods to the set of generation curves the $V_{m a x} / K_{M}$ value was $0.31 \pm 0.03 \mathrm{nM}^{-1} \mathrm{~min}^{-1}$. The result of the fitting procedure is depicted by the solid lines. It is seen that the

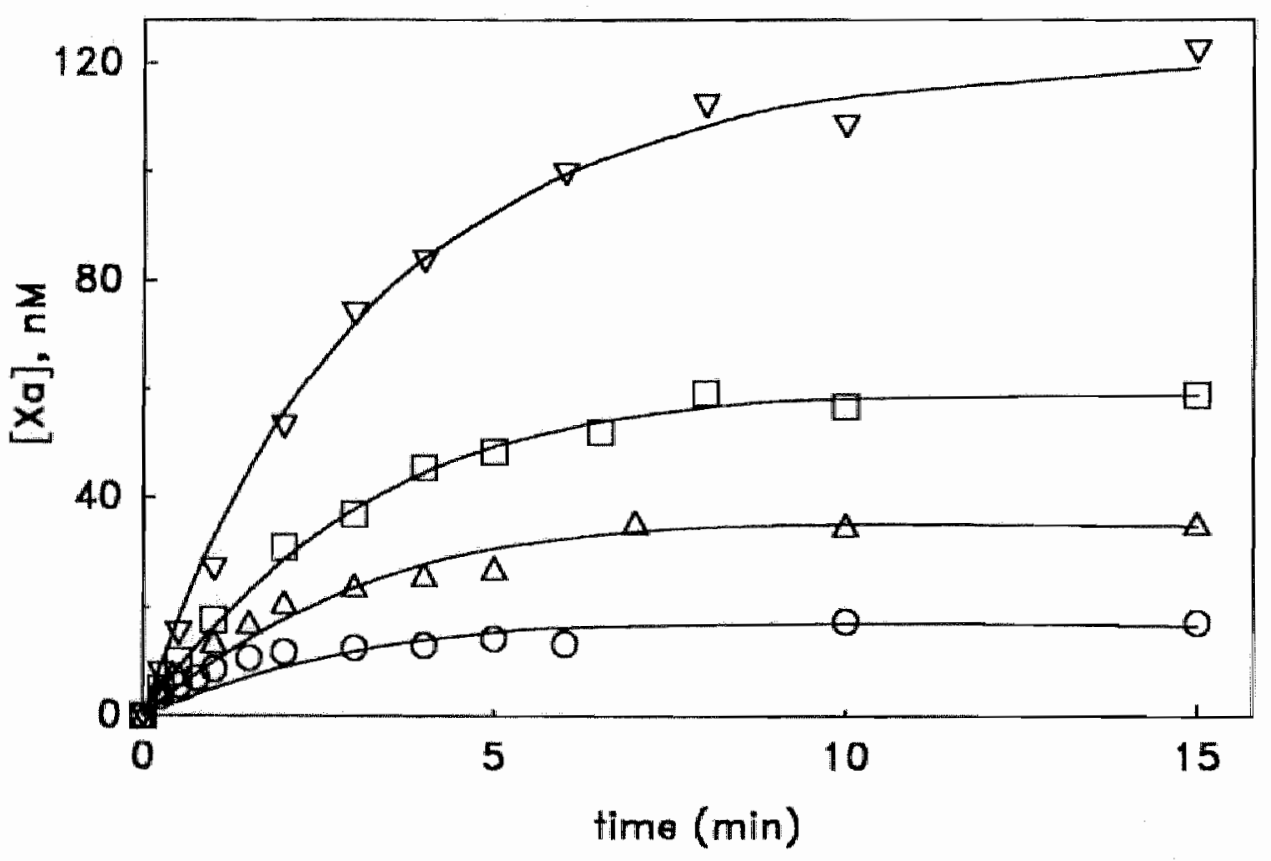

\section{Figure 2}

Factor $X$ Activation in a Buffer System. Factor $X(125 \mathrm{nM})$ was activated by the addition of $\mathrm{f}$ VII $(10 \mathrm{nM})$, thromboplastin $(1 / 30 \mathrm{v} / \mathrm{v})$ and $\mathrm{CaCl}_{2}(3 \mathrm{mM})$ as described in Methods. Symbols represent: $0-018, \Delta-\Delta 36, \quad \square-\square 60$, and $\nabla-\nabla 125 \mathrm{nM}$ fX. 
model fits well to the experimental data points. Because no AT III was present in the experiment, we assumed that there was no inhibition of factor $\mathrm{Xa}$ and we fixed its decay constant to zero. On the other hand, the inactivation of the enzyme (TF/VIIa) cannot be obtained experimentally, therefore, this parameter was used as a dependent one during all the experiments (plasma and buffer) in which factor $X$ was activated with TF/VIIa. As expected from the experimental conditions (no inactivator was present), the decay of the activator (TF/VIIa) was found to be zero. Our findings also point to the apparent absence of a reciprocally activation of factor VII by factor Xa, i.e. no lag phase in the appearance of factor Xa was observed.

We next examined the effect of [AT III-heparin] on TF/VIIa catalyzed factor $X$ activation. A typical example of factor $X a$ generation in the presence of AT III $(0.5 \mu \mathrm{M})$ and varying heparin concentrations is shown in figure 3 . The model was fitted to the set of factor Xa generation curves. Again, the best fit is indicated by the solid lines. The value obtained of $\mathrm{V}_{\text {max }} / \mathrm{K}_{\mathrm{M}}=0.27 \pm 0.01 \mathrm{nM}^{-1} \mathrm{~min}^{-1}$, agrees with the previous one obtained

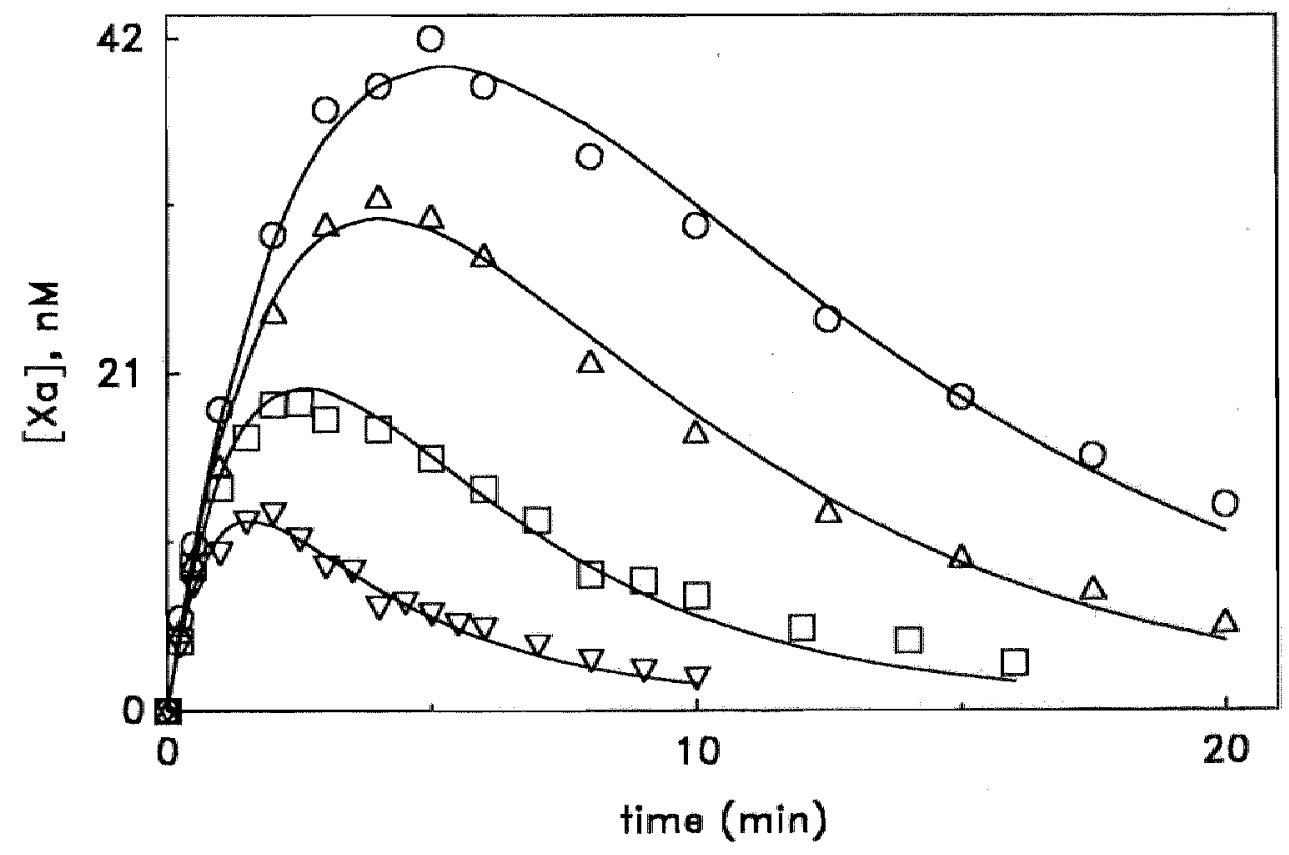

Figure 3

Factor $X$ Activation and Inhibition of Factor Xa in a Buffer System. Factor X (125 nM) was activated by the addition of $\mathrm{f}$ VII $(10 \mathrm{nM})$, thromboplastin $(1 / 30 \mathrm{v} / \mathrm{v})$ and $\mathrm{CaCl}_{2}$ ( $3 \mathrm{mM}$ ), in the presence of $0.5 \mu \mathrm{M}$ of AT III as described in Methods. Symbols indicate: 0.0 Control; $\Delta-\Delta 0.05 ; \square-\square \quad 0.1$; and $\quad \nabla-\nabla \quad 0.2 \mu \mathrm{g} / \mathrm{ml}$ UFH. 
in the absence of heparins $\left(0.31 \pm 0.03 \mathrm{nM}^{-1} \min ^{-1}\right)$. The adjustable parameter $k_{\mathrm{NF} / \mathrm{NI}}$ was found to be zero over a range of heparin concentrations. Thus, under the experimental conditions no neutralization of TF/VIIa activity could be detected. The heparin-dependent pseudo first order rate constants of inhibition of factor $\mathrm{Xa}$, as obtained by the fit procedure are listed in Table 1 . These values were found not to differ from the inhibition of purified human factor $X a$ under the very same experimental conditions but in the absence of factor VII to avoid concomitant factor Xa generation.

Table 1. The Pseudo First Order Decay Constant of Factor Xa in Purified System.

\begin{tabular}{|c|c|c|}
\hline $\begin{array}{l}{[\mathrm{UFH}]} \\
\mu \mathrm{g} / \mathrm{ml}\end{array}$ & $\begin{array}{l}k_{\mathrm{x}_{\mathrm{a}}, \mathrm{f}^{*}} \\
\min ^{-1}\end{array}$ & 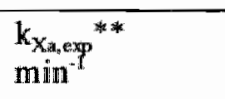 \\
\hline 0 & \pm 0.04 & \pm 0.04 \\
\hline 0.05 & \pm 0.01 & \pm 0.05 \\
\hline 0.10 & \pm 0.03 & \pm 0.03 \\
\hline 0.20 & \pm 0.09 & \pm 0.02 \\
\hline
\end{tabular}

${ }^{*} k_{\mathrm{X}, \mathrm{f}}$ indicates the decay constant of $\mathrm{f} \mathrm{Xa}$ obtained by fitting the model described in Material and Methods, to the experimental data of factor Xa generation in a buffer system as shown in figure 1.

${ }^{*}{ }^{*} \mathrm{k}_{\mathrm{X}, \text { xxp }}$ is the decay of $\mathrm{f} \mathrm{Xa}$ determined independently, by the addition of $30 \mathrm{nM}$ factor Xa to $0.5 \mu \mathrm{M}$ AT III. For details see Methods section.

\section{Factor Xa Generation and Inactivation in RVV-Activated Plasma.}

Because of the factor Xa-mediated TF/VIIa neutralizing properties of TFPI, factor Xa generation in thromboplastin-activated plasma is expected to be a far more complex process than the generation of factor $\mathrm{Xa}$ in the earlier described buffer system. Therefore, we first studied the effect of heparin on factor Xa generation and inactivation in plasma incubated with the factor X converting protein from Russell's Viper venom (RVV-X).

A typical set of factor Xa generation curves induced by RVV-X in plasma containing varying amounts of unfractionated heparin (UFH) is shown in Fig. 4. It has been described that RVV-X is not neutralized in plasma (23), therefore, the decay constant of the activator was set at zero. The rate constants of inhibition of in situ formed factor $\mathrm{Xa}$, as obtained by fitting the model to the set of factor $X$ a generation curves, are listed in Table 2. The $V_{\max } / \mathrm{K}_{\mathrm{M}}$ value was estimated to be $0.78 \pm 0.05 \mathrm{nM}^{-1} \mathrm{~min}^{-1}$. To verify the model in plasma, the estimated decay constants were compared with those obtained from the decay phase of factor Xa generation. However, when the In of the factor Xa activities during the decay phase of the factor Xa generation curve were plotted versus time, concave curves 
were obtained at low heparin concentrations (data not shown). We concluded that no reliable inhibition data could be obtained because of ongoing factor Xa formation during part of the decay phase of the curves.

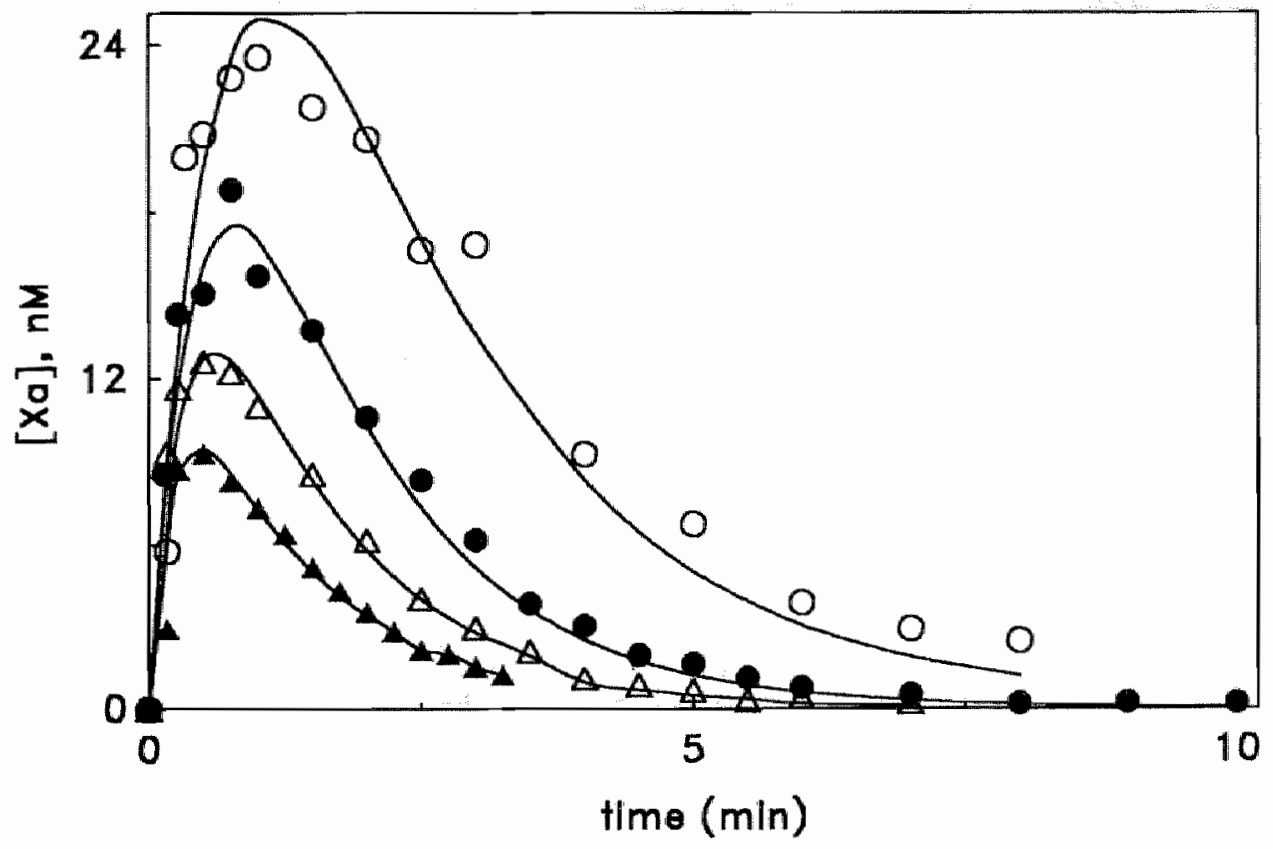

\section{Figure 4}

Factor Xa Generation in $R V V$ - Activated Plasma. Factor $\mathrm{X}$ activation was started by the addition of RVV-X to plasma $(3 \mu \mathrm{g} / \mathrm{ml})$ in the presence of $4 \mathrm{mM}$ free $\mathrm{Ca}^{++}$, and varying concentrations of unfractionated heparin. $O-O$ Control; $-0.2 ; \Delta-\Delta, 0.3$; and $\mathbf{\Lambda}-0.4 \mu \mathrm{g} / \mathrm{ml} \mathrm{UFH}$.

Indeed, when EDTA ( $20 \mathrm{mM}$ final concentration) was added to plasma at the time of peak values of the factor Xa generation curve in the absence of heparin, a linear semilogarithmic plot from which slope the pseudo first order rate constant of inhibition of in situ generated factor Xa could be calculated. Unfortunately, EDTA does abrogate the stimulating effect of $\mathrm{Ca}^{++}$ions on the heparin-dependent inhibition of factor Xa and thus cannot be used (24). However, at high RVV-X concentration $(40 \mu \mathrm{g} / \mathrm{ml})$, all plasma factor $X$ was converted within $30 \mathrm{~s}$. Semilogarithmic plots of the decay phase of the factor Xa generation curve in the absence of heparin activities starting at $30 \mathrm{~s}$, versus time, were indistinguishable from those obtained when factor Xa was added to plasma $\left(k_{\mathrm{Xa}}=0.94 \pm 0.05 \mathrm{~min}^{-1}\right)$. 
This value agrees very well with the rate constant of inhibition of purified human factor $\mathrm{Xa}\left(0.88 \pm 0.09 \mathrm{~min}^{-1}\right)$ determined in recalcified plasma, containing $\mathrm{r}$-hirudin $(2 \mu \mathrm{M})$ to eliminate thrombin-dependent consumption of AT III. From the results shown in Table 2 we conclude that reliable rate constants of factor Xa inhibition in plasma can be obtained from fitting the mathematical model to factor Xa generation curves. In addition it is also shown that with respect to the heparin-dependent inactivation, endogenous and exogenous factor $\mathrm{Xa}$ are indistinguishable.

Table 2. The Pseudo First Order Decay Constant of Factor Xa in RVV-Activated Plasma.

\begin{tabular}{|c|c|c|c|c|}
\hline $\begin{array}{l}{[\mathrm{UFH}]} \\
\mu \mathrm{g} / \mathrm{ml}\end{array}$ & $\begin{array}{l}k_{\mathrm{X}, \mathrm{r} w w / f^{*}} \\
\mathrm{~min}^{-1}\end{array}$ & $\begin{array}{l}\mathrm{k}_{\mathrm{X}_{\mathrm{s}, \mathrm{r}} \mathrm{w}_{\mathrm{N}}} * * * \\
\min ^{-1}\end{array}$ & $\begin{array}{l}\mathbf{k}_{\mathrm{X}_{\mathrm{a}, \mathrm{ex}}} \\
\mathbf{m i n}^{-1}\end{array}$ & \\
\hline 9 & \pm 0.06 & $0.94 \pm 0.05$ & 0.88 & \pm 0.09 \\
\hline 0.2 & \pm 0.17 & $1.82 \pm 0.09$ & 1.69 & \pm 0.07 \\
\hline 0.3 & \pm 0.36 & \pm 0.05 & 2.10 & \pm 0.13 \\
\hline 0.4 & \pm 0.67 & \pm 0.15 & 3.09 & \pm 0.36 \\
\hline
\end{tabular}

* $k_{X_{a}, \text { rwf }}$ is decay constant of factor Xa obtained by fitting the model to the curves of factor Xa generation, setting the enzyme breakdown constant at zero.

** $\mathrm{k}_{\mathrm{X}, \mathrm{rw}}$ is the decay constant of endogenous factor $\mathrm{Xa}$, determined from the inactivation phase of the factor Xa generation curves obtained when plasma was incubated with a high concentration of RVV-X ( $40 \mu \mathrm{g} / \mathrm{ml})$.

*** $\mathrm{k}_{\mathrm{Xa}, \mathrm{exg}}$ is the decay constant of exogenous $\mathrm{f} \mathrm{Xa}$. For experimental details see Materials and Methods section.

\section{Factor Xa Generation and Inhibition in Thromboplastin - Activated Plasma}

a) Factor Xa Generation. From the work of Jesty and coworkers $(5,23)$ it became evident that the conversion of plasma factor $\mathrm{X}$ into its activated form is limited, and greatly depends on the thromboplastin concentration used to initiate plasma clotting. At present, it is generally accepted that the activator complex that consists of TF/VIIa is rapidly destroyed by the plasma protein TFPI as soon as a few nmoles/l of factor $\mathrm{Xa}$ are formed (25).

Undoubtedly, the peak amount of factor Xa generated by the addition of thromboplastin in the absence of heparin (Fig. 5) is largely reduced when compared with that observed in RVV-X activated plasma (Fig. 4), suggesting a slower generation of $\mathrm{f} \mathrm{Xa}$ and/or a rapid inhibition of the activator in plasma, as previously observed by the group of Jesty (5). Renewed addition of thromboplastin confirmed the latter observation: it resulted in renewed factor Xa generation (data not shown). When 
increasing amounts of UFH were added to the plasma, factor Xa peak values became concomitantly reduced (Fig. 5). The most obvious cause is the enhanced inactivation of in situ generated factor Xa. To see whether heparin also affected the half-life time of the activator complex, we used the aforementioned 3-parameter model to fit the experimental data points of figure 5. However, it turned out that the 3-parameter fit could not be used to obtain relaible rate constants of neutralization of the thromboplastin-factor VIIa activity (see Discussion). We therefore decided to obtain independently determined rate constants of inhibition of factor Xa under the conditions of the thromboplastin-catalyzed factor Xa generation. in plasma.

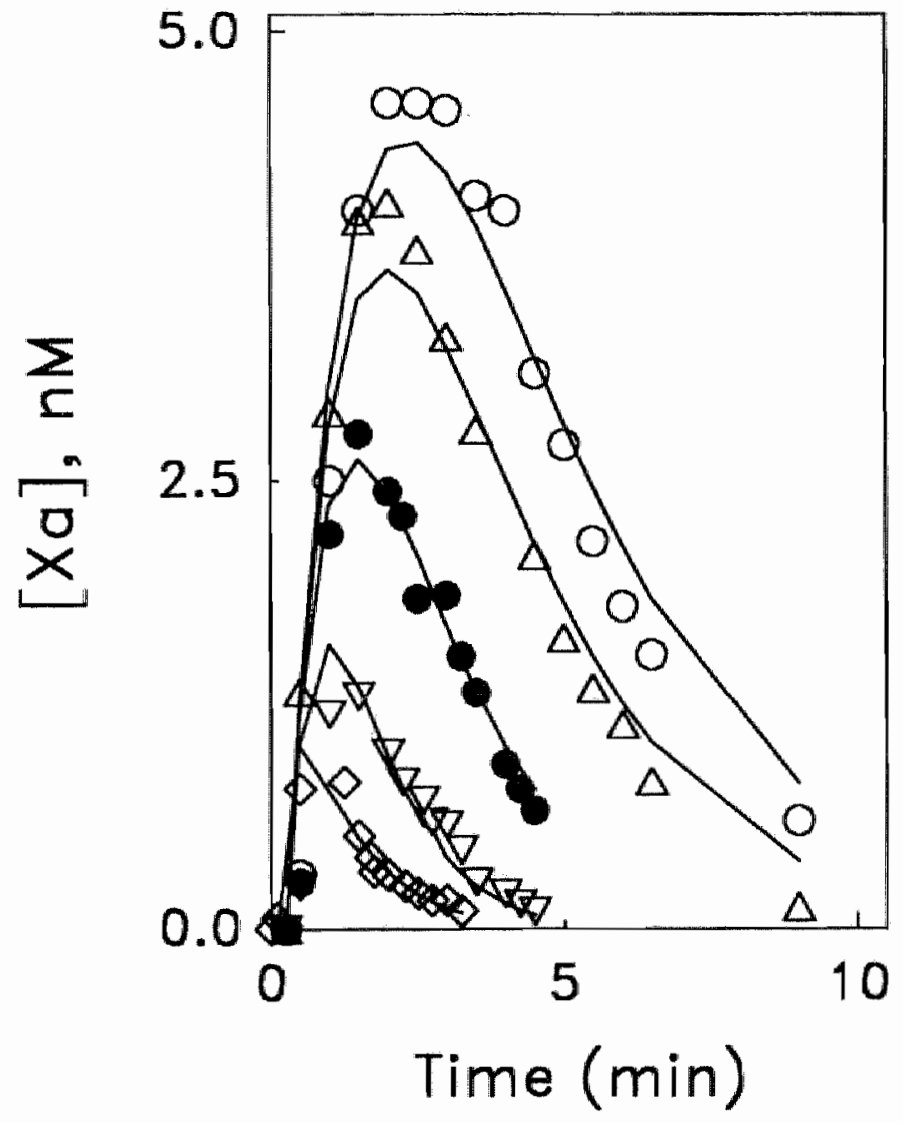

\section{Figure 5}

Factor Xa Generation in Plasma. Plasma $(80 \% \mathrm{v} / \mathrm{v})$ containing $2 \mu \mathrm{M}$ hirudin and varying concentrations of unfractionated heparin was activated by the addition of thromboplastin $1 / 30(\mathrm{v} / \mathrm{v})$ and $20 \mathrm{mM} \mathrm{CaCl}_{2} .0-0$ Control, $\Delta-\Delta \quad 0.1, \bullet-0.2, \nabla-\nabla$ 0.3 , and $\diamond-\diamond 0.5 \mu \mathrm{g} / \mathrm{ml} \mathrm{UFH}$. 
b) The Effect of Heparins on the Inactivation of Factor Xa in ThromboplastinActivated Plasma. Plasma was incubated with thromboplastin/calcium in the presence of hirudin and varying amounts of heparin. After $10 \mathrm{~min}$, when endogenous factor $\mathrm{Xa}$ activity was almost absent, $3 \mathrm{nM}$ purified human factor Xa was added and the decay constant was calculated from the residual factor Xa activities at different time points.

Figure 6 shows the pseudo first order rate constants of inhibition of factor $\mathrm{Xa}$, as a function of the UFH concentration. It is clearly seen that under these conditions, the rate constant of inhibition of factor Xa in the presence of thromboplastin is about half the rate constant determined in the absence of thromboplastin. The latter one, $0.88 \pm 0.09 \mathrm{~min}^{-1}$, is the very same as determined in RVV-X activated plasma $\left(0.94 \pm 0.05 \mathrm{~min}^{-1}\right)$. Apparently, in recalcified plasma, thromboplastin partially protects factor $\mathrm{Xa}$ from inhibition by AT III/heparin.

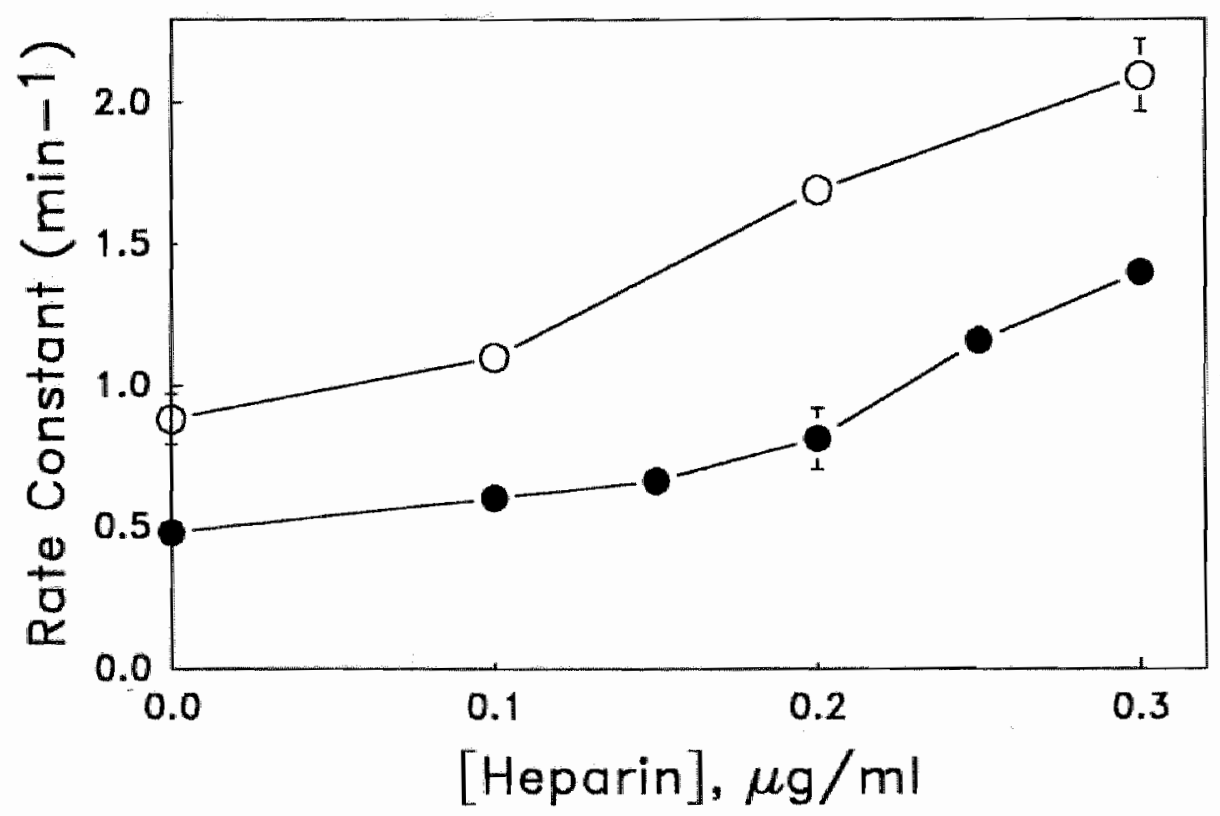

\section{Figure 6}

The Decay Constant of Factor Xa as a Function of the Unfractionated Heparin Concentration. 0.0 Control; - thromboplastin $1 / 30(\mathrm{v} / \mathrm{v})$.

Figure 7 shows the pseudo first order rate constants of inhibition of exogenous factor $\mathrm{Xa}(3 \mathrm{nM})$ in recalcified plasma as a function of the thromboplastin concentration. The final dilution of the plasma was kept constant $(75 \%)$. Undoubtly, the rate constant decreases with increasing 
thromboplastin concentrations. The same observation was made when the experiment was performed in the presence of $0.25 \mu \mathrm{g} / \mathrm{ml} \mathrm{UFH.} \mathrm{To} \mathrm{see}$ whether or not the effect of thromboplastin on the decay constant of factor $\mathrm{Xa}$ was due to the phospholipid component of thromboplastin, we measured the decay constant of factor Xa $(3 \mathrm{nM})$ in the presence of $50 \mu \mathrm{M}$ phospholipids vesicles (80:20, PC:PS) in plasma. The value of $0.92 \pm 0.06$ min $^{-1}$ obtained, suggests that phospholipids per se, do not protect factor $\mathrm{Xa}$ from inhibition in plasma.

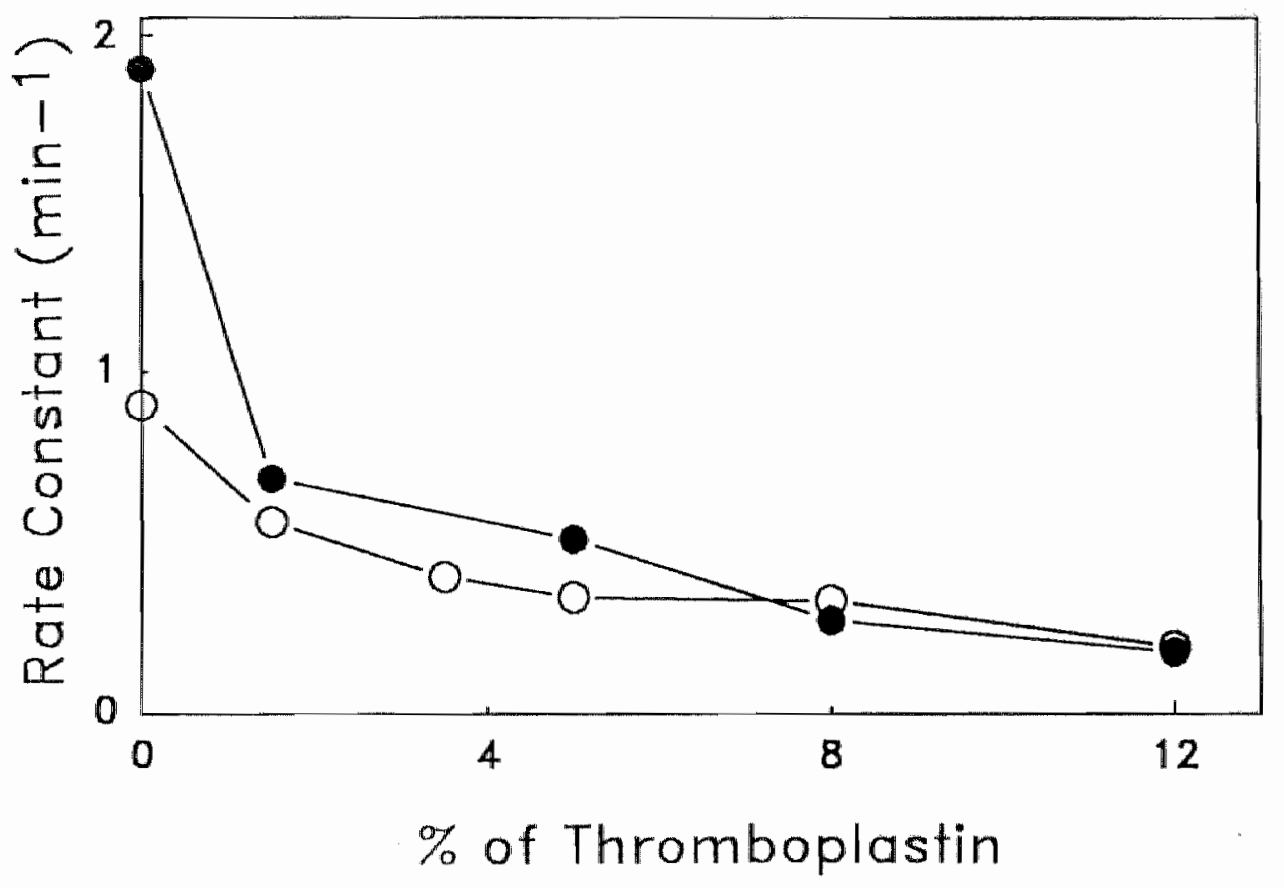

\section{Figure 7}

The Effect of Thromboplastin on the Decay Constant of Factor Xa in Plasma. O-O Control; $0.25 \mu \mathrm{g} / \mathrm{ml}$ UFH.

\section{c) The Effect of Heparins on the Neutralization of Thromboplastin/VIIa Activity}

in Plasma. The set of factor Xa generation curves shown in figure 5 was analyzed for the effect of heparin on the activity of the thromboplastin/factor VIIla. The fixed parameter was the rate constants of inhibition of factor $\mathrm{Xa}$ as determined with $3 \mathrm{nM}$ exogenous factor $\mathrm{Xa}$ in heparinized thromboplastin-activated plasma. The adjustable parameters were $V_{\max } / \mathrm{K}_{\mathrm{M}}$ and the rate constant of inhibition of the activator ( $\left.\mathrm{k}_{\mathrm{TF} / \mathrm{MII}}\right)$. The results are depicted in Table 3.

The same experiments were performed with a low molecular weight heparin (enoxaparin; Table 4), a synthetic ultra low molecular weight 
Table 3. The Effect of Unfractionated Heparin on the Inactivation of Factor Xa and of the TF/VIIa Complex.

\begin{tabular}{lll}
\hline $\begin{array}{l}{[\mathrm{UFH}]} \\
\mathrm{Hg} / \mathrm{ml}\end{array}$ & $\begin{array}{l}\mathrm{k}_{\mathrm{X}}^{*} \\
\mathrm{~min}^{-1}\end{array}$ & $\begin{array}{l}\mathrm{k}_{\text {TFMla }}{ }^{* *} \\
\text { min }^{-1}\end{array}$ \\
\hline 0 & $0.39 \pm 0.01$ & $0.56 \pm 0.06$ \\
0.1 & $0.46 \pm 0.01$ & $0.69 \pm 0.08$ \\
0.2 & $0.74 \pm 0.01$ & $0.88 \pm 0.11$ \\
0.3 & $1.31 \pm 0.04$ & $1.37 \pm 0.30$ \\
0.5 & $3.57 \pm 0.30$ & $0.98 \pm 0.38$ \\
\hline
\end{tabular}

${ }^{*} \mathrm{k}_{\mathrm{Xa}}$, the decay constant of factor Xa was obtained by the addition of $3 \mathrm{nM} \mathrm{FXa}$ to plasma, in the presence of thromboplastin, after most of the endogenous factor Xa has been dissapeard.

${ }^{*}{ }^{*} \mathrm{k}_{\text {TFNII }}$ is the decay constant of TF/VII(a), obtained by fitting the model to the Xa generation curves of figure 5 , and fixing the decay constants of factor $\mathrm{Xa}$ to the vallues depicted.

Table 4. The Effect of Enoxaparin on the Inactivation of Factor Xa and of the TF/VIIa Complex.

\begin{tabular}{|c|c|c|}
\hline $\begin{array}{l}{[\text { enox] }} \\
\mu \mathrm{g} / \mathrm{ml}\end{array}$ & $\begin{array}{l}\mathrm{k}_{\mathrm{x}_{\mathrm{x}}}{ }^{*} \\
\min ^{-1}\end{array}$ & $\begin{array}{l}\mathrm{k}_{\mathrm{TFNHIa}}{ }^{* * *} \\
\min ^{-1}\end{array}$ \\
\hline 0 & $0.39 \pm 0.01$ & $0.60 \pm 0.06$ \\
\hline 0.25 & $0.49 \pm 0.01$ & $0.65 \pm 0.07$ \\
\hline 0.50 & $0.74 \pm 0.03$ & $0.81 \pm 0.11$ \\
\hline 1.00 & $1.01 \pm 0.05$ & $1.99 \pm 0.24$ \\
\hline
\end{tabular}

The model was fitted to the data of figure 8. For details see Table 3

heparin (pentasaccharide), and the fraction of non-depolymerized heparin (UFH) that is devoided of species with affinity for AT III. The factor Xa generation curves at the various concentrations of the different heparin preparations are shown in figure 8 . From Table 5 , we see that the concentration that causes $50 \%$ of inhibition $\left(\mathrm{IC}_{50}\right)$ of factor Xa generation are about the same for UFH and pentasaccharide, and that enoxaparin requires a higher concentration to induce the same effect than UFH and PS. The low affinity fraction had almost no effect. 


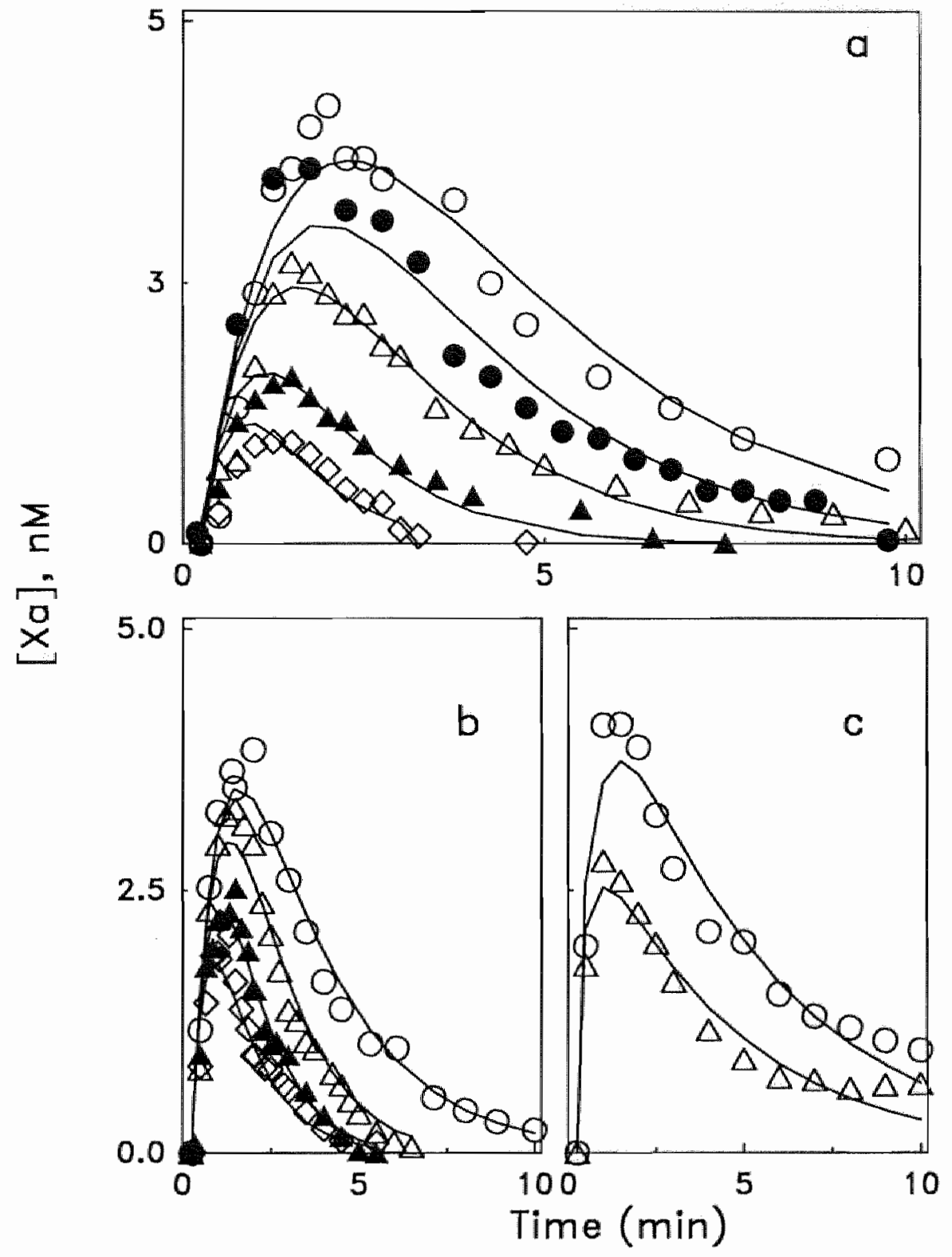

Figure 8

Factor Xa generation in plasma. Plasma ( $80 \% \mathrm{v} / \mathrm{v})$ containing $2 \mu \mathrm{M}$ hirudin and varying concentrations of heparin was activated by the addition of thromboplastin $1 / 30$ (v/v) and $20 \mathrm{mM} \mathrm{CaCl}_{2}$. O-O Control. a) Enoxaparin: - $0.25 ; \Delta-\Delta 0.5 ; \Delta-\Delta$ 1; and $\diamond 2 \mu \mathrm{g} / \mathrm{ml}$. b) Pentasaccharide: $\Delta-\Delta 0.05 ; \Delta-\Delta 0.1$; and $\diamond \Delta 0.2 \mu \mathrm{g} / \mathrm{ml}$. c) Low Affinity Fraction: $\Delta-\Delta 10 \mu \mathrm{g} / \mathrm{ml}$ 
That indeed a critical chainlength is needed became apparent from experiments performed with the synthetic pentasaccharide heparin $(\mathrm{Mr}=1714)$. This heparin did not stimulate the neutralization of the TF/VIIa activity in plasma (Table 5). Surprisingly, the fraction with low affinity for AT III that was prepared from UFH was also unable to stimulate the decay of the TF/VIIa activity in plasma, indicating that, besides a critical chainlength also the interaction with AT III is involved (Table 5).

Table 5. The Inhibitory Concentration $50 \%$ of Factor Xa generation.

\begin{tabular}{lclc}
\hline Heparin & $\begin{array}{l}\mathrm{IC}_{50}{ }^{*} \\
(\mu \mathrm{g} / \mathrm{ml})\end{array}$ & $\begin{array}{l}\mathrm{IC}_{5(\mathrm{mCl} M)^{* *}}{ }^{* *} \\
(\mu \mathrm{g} / \mathrm{ml})\end{array}$ & $\begin{array}{l}\Delta \mathrm{t}^{1 / 2} \\
\min \end{array}$ \\
\hline UFH & 0.23 & 0.076 & 0.48 \\
Enox & 0.77 & 0.066 & 0.46 \\
LA & $>10.0$ & - & $>0.18$ \\
PS & 0.20 & - & -0.30 \\
\hline
\end{tabular}

${ }^{*} \mathrm{IC}_{\$_{0}}$ is the concentration necessary to allow the $50 \%$ inhibition of the factor Xa generation. ${ }^{*} \mathrm{IC}_{50} \mathrm{ACH}$ ) is the $\mathrm{IC}_{50}$ expressed as $\mathrm{ACLM}$. See text for further explanation.

*** $\Delta t^{1 / 2}$ is the difference between the half-life time of TF/VIIa in the absence of heparin (control), and the half-life time at the concentration of heparin that induces the $50 \%$ of inhibition of factor $\mathrm{Xa}$ generation.

\section{d) Neutralization of TF/VIIa in TFPI-depleted plasma.}

Our next step was to investigate whether the effect of heparin on the half-life time of TF/VIIa was the result of a stimulating effect on the TFPImediated neutralization of TF/VIIa activity in plasma. To this end, we studied TF/VIIa-mediated factor Xa generation in plasma, but this time in plasma previously incubated with a rabbit polyclonal $\operatorname{IgG}$ directed against human TFPI.

Figure 9 shows the experimental data points as well as the result of the fit procedure (solid lines). It can be seen that the peak of the factor $\mathrm{Xa}$ generation curve in TFPI-neutralized plasma is about 3 times higher when compared to that of normal plasma. As well, factor Xa activity lasted for a significant longer period than in normal plasma.

The curves were analyzed using the mathematical model with the independently-determined decay constants of factor Xa shown in Table 6. The values obtained revealed that the rate constant of inhibition of factor $\mathrm{Xa}$ in thromboplastin-activated plasma is not modified in the absence of TFPI. In addition, the activity of the activator, TF/VIIa, was constant during the time of the experiment, even in the presence of heparin (Table 6). 


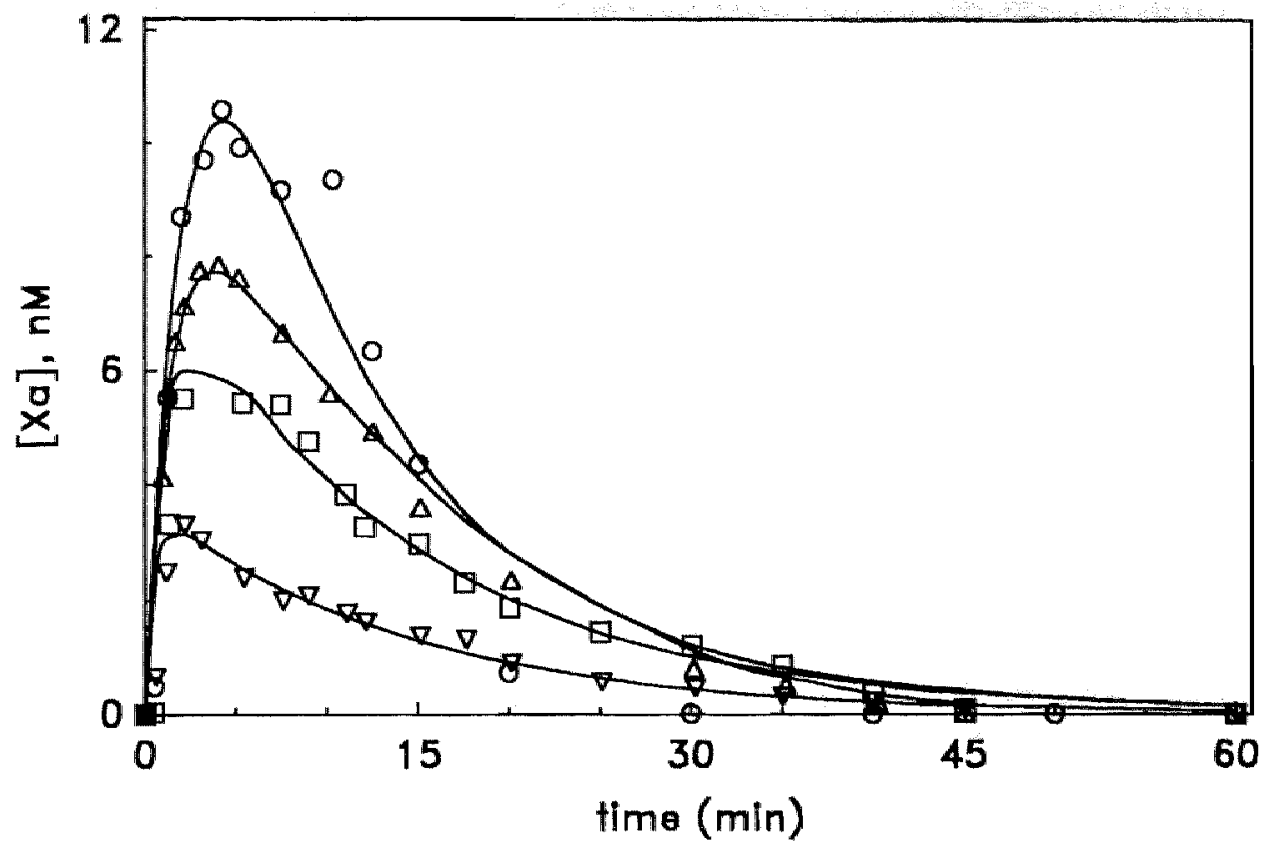

Figure 9

Factor Xa Generation in TFPI-Neutralized Plasma. $80 \%$ plasma (see Methods), was activated with thromboplastin and $\mathrm{CaCl}_{2}$, as described in fig 6 and 8 , in the presence of various heparin concentrations. 0.0 Control; $\Delta-\Delta \quad 0.2, \quad \square-\square 0.3, \nabla-\nabla 0.45 \mu \mathrm{g} / \mathrm{ml}$ unfractionated heparin.

Table 6. The Effect of Unfractionated Heparin on the Inactivation of Factor Xa and of TF/VIIa complex in TFPI-Neutralized Plasma.

\begin{tabular}{lll}
\hline $\begin{array}{l}\text { UFH] } \\
\mu \mathrm{g} / \mathrm{ml}\end{array}$ & $\begin{array}{l}\mathbf{k}_{\mathrm{Xa}_{\mathrm{a}}{ }^{*}} \\
\mathrm{~min}^{-1}\end{array}$ & \multicolumn{1}{l}{$\begin{array}{l}\mathbf{k}_{\mathrm{TFNHIa}} \\
\mathrm{min}^{-1 *}\end{array}$} \\
\hline 0 & $0.55 \pm 0.02$ & $0.02 \pm 0.01$ \\
0.2 & $0.76 \pm 0.04$ & $-0.03 \pm 0.02$ \\
0.3 & $1.33 \pm 0.07$ & $-0.01 \pm 0.02$ \\
0.45 & $1.50 \pm 0.11$ & $-0.01 \pm 0.04$
\end{tabular}

* $\mathrm{k}_{\mathrm{Xa}}$, the decay constant of factor Xa was obtained following the addition of $30 \mathrm{nM} \mathrm{f}$ $\mathrm{Xa}$, after most of the endogenous factor $\mathrm{Xa}$ had been disappeared. ( 30 minutes after $\mathrm{TF} / \mathrm{Ca}^{++}$addition); they were used as independent parameters in the fit.

** $\mathbf{k}_{\text {TFNII }}$, the decay constant of TF/VII(a), was obtained by fitting the model to the Xa generation curves of figure 9 , and fixing the decay constants of factor $X a$ to the values depicted. $k_{\text {TFNII }}$ was obtained from a simultaneous fit of all the curves. 
It is our conclusion that heparin stimulates the TFPI-mediated neutralization of the activity of the thromboplastin/factor VIIa complex. In addition, we confirm that the factor $X$ converting activity of the thromboplastin/factor VIIa complex was not neutralized by [AT III-heparin].

\section{DISCUSSION}

In this study we have used a 3-parameter model to describe the factor $\mathrm{Xa}$ generation in thromboplastin-activated plasma. The following assumptions were made:

1) Factor $X$ activation in plasma follows Michaelis-Menten kinetics.

2) Inhibition of TF/VIIa follows first order kinetics

3) Also, the inhibition of factor Xa follows first order kinetics.

Obviously, the model we have proposed is an oversimplification of a rather complex system. It took not into account feedback reactions (figure 1): a) factor Xa stimulates its own generation by activating factor VII, and b) factor Xa inhibits its own generation by the formation of a quaternary complex with TFPI, tissue factor, and factor VIIa (9).

Nevertheless, when the model was used in a rather simple reaction system containing purified factors VII and X and thromboplastin, the factor $\mathrm{Xa}$ generation could be adequately described by the model (figure 2 ). Thus, activation of factor VII by factor Xa appears to be very fast, otherwise a lag phase in factor Xa generation should have been observed. Even in the presence of AT III and UFH, when the half-life time of factor Xa is short ( $0.62 \mathrm{~min}$ compared to $5.3 \mathrm{~min}$ in the absence of heparin), no lag phase in the factor Xa generation was observed. We concluded that for the purified system described, our assumption that factor $\mathrm{Xa}$ formation follows simple Michaelis Menten kinetics is correct. Further support for the validity of the model came from the finding that the rate constants of inactivation of factor $\mathrm{Xa}$ in the presence of AT III and varying amounts of UFH as obtained by the fitting procedure, were the very same as those determined independentlly, i.e. using exogenous factor Xa.

In the case of a more complex reaction system, plasma, but using a simple activator (factor $\mathrm{X}$ converting protein from Russell's Viper venom), our model was also found to be valid. The rate constant of inhibition of factor $\mathrm{Xa}$ in plasma containing varying amounts of heparin as determined by the fit procedure were the same as those obtained when purified human factor Xa was added to plasma. As expected, the rate constant of inactivation of the activator was found to be (close to) zero, also in the presence of heparin.

When the thromboplastin-catalyzed factor Xa generation in plasma was analyzed using the 3-parameter model, we noticed a dependency between 
the rate constant of inhibition of factor $\mathrm{Xa}$ and that of the activator (TF/VIIa). In order to obtain a reliable estimate of the rate constant of neutralization of the TF/VIIa activity, the rate constant of inhibition of factor Xa was determined independently and used in the model as a fixed parameter. In agreement with Jesty (23), we found that the rate constant of inhibition of factor $\mathrm{Xa}$ was influenced by thromboplastin. Indeed, from the experiments shown in figure 7, we concluded that in plasma, thromboplastin either protects factor Xa from inhibition mediated by AT III-heparin, or neutralizes heparin. Therefore, the only way to obtain a reliable estimation of the factor $\mathrm{Xa}$ inhibition rate constant was the addition of exogenous factor $\mathrm{Xa}$ to thromboplastin-activated plasma at the time point that most of the endogenous factor Xa was inactivated by AT III. Since the plasma also contained hirudin, a very potent and specific inhibitor of thrombin, the consumption of AT III could be neglected. Following the aforementioned procedure, we found that the rate constant of neutralization of the TF/VIIa activity increased with increasing amounts of unfractionated heparin. Because neutralization of the activator activity was absent in plasma treated with anti-TFPI, we concluded that heparin stimulates the neutralization of the TF/VIIa activity by TFPI. This finding contrasts the observations of Broze et al (9). This group reported that in purified systems, the rapid inactivation of factor $\mathrm{Xa}$ in the presence of [AT III-heparin] abrogates the formation of the quaternary complex [TFPI, TF, VIIa, Xa], necessary to allow TF/VIIa inhibition.

Interestingly, a low molecular weight heparin (enoxaparin) was also able to stimulate neutralization of the activator, but was less potent on a weight basis. The half-life time of TF/VIIa $(1.2 \mathrm{~min})$ decreased to 0.7 minutes with 0.23 and $0.75 \mu \mathrm{g} / \mathrm{ml}$ of UFH and enoxaparin, respectively. On the basis of the molecular distribution of these heparins, the concentrations can be calculated from the amount $(\%)$ of AT III high affinity material above 5,400 D (ACLM; refs. 27, 28, 29). The values then found are 0.076 and $0.066 \mu \mathrm{g} / \mathrm{ml}$ respectively for UFH and enoxaparin. In keeping with the notion that the AT III high affinity material, but also the molecular features with MW $>5,400$ are necessary for the inhibition of TF/VIIa, is the observation that an ultra low molecular weight heparin (synthetic pentasaccharide representing the AT III binding site of heparin) did not affect the half-life time of the TF/VIlla complex in plasma. Quite puzzling, in addition, is our observation that heparins with molecular weight higher than 5,400 but lacking the AT III binding site were also not able to stimulate the neutralization of TF/VIIa. This finding suggests that besides the chainlength also the sites with high affinity for AT III are essential to stimulate the neutralization of TF/VIIa by TFPI.

At present, the mechanism behind the stimulatory effect of heparin remains unclear. Although it has been reported that heparin stimulates the 
interaction between factor Xa and TFPI (9), we feel that heparin must act in a different way, because there is no evidence that the AT III binding site is involved in these stimulatory action. Moreover, there is no evidence that the interaction between factor Xa and TFPI is the rate limiting step in the formation of the quaternary complex, [TFPI-TF-VIIa-Xa], that ultimately leads to neutralization of the TF/VIIa activity.

In conclusion, our present work has revealed that heparin does influence the generation of factor $\mathrm{Xa}$ in plasma by shortening the half-life time of the activator, not because of an inhibitory effect on the enzymatic activity (heparin-stimulated inactivation of factor VIIa), but via the TFPI/Xa-mediated neutralization of the TF/VIIa activity.

\section{ACKNOWLEDGMENTS}

We wish to thank Mrs. J. Govers for providing us purified RVV-X, and R. Blezer for his excellent technical assistance.

\section{References}

1) Rapaport, S.I.: Inhibition of factor VIla/tissue factor-induced blood coagulation: With particular emphasis upon a factor Xa dependent inhibitory mechanism. Blood 73; 2 : $359-365 ; 1989$.

2) Rao, L.V.M.; Rapaport, S.I.; and Bajaj, S.P.: Activation of human factor VII in the initiation of tissue factor-dependent coagulation. Blood 68; 3: 685-691; 1986 .

3) Rao, L.V.M.; Rapaport, S.I.: Studies of a mechanism inhibiting the initiation of the extrinsic pathway of coagulation. Blood 69;645-651; 1987.

4) Wildgoose, P.; Berkner, K.L.; Kisiel, W.: Synthesis, purification, of an $\operatorname{Arg}_{152} \rightarrow$ Glu site-directed mutant of recombinant human blood clotting factor VII. Biochemistry 29: 3413-3420; 1990 .

5) Morrison, S; and Jesty, J.: Tissue factor-Dependent activation of tritium-labeled factor IX and factor $X$ in human plasma. Blood 63. 1338-1347; 1984.

6) Hubbard, A.R.; Jennings, C.A.: Inhibition of tissue thromboplastin-mediated blood coagulation. Thromb. Res. 42; 489-498; 1986.

7) Hubbard, A.R.; and Jennings, C.A.: Inhibition of the tissue factor-factor VII complex: Involvement of factor $\mathrm{Xa}$ and lipoproteins. Thromb. Res. 46:527-537; 1987. 
8) Broze, G.J.; Miletich, J.P.: Characterization of the inhibition of tissue factor in serum. Blood 69; 1: 150-155; 1987.

9) Broze, G.J.; Warren, L.A.; Novotny, W.F.; Higuchi, D.A; Girard, J;J.: Miletich JP. The lipoprotein-associtated coagulation inhibitor that inhibits the factor VIItissue factor complex also inhibits factor Xa. Insight into its possible mechanism of action. Blood 71: 2: 335-343; 1988.

10) Mertens, K.; Bertina, R.M.: Pathways in the activation of human coagulation factor X. Biochem. J. 185: 647-658; 1980.

11) Lindhout, T.; Kop-Klassen, B.H.M.; Hemker, H.C.: Activation of decarboxyfactor $\mathrm{X}$ by a protein from Russell"s Viper venom. Purification and partial characterization of activated decarboxyfactor X. Biochim. Biophys. Acta. 533: 327-341; 1978.

12) Smith, R.L.: Titration of activated bovine factor X. J. Biol. Chem. 262: 1126811274; 1973.

13) Lindhout, T.; Govers-Riemslag, J.W.P.; van der Waard, P.; Hemker, H.C; Rosing, J.: Factor Va-Factor Xa interaction. Effect of phospholipid vesicles of variying composition. Biochemistry 21: 5494-5502; 1982.

14) Govers-Riemslag, J.W.P.; Speijer, H.; Zwaal, R.F.A.; Rosing, J.: The effects of bovin prothrombin fragment 1 and fragment 1.2 on prothrombin activation. Thromb. Res. 38: 375-388; 1985 .

15) Owren, P.A.; Aas, K.: The control of dicumarol therapy and the quantitative determination of prothrombin and proconvertin. Scand J. Clin. Lab. Invest. 3: 201218; 1951.

16) Thaler, E.; Schmer, G.: A simple two-step isolation procedure for human and bovine antithrombin III (heparin cofactor): a comparison of two mehtods. $\mathrm{Br}$. J Haematol. 31: 223-243; 1975.

17) Miller-Anderson, M.; Borg, H.; Anderson, L.O.: Purification of antithrombin III by affinity chromatography. Thromb. Res. 5; 439-452; 1974.

18) Schifman, S.; Theodor, I.; Rapaport, S.: Separation from Russel's Viper venom of one fraction reacting with factor $\mathrm{X}$ and another reacting with factor $\mathrm{V}$. Biochemistry 8: 1397-1404; 1969.

19) Pieters, J.; Lindhout, T.: The Limited importance of factor Xa inhibition to the anticoagulant property of heparin in thromboplastin activated plasma. Blood 72: 2048-2052; 1988.

20) Press, W.H.; Flanery, B.P.; Teukolski, S.A.; Vetterling, W.T.: in Numerical Recipes. New York, Cambridge University Press, pp 547-560; 1986. 
21) Gill, P.E; Murray, W.: Algorithms for the solution of the non-linear least squares problem. SIAM J. Num. Anal. 15: 977-992; 1978.

22) Beck, J.V.; Arnold, K.J.: Parameter estimation in engineering and science. New York, NY: Wiley, pp 378-387; 1977.

23) Jesty, $J$.: Analysis of the generation and inhibition of activated coagulationfactor $X$ in pure systems and in human plasma. J. Biol. Chem. 261; 19: 8695-8702; 1986.

24) Schoen, P.; Lindhout, T. Willems, G.; Hemker, H.C.: Antithrombin III-dependent anti-prothrombinase activity of heparin and heparin fragments. J. Biol. Chem. 264: 10002-10007; 1989.

25) Girard, T.J.; Warren, L.A.; Novotny, W.F.; Likert, K.M.; Brown, S.G.; Miletich, J.P.; Broze, G.J.: Functional significance of the Kunitz-type inhibitory domains of lipoprotein-associated coagulation inhibitor. Nature 338: 518-520; 1989.

26) Jesty, J.: The inhibition of activated bovine coagulation factors $X$ and VII by antithrombin III. Archives of Biochemistry and Biophysics. 185; 1, 165-173; 1978.

27) Hemker, H.C.; Béguin, S.; Bendetowicz, A.V.; Wielders, S.: The determination of the levels of unfractionated and low molecular weight heparins in plasma. Their effect on thrombin mediated feedback reactions in vivo. Preliminary results on samples after subcutaneous injection. Haemostasis vol. $21, \mathrm{n}^{\circ} 4: 258-272 ; 1991$.

28) Bendetowicz, A.V; Pacaud, E.; Béguin, S.; Uzan, A.; Hemker, H.C.: On the relationship between molecular mass and anticoagulant activity in a low molecular weight heparin (enoxaparin). To be published in Thromb. Haemost.; 1992.

29) Béguin, S.; Wielders, S.; Lormeau, J.C.; Hemker, H.C.: The mode of action of CY 216 and CY 222 in plasma. To be published in Thromb. Haemost.i 1992. 


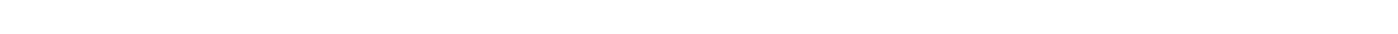

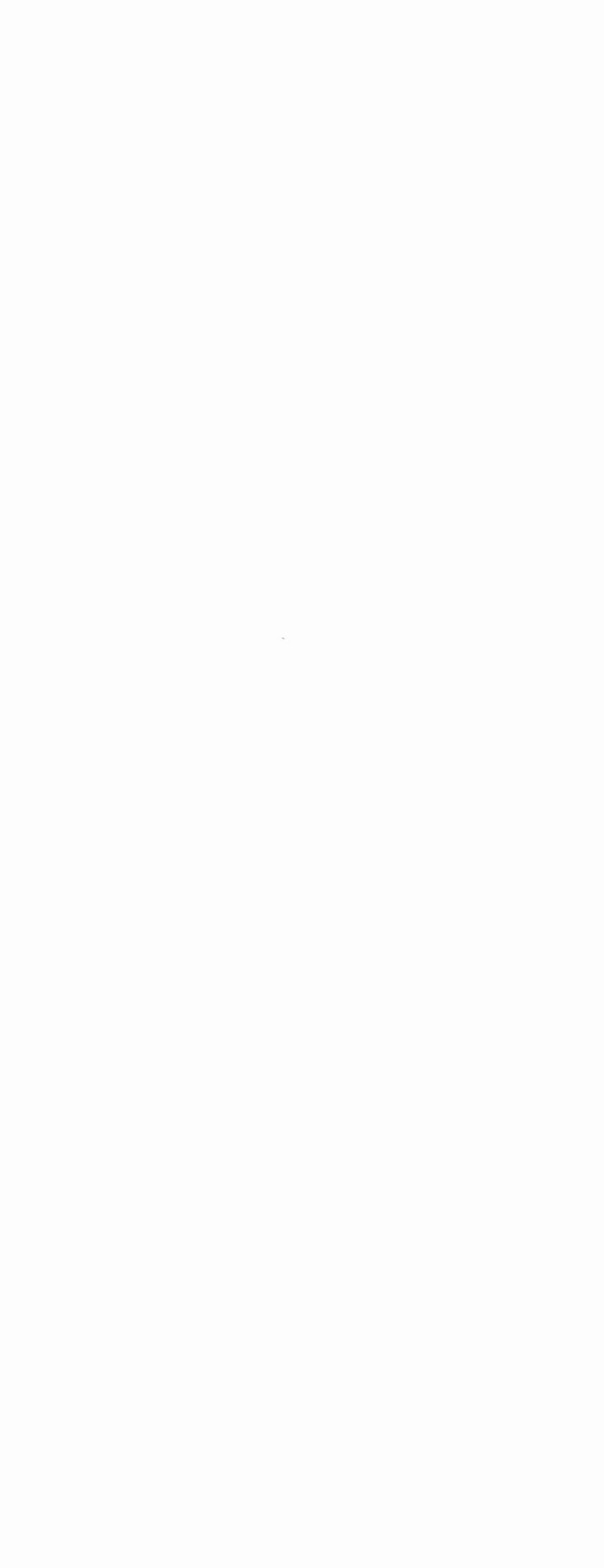





\section{THE DETERMINATION OF THE LEVELS OF UNFRACTIONATED HeParin and Low Molecular Weight HeParins in Plasma. Their Effect on Thrombin Mediated Feedback Reactions in vivo. Preliminary Results on Samples AFter Subcutaneous Injection.*}

SUMMARY

The concentration of two different heparin species in plasma samples can be determined via their catalytic effects on the inactivation of factor Xa (F.Xa) and thrombin by antithrombin III. Because all heparin material with high affinity for ATIII (HAM) catalyses the inactivation of factor Xa we can define a Standard Independent Unit (SIU) of HAM as that amount that, in plasma containing $1 \mathrm{\mu M}$ of ATIII, will raise the (pseudo-) first order breakdown constant of factor $\mathrm{Xa}$ by $1 \mathrm{~min}^{-1}$. Only material above the critical chainlength of 17 monosaccharide units (Above Critical Chainlength Material, ACLM) will catalyse the inactivation of thrombin. We can therefore define a Standard Independent Unit of ACLM as that amount of heparin that, in plasma containing $1 \mu \mathrm{M}$ of ATIII will raise the (pseudo-) first order breakdown constant of thrombin by $1 \mathrm{~min}^{-1}$. Of any given heparin preparation we can determine the specific HAM and ACLM activities in terms of SIU $/ \mathrm{mg}$, by determining the breakdown constants of factor $\mathrm{Xa}$ and thrombin in plasma spiked with the heparin. On basis of the breakdown constants found in a plasma sample we can then determine the levels of HAM and ACLM.

The difference in biological half life time of the higher- and lower MW fractions of a heparin will cause unequal elimination of HAM and ACLM after injection. We therefore assessed these fractions separately by determining their specific activities separately.

It is demonstrated how this procedure can be applied to plasma samples obtained after subcutaneous injection of unfractionated heparin (UFH) and of two types of low molecular weight heparin (LMWH).

Preliminary results show that: a) About three times more of UFH activity than of LMWH activity has to be injected to obtain the same levels of ACLM in the plasma. The specific activity of UFH is much higher than that of LMWH, therefore the weight, and a fortiori the molar quantities of LMWH injected are much higher than those of UFH. Only with the LMWHs significant amounts of BCLM are found, which rises higher and persists longer than the ACLM. This material however has only a minor effect on

\footnotetext{
*Based on: H.C. Hemker; S. Béguin; A.V. Bendetowicz and S. Wielders. Haemostasis vol. $21 N^{\circ} 4: 258-272 ; 1991$.
} 
the biological effects measured (see below).

In platelet poor plasma we determined three biological effects: a) the thrombin generation curve; b) the factor $\mathrm{Xa}$ generation curve and c) the course of prothrombin conversion. We also assessed the thrombin generation curve in PRP. Factor $X a$ inhibition does not lead to proportional inhibition of prothrombin converting activity. This can be explained from the enzymology of prothrombinase. The difference between UFH and LMWHs can therefore not be explained in terms of antithrombin and anti-factor Xa activity. The essential difference between UFH and LMWH appears in platelet rich plasma, where thrombin generation is both inhibited and retarded by LMWHs while it is only retarded but not inhibited by UFH.

\section{INTRODUCTION}

In clinical and pharmacological studies anti-factor $\mathrm{Xa}$ activity appears as a sensitive detector of heparins in plasma (1 and references therein). From fundamental studies (2) appears that rather the effect of heparins on the feedback activation of the clotting mechanism by thrombin is the point of attack of heparins ( 2 and references therein, 3,4$)$. Here an apparent paradox arises: Heparin in vitro seems to act via inhibition of thrombin but the activity in samples from subjects receiving heparin is adequately rendered by the anti-factor $\mathrm{Xa}$ action. It is the purpose of this chapter to discuss this paradox. We will suggest a way out by introducing a clear separation between the estimation of the level of two different kinds of active heparin on the one hand and their effects on the different aspects of the biological system of thrombin generation on the other.

All heparins that bind with high affinity to AT III do so via the specific pentasaccharide region $(5,6)$ and all heparins that bind to AT III increase its anti-factor $\mathrm{Xa}$ activity. This activity is therefore in principle suitable for measuring that part of injected heparin that contains this pentasaccharide region (High Affinity Material, HAM).

Only high-affinity heparins with a minimal chainlength of 18 monosaccharide units, i.e. with a $\mathrm{MW}>5400$, will support the antithrombin activity of AT III (7-13). The high affinity material above the critical chain length of 17 units, (ACLM) can therefore be specifically measured by the antithrombin activity that it induces. ACLM is a subfraction of HAM. The other subfraction is the below critical chainlength material (BCLM) that only enhances factor $\mathrm{Xa}$ inactivation and that has no effect on thrombin inactivation. No specific test is available for this material but it can be calculated from the difference between HAM and ACLM. 
Anti-factor $\mathrm{Xa}$ activity is routinely measured in the virtual absence of $\mathrm{Ca}^{++}$ions, in order to prevent concomitant factor $\mathrm{Xa}$ generation. Different types of heparin react differently to the ambient $\mathrm{Ca}^{++}$ concentration $(14,15)$. The action of a heparin on factor $\mathrm{Xa}$ in wivo, at normal $\mathrm{Ca}^{++}$concentration, can therefore not automatically be estimated on basis of common anti-factor Xa tests.

Also the assessment of antithrombin activity in samples from in vivo experiments is not necessarily ideal. It is often not measured directly but infered from the prolongation of the activated partial thromboplastin time or the thrombin time (see e.g. 16). These methods are as convenient as they are imprecise (17) and give only semiquantitative information on the magnitude of the antithrombin effect.

The common laboratory tests for heparin in plasma samples are therefore not ideally suited to quantitate the anticoagulant effect of different heparins.

In this chapter we propose to use the specific antithrombin- and anti-factor $\mathrm{Xa}$ activity of a heparin preparation to determine the concentration of respectively, the ACLM and the total HAM fraction in plasma samples. When these are known we can then determine the effects of the circulating amounts of heparin on biological functions such as thrombin generation in platelet poor and platelet rich plasma, prothrombin conversion velocity and factor $\mathrm{Xa}$ generation.

We tested this approach in a pilot experiment in which we injected UFH and two LMWH preparations (A and B) subcutaneously into healthy volonteers. In the plasma samples we determined the increase of the decay constants of thrombin and factor Xa. From these data and the specific activities of the heparins, we calculated the course of the concentrations of ACLM and BCLM.

\section{The Standard-Independent Unit of Heparin}

At pharmacologically relevant concentrations, in plasma, the increase of the pseudo first order decay constant of thrombin is linearly dependent upon both the concentration of heparin and the concentration of AT III (18 and discussion). This property can be used to define a standard-independent unit of heparin (SIU) as that amount of heparin that, when added to one $\mathrm{ml}$ of plasma containing one $\mu \mathrm{M}$ of AT III increases the decay constant of a coagulation enzyme by one inverse minute $\left(\min ^{-1}\right)$. The unit can be based on factor Xa inactivation to define a SIU of total HAM or it can be based on thrombin inactivation to define a SIU of ACLM.

\section{The Specific Activities of a Heparin}

The specific activity (SA) of a heparin preparation can be expressed in terms of SIU per $\mu \mathrm{g}$ of material. The factor Xa based SA (SA-Xa) is a 
function of the HAM material. If the HAM content of a heparin is known, it is logical to express the SA-Xa per $\mu \mathrm{g}$ of HAM. Analogously SA-IIa is a function of ACLM and therefore it should be expressed in terms of that substance. Inversely, once SA-Xa of the HAM fraction of a given heparin is known, we can calculate the HAM concentration in an unknown sample from the decay constant of factor Xa. Completely analogously we can calculate the ACLM concentration from the decay constant of thrombin and SA-IIa. We might think of determining SA's in molar rather than in weight units but this does not seem possible with the highly polydisperse preparations used.

Although the SIU is independent of a standard, it does not obliterate the use of a good standard preparation because the precise determination, in absolute terms, of specific activities will need a specialised laboratory. Comparative measurements are easier, so that good standard HAM and ACLM heparin preparations remain useful.

\section{MATERIALS AND METHODS}

\section{Materials}

Heparins. Calciparine, LMWA and LMWB were obtained from the dispensary of the hospital. The figures for HAM and ACLM content were obtained from previous work (chapter $2,11,12$ ). Because no conclusions as to pharmacological properties should be drawn from an experiment in which each heparin was administered to one subject only we will not reveal the identity of the heparins.

The chromogenic substrate for thrombin H.D-Phe-Pip-Arg-pNA (S2238), was obtained from Kabi, Sweden.

Proteins. Reptilase was obtained from Boehringer Mannheim (Mannheim, W. Germany) and dissolved according to the instructions of the manufacturer. Human brain thromboplastin was prepared acording to Owren and Aas (19). Before use it was diluted 1:30 to 1:40 with buffer A containing $0.1 \mathrm{M} \mathrm{Ca}^{++}$so as to clot a mixture of $30 \mu \mathrm{l}$ of thromboplastin, $30 \mu \mathrm{l}$ of buffer $\mathrm{A}$ and $120 \mu \mathrm{l}$ of plasma in $70-80$ seconds. Recombinant hirudin was a kind gift of Dr. R.B. Wallis (Ciba-Geigy, Horsham,UK).

Plasmas. The heparins were injected subcutaneously in two healthy volunteers. Blood was taken by antecubital venapuncture before the injection, and at $45 \mathrm{~min}$ (UFH only), at $1.5,3,5,7 \mathrm{~h}$ (all three preparations) and at $9 \mathrm{~h}$ (LMWHs only). Platelet poor plasma (PPP) and platelet rich plasma (PRP) were obtained according to standard procedures (20). 
Blood was collected on $0.13 \mathrm{M}$ trisodium citrate; nine parts of blood to one part of citrate solution. Platelet rich plasma (PRP), platelet poor plasma (PPP) and defibrinated plasma were obtained as previously published (20). As it was previously shown, the concentration of factors II, VII, VIII, IX, X, XI and XII does not change significantly by the reptilase treatment (20).

\section{Methods}

\section{Activity measurements}

The decay constant of thrombin was determined as described in ref. 20, i.e. in a system where thrombin generation was inhibited the half life time ( $\left.t_{1 / 2}\right)$ of thrombin activity was measured and the decay constant was obtained as $\ln 2 / t_{1 / 2}$.

The decay constant of factor Xa was determined as in ref. 15 .

Thrombin generation in plasma was determined and the constant of inactivation of endogenous thrombin were determined according to ref. 20 . In short $240 \mu \mathrm{l}$ of defibrinated plasma is supplemented with $60 \mu \mathrm{l}$ of buffer A, containing heparin at the desired concentration and incubated for 5 min at $37^{\circ} \mathrm{C}$. At zero time, thrombin generation is started by the addition of 60 $\mu \mathrm{l}$ of a solution containing $100 \mathrm{mM}$ of $\mathrm{CaCl}_{2}$, and diluted human brain thromboplastin. At intervals, a $10 \mu \mathrm{l}$ aliquot of the mixture is sampled into a disposable plastic cuvette containing buffer and chromogenic substrate (for details see ref. 20). The amidolytic activities in the plasma samples are calculated from the O.D., and expressed as the equivalent concentration of thrombin (in nM), according to a reference curve obtained with active site titrated purified human $\alpha$ thrombin.

The generation of prothrombinase activity is calculated from the amidolytic activity curve of thrombin generation as described previously (20). Briefly, the observed amidolytic activity is the sum of thrombin activity and the partial activity of $\alpha_{2} \mathrm{M}$-thrombin complex. The rate of thrombin generation at any moment is the sum of two processes: a) The conversion of prothrombin into thrombin by prothrombinase and b) the decay of thrombin by the action of plasma protease inhibitors. The rate of inhibition of thrombin at any time can be calculated from the concentration of thrombin at that moment and the pseudo-first order rate constant of thrombin inhibition by antithrombin III $\left(\mathrm{k}_{1}\right)$ and $\alpha_{2}$-macroglobulin $\left(\mathrm{k}_{2}\right)$. The rate of prothrombin activation (prothrombinase activity) then can be calculated from the observed rate of generation of amidolytic activity and 
the rate of thrombin inhibition.

Factor Xa generation. Plasma $(240 \mu \mathrm{l})$ was incubated with $60 \mu \mathrm{l}$ thromboplastin diluted $1: 6$ in $100 \mathrm{mM} \mathrm{CaCl}$ containing $10 \mu \mathrm{M}$ r-hirudin. At timed intervals samples were taken and assayed for factor $\mathrm{Xa}$ activity using a two stage bioassay in which factor $\mathrm{Xa}$ is the rate limiting component of prothrombinase (i.e. phospholipids and factor $\mathrm{Va}$ are present in excess) and prothrombin is the substrate (21).

\section{RESULTS}

\section{Specific activities}

In normal plasma, with a known amount of AT III and spiked with known amounts of the heparins we determined the specific anti-thrombin and anti-factor Xa activities for the heparins used. From this and the HAM content we calculated the specific anti-factor Xa activity of the HAM fraction. In a similar way the specific anti-thrombin activity of the ACLM subfraction was determined (table 1).

Table 1. Properties of the Material Injected

\section{$\underline{\text { UFH }}$ LMWHA LMWHB}

Peak mol. weight $(\mathrm{kD})$

High aff. material (HAM) $(\%)^{*}$

HAM $>5.4 \mathrm{kD}(\mathrm{ACLM})(\%)^{* * *}$

HAM $<5.4 \mathrm{kD}$ (BCLM) $(\%)^{* *}$

Antithrombin spec.act.***

total

ACLM

Antifactor Xa spec.act.****

total

HAM

Ratio antithrombin:anti-Xa

\section{5}

33

33

0

10.33

31.0

3.37

10.21

3.1
5.1

24

13

11

4.4

1.4

8.6

5.4

2.36

1.70

$18.2 \quad 19.8$

0.66

0.55

2.75

3.93

$3.6 \quad 3.1$

* For determination see chapter 2

** From refs. 11 and 12.

*** In $\min ^{-1} / \mu \mathrm{M}$ AT III/ $(\mu \mathrm{g} / \mathrm{ml}$ heparin $)$ 


\section{The course of heparin concentrations after SC injection}

The three heparins were injected subcutaneously in healthy male volunteers in doses as indicated in table 2 . In this table the amounts of material injected are also recalculated in terms of standard independent units. It is surprising to see that, contrary to what might be gathered from the current liteature, injection of LMWHs does not automatically mean administration of large amounts of anti-factor Xa activity. In fact the amounts of antithrombin activity as well as that of anti-factor Xa activity injected with the LMWHs is around $30 \%$ of that injected with UFH (table 1).

Table 2. Data on the Doses Injected.

\section{UFH LMWHA LMWHB}

\begin{tabular}{|c|c|c|}
\hline $\begin{array}{l}\text { Weight of subject }(\mathrm{kg}) \\
\text { total antithrombin }{ }^{*} \\
\text { total anti factor Xa }\end{array}$ & $\begin{array}{r}85 \\
228 \\
74.4\end{array}$ & $\begin{array}{c}89 \\
69 \\
19.3\end{array}$ \\
\hline
\end{tabular}

Dose in $\mathrm{mg}$ (calculated)

$\begin{array}{lccc}\text { total } & 22 & 29 & 45 \\ \text { HAM } & 7.3 & 7.0 & 6.3 \\ \text { ACLM } & 7.3 & 3.8 & 3.8 \\ \text { BCLM } & 0 & 3.2 & 2.5\end{array}$

* Standard independant kilo-units, $\min ^{-1} / \mu \mathrm{M}$ AT III x 1000 (see text).

We determined the increase of the decay constant for thrombin and for factor Xa after injection of the three heparins in amounts as indicated in table 1. After normalisation for the AT III levels of the individual plasmas this led to the course of the plasma levels expressed in SI units as shown in fig 1. The ratio of the antithrombin over the antifactor Xa activities scatters around unity (fig. 2). Via the specific activities we then calculated the HAM levels from the increase of the factor Xa decay constants, while the ACLM levels were obtained from the increase of the thrombin decay constants. The difference between HAM and ACLM is the high affinity material with a molecular weight below the critical limit for thrombin inactivation, i.e. BCLM (fig. 3).

It is evident that the concentrations found in the plasma differ more than can be explained from the difference in the amounts injected. The large amount of antithrombin activity injected with UFH causes lower plasma concentrations of ACLM than the much smaller amounts injected 

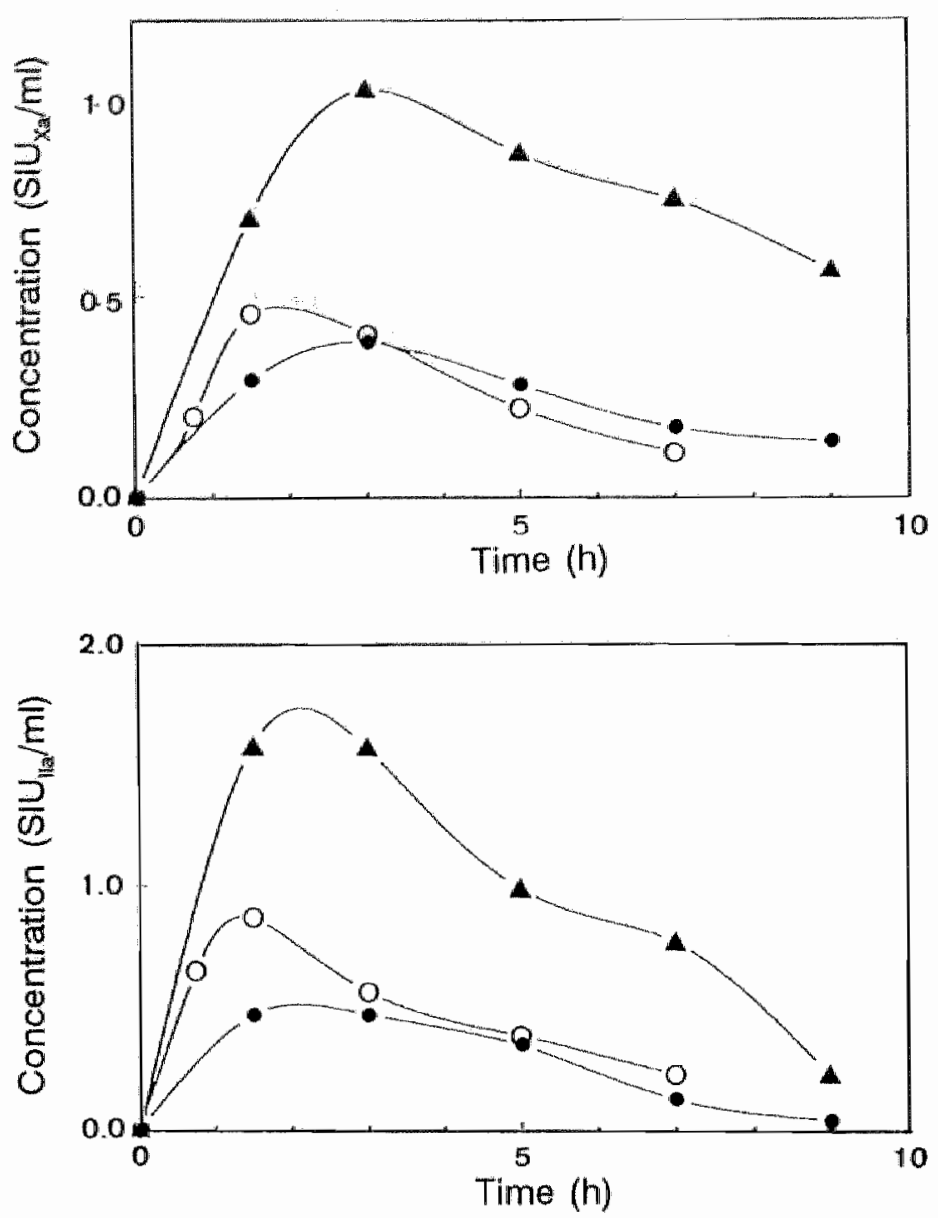

Figure 1. Heparin activities in SIU after subcutaneous injection. Top: Total high affinity material on basis of anti-F.Xa activity; Bottom: Above critical chainlength high affinity material on basis of antithrombin activity. O-O UFH; - LMWA;

A-A LMWB.

with the LMWHs. This can be attributed to the lower bioavailability and shorter half life of UFH $(22,23)$. Also the roughly twofold difference between the two LMWHs is insufficiently explained by the doses injected and might be due to differences between the heparins and biological variation between the volunteers. As can be expected from the molecular weight distribution, neglictible amounts of BCLM are found after injection of UFH, whereas large amounts of this material can be detected after injection of the LMWHs. It is readily seen that the BCLM persists longer 
in the circulation than the ACLM from the same LMWH does. Probably a longer half-life time and a higher bioavailability as compared to ACLM accompany its lower molecular weight.

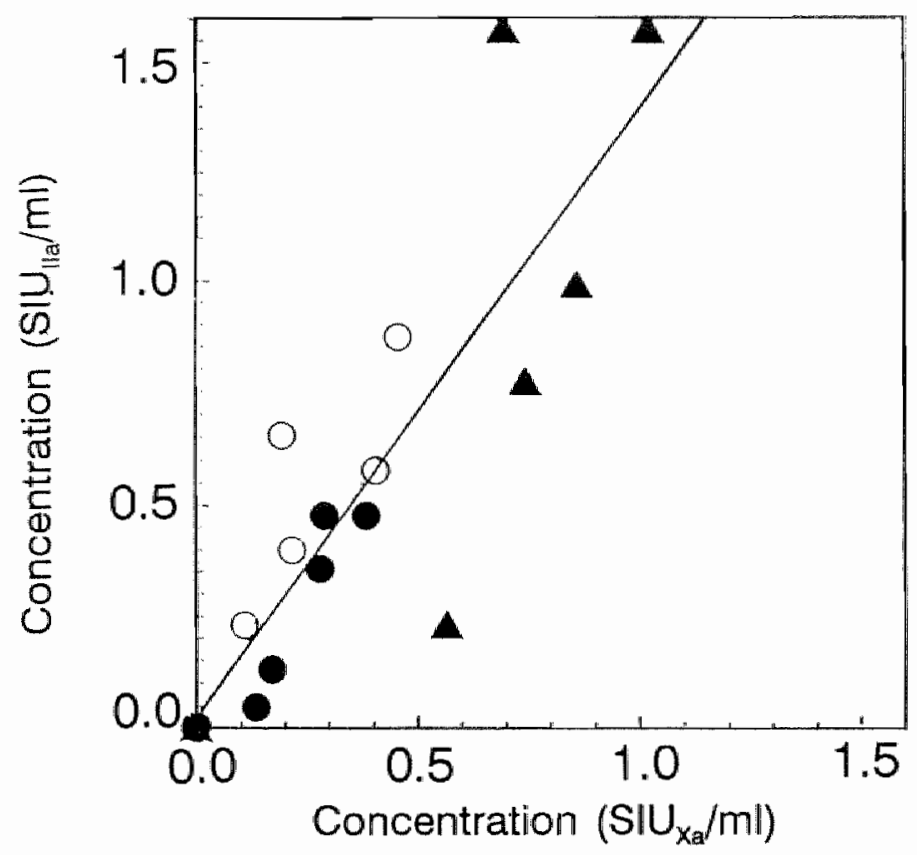

Figure 2. Correlation between thrombin based and factor Xa based SIU. O.O UFH; - LMWA; $\triangle-\triangle$ LMWB.

Inhibition of thrombin- and factor Xa generation. and of prothrombin conversion

In fig. 4 we see the effect of heparin injection on the peak activities of the thrombin generation curves executed in each sample. It should be noted that inhibition of thrombin peaks in these experiments reflects the combined effect of increased thrombin breakdown and inhibition of prothrombin conversion (24). The inhibition of prothrombin conversion necessarily causes a proportional inhibition of the thrombin peak. The amount of inhibition of the thrombin peak above that of prothrombinase consequently is caused by increased thrombin inactivation. The latter in UFH samples in fact contributes all and in LMWH samples more than half of the total inhibition (fig. 4 upper frame). It is interesting to see that with the LMWHs an inhibition of the thrombin peak, that must be attributed to 


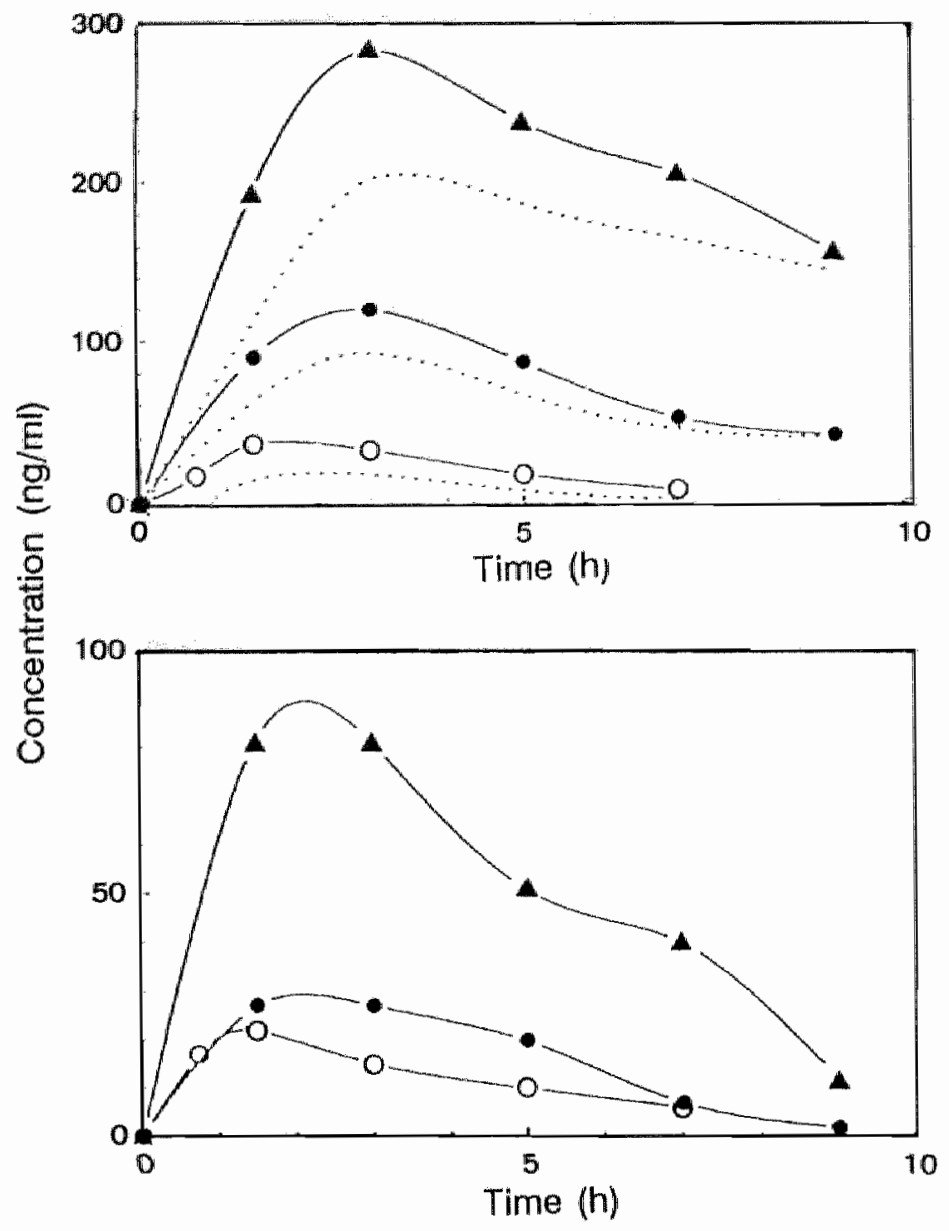

Figure 3. Levels of active heparin after subcutaneous injection. Top: Total- and below critical chainlength high affinity material. Bottom: Above critical chainlength high affinity material. O-O UFH; -- LMWA; $\triangle$ - $\triangle$ LMWB.

thrombin breakdown, persists longer than with UFH (fig. 4 lower frame).

In the earlier hours, the inhibition of factor Xa generation is about the same as the inhibition of thrombin generation (figs. 4 and 5). The ratio of the inhibitions varies with time. The excess inhibition of factor Xa in the later hours can be attributed to the presence of relatively high concentrations of BCLM at that moment (cf. fig. 3). The inhibition of prothrombinase is much smaller than the inhibition of factor $\mathrm{Xa}$ in all instances (fig. 5, upper frame), and the inhibition of factor $\mathrm{Xa}$ is not linearly related to inhibition of prothrombinase (fig.5, lower frame). 

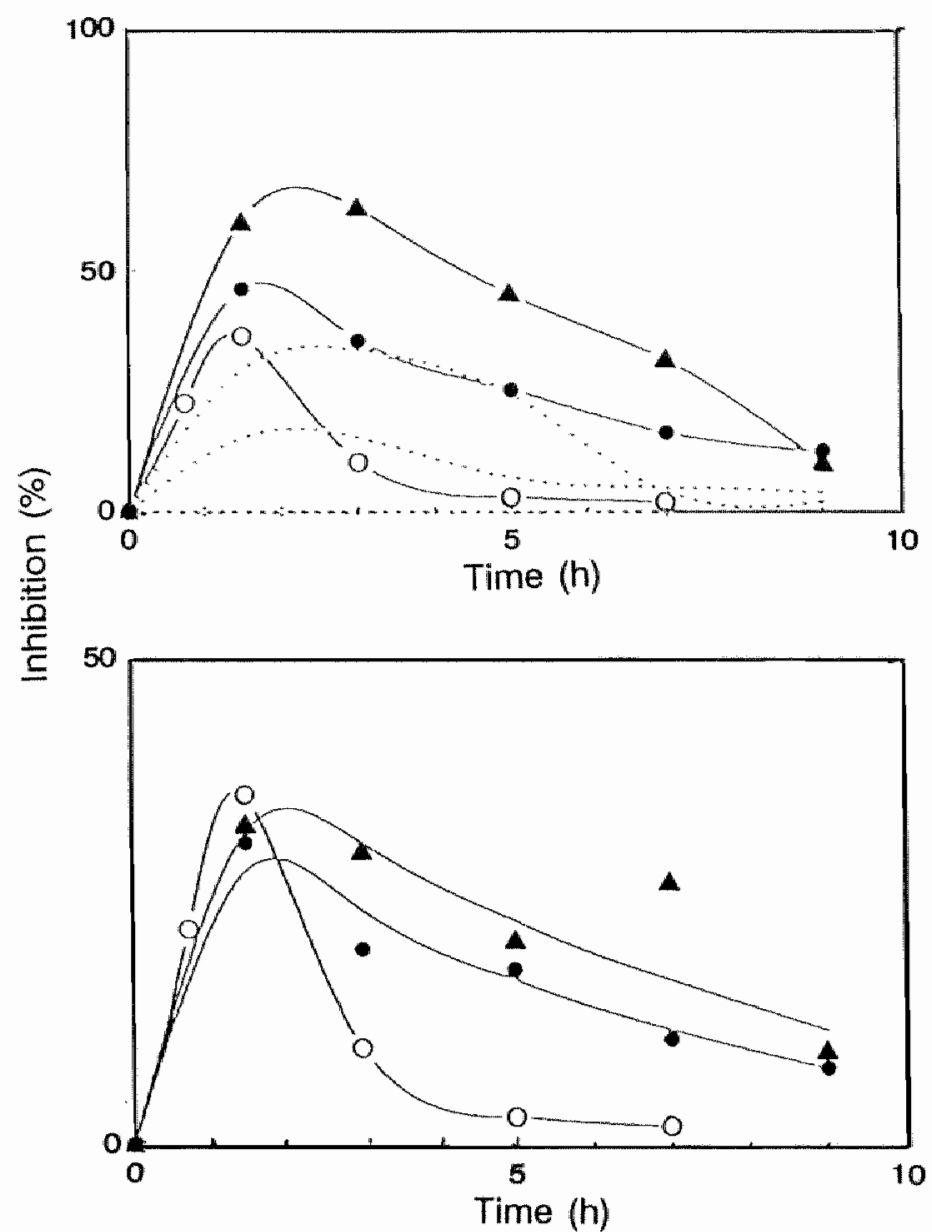

Figure 4. Inhibition of thrombin- and prothrombinase peaks. Top: Inluibition of thrombin peaks (drawn lines) and prothrombinase peaks (dotted lines). Bottom: Inhibition of the thrombin peak that cannot be attributed to prothrombinase inhibition. O-O UFH; - LMWA; $\triangle-\triangle$ LMWB.

\section{Thrombin inhibition in PRP}

An important difference between UFH and LMWHs is to be found when thrombin generation curves are executed in PRP. Whereas UFH looses its capacity to inhibit thrombin generation in the presence of platelets, both LMWHs tested retain activity under these circumstances (fig 6). 

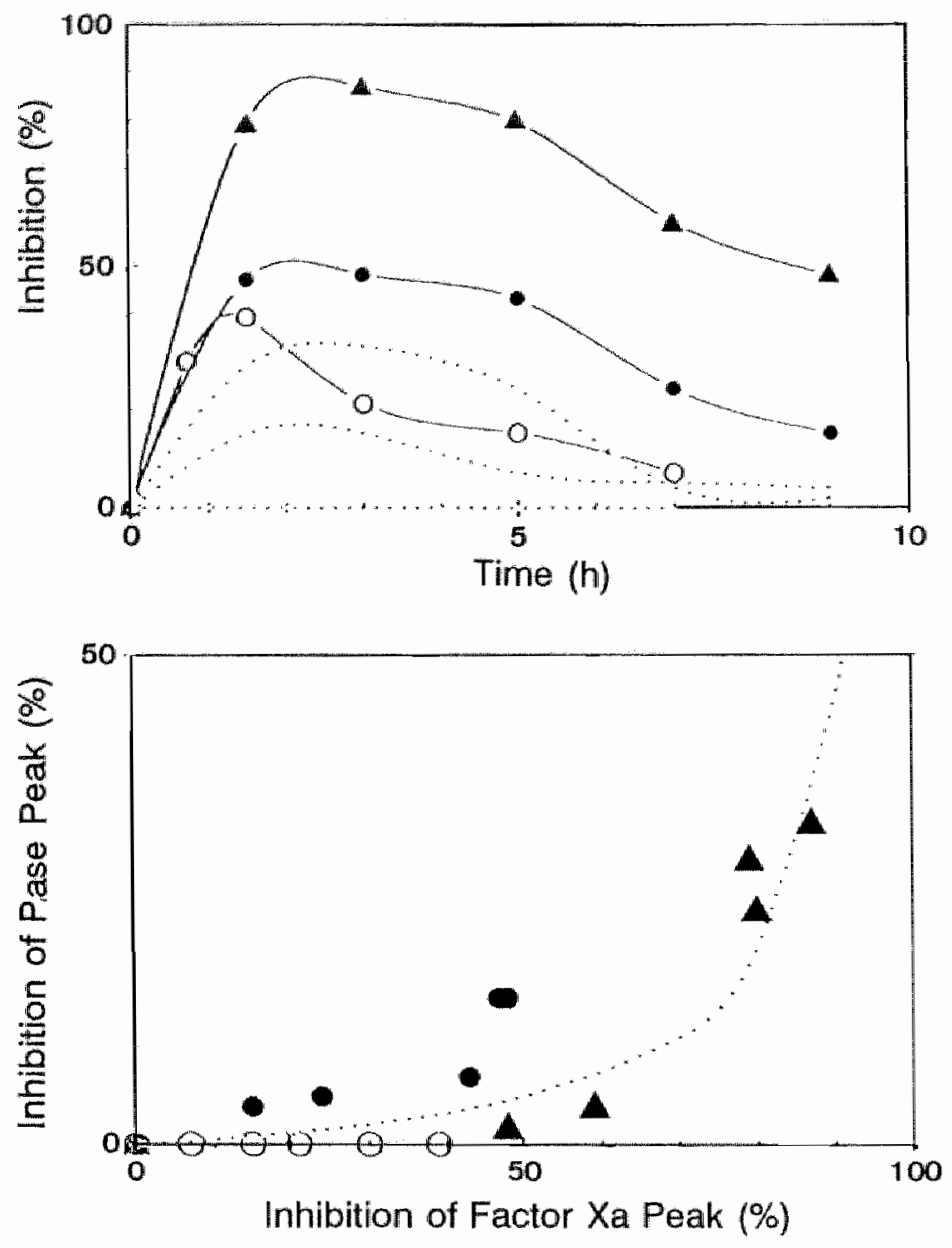

Figure $5_{n}$ Inhibition of factor $X a-$ and prothrombinase peaks. Top: Inhibition of factor Xa peaks (drawn lines) and prothrombinase peaks (dotted lines). Bottom: Inhibition of prothrombinase as a function of inhibition of factor Xa. O-O UFH; LMWA; A-A LMWB. 

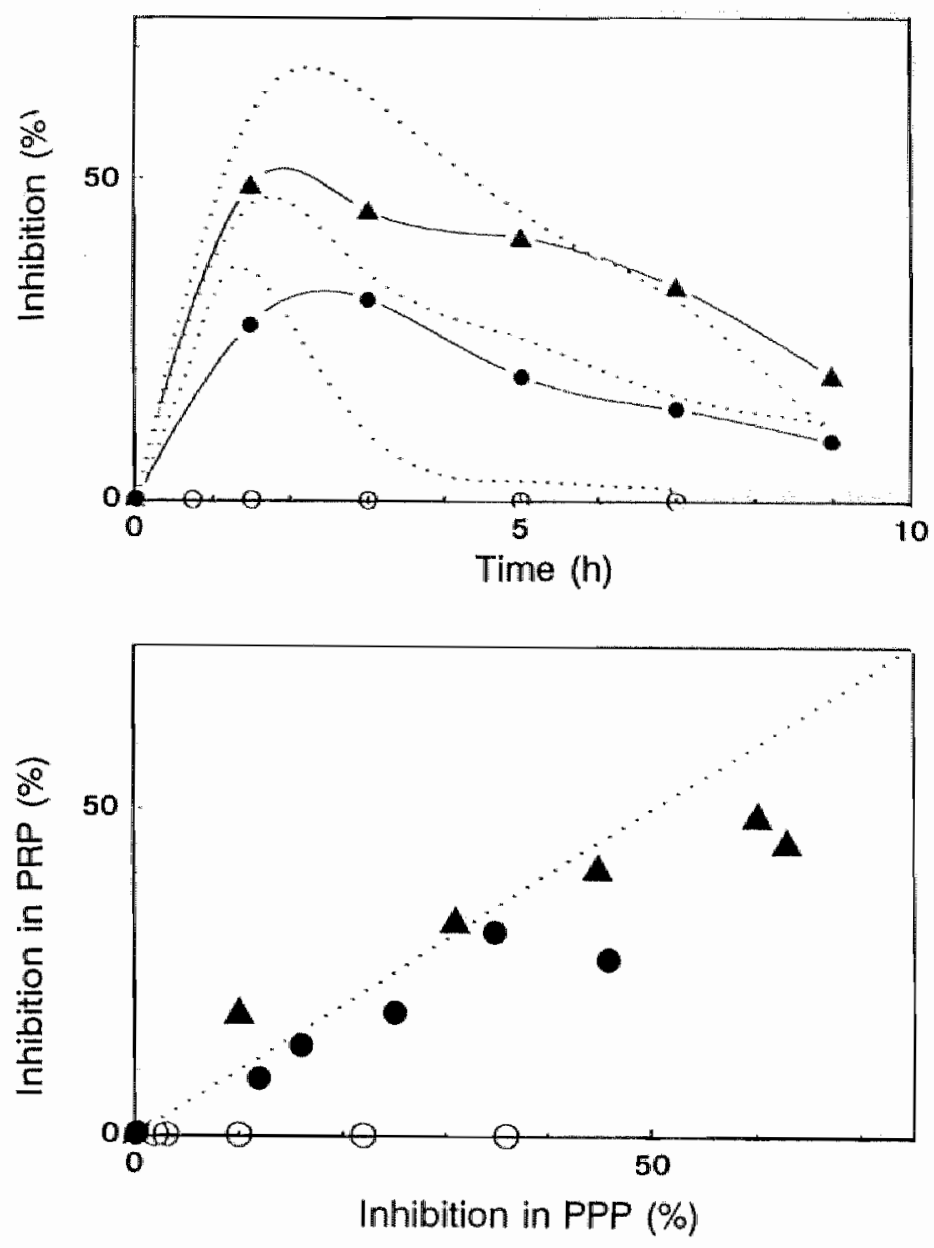

Figure 6. Inhibition of thrombin peaks in platelet rich- and platelet poor plasma. Top: Inhibition of thrombin peaks in PRP (drawn lines) and in PPP (dotted lines). Bottom: Inhibition of the thrombin peak in PRP as a function of the inhibition in PPP. O-O UFH; O-O LMWA; $\triangle$-A LMWB.

\section{DisCUSSION}

It is the purpose of this chapter to use recent theoretical insights in the mode of action of heparins as a basis for a rational approach to the interpretation of the data obtained in plasma samples from persons to which heparin has been administered. The results are given as obtained with three types of heparin, each administered to one volunteer only. These 
are practical examples and illustrations to the proposed approach. Any conclusions that are drawn on the behaviour in vivo of UFH and LMWHs are necessarily preliminary and will have to be repeated in larger groups of subjects to allow for the influences of experimental and inter- as well as intraindividual variability.

All heparins in clinical use are highly heterogeneous, both in molecular weight and in AT III affinity. Only the material with high affinity to AT III will directly affect the clotting mechanism. The catalytic properties of the HAM vary with $M W$. The most distinct variation is that material below the critical chain length of 17 sugar units ( $\mathrm{MW}<5400$ ), looses its capability to catalyse thrombin breakdown whereas it retains its anti-factor Xa activity down to the size of a pentasaccharide ( $M W \geq 1500$ ). There may be variation of specific activity within these groups but in first approximation the anticoagulant properties of a mixed heparin can be expressed by its content of above- and below critical chain length material (ACLM and BCLM).

When the HAM, ACLM and BCLM concentrations in a plasma sample are known, we can try to relate any observed biological effect, such as APTT, inhibition of thrombin generation, performance in a thrombosis model or clinical performance to these concentrations.

We realize that this is only a first step in analyzing the effects of heparin heterogeneity. Complications may arise from different sources: a) Within the ACLM and the BCLM class the specific activities may vary with molecular weight. Indeed, in the plasma millieu, we have found that there is a difference between UFH and LMWH in this respect, yet between different MW fractions of one type of LMWH the specific activities were surprisingly similar $(11,12)$.

b) Heparins may mobilise endogenous anticoagulants in the circulation (e.g. 24-27), that will evidently not be quantitated via specific activities.

c) It remains possible that the antithrombotic properties of heparin are not related to their anticoagulant action. For the moment we bypass this hypothesis, that may however be readily revived at the moment that no satisfying correlation is found between anticoagulant- and antithrombotic effects.

The ultimate consequence of anticoagulant therapy is the diminution of the amount of free thrombin that arises in clotting plasma. The fact that pentasaccharide (29) as well as dermatan sulfate (30) show an antithrombotic effect in animals, whereas pentasaccharide acts on factor Xa only, and hence on prothrombin conversion, while dermatan sulfate only increases thrombin breakdown, suggests strongly that it is immaterial wether thrombin is diminished by inhibition of prothrombin conversion or by enhancement of thrombin breakdown.

The levels of thrombin that are obtained in clotting plasma are the result of the combined action of heparin on prothrombin conversion and 
on thrombin decay:

prothrombinase

antithrombin

prothrombin

thrombin

inactive thrombin

An increase in antithrombin activity under influence of ACLM will lead to a proportional decrease of the amount of thrombin present. A decrease of factor $\mathrm{Xa}$, as caused by both ACLM and BCLM, will cause a decrease of prothrombinase activity, but that activity, under the conditions in clotting plasma, is not linearly proportional to the amount of factor Xa present, so that factor $\mathrm{Xa}$ inhibition will not lead to a directly proportional decrease of prothrombinase activity (24).

Prothrombinase is a tripartite complex of factors $\mathrm{Xa}$ and $\mathrm{Va}$ and phospholipid arising from simple chemical equilibria (31). Pieters e.a. (24) found that in clotting plasma, under our conditions, factor $\mathrm{Va}$ is the limiting prothrombinase component and that factor $\mathrm{Xa}$ is formed at levels of around $10 \mathrm{nM}$ i.e. in large excess over the limiting factor Va. The binding constant of factor Xa to phospholipid bound factor $\mathrm{Va}$ is $0.1 \mathrm{nM}$ (32). This means that at $0.3 \mathrm{nM}$ factor $\mathrm{Va}$ and $10 \mathrm{nM}$ factor $\mathrm{Xa}, 99 \%$ of factor $\mathrm{Va}$ is bound to factor $\mathrm{Xa}$ in prothrombinase. With $1 \mathrm{nM}$ of factor $\mathrm{Xa}$ still $91 \%$ of factor $\mathrm{Va}$ will be bound. This means that the inhibition of factor Xa will have to be very important before any inhibition of prothrombinase will be observed. Therefore antithrombin activity of a heparin results in immediate, proportional inhibition of thrombin formation, whereas anti-factor $\mathrm{Xa}$ activity does not result in a proportional inhibition of prothrombinase, as can be seen from fig. 5 .

Ever since Yin suggested that inhibition of factor $\mathrm{Xa}$ would be a more efficient means to prevent thrombosis than inhibition of thrombin (33), it was implicitely understood that the anti $\mathrm{Xa}$ activity induced by a heparin could be an important indicator of its antithrombotic properties. It came therefore as a surprise that heparins, when added to plasma appeared not to cause an important inhibition of prothrombin conversion, with the understandable exception of the ultra low molecular weight- or P-type varieties, that contain hardly any ACLM and consequently show hardly any antithrombin activity $(3,4,34,35)$. It appears that the enhanced inhibition of factor Xa that is reputedly observed with LMWHs, does not or hardly appear as inhibition of prothrombin conversion, so that the differences between UFH and LMWH cannot be explained on this basis. This was the more confusing because the anti-Xa activities measured in plasma show a good correlation with antithrombotic efficiency ( 1 and ref. therein). It should be kept in mind that it is entirely possible that the anti-factor $\mathrm{Xa}$ action is a marker of heparin activity while not being itself the instrument of heparin action. Recent observations on the effect of the $\mathrm{Ca}^{++}$ concentration in plasma on the anti-factor Xa action shed further doubt on the relevance of conventionally measured anti-factor $\mathrm{Xa}$ activities for the 
anticoagulant effect of a heparin $(14,15)$.

It appears impossible to explain the action of heparins without refering to the effect of heparins on thrombin mediated feedback reactions. It becomes increasingly apparent that the positive feedback exerted by thrombin on the procoagulant properties of blood platelets, and inversely the neutralising effect of platelet factor 4 on heparins may be important mechanisms to explain the difference between UFH and LMWHs. From fig. 6 it is evident that LMWHs retain their activity in the presence of platelets, whereas UFH does not. This behaviour of thrombin generation in PRP was to be expected from previous observations in spiked plasmas (36). The doses of LMWH given, although roughly equivalent to the UFH dose from clinical dose finding experiments, represent a much larger number of molecules, due to the much lower specific activities of the LMWH (table 2). Along with the active fractions, an important amount of low affinity material is injected (fig. 2). These molecules compete with active heparin from the neutralization by $\mathrm{PF} 4$ released by activated plateletes.

Apart from this effect, the main difference between UFH and LMWH probably has to be found in its pharmacological properties. Fig. 3 suggests that after injection of LMWH, not only much more BCL material reaches the bloodstream but also that the ACLM shows a better bioavailability. From table 2 we see that the LMWH injections contain roughly half as much ACLM as the UFH injection. Yet from fig. 2 it is seen that in the circulation the ACLM levels obtained are equal or higher. From fig. 4 it is seen that the effect on overall thrombin generation is higher and longer lasting.

BCLM persists in the circulation longer then ACLM does. The persistent inhibition of thrombin generation obtained with LMWHs between 5 and 10 hours after injection can be explained by the activity of this material. The possibility of an endogenous anticoagulant released under the influence of the heparin injection must be left open however. Anyhow, here a difference between the in vivo situation and the situation in spiked plasma becomes apparent. The LMWH injected probably contains material with different half-live times so that injection results in an in vivo fractionation of the LMWH injected, and the heparin circulating between 5 and 10 hours after injection will become gradually enriched in BCLM.

\section{REFERENCES}

1) Lane,D.A.; Ryan.: Heparin and Low molecular weight Heparin: Is Anti-factor Xa Activity Important? J. Lab. Clin. Med. 114: (4): 331-357; 1989.

2) Ofosu, F.: Modulation of the enzymatic activity of $\alpha$-thrombin by polyanions: 
consequences on intrinsic activation of factor V and factor VMI Haemostasis 21, 4: 240-247; 1991.

3) Hemker, H.C.: The mode of action of heparin in plasma. In: Thrombosis and Haemostasis, pp. 17-36; 1987. M. Verstraete, $J$. Vermijlen, R. Lijnen and $J$. Arnout edts. I.S.T.H. and Leuven university press.

4) Béguin, S.; Lindhout, T.; Hemker, H.C.: The mode of action of heparin in plasma. Thromb. Haemostas. 60: 457-462; 1988.

5) Thumberg, L.; Backstrom,G.; Grundberg, H.; Riesenfeld, J.; Lindaln, U.: The Molecular Size of the Antithrombin-Binding Sequence in Heparin. FEBS-Letter, 117 (1): 203-206; 1980 .

6) Choay, J.; Lormeau, J.C.; Petitou, M.; Sinay, P.; Fareed, J.: Structural Studies on a Biologically Active Hexasaccharide obtained from Heparin. Ann. N. Y. Acad. Sci. 370: 644-649: 1981.

7) Andersson, L.O.; Barrowcliffe, T.W.; Holmer, E.; Johnson, E.A.; Soderstroni, G.: Molecular Weight Dependency of the Heparin. Potentiated Inhibition of Thrombin and Activated Factor X. Effect of Heparin Neutralization in Plasma. Thromb. Res.: 15: 531-541; 1979 .

8) Lane, D.A.; Denton, J.; Flynn, A.M.; Thumberg, L.; Lindahl, U.: Anticoagulant activities of heparin oligosaccharides and their neutralization by platelet factor 4 . Biochem. J. 218: 725-732; 1984 .

9) Danielsson, A.; Raub, E.; Lindahl, U.; Björk, I.: Role of ternary complexes, in which heparin binds both antithrombin and proteinase, in the acceleration of the reactions between antithrombin and thrombin or factor Xa. I. Biol.Chem.*261(33): 15467-73; 1986.

10) Holmer, E. Mattsson, C. Nilsson, S. Anticoagulant and Antithrombotic Effects of Heparin and Low Molecular Weight Heparin Fragments in Rabbits. Thromb, Res. 25: $475-485 ; 1982$.

11) Béguin, S.; Wielders, S; Hemker, H.C.: The Mode of Action of CY216 and CY222 in Plasma. To be published in: Thromb. Haemost.; 1991.

12) Bendetowicz, A.V.; Pacaud, E.; Béguin, S.; Uzan, A.; Hemker, H.C.: On the relationship between molecular mass and anticoagulant activity in a low molecular weight heparin (enoxaparin). To be published in: Thromb. Haemost.; 1991.

13) Schoen, P.; Lindhout, T.; Willems, G.; Hemker, H.C.: Antithrombin III Dependent Anti-Prothrombinase Activity of Heparins of Various Molecular Weight. J.Biol.Chem.: 264 (17): 10002-10007; 1989 .

14) Barrowcliffe, T.W.: Shirley-Le, Y. The Effect of Calcium Chloride on Anti-Xa 
Activity of Heparin and Its Molecular Weight Fractions. Thromb. Haemost: 62 (3): 950-954. 1989.

15) Schoen, P.; Franssen, J." Hemker, H.C.; Lindhout, T.: Low Molecular weight heparin-catalyzed inactivation of factor $\mathrm{Xa}$ and thrombin by antithrombin III. Effect of platelet factor 4. Thromb. Haemost. 66 (4). 435-441; 1991 .

16) Cadroy, Y:; Harker, L.A; Hanson, S.R: Inhibition of platelet dependent thrombosis by low molecular weight heparin (CY 222): comparison with standard heparin. J. Lab. Clin. Med 114:349-357; 1989.

17) Putten-van, J.J., Ruit-van-de, M.; Beunis, M.; Hemker, H.C.: Interindividual Variation in Relationships between Plasma Heparin Concentration and the Results of Five Heparin Assays. Clin. Chim. Acta 122: 261-270; 1982.

18) Béguin, S.; Hemker, H.C.: The Consumption of Antithrombin III and Heparin during the Clotting Process, its Influence on the Thrombin Decay Constant. In press.

19) Owren, P.A. Aas, K. The Control of Dicumarol Therapy and the Quantitative Determination of Prothrombin and Proconvertin. Scand. J Lab. Invest. 3: 201-218; 1951.

20) Hemker, H.C. Willems, G.M. Béguin, S. A Computer Assisted Method to Obtain the Prothrombin Activation Velocity in Whole Plasma Independent of Thrombin Decay Processes. Thromb. Haemost. 56; 9-17; 1986.

21) Pieters, J.; Lindhout, T.; Hemker, H.C. In Situ Generated Thrombin is the Only Enzyme that Effectively Activates Factor VIII and Factor $V$ in Thromboplastin-Activated Plasma. Blood, 74(3): 1021-1024; 1989.

22) Aiach, M.; Michaud, A.; Balian, J.L.; Lefebvre, M; Woler, M.; Fourtillan, J. A new low Molecular Weight Heaprin Derivative. In vitro and in vivo Studies. Thromb. Res: $31: 611-621 ; 1983$.

23) Bergqvist, D. Hedner, U. Sjorin, E. Holmer, E. Anticoagulant Effects of two Types of Low Molecular Weight Heparin Administered Subcutaneously. Thromb. Res. 32: 381-391; 1983 .

24) Hemker, H.C.; Bếguin, S. Mode of action of unfractionated and low molecular weight heparins on the generation of thrombin in plasma. Haemostasis suppl. 1, 812., 1990 .

25) Barrowcliffe, T.W.; Eggleton, C.A.; Stocks, J. Studies of Anti-Xa Activity in Human Plasma. II: The Role of Lipoproteins. Thromb. Res.; 27: 15-195; 1982.

26) Barrowcliffe, T.W.: Antithrombotic Action of Hepatic Triglyceride Lipase-Fact or Fiction-Rejoinder. Thromb. Haemost. 57:242; 1987. 
27) Sandset, P.M; Abildgaard, U.: Extrinsic pathway inhibitor - The key to feedback control of blood coagulation initiated by tissue thromboplastin. Haemostasis $21,(4)$ : 219-239; 1991.

28) Abildgaard, U. Lindahl A. K; Sandset, P.M. Heparin requires both antithrombin and extrinsic pathway inhibitor for its anticoagulant effect in blood. Haemostasis $21,(4) ; 254-258 ; 1991$.

29) Walenga, J.M. Fareed, J. Petitou, M. Samama, M. Lormeau, J.C. Choay, d. Intravenous Antithrombotic Activity of a Synthetic Heparin Pentasaccharide in a Human Serum Induced Stasis Thrombosis Model. Thromb. Res. 43:243-248; 1986.

30) Dol, F.; Caranobe, C.; Dupouy, D.; Petitou, M.; Lormeau, J.C.; Chaoy, J.; Sie, P.; Boneu, B. Effects of Increased Sulfation of Dermatan Sulfate on its in vitro and in vivo Pharmalogical Properties. Thromb. Res.: 52: 153-164; 1988.

31) Hemker, H.C. Esmouf, M.P. Hemker, P.W. Swart, A.C.W. Mac Farlane, R.G.: Formation of Prothrombin converting Activity. Nature, 215: 248-251; 1967.

32) Lindhout, M.J.; Govers-Riemslag, J.W.P.; Waart-van-de, P.; Hemker, H.C.; Rosing, J. Factor Va - Factor Xa Interaction.: Effects of Phospholipid Vesicles of varying Composition. Bilochemistry $21: 5494-5502 ; 1982$.

33) Yin, E.T.; Wessler, S.; Stoll, P.J. Rabbit Plasma Inhibitor of the Activated Species of Blood Coagulation Factor X. J. Biol. Chem.: 246 (11): 3694-3702; 1971.

34) Béguin, S; Choay, J ; Hemker, H.C. The Action of Synthetic Pentasaccharide on Thrombin Generation in Whole Plasma. Thromb. Haemost.; 61(3): 397-401; 1989.

35) Béguin, S.; Mardiguian, J.; Hemker, H.C.: The mode of action of a low molecular weight heparin preparation (PK 10169) and two of its major components on thrombin generation in plasma. Thromb. Haemost. 61: 30-34:1989.

36) Béguin, S.; Lindhout, T.; Hemker, H.C. The Effect of Trace Amounts of Tissue Factor on Thrombin Generation in Platelet Rich Plasma its Inhibition by Meparin. Thromb. Haemost.; 61(1): 25-29; 1989. 



\section{THE EFFECT OF SUbCUTANEOUS INJECTION OF UNFRACTIONATED AND LOW MOLECULAR WEIGHT HEPARIN on Thrombin Generation in Platelet Poor Plasma. A STUdy IN HUMAN VOLUNTEERS.}

\section{SUMMARY}

The approach suggested in chapter 4 , to measure the levels of circulating active heparin has been applied to twelve healthy volunteers. Two independent doses of a LMWH (enoxaparin), and one single dose of unfractionated heparin were injected subcutaneously.

Enoxaparin catalyzed more efficiently than UFH the ex vivo pseudo-first order decay constant of both factor $\mathrm{Xa}$ and thrombin inhibition.

The HAM fraction of UFH disappears from circulation with an apparent half life time of $3.04 \pm 0.41 \mathrm{~h}$; that of LMWH with $5.61 \pm 0.36 \mathrm{~h}$. The BCLM fraction did not appear in UFH. In LMWH its half life time was practically identical to that of total HAM. The ACLM of the two heparins was cleared from circulation with an apparent half-life of $2.24 \pm 0.18 \mathrm{~h}$. It was not dependent on the heparin preparation or dose.

Unfractionated heparin was less effective than enoxaparin with respect of the inhibition of thrombin, prothrombinase and factor Xa generation.

The catalysis of the inhibition of factor $X a$ generation, and of the AT III dependent decay constant of factor $X$ a mediated by UFH persisted as long as the inhibition of thrombin. It must be attributed to the ACL heparin fraction. The effect of enoxaparin on factor Xa generation and factor Xa decay increased with increasing doses, and persisted somewhat longer in circulation than the effect on both thrombin generation and thrombin decay constant. The longer persistence of this activity compared to UFH was due to the circulating levels of BCLM, that was eliminated slower than ACLM.

There is a perfect linear correlation between inhibition of factor $\mathrm{Xa}$ generation and of thrombin generation. There is not a linear relation however between factor $X_{a}$ inhibition and prothrombinase inhibition because the relation between inhibition of the factor $X$ a generation and the inhibition of prothrombin conversion is hyperbolical, as should be expected from theory.

We conclude that both $A C L$ and BCL material of enoxaparin cooperate in the overall inhibition of factor IIa and factor $\mathrm{Xa}_{\mathrm{a}}$ generation. 


\section{INTRODUCTION}

Presently available laboratory methods for the measurement of (LMW) heparins activity are based on the effect of heparin on one of the available tests of the clotting system (APTT, Heptest, anti-factor Xa activity, etc), and do not necessarilly reflect the in vivo antithrombotic effect of these drugs. We would like to measure the levels of active material circulating, and then establish the relation between these levels with the antithrombotic-and bleeding effects on the one hand, and with the outcome of the current laboratory tests on the other. From the literature, semiquantitative methods are known that measure circulating heparin in $\mu \mathrm{g} / \mathrm{ml}(1$ and refs. therein). These estimate total heparin material and not the concentration of active heparin.

From chapters 2 and 4 it emerged that:

a) It is necessary to distinguish two types of active heparin, ACLM (MW $\geq 5,400$ ) that has both anti-factor Xa activity and antithrombin activity, and BCLM $(5,400>\mathrm{MW}>1,500)$ with anti-factor $\mathrm{Xa}$ activity only.

b) The variation of anti-factor $\mathrm{Xa}$, and antithrombin activities with MW within these fractions of enoxaparin is sufficiently uniform to treat them as homogeneous substances.

c) It is possible to calculate ACLM and BCLM active levels from antithrombin and anti-factor $\mathrm{Xa}$ activities measured in plasma samples from people that received heparin.

With this approach we hope to contribute to the solution of some of the open questions on heparin pharmacology.

Johnson (2), was the first to show, in 1976 that a low molecular weight heparin produced by gel filtration, when given subcutaneously to man produced higher blood levels by an anti-Xa clotting assay than was achieved with standard heparin. This effect of LMWH was confirmed in several studies (3-6). Also the anti-factor Xa activity of LMWH was shown to persist longer than the antithrombin activity does (7-9). The antithrombin activity of LMWH remains in circulation for about 8 hours, while the anti-factor $\mathrm{Xa}$ is detectable at least during 18 hours (7-9). The antifactor Xa activity of UFH is eliminated faster than that of LMWH. Also the levels of anti-factor Xa activity of UFH are parallel to the circulating levels of the antithrombin activity. In addition, several investigations demonstrated a high bioavailability of LMWH compared to that of UFH ( $\sim 95 \%$ for LMWH, and $\sim 30 \%$ for UFH; $7,10-12)$. One of the purposes of this chapter is to try to explain these differences. A reduced risk of bleeding at an equal or better antithrombotic effect was found with LMWH as compared to UFH $(13,14)$. This suggested that the anti-factor Xa activity could be a marker of the antithrombotic effect of heparins, while the bleeding risk was attributed to the anti-factor IIa 
activity (15). Thereafter, it has been observed that there is no strict relation between antithrombotic potency and anti-Xa activity $(16,17)$. On the other hand it is known that, at least in vitro, LMWH owe their main action to the inhibition of thrombin (18-21), and thrombin mediated feedback reactions. (19-23). Also the large therapeutic window of LMWH has not been confirmed by later research $(24,25)$. Whether or not there is a special place for anti-factor $\mathrm{Xa}$ activity is unclear, but if there is, then it should become evident from the measurement of BCLM levels. It is not a priori be illogical to assume a relative important role of BCLM material in vivo, in view of the fact that this material resists complete neutralization by products from activated platelets.

In this chapter, we therefore determine: a) The course of ACLM and BCLM levels after subcutaneous injection of one dose of UFH and two doses of enoxaparin to twelve healthy volunteers. In the same samples we also measure thrombin generation and factor $\mathrm{Xa}$ generation and we calculate prothrombin conversion velocities from the thrombin generation curves.

\section{MATERIALS AND METHODS}

Subjects studied. Twelve healthy male volunteers of 20-30 years old gave informed consent. Their clinical chemistry, haematological and haemostatic laboratory values were within the normal range (Dr. Thebault, Paris). The study was designed as a double blind cross-over in which each subject received in random order a) $5000 \mathrm{IU}$ of unfractionated heparin (Fournier), b) $40 \mathrm{mg}$ of enoxaparin and c) $1 \mathrm{mg} / \mathrm{kg}$ body weight of enoxaparin. There was a 7 days' wash-out between the injection of the heparins. Blood samples were collected before the heparin injection ( 0 time), and 45 minutes, $1.5,3,5,8,12,18$, and 24 hours after the injection.

Heparins. Syringes of 5,000 IU of heparin Fournier, and syringes of $40 \mathrm{mg}$, and $1 \mathrm{mg} / \mathrm{kg}$ body weight of the LMWH enoxaparin were obtained from Rhône-Poulenc Rorer, Vitry s/Seine, France.

Functional AT III concentration. In the zero-time plasma of the twelve volunteers we determined the decay constant of thrombin. From the specific antithrombin activity of AT III (1.508 $\mathrm{min}^{-1} / \mu \mathrm{M}$ AT III) we calculated the functional AT III concentration in the plasma of each volunteer.

Determination of the Standard Independent Units. The anti-factor Xa activity and antithrombin activity were expressed in Standard Independent Units as defined in the previous chapter. In short, we determined the increase of the 
factor Xa-and thrombin decay constants caused by injection of heparin and devided this figure by the AT III concentration so as to normalise for this variable.

Determination of the levels of Active Heparin in $\mathrm{ng} / \mathrm{ml}$. The SIU units of antifactor $\mathrm{Xa}^{-}$and antithrombin activity were converted into ACLM and BCLM as explained in the previous chapter. The anti-factor Xa level in SIU was devided by the specific antifactor Xa activity of the HAM fraction to obtain the HAM (= ACLM + BCLM) level. Similarily, the ACLM leve was calculated from the antithrombin activity. The BCLM level was calculated as (HAM - ACLM). The specific activities were: Anti-factor Xa: 10.21 and $3.93 \mathrm{~min}^{-1} / \mathrm{\mu g} / \mathrm{ml}$ for $\mathrm{UFH}$ and enoxaparin respectively. Antithrombin: 31 and $19.8 \mathrm{~min}-1 / \mu \mathrm{g} / \mathrm{ml}$ for UFH and enoxaparin respectively.

With one exception, the laboratory methods used were those described in the previous chapter. The source of human thrombin was an activated (thromboplastin and $\mathrm{CaCl}_{2}-17 \mathrm{mM}$-) euglobulin fraction from human plasma that contained $1000 \mathrm{nM}$ thrombin/ml. The thrombin concentration in the euglobulins fraction was measured with an amydolitic assay (19).

The decay constant of thrombin was determined by the addition of 70 nM human thrombin (final concentration) to a $60 \%$ diluted plasma. At time intervals, $10 \mu l$ sample was added to disposable cuvettes, and measured as previously described (19).

\section{RESULTS}

\section{Normal Values}

The 36 zero-time values gave us an opportunity to estimate the normal values of the AT III concentration, the $k_{\text {dec }}$ of factor Xa per $\mu$ M AT III and the peak values of thrombin-and factor Xa generation curves. Also the mean course of a normal thrombin generation curve and a normal factor Xa generation curve could be obtained from these samples (Table $1)$.

\section{Post-heparin samples.}

\section{a) Determination of Heparin Activities.}

We determined the increase of the decay constant of factor Xa and thrombin, after the injection of UFH and enoxaparin, i.e. the heparin activities in terms of the newly proposed SI Units. From figure 1, we can observe that the maximal activity of both SIU, antithrombin and anti-Xa was found 3 hours after injection. The SIU antifactor $\mathrm{Xa}$ were 
sistematically lower than SIU-antithrombin. From table 2 it can be seen that subcutaneously injected UFH causes very low levels of activity, both antithrombin and anti-factor $\mathrm{Xa}$, compared to enoxaparin.

The levels of SIU-anti Xa of UFH, decreased in parallel with the SIU-anti IIa. In contrast, the levels of SIU-anti-Xa remained relatively high after 8 hour.

Table 1. Normal Values Obtained from the Zero-Time Samples.

AT III

$\mathrm{K}_{\text {dec }}$ of thrombin

$\mathrm{k}_{\mathrm{dec}}$ of factor Xa

Thrombin peak

Factor Xa peak

$$
\begin{aligned}
& 1.91 \pm 0.04 \mu \mathrm{M} \\
& 1.49 \pm 0.02 \mathrm{~min}^{1 /} / \mu \mathrm{M} \text { AT III* } \\
& 0.65 \pm 0.02 \mathrm{~min}^{-1} / \mu \mathrm{M} \text { AT III* } \\
& 140.60 \pm 2.83 \mathrm{nM} \\
& 4.53 \pm 0.20 \mathrm{nM}
\end{aligned}
$$

* This is not an independent variable but the specific activity of AT III that reappears after division of the decay constant found by the AT III concentration.

Table 2. Maximal $(h=3)$ Values of the Variables

\begin{tabular}{lllll}
\hline Variable & Unit & UFH & Enox 40 & Enox $1 \mathrm{mg} / \mathrm{kg}$ \\
\hline $\mathrm{k}_{\text {dec }} \quad$ IIa & $\min ^{-1}$ & $\mathbf{3 . 3 8} \pm 0.38$ & $4.29 \pm 0.27$ & $7.00 \pm 0.68$ \\
$\mathrm{k}_{\text {dec }} \quad$ Xa & $\min ^{-1}$ & $1.33 \pm 0.21$ & $2.64 \pm 0.11$ & $3.86 \pm 0.26$ \\
SIU Anti-IIa & SIU & $1.88 \pm 0.38$ & $2.78 \pm 0.27$ & $5.50 \pm 0.68$ \\
SIU Anti-Xa & SIU & $0.63 \pm 0.11$ & $2.10 \pm 0.11$ & $3.49 \pm 0.17$ \\
Inhib. IIa gen. & $\%$ & $45 \pm 5$ & $69 \pm 3$ & $86 \pm 2$ \\
Inhib. prothr.ase & $\%$ & $13 \pm 5$ & $31 \pm 6$ & $52 \pm 5$ \\
Inhib. Xa gen. & $\%$ & $47 \pm 6$ & $76 \pm 6$ & $94 \pm 2$ \\
HAM & $\mathrm{ng} / \mathrm{ml}$ & $61 \pm 11$ & $534 \pm 29$ & $887 \pm 44$ \\
ACLM & $\mathrm{ng} / \mathrm{ml}$ & $61 \pm 11$ & $127 \pm 18$ & $246 \pm 37$ \\
BCLM & $\mathrm{ng} / \mathrm{ml}$ & - & $407 \pm 9$ & $641 \pm 12$
\end{tabular}

\section{b) The Levels of Active Heparins}

From the specific activities of the active species HAM and ACLM of the heparins injected (chapter 2) and the SIU-aIIa and SIU-aXa values measured, we calculate the HAM and ACLM levels attained in the circulation; BCLM was obtained from the difference. Even though the amount of ACLM injected with UFH was higher than with enoxaparin, the 
levels found after UFH injection are much lower than those after enoxaparin. In addition enoxaparin gives rise to high circulating levels of BCLM, which UFH does not. (fig. 2, table 2). From the semilogaritmic plot of the time course ACLM of the three curves shown in fig. 2 (inset), the apparent half-life of elimination of ACLM was: $2.24,2.03$ and $2.48 \mathrm{~h}$ for UFH, enoxaparin $40 \mathrm{mg}$ and enoxaparin $1 \mathrm{mg} / \mathrm{kg}$. Neither of them is significantly different from the average: $2.24 \pm 0.18 \mathrm{~h}$.
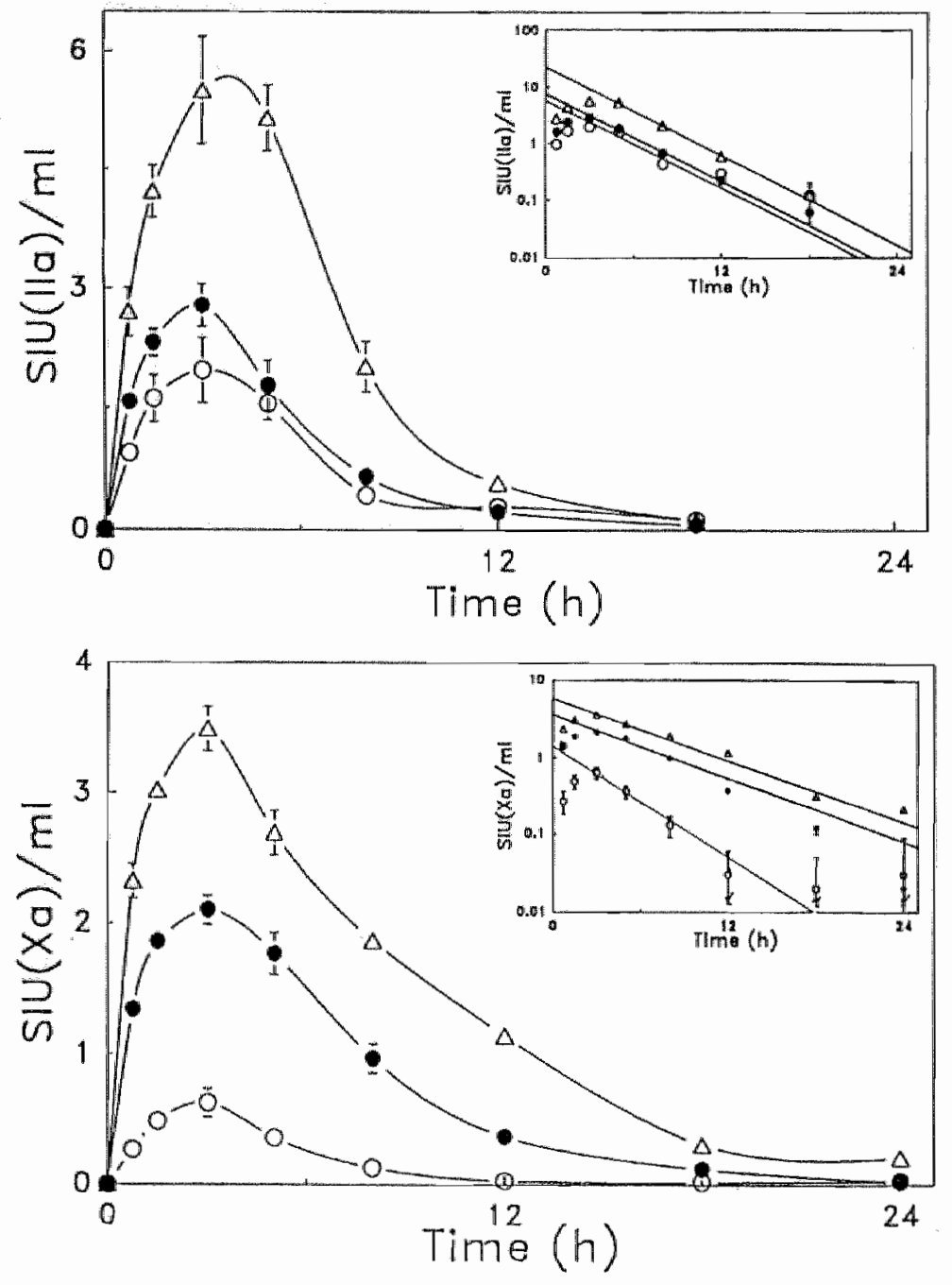

\section{Figure 1}

The Time-Course of Heparin Activity in Standard-Independent Units. Upper frame: Anti-IIa SIU; Lower frame: Anti-Xa SIU. Insets: Semilogarithmic plots. O-O UFH $5000 \mathrm{IU}_{n}-1$ enoxaparin $40 \mathrm{mg}, \Delta-\Delta$ enoxaparin $1 \mathrm{mg} / \mathrm{kg}$ bw. 


\section{c) The Inhibition of Thrombin Generation and Prothrombinase}

UFH and enoxaparin induce maximum inhibition of thrombin generation between 1.5 and 3 hours after injection. Enoxaparin gives higher- and longer lasting inhibitions than UFH does. A near maximal inhibition was still observed at the $5^{\text {th }}$ hour after injection of enoxaparin 1 $\mathrm{mg} / \mathrm{kg}$ (table 3 and figure 3 ). The high dose of enoxaparin induced significant inhibition up to the 12 hour after injection. From ref. 19 we know that the observed inhibition of thrombin generation is the combined
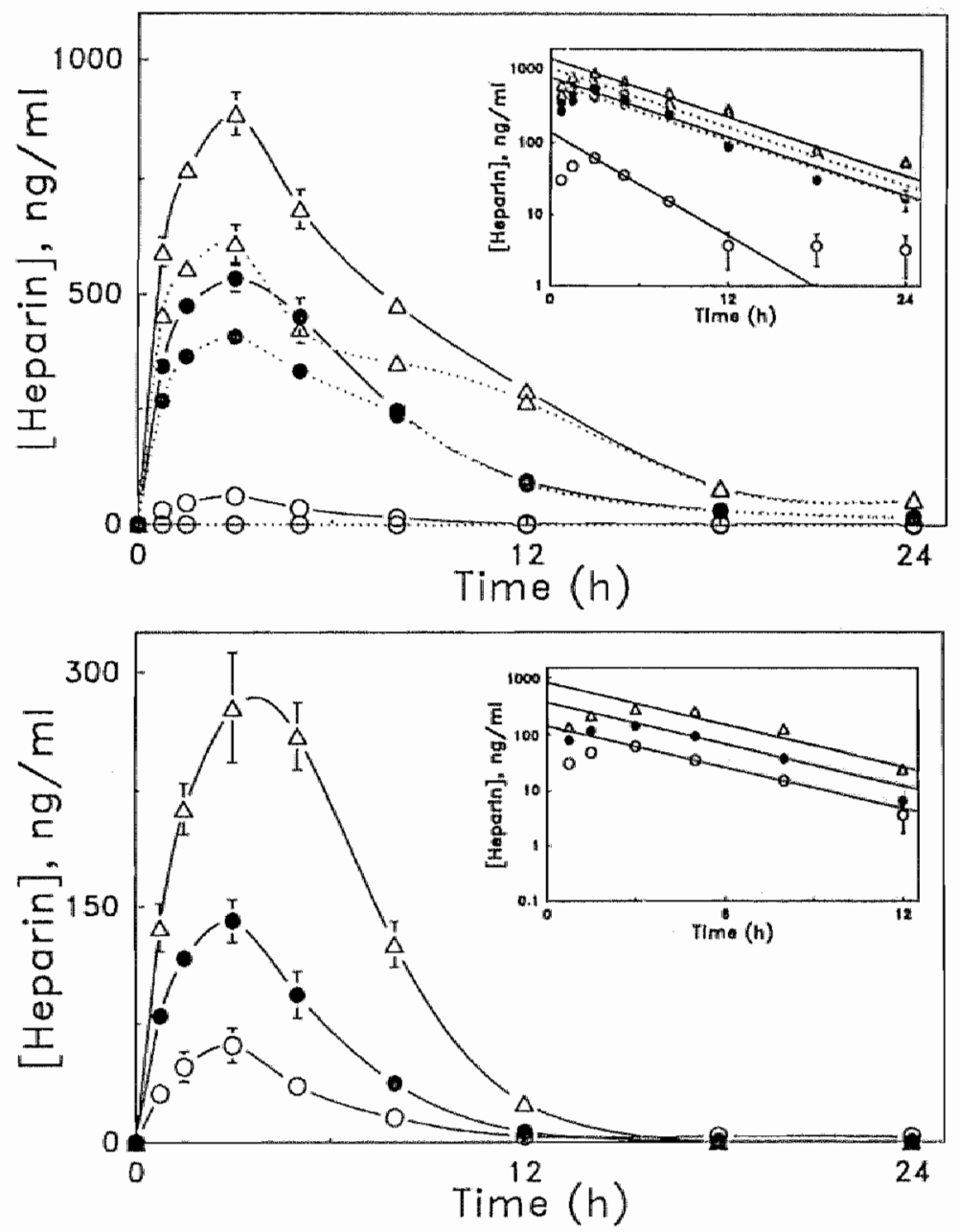

Figure 2

The Time-Course of Active Heparin Levels in $\mathrm{ng} / \mathrm{ml}$. Upper frame: HAM (solid) and BCLM (dotted); Lower frame: ACLM. Insets: Semillogaritmic plots. O-O UFH 5000 IU, - enoxaparin $40 \mathrm{mg}, \Delta-\Delta$ enoxaparin $1 \mathrm{mg} / \mathrm{kg}$ bw. 
Table 3. The Recovery of the Active Heparins (HAM) After Subcutaneous Injection*

\begin{tabular}{|c|c|c|c|c|c|c|c|}
\hline & & \multicolumn{2}{|l|}{$\mathrm{UFH}$} & \multicolumn{2}{|l|}{$E-40$} & \multicolumn{2}{|c|}{ E-1mg/kg } \\
\hline & & Total & HAM & Total & HAM & Totall & HAM \\
\hline Injected (mg) & & 29 & 8.7 & 40 & 5.6 & 75 & 10.5 \\
\hline Peak plasma level & $\mathrm{ng} / \mathrm{ml}$ & (204) & 61 & $(3812)$ & 533 & $(6340)$ & 887 \\
\hline Extrap 0 -time level & $\mathrm{ng} / \mathrm{ml}$ & $(557)$ & 167 & $(6679)$ & 935 & $(9957)$ & 1394 \\
\hline Min. recowery & $\mathrm{mg}$ & $(1.06)$ & 0.319 & $(20)$ & 2.78 & (33) & 4.62 \\
\hline Max. recovery & $\mathrm{mg}$ & $(2.9)^{\prime}$ & 0.87 & $(34.7)$ & 4.86 & $(51.8)$ & 7.25 \\
\hline Min. recovery & $\%$ & - & 4 & - & 50 & - & 44 \\
\hline Max. recovery & $\%$ & - & 10 & - & 87 & - & 69 \\
\hline
\end{tabular}

* The recovery is calculated as the percentage of the High Affinity Material injected. For details, see text.

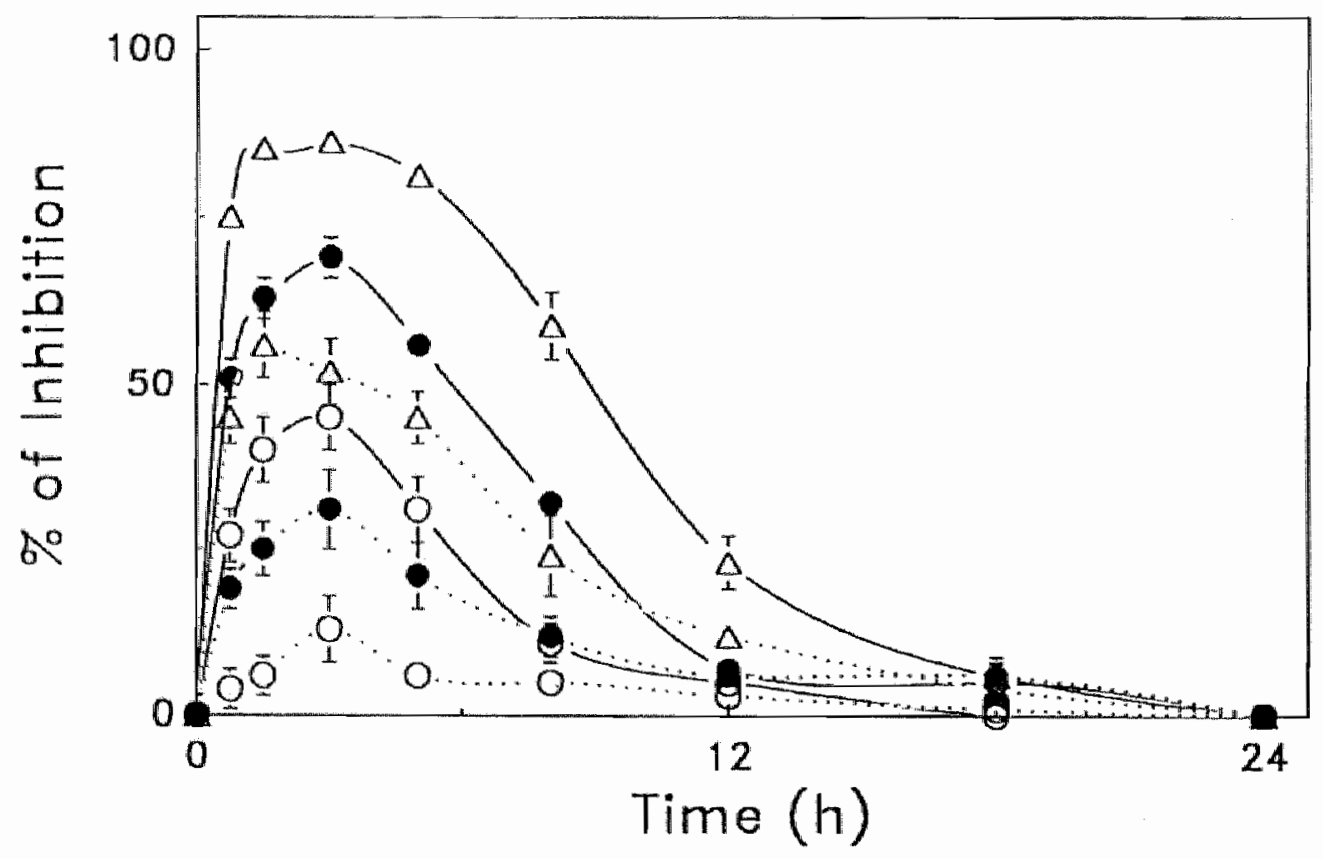

\section{Figure 3}

The Inhibition of the Peak Values of Thrombin and Prothrombinase. Solid lines: Thrombin. Dotted lines: Prothrombinase. O-O UFH $5000 \mathrm{IU}$, -0 enoxaparin $40 \mathrm{mg}$, $\Delta-\Delta$ enoxaparin $1 \mathrm{mg} / \mathrm{kg} \mathrm{bw}$. 
effect of thrombin breakdown, and inhibition of prothrombin conversion and that the contribution of prothrombinase inhibition can be calculated from the thrombin generation curve and the relevant breakdown constant of thrombin. In figure 3 we show the course of the peak inhibitions of prothrombinase after injection of the different heparins. Injection of unfractionated heparin has almost no effect on prothrombinase, as could be expected from in vitro results (19). In contrast, enoxaparin induced a marked, dose dependent inhibition of prothrombinase untill at least 12 hours after injection.

\section{d) Factor Xa generation}

As it is shown in figure 4, factor $\mathrm{Xa}$ generation is significantly inhibited by the three doses of heparin employed. Again the maxima are at $t=3$. The effect of enoxaparin changed little between 1.5 and 5 hours after injection. The effect is dose dependent. In contrast to antithrombin activity the inhibitory activity of enoxaparin on factor $\mathrm{Xa}$

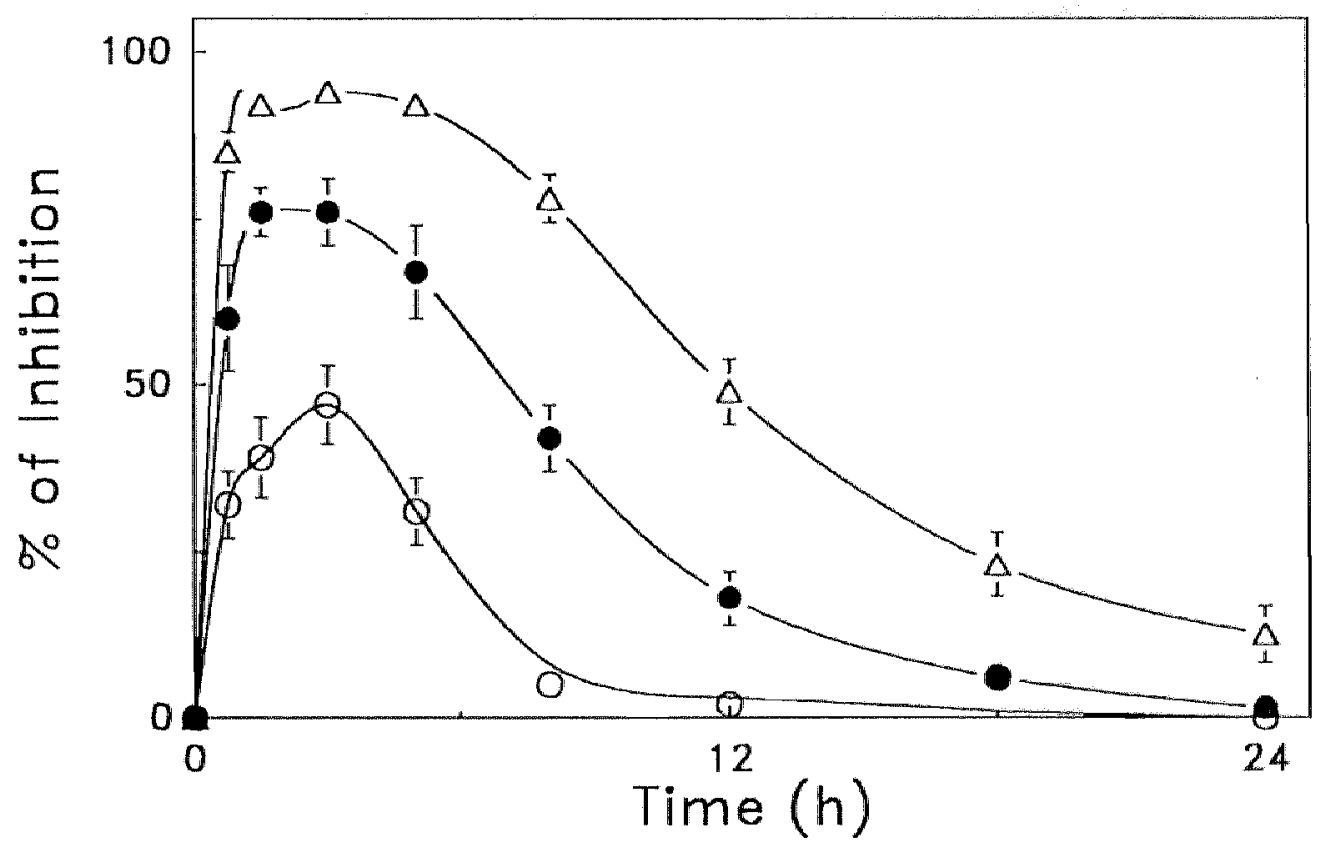

\section{Figure 4}

The Inhibition of the Peak Value of Factor Xa. O-O UFH 5000 IU, -- enoxaparin 40 $\mathrm{mg}, \Delta-\Delta$ enoxaparin $1 \mathrm{mg} / \mathrm{kg}$ bw. 


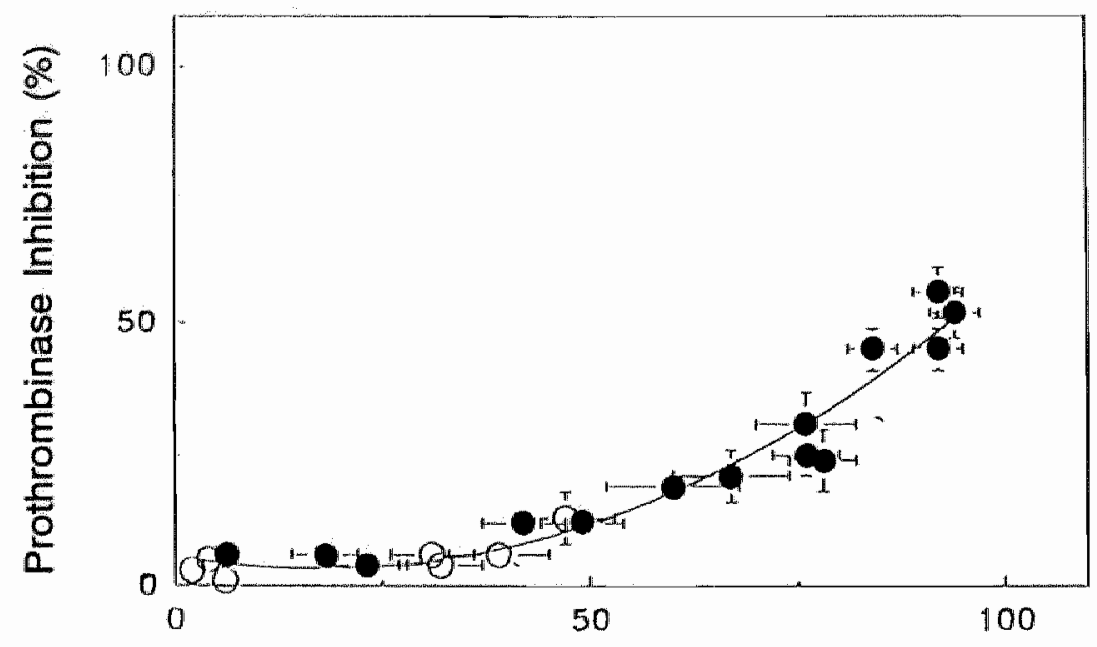

Factor Xa Inhibition (\%)

\section{Figure 5}

The correlation between the inhibition of prothrombinase and of factor Xa generation. O-O UFH, -O enoxaparin

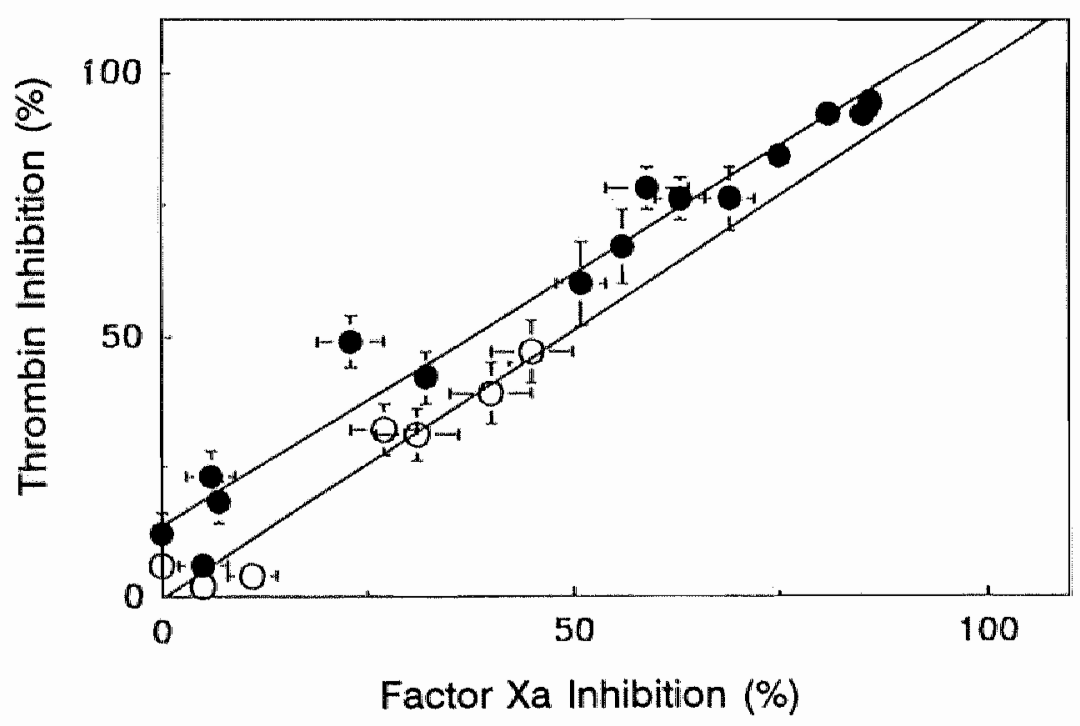

\section{Figure 6}

The correlation between the inhibition of Factor Xa- and of thrombin generation. O-O UFH, enoxaparin. 
generation persists during 18 hours with the low dose, and at least $24 \mathrm{~h}$ with the high dose. Yet, as it was previously surmised from in vitro experiments (2628 ), the inhibition of factor $\mathrm{Xa}$ did not produce a linear inhibition of prothrombinase $(26,27)$. This is seen from comparison between figs. 3 and 4 , but more easily from fig. 5 . As it is observed from figure 6 , the inhibition of factor Xa generation and the inhibition of thrombin generation show a linear relationship.

\section{Heparin Recovery after Subcutaneous Injection}

Knowing the amount of active heparin (HAM) injected, we tried to estimate the heparin recovery (Table 3 ). As a lower limit of the circulating concentration we regard the amount of heparin circulating in the plasma at the heparin peak value, 3 hours after injection, i.e. the peak level multiplied by the estimated plasma volume. To obtain the higher limit of heparin levels we determined a theoretical zero-time plasma concentration by logarithmic extrapolation of the descending part of the curve to zero-time. This can be regarded as the concentration that should be obtained by intravenous injection in order to obtain the same plasma concentrations after 6 hours. The total amount in the circulation is then calculated as plasma concentration ( $x$ ) plasma volume. This is anyhow a minimum because heparin is known to be not uniquely restricted to the fraction present in solution in plasma.

\section{DISCUSSION}

In this chapter we want to contribute to the discussion on the time course of a) the antithrombin and antifactor $\mathrm{Xa}$ activities after subcutaneous injection of heparins, and b) the anti-factor Xa activity induced by injection of UFH compared to that caused by a LMWH. This we can do in terms of the material injected (ACLM and BCLM) rather than in terms of activity, which avoids the confusion brought about by the fact that the ACLM species carries both activities. This approach has been made possible by using the principles explained in the previous chapter for the determination of the levels of heparin.

\section{The Levels of Circulating Heparin}

The first thing that strikes the eye is that the activities obtained by injection of LMWH are much higher than those obtained with UFH (fig.1). This is based on higher concentrations of active materials, a fortioni of BCLM that is practically absent after injection of UFH but, surprisingly, also of ACLM. Not surprisingly the levels of the total active heparin (HAM), as well as the ACLM and BCLM increase with increasing doses of enoxaparin.

From the molecular distribution we know that UFH contains practically 
no BCLM. In spite of the comparable amounts of ACLM injected with UFH only a minor amount reaches the circulation. The low recovery of the ACLM from UFH (3-10\%) may be attributed to the molecular sieve effect of the subcutaneous barrier. UFH contains molecules with MW up to $30,000 \mathrm{D}$ and the very high MW species of UFH may not be able to reach the circulation. The few species that attain the circulation are equivalent to a small fraction $(<10 \%)$ of the material injected. In contrast, the recovery of enoxaparin after subcutaneous injection is $>50 \%$, indicating that enoxaparin has a lower threshold than UFH to reach the blood circulation. BCLM is not found to any appreciable extent after injection of UFH but large, persistent and dose dependent levels are found after injection of enoxaparin, their half-life time is $5.61 \pm 0.36$ hours (fig. 2). The half-life time of ACLM is around $2.24 \pm 0.18$ $h$, independent of the source of the ACLM. This is surprising, because the half-life time of the UF-heparin effect is reportedly around one hour (29). The most simple explanation may be that the half-life time of subcutaneously administrated heparin follows the elimination pattern of low doses of I.V. heparin, that show a prolonged survival.

Many authors (see introduction) have reported that the anti-factor Xa activity of a LMWH persists longer than the antithrombin activity does. This is now readily explained by the different elimination pattern of the two molecular species present in LMW heparins. Up to now this observation has been blurred by the fact that the disappearence from circulation of ACLM causes the desappearence of both antithrombin and antifactor $\mathrm{Xa}$ activities.

\section{The effect of Heparins on Thrombin, Prothrombinase, and Factor Xa Generation}

From the data presented in SI units it is seen that the inactivation of thrombin is always more pronounced than the inactivation of factor $\mathrm{Xa}$. Yet the inhibition of the peaks of factor $\mathrm{Xa}$ and IIa generation is about the same in all samples tested (fig. 6). A possible explanation for the excess of inhibition of factor Xa generation may be found in the effect of heparins on TFPI. As we showed in chapter 3, (LMW)heparin impairs factor Xa generation via its activity on the tissue factor pathway inhibition (TFPI) (chapter 3). This effect may be more marked in ex vivo samples than in vitro experiments because the injection of (LMW)heparin increases the circulating levels of TFPI $(30,31$, 32). The trigger used for thrombin generation was also thromboplastin, so we could hypothesize analogously in the case of thrombin generation. But then it should be reminded that the relation between factor $\mathrm{Xa}$ inhibition and prothrombinase is not linear but hyperbolical (fig. 5).

\section{ACKNOWLEDGMENT}

We thank R. Blezer for his expert technical assistance. 


\section{References}

1) Jacques, L.B.; Wice, S.M.; Hiebert, L.M. Determination of absolute amounts of heparin and of dextran sulfate in plasma in microgram quantities. In press 1990.

2) Johnson, E.A.; Kirkwood, T.B.L.; Striling, Y.; Perez-Requejo, J.L. Ingram, G.I.C.; Bangham, D.R.; Brozovic, M.: Four heparin preparations: Anti-Xa potentiating effect of heparin after subcutaneous injection. Thrombos. Haemostas. 35; 586-591; 1976.

3) Yin, E.T.; Wessler, S.; Stoll, P.J.: Biological properties of the naturally occuring inhibitor to activated factor X. J. Biol. Chem. 246: 3703-3711; 1971.

4) Teien, A.N.; Lie, M.; Evaluation of amidolytic heparin assay methodl. Increased sensitivity by adding purified antithrombin III, Thromb. Res: $10: 399-410 ; 1977$.

5) Bara, L.;, Combe-Tamzali, S.; Conard, J.; Horellou "M.H.; Samama, M.: Modifications biologiques induites par trois héparines de bas poids moléculaire: PK 10169, Kabi 2165 et CY 216 , comparées à l'héparine non fractionnée, injectées par voie souscoutanée chez le volontaire sain, et en chirurgie générale chez le sujet âgé en médecine. J. Mal. Vasc:; 12: 78-84; 1987.

6) Harenberg, J.; Würzner, B.; Zimmermann, R.; Schettler, G..: Bioavailability and antagonization of the low molecular weight heparin CY 216 in man. Thromb. Res. 44: 549-554; 1986.

7) Bara, L.; Billaud, $\mathbb{E}_{\text {; }}$ Kher, A.; Samama, M.: Increased anti-Xa bioavailabillity for a low molecular weight heparin (PK 10169) compared with unfractionated heparin. Sem. Thromb. Haemost.; 11, 3: 316-317; 1985 .

8) Bara, L.; Billaud, E.; Gramond, G.; Kher, A.; Samama, M.: Comparative pharmacokinetics of a low molecular weight heparin (PK10169) and unfractionated heparin after intravenous and subcutaneous administration. Thromb. Res; 39:631-636; 1985.

9) Bratt, G.; Törnebohm, E.; Lockner,D.; Bergström, K.: A human pharmacological study comparing conventional heparin and a low molecular weight heparin fragment. Thromb. Haemost. 53: 208-211; 1985.

10) Berqvist, D.; Hedner, U.; Sjorin, E.; Holmer, E.: Anticoagulant effects of two types of low molecular weight heparin administered subcutanously. Thromb. Res.32; 381-391; 1983.

11) Emanuele, R.M.; Fareed, J.: The effect of molecular weight on the bioavailability of heparin. Thromb. Res. 48; 591-596; 1987.

12) Pedersen, P.C.; Ostergaard, P.B.; Hedner, U.; Bergqvist, D.; Mätzch, T.: Pharmacokinetics of a low molecular weight heparin, logiparin, after intravenous and subcutaneous administration to healthy volunteers. Thromb, Res. $61 ; 477-487 ; 1991$. 
13) Thomas, D.P*; Merton, R.E; Lewis, W.E.; Barrowcliffe, T.W.: Studies in man and experimental animals of a low molecular weight heparin fraction. Thromb. Haemost. 45; 21. 218: 1981

14) Andriuoli, G.; Mastacchi, R.; Barbanti, M.; Sarret, M.: Comparison of the antithrombotic and haemorrhagic effects of heparin and a new low molecular weight heparin in rats. Haemostasis $15 ; 324-330 ; 1985$.

15) Cade, J.F.; Buchanan, M.R.; Boneu, B.; Ockelford, P.A.; Carter, C.J.; Cerskus, A.L.; Hirsh, J.: A comparison of the antithrombotic and hemorrhagic effects of low molecular weight heparin fractions. Thromb. Res, 35, 613-625; 1984.

16) Holmer, E.; Mattsson, C.; Nilsson, S.: Anticoagulant and antithrombotic effects of heparin and low molecular weight heparin fragments in rabbits. Thromb. Res.; $25: 475$ 485; 1982.

17) Mătzsch, T.; Bergqvist, D.; Fredin, H.; Hedner, U.; Ostergaard, P.: Influence of a low molecular weight heparin on the inhibition of factor $\mathrm{Xa}$ and thrombin in hip surgery. Thromb. Res. 56:559-564; 1989.

18) Ofosu; F.A.; Blajchman, M.; Modi, G.; Cerskus, A.L.; Hirsh, J.: Activation of factor $X$ and prothrombin in antithrombin III depleted plasama. Thromb. Res.; 23; 331-45; 1982.

19) Hemker, H.C.: The mode of action of heparin in plasma. Thromb. Haemost. pp 1736; 1987. Ed: Verstraete, M.; Vermylen, J; Lijnen, H.R. and Arnout, J.: I.S.T.H. and Leuven University Press.

20) Béguin, S.; Lindhout, T.; Hemker, H. C.: The mode of action of heparin in plasma. Thromb. Haemost.; $60 ; 457-462 ; 1988$.

21) Hemker, H.C.; Béguin; S.: Mode of action of Unfractionated and Low Molecular Weight Heparin on the Generation of Thrombin in Plasma. Haemostasis: 20 (suppl. 1). 81-92; 1990.

22) Ofosu, F. A.; Sie, P.; Modi, G.J.; Fernandez, F.; Buchanan, M.; Blajchman, M.A.; Boneu, B. and Hirsh, J.: The inhibition of thrombin-dependent positive-feedback reactions is critical to the expression of the anticoagulant effect of heparin. Biochem. J. 243, 579-588; 1987.

23) Ofosu, F.A.; Blajchman, M.A.; Modi, G.J.; Smith, L.M.; Buchanan, M.R.; Hirsh, J.: The importance of thrombin inhibition for the expression of the anticoagulant activites of heparin, dermatan sulfate, low molecular weight heparin and pentosan polysulfate. Br.J. Haematol.; 60: 695-704; 1985.

24) Pangrazzi, J.; Abbadini, M.; Zameta, M.; Naggi, A.; Torri, G.; Casu, B.; Donati, M.B.: Antithrombotic and bleeding effects of a low molecular weight heparin fraction. Biochem. Pharmacol. 34, 3305-3308; 1985. 
25) Diness, Y.; Nielson, J.I; Pedersen, P.C.; Wolfbrandt, $\mathbb{K} . H$. ; Ostergaard, P.B.: A comparison of the antithrombotic and hemorrhagic effects of low molecular weight heparin (PHN-1) and conventional beparin. Thromb. Haemost. 55, 410-414, 1986.

26) Hemker, H.C. Esnouf, M.P. Hemker, P.W. Swart, A.C.W.; Mac Farlane, R.G.: Formation of Prothrombin converting Activity. Nature, 215: 248-251; 1967.

27) Lindhout, M.J.; Govers-Riemslag, J.W.P.; Waart-van-de, P.; Hemker, H.C.; Rosing, J. Factor Va - Factor Xa Interaction.: Effects of Phospholipid Vesicles of varying Composition. Biachemistry, 21: 5494-5502; 1982.

28) Pieters J, Lindhout T, Hemker H C: In situ generated thrombin is the only enzyme that effectively activates factor VIII and factor $\mathrm{V}$ in thromboplastin activated plasma. Blood, 1021-1024; 1989 .

29) Swart, de, C.A.M.; Nijmeyer, B.; Andersson, L. Holmer, E.; Verschoor, L.; Bouma, B.N.; Sixma, J.J.: Elimination of high affinity heparin fractions and their anticoagulant and lipase activity. Blood 6; 4: 836-842; 1984 .

30) Laforest, M.D.; Colas-Linhart, N.; Guiraud-Vitaux, F.Bok, B.; Bara, L.; Samama, M.; Marin, J.; Imbault, F.; Uzan, A.: Pharmacokinetics and biodistribution of technetium $99 \mathrm{~m}$ labelled standard heparin and a low molecular weight heparin (enoxaparin) after intravenous injection in normal volunteers. Br. J. Haematol.; 77: 201-208; 1991.

31) Sandset. P.; Abilgaard, U.; Larsen, A.L.: Heparin induces release of extrinsic coagulation pathway inhibitor (EPI). Thromb. Res.; 50: 803-813; 1988.

32) Lindahl, A.K.; Abilgaard, U.; Larsen, M.L.; Aamodt, L.M.; Nordfang, O.; Beck, T.C.: Extrinsic pathway inhibitor (EPI) and the post-heparin anticoagulant effect in tissue thromboplastin induced coagulation. Thromb. Res. Suppl XIV; 39-48; 1991. 



\section{THE EFFECT OF SUBCUTANEOUS INJECTION OF UNFRACTIONATED AND LOW MOLECULAR WEIGHT HEPARIN on Thrombin Generation in Platelet Rich Plasma. A STUdY IN HUMAN VOLUNTEERS.}

\section{SUMMARY}

The time-course of the inhibition of thrombin generation in platelet rich plasma was studied after subcutaneous injection to healthy volunteers of a single dose of unfractionated heparin ( $5000 \mathrm{IU})$ and two different doses of the low molecular weight (LMWH) enoxaparin ( $40 \mathrm{mg}$, and $1 \mathrm{mg} / \mathrm{kg} \mathrm{bw}$ ). Both heparins were able to delay the onset of thrombin generation. Enoxaparin inhibited the amount of thrombin generated, and UFH did not. The effect on thrombin generation was dependent upon the dose of enoxaparin. Platelet factor 4 (PF4), the main heparin neutralizing protein released by platelets, completely neutralized the specific antithrombin activity of both, unfractionated heparin, and enoxaparin. On the other hand, the antifactor Xa activity of enoxaparin was only partly neutralized. Thus, inhibition of thrombin generation in platelet rich plasma was not due to a direct antithrombin activity.

\section{INTRODUCTION}

There are good arguments to believe that antithrombin activity of heparins is crucial to their anticoagulant effect $(1-10)$. It is well documented that heparin and LMWH owe their anticoagulant activity mainly to the AT III dependent inhibition of thrombin and factor Xa (1-6, 9-21). Antifactor $X a$ activity is exerted by all heparin containing the specific pentasaccharide sequence that allows binding to AT III ( $\mathrm{MW}>1500$; refs 7, 8). Anti-thrombin activity and antifactor IXa activity requires, in addition, a $\mathrm{MW}>5400$. All heparins with AT III high affinity material. (HAM) catalyze factor Xa inhibition, but only the species above the critical chainlength of 5400 , or ACLM, catalyze thrombin inhibition.

It has been reported that PF4 neutralizes completely the antithrombin and the antifactor Xa activity of UFH. It also neutralizes completely the antithrombin activity of LMWH's, but not their anti-factor $\mathrm{Xa}$ activity (22- 25 and references therein). Experiments done by our group, showed that in purified systems, an excess of PF4 is required to 
neutralize completely the antifactor Xa activity of LMWH (26).

In an ex-vivo study performed by Michalski et al (24) it has been found that (protamine and) platelet factor 4 neutralized only partly ( $~ 50$ $\%$ ) of the antifactor Xa activity of a LMWH fraction. Lane et al (22) demonstrated in a set of experiments performed in-vitro, that the antithrombin and the antifactor $\mathrm{Xa}$ activities of heparin fragments of $\geq 18$ saccharides unit are completely neutralized by $P F 4$, while decreasing $M W$, increases the refractivity for the neutralization. In addition, Denton et al (23) showed that an octa-decasaccharide possessing exclusively anti-factor $\mathrm{Xa}$ activity is only for $\sim 50 \%$ neutralized by platelet factor 4 . Thus, it seems that ACLM is readily neutralized and tightly bound by PF4, while BCLM is not.

The current experience suggests that the levels and size of heparin molecules present in circulation after subcutaneous injection will favour the persistance of BCLM. As described in chapters 4 and 5 , we developed a way to assess ACLM and BCLM levels.

In this chapter we investigate in twelve healthy male volunteers the effect of a subcutaneous injection of unfractionated heparin (5000 IU), and two independent doses of enoxaparin (40 $\mathrm{mg}$, and $1 \mathrm{mg} / \mathrm{kg} \mathrm{bw}$ ) on thrombin generation in PRP. We also investigated wether ACLM and/or BCLM activity could be demonstrated in serum of PRP, i.e. after maximal thrombin activation of the platelets.

\section{MATERLALS AND METHODS}

Platelet rich plasma. Blood was collected on $0.13 \mathrm{M}$ trisodium citrate; nine parts of blood to one part of citrate solution. Platelet rich plasma (PRP), was obtained after centrifugation of the blood at $1.100 \mathrm{rpm}$, during $10 \mathrm{~min}$. at room temperature. Experimenets on PRP were carried out within one hour after venipuncture.

Thrombin Generation was performed according to ref. (2). Briefly, $240 \mu \mathrm{l}$ of PRP is supplemented with $60 \mu$ of buffer $A$, and incubated for $5 \mathrm{~min}$ at 37 ${ }^{\circ} \mathrm{C}$. At zero time, thrombin generation is started by the addition of $60 \mu 1$ of a solution containing $17 \mathrm{mM}$ of $\mathrm{CaCl}_{2}$ (final concentration), and traces of human brain thromboplastin (a $1 / 10$ dilution of a thromboplastin concentration that produces a clotting time of $\sim 70$ seconds in the same system, but in the absence of platelets). At intervals, a $10 \mu \mathrm{l}$ aliquot of the mixture is sampled into a disposable plastic cuvette containing buffer $490 \mu \mathrm{l}$ of and $0.2 \mathrm{mM} \mathrm{S}-2238$, as described in ref. 2 .

Serum rich in Platelet Factor 4 was obtained after triggering coagulation in 
PRP with diluted thromboplastin, in the conditions described in the previous section. Serums were immediately frozen at $-80^{\circ} \mathrm{C}$. ters.

All other material and methods were described in the previous chap-

\section{RESULTS}

The Effect of Subcutaneous Injection of Heparins on the overall Thrombin Generation in Platelet Rich Plasma.

Typical curves of thrombin generation after the injection of heparin are shown in figure 1 . The time-course of the average of the thrombin peak inhibition is shown in figure 2 . It can be seen from figure $1 \mathrm{a}$ and 2 , that unfractionated heparin has virtually no effect on thrombin generation in PRP. On the other hand, from figures $1 \mathrm{~b}, 1 \mathrm{c}$ and 2 , it is seen that enoxaparin was able to inhibit the generation of thrombin in a dosedependent manner. The maximal effect probably is obtained between 1.5 and $3 \mathrm{~h}$. The percentage of inhibition is shown in table 1 .

\section{Table I}

The Inhibition of Thrombin Generation in Platelet Rich Plasma

\begin{tabular}{llll}
\hline & \multicolumn{3}{c}{ Percentage of Inhibition* } \\
\multirow{2}{*}{$\begin{array}{l}\text { Time } \\
\text { (h) }\end{array}$} & UFH 5000 IU & Enox $40 \mathrm{mg}$ & Enox $1 \mathrm{mg} / \mathrm{kg}$ \\
\hline 1.5 & $<10$ & $18 \pm 4$ & \\
3 & $<10$ & $26 \pm 4$ & $46 \pm 3$ \\
5 & $<10$ & $17 \pm 4$ & $36 \pm 3$ \\
8 & $<10$ & $9 \pm 5$ & $28 \pm 5$ \\
\hline
\end{tabular}

\footnotetext{
* The percentages of the overall thrombin generation inhibition were calculated comparing the peak values obtained at $1.5,3,5$ and 8 hs to that found in the pre-heparin sample.
}

The Effect of Subcutanous Injection of Heparins on the Lag Time of Thrombin Generation

We define the lag time that preceedes thrombin formation as the time necessary to generate $20 \mathrm{nM}$ of thrombin. The results shown in figure 3 demonstrate that all the heparin preparations were able to delay it. The prolongation was maximal at $1.5 \mathrm{~h}$.

The effect of enoxaparin on the lag-phase was higher than that of UFH. A dose-dependency was observed. 


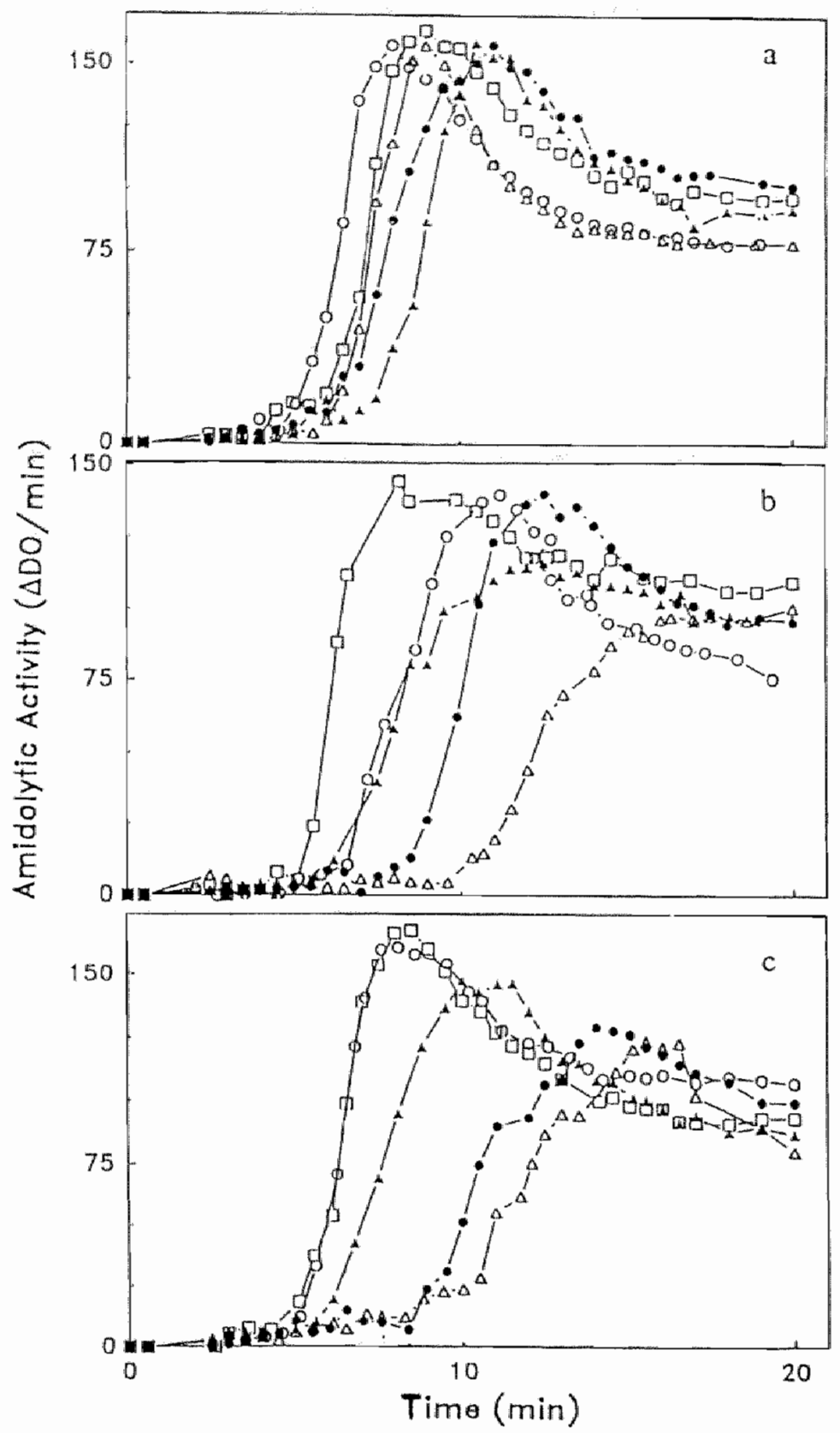

\section{Figure I}

Thrombin generation in PRP. Panel a: UFH. Panel b: Enoxaparin, $40 \mathrm{mg}$. Panel c: Enoxaparin, $1 \mathrm{mg} / \mathrm{kg}$ bw. Symbols represent: $\mathrm{O}-\mathrm{O}$ Control; $-1.5 ; \Delta-\Delta \mathrm{3}$; 4 -4 5 ; and $\square-8 \mathrm{~h}$ after the respective injections. 


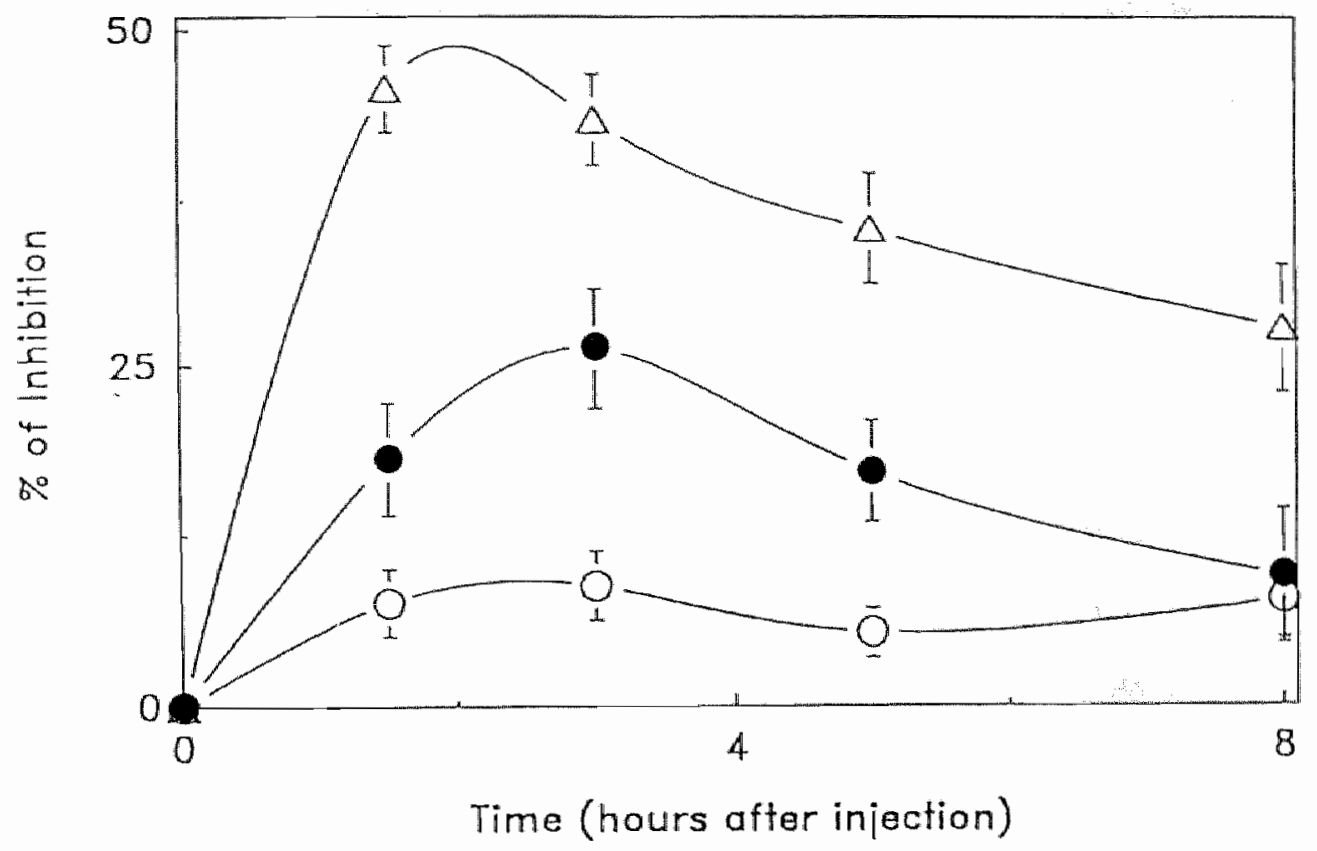

\section{Figure 2}

The Time Course of The Inhibition of Thrombin Generation. The percentages of the inhibition were obtained after comparing the inhibitions (in $\mathrm{nM}$ thrombin) to their respective control runned before the injection of the heparins. O-O UFH; enoxaparin $40 \mathrm{mg}$; and $\Delta-\Delta$ enoxaparin $1 \mathrm{mg} / \mathrm{kg}$ bw.

\section{The Residual Standard-Independent Units of Heparins}

From table 2, it can be seen that the decay of thrombin is not affected in the serum obtained after addition of thromboplastin/Ca ${ }^{++}$to PRP. This provides the evidence that no ACLM activity persisted in the serum of PRP. In contrast, in a pilot experiment done in one of the volunteers, residual BCLM activity could be observed: The results depicted in table 2 indicate the decay constant of factor Xa in serum of PRP was indeed modified. From this, we have calculated the Standard-Independent Units (anti-Xa). 'The time course of SIU (Xa) is shown in figure 4. 


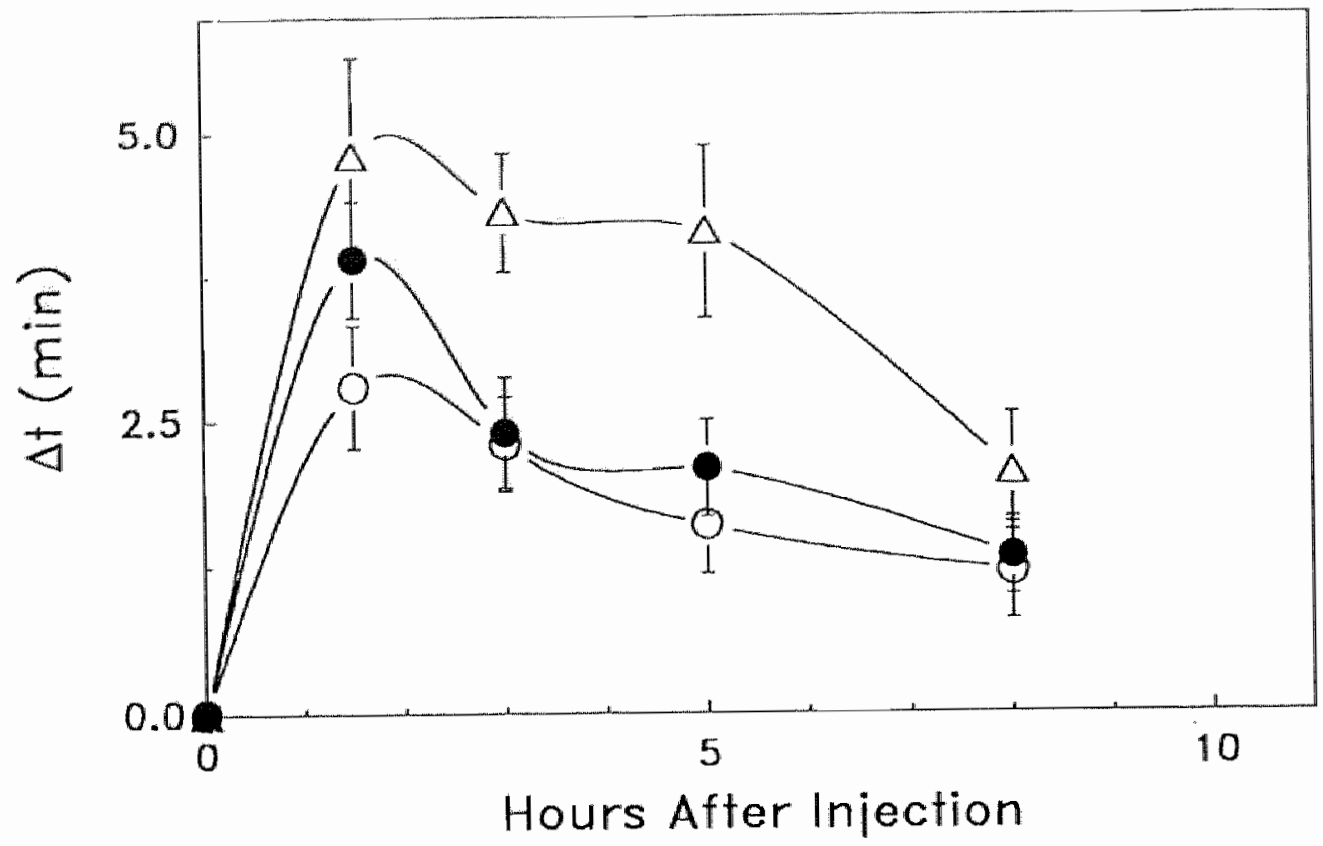

Figure 3

The Time Course of the Prolongation of the Thrombin Generation Lag Time Preceeding Thrombin Generation. The lag time was taken as $20 \mathrm{nM}$ of thrombin. O-O UFH;

- enoxaparin $40 \mathrm{mg}$; and $\Delta-\Delta$ enoxaparin $1 \mathrm{mg} / \mathrm{kg}$ bw.

\section{Table 2}

The Decay Constant of Thrombin in Senum, After Thrombin Generation in PRP*

\begin{tabular}{llll}
\hline $\begin{array}{l}\text { Time } \\
\text { (h) }\end{array}$ & UFH 5000 IU & Enox 40 mg & Enox $1 \mathrm{mg} / \mathrm{kg}$ \\
\hline 0 & $1.01 \pm 0.09$ & $1.09 \pm 0.10$ & $1.06 \pm 0.09$ \\
1.5 & $1.04 \pm 0.10$ & $1.07 \pm 0.10$ & $1.03 \pm 0.09$ \\
3 & $1.08 \pm 0.10$ & $1.01 \pm 0.09$ & $1.06 \pm 0.09$ \\
5 & $0.99 \pm 0.09$ & $1.06 \pm 0.09$ & $1.02 \pm 0.09$ \\
8 & $0.99 \pm 0.09$ & $1.09 \pm 0.09$ & $0.96 \pm 0.09$
\end{tabular}

* For experimental details see methods. 


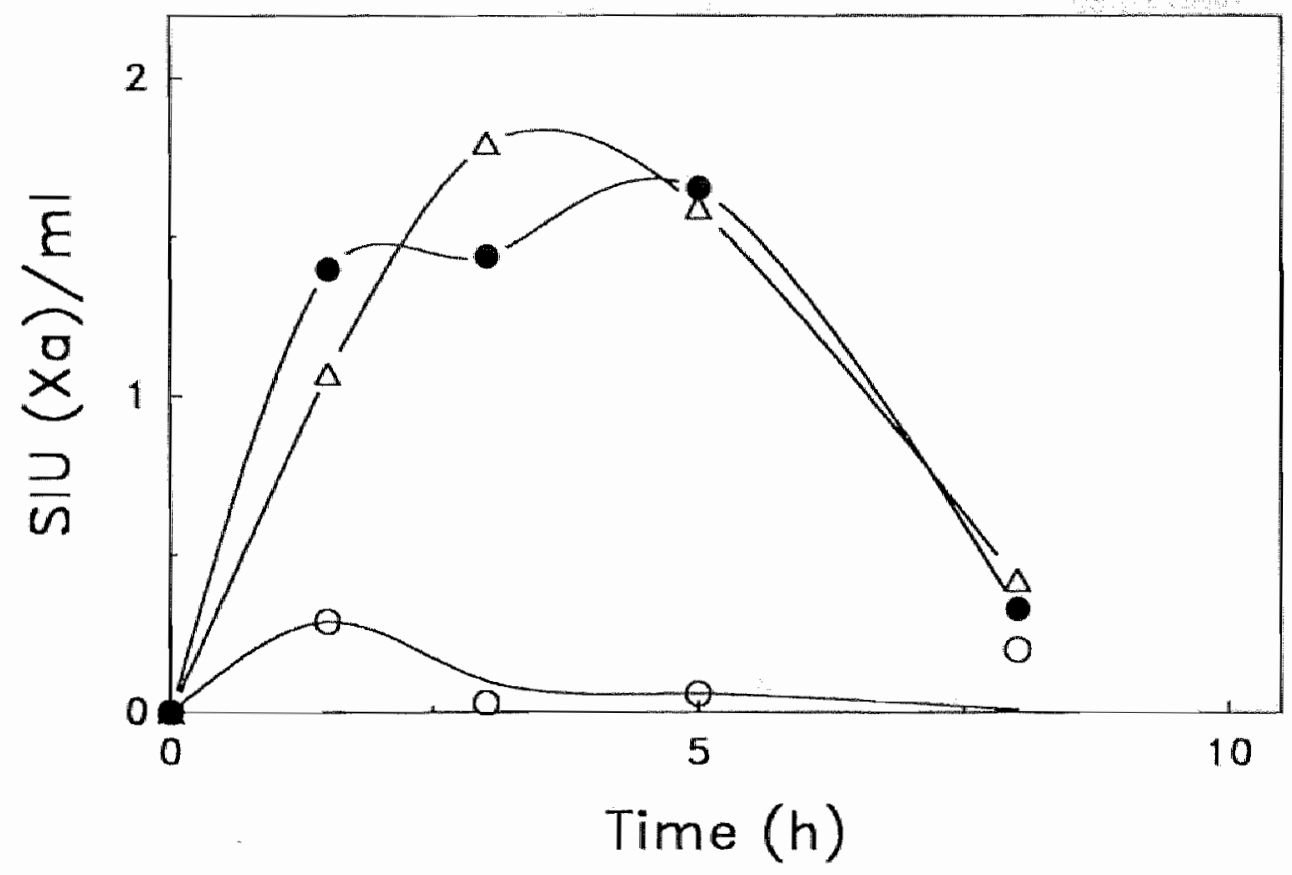

\section{Figure 4}

The Time Course of the SIU(Xa) in Plateler Rich Plasma. For legends, please see fig. 3

\section{Table 3}

The Decay Constant of Factor Xa in Serum, After Thrombin Generation in PRP*

\begin{tabular}{llll}
\hline $\begin{array}{l}\text { Time } \\
\text { (h) }\end{array}$ & UFH 5000 IU & Enox 40 mg & Enox $1 \mathrm{mg} / \mathrm{kg}$ \\
\hline 0 & $0.46 \pm 0.06$ & $0.55 \pm 0.13$ & $0.52 \pm 0.16$ \\
1.5 & $0.65 \pm 0.05$ & $1.49 \pm 0.14$ & $1.23 \pm 0.15$ \\
3 & $0.48 \pm 0.09$ & $1.52 \pm 0.16$ & $1.71 \pm 0.21$ \\
5 & $0.50 \pm 0.07$ & $1.66 \pm 0.25$ & $1.58 \pm 0.09$ \\
8 & $0.59 \pm 0.12$ & $0.77 \pm 0.16$ & $0.76 \pm 0.09$
\end{tabular}

* The reported values were obtained from one volunteer for UFH, and from another for the two doses of enoxaparin. 


\section{DISCUSSION}

The results presented in this chapter demonstrate that in the presence of heparin-neutralizing proteins released by platelets during coagulation of PRP, unfractionated heparin given subcutaneously in a dose of $5000 \mathrm{IU}$ does not cause inhibition of the thrombin peak in PRP, although it did prolong the lag time of the burst. This was expected on basis of earlier experiments done with UFH added to PRP (6). In contrast, enoxaparin, dose dependently, both inhibits the thrombin peak and retards the lag-phase. This again is in accordance with in-vitro results $(27,28)$. The explanation for these findings must be based in the effect of release products of platelets on heparin $(22-24,26)$.

All available data up to this moment support the idea that ACLM can be neutralized completely by PF4, whereas BCLM is neutralized incompletely, probably because of the infavourable binding characteristics. Denton and coworkers (23) demonstrated that in a purified system containing AT III and factor Xa to which PF4 was added, the antifactor Xa activity of an 8-10 unit saccharide is only partly neutralized, while the antifactor Xa of a 16 unit saccharide (possessing also antithrombin activity), was completely neutralized. It was also shown that the addition of purified PF4 to samples containing unfractionated heparin neutralized completely both antifactor Xa and antithrombin activities, while when PF4 was added to samples containing LMWH only partial neutralization of the antifactor $\mathrm{Xa}$ activity was found. An excess of PF4 was required to neutralize completely the antifactor Xa activity of LMWH (26).

Due to the molecular distribution of UFH (largely ACLM) catalysis of factor $\mathrm{Xa}$ and thrombin inhibition cannot take place in the presence of PF4.

The inhibition of the overall thrombin generation in platelet rich plasma mediated by enoxaparin, which is composed of both, ACLM and $B C L M$, can be described in terms of a cooperative phenomenom that consists of: first, the inhibition of thrombin traces before platelet activation occurs (i.e. prolongation of the lag phase), and second, inhibition of the overall thrombin generation due mainly to factor $\mathrm{Xa}$ inhibition. A pure ACLM (i.e. UFH) will retard the outburst of thrombin because it lowers the levels of free thrombin that, during the lag phase, incites the activation of platelets. As soon as the platelets are activated, the ACLM is neutralized, up to a concentration of heparin of $0.4 \mathrm{U} / \mathrm{ml}$. BCLM will also (less efficiently) act during the lag phase, but will resist neutralisation and retain activity during the thrombin burst.

In accordance with this view we find no antithrombin activity in serum of PRP (table 2), whereas antifactor Xa activity is partly retained in enoxaparin (table 3, and figure 4). It must be noted that the AT III level in 
serum is about half of that in plasma, so that we cannot immediately interprete the values obtained in terms of BCLM concentrations. The absence of any response of the anti-IIa activity shows that no ACLM material "survived" the clotting of PRP.

We could calculate the residual BCLM levels if we assume that the decay constants of thrombin allow quantitation of AT III. For practical reasons this is not possible. Indeed, the BCLM is obtained, as indicated in chapters 4 and 5, after substracting ACLM from HAM. Both of those variables, are obtained from the S.I.U., and the respective Specific Activities of the ACLM and HAM of a heparin preparation. The neutralization of ACLM in serum of PRP makes this calculation impossible to obtain. A preparation of exclusively BCLM of enoxaparin would be necessary to complete this item. However, the levels of active heparin after thrombin generation in PRP can be calculated in SIU (figure 4).

From the previous findings we can surmize that the activity of a heparin in circulation will be determined by a compromise between its potential capacity to catalyze thrombin (and factor $\mathrm{Xa}$ ) inhibition, and its residual activity after neutralization by PF4 at the moment and site in which platelet release reaction (i.e. the thrombus fomation) is occuring. In addition, its bioavailability will be determined by the molecular size of the species injected. The results broach the question of what makes a "good" heparin. On this we can only speculate. ACLM on a weight basis is much more effective than BCLM. If levels of ACLM can be mantained that prevent platelet activation beyond a small area of high trigger intensity, i.e. in a wound or just around a thrombogenic focus, then we would have an almost ideal preventive drug. BCLM, in relatively high doses would retain its activity even around a growing thrombus and would therefore be a suitable candidate for a therapeutic drug. The results of Cadroy et al (29), who showed that antifactor Xa activity is not without importance for the inhibition of experimental thrombosis fit in this hipothesis.

ACKNowledGement. We thank Richard Knebel for his helpfull technical assistance.

\section{REFERENCES}

1) Hemker, H.C.: The mode of action of heparin in plasma. XIth Congr. Thromb. Haemostas.; pp 17-36; 1987. Ed: Verstraete, M.; Vermylen, J; Lijnen, H.R and Arnout, J.: I.S.T.H. and Leuven University Press.

2) Hemker, H.C.; Willems, G.M. and Béguin, S. A computer assisted method to 
obtain the prothrombin actration velocity in whole plasma independent of thrombin decay processes. Thromb. Haemostas; $56,9-17,1986$.

3) Bếguin, $\mathrm{S}$; Lindhout, T.; Hemker, H. C.: The mode of action of heparin in plasma. Thromb. Haemost, $60 ; 457-462 ; 1988$.

4) Hemker, H.C.; Béguin; S.: Mode of action of Unfractionated and Low Molecular Weight Heparin on the Generation of Thrombin in Plasma. Haemostasis; 20 (suppl. 1). $81-92 ; 1990$.

5) Béguin, S.; Choay, J; Hemker, H.C.: The action of a synthetic pentasaccharide on thrombin generation in whole plasma. Thromb. Haemostas.; 61: 397-401; 1989.

6) Béguin, S.; Lindhout, T.; Hemker, H. C.: The effect of trace amounts of tissue factor on thrombin generation in platelet rich plasma; Its inhibition by heparin. Thromb. Haemost; 61: 25-29; 1989.

7) Choay, J.; Lormeau, J.C.; Sinaij, I.; Casu, B.; Gati G.: Structure-Activity relationship in heparin: $A$ synthetic pentasaccharide with high affinity for antithrombin III and eliciting high anti-factor Xa activity. Biochem. Biophys. Res. Comm, 116: 492-499; 1983.

8) Riesenfeld, J,; Thunberg, L.; Höök, M;; Lindhal, U.: The antithrombin binding sequence of heparin. Location of $\mathrm{N}$ sulfate groups. I. Biol. Chem; $5: 389$ - 394; 1981 .

9) Ofosu, F. A.; Sie, P.; Modi, G.J.; Fernandez, F.; Buchanan, M.; Blajchman, M.A.; Boneu, B. and Hirsh, J.: "The inhibition of thrombin-dependent positive-feedback reactions is critical to the expression of the anticoagulant effect of heparin. Biochem. J. $243,579-588 ; 1987$.

10) Ofosu, F.A.; Blajchman, M.A.; Modi, G.J.; Smith, L.M.; Buchanan, M.R.; Hirsh, $J_{\text {.: }}$ The importance of thrombin inhibition for the expression of the anticoagulant activites of heparin, dermatan sulfate, low molecular weight heparin and pentosan polysulfate. Br. J Haematol ; 60: 695-704; 1985 .

11) Jordan, R.; Beeler, D.; Rosenberg, R.D.: Fractionation of low molecular weifht heparin species and their interaction with antithrombin. J. Biol. Chem. 254: 29022913:1979.

12) Atha, D.H.; Lormeau, J.C.; Petitou, M; Rosenberg, R.D.; Choay, J: Contribution of 3-0-and 6-o-sulfated glucosamine residues in the heparin-induced conformational change in antithrombin III. Biochemistry; 26: 6454-6461; 1987.

13) Lam, L.H.; Silbert, J.E.; Rosenberg, R.D.: The separation of active and inactive froms of heparin. Bhiochem. Biophys. Res. Commun.; 69: 570-577; 1976.

14) Höök, M.; Bjork, I.; Hopwood, J.; Lindahl, U.: Anticoagulant activity of heparin; Separation of high-activity and low activity heparin species by affinity c- 
hromatography on immobilized antithrombin. FEBS Letters 66:90-93; 1976.

15) Barrowcliffe, T.W.; Merton, R.E.; Havercroft, S.J.; Thunberg, L.; Lindhal, U.: Effect of heparin oligosaccharides with high affinity for antithrombin III in experimental venous thrombosis. Thromb. Resarch; 34: 125-133; 1984.

16) Thomas, D,P.; Merton, R.E.; Barowcliffe, T.W,; Thunberg, L.; Lindahl,U.; Effects of heparin oligosaccharides with high affinity for antithrombin III in experimental venous thrombosis. Thrombos. Haemostas.: 47: 244-248; 1982 .

17) Barrowcliffe, T.W.; Merton, R.E.; Havercroft, S.J.; Thunberg, L.; Lindahl, U. and Thomas, D.P.: Low affinity heparin potentiates the action of high-affinitty heparin oligosaccharides. Thromb. Res.; 34: 125-133; 1984.

18) Ofosu; F.A.; Blajchman, M.; Modi, G.; Cerskus, A.L.; Hirsh, J.: Activation of factor $\mathrm{X}$ and prothrombin in antithrombin III depleted plasama. Thromb. Res.; 23: $331-45 ; 1982$.

19) Walker, F.J.; Esmon, C.T.: Interaction Between heparin and Factor Xa. Inhibition of prothrombin activation. Biochem. Bioplyys. Acta; 585: 504-515; 1979.

20) Thunberg, L.; Lindahl, U.: On the molecular weight dependence of the anticoagulant activity of heparin. Biochem. J.; 181: 241-243; 1979.

21) Walenga, J.M.; Bara, L.; Petitou, M.; Samama, M.; Fareed, J. and Choay, J.: The inhibition of the generation of thrombin and the antithrombotic effect of a pentasaccharide with sole anti-factor Xa activity. Thromb. Res.; $51,23-33 ; 1988$.

22) Lane, D.A.; Denton, J.; Flynn, A.; Thunberg, L.; Lindahl, U.: Anticoagulant activites of heparin oligosaccharides and their neutralization by platelet factor 4 . Biochem. J.; 218: 725-732; 1984 .

23) Denton, J.; Lane, D.J.; Thunberg, L.; Slater, A.M.; Lindhal, U.: Binding of platelet factor 4 to heparin oligosaccharides. Biochem. J.; 209: 455-460; 1983 .

24) Michalski, R.; Lane, D.A.; Pepper, D.S.; Kakkar, V.V.: Neutralization of heparill in plasma by platelet factor 4 and protamine sulphate. Br. J. Haematol.: 38:561-561: 1978.

25) Doutremepuich, C.; Bonini, F; Toulemonde, F.; Bertrand, H.; Bayrou, B.; Quilichini, R.: In vivo neutralization of low molecular weight heparin fraction $\mathrm{CY} 216$ by protamine. Sem. Thromb. Hemost.; 11, 3: 318-322; 1985.

26) Schoen, P.; Lindhout, T.; Franssen, J.; Hemker, H.C.: Low Molecular weight heparin-catalyzed inactivation of factor Xa and thrombin by antithrombin III. Effect of platelet factor 4 . Thromb. Haemostas.66 (4): 435-441; 1991.

27) Béguin, S.; Hemker, H.C.: Mode of action of enoxaparin in plasma. Acta Chir. 
Scand Suppl. 556:51-56; 1990.

28) Béguin, S.; Wielders, S.; Lormeau, J.C.; Hemker, H.C.: The mode of action of CY 216 and CY 222 in plasmat. To be published in: Thromb. Haemostas.; 1991.

29) Cadroy, Y.; Harker, L.A.; Hanson, S.R.: Inhibition of platelet-dependent thrombosis by low molecular weight heparin (CY222): Comparison with standard heparin. J. Clin. Med.: 349-357; 1989. 


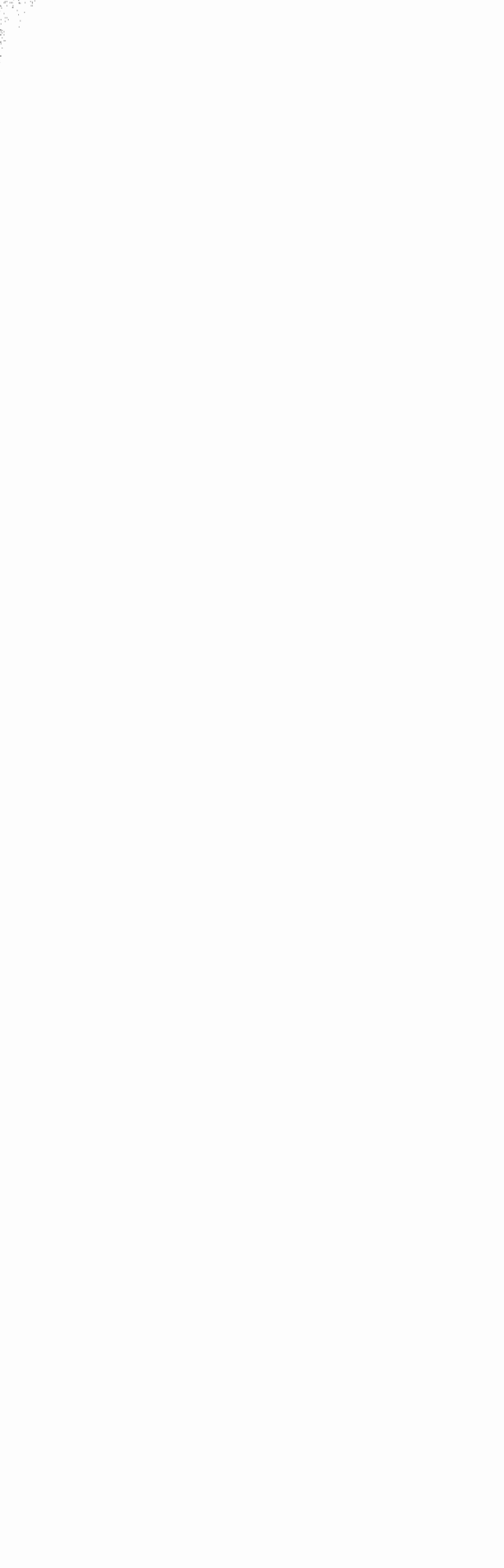




\section{General Discussion}

Anticoagulant properties of tissue extractions such as heparin are documented at least since the end of the XIX century. Since the 1970's, structural modifications of natural heparin were done. Investigations with respect to the dependency of chainlength of heparins and the inhibitory activity were performed: It was observed that the AT III-dependent thrombin inhibition is catalyzed by a minimal chainlength of 18 saccharides $(1,2)$, while inhibition of factor $\mathrm{Xa}$ is due exclusively to a specific pentasaccharide sequence (3). It was observed that the specific activities (antithrombin and/or antifactor Xa) increase with MW $(1,2,4)$. Until now, the reason for this relationship between MW and anticoagulant activity of heparin derivatives has not yet been investigated. Thus, in chapter 2 we studied a series of fractions obtained from enoxaparin, on the overall thrombin formation in plasma. The analysis of the molecular distribution indicated that the fractions tested were sufficiently monodisperse (weight $M W /$ number $M W \sim 1$ ). Using a fluorometric method, we measured the content of AT III-high affinity material (HAM), and observed that it decreases with MW. This is probably a consequence of the method used for the preparation of enoxaparin. Random cleavage may sever the binding site with AT III so that higher molecular weight fractions possess higher specific activities.

The effect of the fractions on the inhibition of thrombin generation and prothrombinase was studied according to the method described by Hemker and Béguin $(5,6)$. From the fractions studied we have been able to distinguish two groups of heparins: Heparin fractions without significant antithrombin activity (N6-N14; $1,800<\mathrm{MW}<4,200$ ) that we call $\mathrm{P}$ type heparins, and heparin fractions that inhibit thrombin generation primarily via thrombin inhibition ( $\mathrm{MW} \geq 6000$ or $\mathrm{S}$ type heparins). We observed in agreement with previous data from the literature, that heparin fragments need a minimal MW of $\sim 5,400$ to catalyze thrombin inhibition. Thus, when antithrombin activity is concerned, heparin with HAM, and a MW above the critical chainlenght of 18 monosaccharide units (ACLM) is required. The HAM below the critical chainlenght of 18 monosaccharides we call BCLM.

We observed that ACLM species are more active than the BCL.M ones. This must be attributed to their antithrombin activity. Within the ACLM fractions, no significant systematic variation of the specific activity 
can be observed with the chainlenght, neither when expressed on a weight, or on a molar basis. On a weight basis, the potency to catalyze thrombin inhibition increases with MW, but, when calculated as AT III high affinity material above the critical chainlength of 18 saccharides $(5,400 \mathrm{D})$, the differences tend to vanish. Lower than $5,400 \mathrm{D}$ fractions owe their anticoagulant activity exclusively to their antifactor $\mathrm{Xa}$ activity. We showed that the inhibition of thrombin generated by the intrinsic pathway requires less heparin than the extrinsic one. This is likely to be due to their antithrombin activity, which inhibits the feedback activation of factor VIII (6).

We observed that heparin fractions that contain exclusively antifactor Xa activity are poor anticoagulants in vitro. In addition, the MW distribution of enoxaparin shows that it contains a low proportion of species with $\mathrm{MW} \geq 9,000$. Hence, we conclude that the anticoagulant activity of enoxaparin might be located in fragments between 20 and 30 saccharides.

Antifactor Xa activity of heparins are often studied using systems based on the inhibition of factor $\mathrm{Xa}$ added to a plasma sample. These models do not account for the effect of $\mathrm{Ca}^{++}$, although it was observed that $\mathrm{Ca}^{++}$ions influences the activity of heparin $(7,8)$, and neither for the complex reactions of positive and negative feedback in which factor $\mathrm{Xa}$ is involved. Therefore, in chapter 3 we studied in plasma the ability of various heparin types to a) to inhibit the generation of factor $\mathrm{Xa}, \mathrm{b}$ ) to catalyze the AT III dependent inhibition of factor Xa. We showed that the serineprotease factor VIIa is not inhibited by AT III. Thus, in the present experimental conditions, the only action of AT III is on factor Xa inhibition, both in the absence and in the presence of heparin. The absence of a prolongation of the lag phase that preceedes factor Xa generation demonstrates the high efficiency of factor Xa to activate factor VII.

We observed that thromboplastin interferes with the AT III dependent inhibition of factor $\mathrm{Xa}$. This phenomenom might be due either to a protection of the interaction Xa-AT III and/or to a neutralization of heparin due to thromboplastin.

A mathematical model was used to analyze kinetic parameters of the formation of factor $\mathrm{Xa}$, and also of its velocity of inhibition. The curves of factor Xa generation obtained after the addition of TF/VII(a) to plasma were fitted to the model. The effect of heparin(s) on the half-life of the activator [TF/VIIa] was studied. We observed that heparins with MW $\geq 5,400$ containing AT III high affinity material are able to decrease the half-life time of [TF/VIIa]. We demonstrated that this effect is due to a potentiation of the anti [TF/VIIa] activity of the Tissue Factor Pathway Inhibitor (TFPI). Our findings in human plasma are partly in disagreement with those of Broze et al (9). These investigators showed that, in a purified 
system, the presence of AT III-heparin impedes the formation of the quaternary complex [TFPI/TF/VIIa/Xa], that is necessary for the inhibition of TF/VIIa. The results from this chapter indicate that the activity of (LMW)heparins is not limited to their AT III dependent activity. However, to what extent the in vivo inhibition of TF/VIIa, as well as the inhibition of factor Xa by TFPI are important, remains to be established.

From chapters 2 and 3 we can conclude that a minimal chainlenght; as well as AT III-HAM are of crucial importance for the inhibition of both, thrombin generation and factor Xa generation. Also, the presence of such heparin structures might stimulate the interaction of factor Xa with other inhibitors (i.e: TFPI).

From the literature it is known that the antithrombotic activity of heparin derivatives remains present in Low Molecular Weigth Heparins (LMWH). Some experiments suggested that LMWH might induce less bleeding than UH (10-12). Later research did not confirm this property of LMWH $(13,14)$. Until now, no laboratory test has been found to be correlated to the occurence of bleeding (13-17). It was also observed that LMWH's hardly influences the classic tests used for monitoring heparin levels, except for anti-factor Xa tests $(11,1.5,18-20)$. Until now, the (antiXa) activity of LMWH is the test most frequently used to monitor the effect of s.c. LMWH. The disadvantage of "anti-Xa" tests, is that they evaluate total HAM only, i.e. the presence of structures with both ACLM and BCLM. As we have seen in chapter 2, ACLM and BCLM have quite different effects on the overall coagulation. We therefore studied the effect of subcutaneously injected heparin in terms of the concentration of these species, and their effect on clotting parameters.

In chapter 4 we propose an analytical scheme to measure the active circulating heparin. To this aim we first determined the specific activities (anti-factor Xa and antithrombin) of the active species HAM and ACLM of each (LMW) heparin (in min $^{-1}$. $\mu \mathrm{gml} . \mu \mathrm{M}$ AT III). We defined a Standard Independent Unit (SIU), as that amount of heparin that, when present in a plasma containing $1 \mu \mathrm{M}$ AT III increases the pseudo-first order decay constant of a serine protease (thrombin or factor Xa) by $1 \mathrm{~min}^{-1}$. From the levels of SIU, and knowing the specific activities of the heparins it is possible to calculate the circulating concentrations of 1) HAM; 2) ACLM; 3) BCLM. In chapter 5 we measured the plasma levels of active circulating heparin in 12 healthy volunteers that received UFH (5000 IU), and enoxaparin (40 mg, and $1 \mathrm{mg} / \mathrm{kg}$ bw). Our results showed that a) LMWH causes higher levels of HAM and ACLM than UFH does; b) LMWH causes BCLM to appear in circulation, while UFH does not. The activity of UFH is only due to ACLM as can be expected, because it contains no BCLM. 
With respect of the dose injected, the percentage of recovery of UFH is very low (4-10\%). This might be attributed to the molecular sieve effect induced by the subcutaneous barrier. In contrast, enoxaparin has a lower threshold than UFH to reach the vascular stream, and a recovery of $\sim 50$ $\%$ of its HAM can be obtained.

The apparent half-life of elimination of ACLM was independent of the source or injected amount of ACLM, and was $2.24 \pm 0.18 \mathrm{~h}$. This is in contrast with previous reports in which the half-life of UFH was reported to be $1 \mathrm{~h} \mathrm{(21)}$. It is possible that the half-life time of subcutaneously administered heparin follows the elimination pattern of low doses of i.v. heparin, showing a prolonged survival, or that the half-life time measured is influenced by continuous release from the injection site.

BCLM is not found to any appreciable extent after the injection of UFH. A large, persistent and dose dependent concentration are found after the injection of enoxaparin. Its half-life of elimination was determined as $5.61 \pm 0.36 \mathrm{~h}$. This again is higher than the values from the literature, probably due to the same reasons cited above.

It has been previously described that the anti-factor $\mathrm{Xa}$ activity of LMWH persists in circulation longer than that of UFH. Such a constatation is now readily explained by the different elimination pattern of the two molecular species present in LMWH. Until now, this observation was masked because of the fact that ACLM shows both antithrombin and antifactor $\mathrm{Xa}$ activities.

In spite of the fact that the activity levels (in SIU) indicate that the inhibition of thrombin is higher than that of factor $\mathrm{Xa}$, we observed that the inhibition of the generation of thrombin and of Xa did not differ. An explanation for this finding can be obtained from chapter 3 . The activator of coagulation in both tests was thromboplastin. In addition to the AT III dependent inhibition of the proteases, a decrease of their generation might be also due to either an increased anti-[TF/VIIa] activity of the TFPI in the presence of (LMW)heparins, as we have shown in chapter 3, or/and to higher circulating levels of TFPI induced after the injection of (LMW)heparins. Indeed, studies by Lindahl et al (22) showed the increase of TFPI levels after heparin injection. In addition, very recently Novotny (23) et al identified a heparin releasable pool of TFPI.

Several publications $(2,24,25)$ showed that the anti-factor Xa activity of heparins is partly neutralized by PF4 at concentrations that completely neutralize antithrombin activity. Also, a minimal chainlenght is necessary for the interactions with neutralizing proteins and heparin $(2,24,25)$. In chapter 6 we investigated in 12 healthy volunteers the effect of subcutaneously injected unfractionated heparin and enoxaparin on the $e x$ vivo generation of thrombin in platelet rich plasma (PRP). We observed 
that only enoxaparin is able to inhibit the generation of thrombin in PRP, and in a dose-dependent fashion. The AT III- dependent decay constant of thrombin in serum rich in PF4, obtained from PRP recalcified in the presence of thromboplastin, remained invariable before or after the (LMW)heparin injection. In contrast, we showed that the decay constant of factor Xa, in serum obtained under the same conditions, increased with respect of the control sample, but only if enoxaparin was present. We explain this finding by the presence of BCLM only occuring after the injection of enoxaparin. The results indicate that the activity of a heparin in circulation will be governed by a compromise between its permeability to the subcutaneous barrier, its potential capacity to catalyze thrombin- and factor Xa inhibition, and its residual activity after neutralization by PF4 at the moment and site in which platelet release reaction (i.e. the thrombus formation) is occuring.

On a weight basis, ACLM is much more effective than BCLM. If levels of the former species can be maintained that induce the inhibition of the first thrombin traces, so that they prevent platelet activation beyond a small area of high trigger intensity, i.e. in a wound or just around a thrombogenic focus, then we will have an almost ideal preventive drug. $B C L M$, in relatively high concentrations retains its activity even around a growing thrombus, and therefore would be a suitable candidate for a therapeutic drug.

\section{References}

1) Andersson, L.O.; Barrowcliffe, T.W.; Holmer, E.; Johnson, E.A.; Sodenstrom, G.: Molecular weight dependency of the heparin potentiated inhibition of thrombin and activated factor X. Effect of heparin neutralization in plasma. Thromb. Res, 15, 531. $\underline{541,1979}$.

2) Lane, D.A.; Denton, J.; Flynn, A.; Thunberg, L.; Lindahl, U.: Anticoagulant activites of heparin oligosaccharides and their neutralization by platelet factor 4 . Biochem. J.; 218: 725-732; 1984 .

3) Choay,J.; Lormeau, J.C.; Sinay, P.; Casu, B.; Gatti, G.: Structure-activity relationship in heparin: A synthetic pentasaccharide with high affinity for antithrombin III and eliciting high anti-factor Xa activity. Biochem. Biophys. Res. Comm. 116:492-499, 1983.

4) Bara, L.; Mardiguian, J.; Samama, M.: In vitro effect on Heptest of low molecular weight beparin fractions and preparations with various anti-IIa and anti-Xa activities. Thromb. Res. 57: 585-592; 1990. 
5) Hemker, H.C: The mode of action of heparin in plasma. Thrombosis and Haemostasis; pp 17-36; 1987. Ed: Verstraete, M.; Vermylen, J; Lijnen, H.R. and Arnout, J.: I.S.T.H. and Leuven University Press.

6) Béguin, $S$; Lindhout, $T$.; Hemker, $H$. C.: The mode of action of heparin in plasma. Thromb. Haemostas.; 60: 457-462; 1988.

7) Barrowcliffe, T.W.; Shirle Le, Y.: The effect of calcium chloride on anti-Xa activity of heparin and its molecular weight fractions. Thrombos. Haemostas. 62 (3): 95-954: 1989 .

8) Schoen, P.; Lindhout. T.; Willems, G.; Hemker, H.C.: Antithrombin III-dependent anti-prothrombinase activity of heparin and heparin fragments. J. Biol. Chem. 264: 10002-10007; 1989 .

9) Broze, G.J.; Warren, L.A.; Novotny, W.F; Higuchi, D.A.; Girard, J.J.; Miletich, J.P.: The lipoprotein-associated coagulation inhibitor that inhibits the factor VIItissue factor complex also inhibits factor Xa: Insight into its possible mechanism of action. Blood 71: 335-343; 1988 .

10) Cade, J.F.; Buchanan, M.R.; Boneu, B.; Ockelford, P.A.; Carter ${ }_{*}$ C.J.; Cerskus, A.L.; Hirsh, J.: A comparison of the antithrombotic and hemorrhagic effects of low molecular weight heparin fractions. Thromb. Res. 35, 613-625; 1984.

11) Thomas, D.P.; Merton, R.E.; Lewis, W.E.; Barrowcliffe, T.W.: Studies in man and experimental animals of a low molecular weight heparin fraction. Thromb. Haemost. 45; 214-218; 1981.

12) Andriuoli, G.; Mastacchi, R.; Barbanti, M.; Sarret, M.: Comparison of the antithrombotic and haemorrhagic effects of heparin and a new low molecular weight heparin in rats. Haemostasis $15 ; 324-330 ; 1985$.

13) Pangrazzi, J.; Abbadini, M.; Zameta, M.; Naggi, A.; Torri, G.; Casu, B.; Donati, M.B.: Antithrombotic and bleeding effects of a low molecular weight heparin fraction. Biochem. Pharmacol. 34, 3305-3308; 1985.

14) Diness, X,; Nielson, J.I; Pedersen, P.C.; Wolfbrandt, K.H.; Ostergaard, P.B.: A comparison of the antithrombotic and hemorrhagic effects of low molecular weight heparin (PHN-1) and conventional heparin. Thromb. Haemostas. 55: 410-414, 1986.

15) Bara, L.,; Combe-Tamzali, S.; Conard, J.; Horellou, M.H.; Samama, M.: Modifications biologiques induites par trois héparines de bas poids moléculaire: PK 10169, Kabi 2165 et CY 216, comparées à l'héparine non fractionnée, injectées par voie sous-coutanée chez le volontaire sain, et en chirurgie générale chez le sujet âgé en médecine. J. Mal. Vasc.; 12: 78-84; 1987.

16) Holmer, E.; Mattsson, C.; Nilsson, S.: Anticoagulant and antithrombotic effects of heparin and low molecular weight heparin fragments in rabbits. Thromb. Res. 25: 
475-485: 1982.

17) Mätzsch, T.; Bergqvist, D.; Fredin, H.; Hedner, U.; Ostergaard, P.: Influence of a low molecular weight heparin on the inhibition of factor Xa and thrombin in hip surgery. Thromb. Res. 56: 559-564; 1989.

18) Johnson, E.A; Kirkwood, T.B.L.; Stirling, Y.; Perez-Requejo, J.L.; Ingram, G.I.C.; Bangham, D.R.; Brozovic, M.: Four heparin prepartions: anti-Xa potentiating effect of heparin after subcutaneous injection. Thromb. Haemostasis 35: 586-591: 1976.

19) Yin, E.T.; Wessler, S.; Stoll, P.J.: Biological properties of the naturally occuring inhibitor to activated factor X. J. Biol. Chem. 246*3703-3711; 1971.

20) Teien, A.N. Lie, M.: Evaluation of amidolytic heparin assay method. Increased sensitivity by adding purified antithrombin III. Thromb. Res. 10: 399-410; 1977.

21) Swart, de, C.A.M.; Nijmeyer, B.; Andersson, L. Holmer, E.; Verschoor, L.; Bouma, B.N.; Sixma, J.J.: Elimination of high affinity heparin fractions and their anticoagulant and lipase activity. Blood 6; 4; 836-842; 1984.

22) Lindahl, A.K.; Abildgaard, U.; Larsen M.L.; Aamodt L.M.; Nordfang, O.; Beck, T.: Extrinsic Pathway Inhibitor (EPI) and the post-heparin anticoagulant effect in tissue thromboplastin induced coagulation. Thromb. Res. Suppl 14; 39-48; 1991.

23) Novotny, W.F.; Palmier, M.; Wun T.C.; Broze, G.J.; Miletich, J.P. Purification and properties of heparin-releasable lipoprotein-associated coagulation inhibitor. Blood 78 (2): 394-400; 1991 .

24) Denton, J.; Lane, D.J.; Thunberg, L.; Slater, A.M.; Lindhal. U.: Binding of platelet factor 4 to heparin oligosaccharides. Biochem. J.: 209: 455-460; 1983 .

25) Michalski, R.; Lane, D.A.; Pepper, D.S.; Kakkar, V.V.: Neutralization of heparin in plasma by platelet factor 4 and protamine sulphate. British. J of Haematol. 38 : 561-561; 1978. 



\section{SUMMARY AND CONCLUSIONS}

Chapter 1 gives a review on heparins as well as an overview of present insights in the mechanism of blood coagulation.

In Chapter 2 we investigate how the anticoagulant activity is partitioned among different molecular weight fractions of a low molecular weight heparin (enoxaparin). We show that the percentage of material with high affinity (HAM) to antithrombin III (AT III) of heparin fractions increases with increasing molecular weight. Much of the variation of the anticoagulant activity with molecular weight that has been reported for heparins can be shown to be essentially due to variations of HAM content. We define within the HAM fraction two essentially different types of material: material above the critical chainlength of 18 saccharides -ACLM$(\mathrm{MW} \geq 5,400)$, that has both antithrombin and anti-factor Xa activity, and material below that chainlength (BCLM), that has only anti-factor Xa activity. We demonstrate that the specific catalytic activity for the inactivation of thrombin does not vary significantly between the fractions when expressed in terms of ACLM. Also the potency to inhibit prothrombin conversion does not vary significantly between the fractions when expressed in terms of HAM. In-vitro, ACLM is a much more active material than BCLM is. The main active species of enoxaparin must be thought to have a chainlength between 20 and 30 saccharide units.

In Chapter 3 we observed that in a system containing isolated tissue factor-F. VIIa complex (TF/VIIa), AT III, heparin and factor X, the generation of factor Xa is not impaired. We conclude that AT III-heparin does not inhibit factor VIIa. In this system, the inhibition of factor Xa generation is only due to the increase of the AT III dependent pseudo-first order decay constant of factor Xa. In plasma, when a simple factor $X$ activator, as the activating enzyme from Russells Viper venom (RVV-X) is used, factor Xa generation is inhibited also exclusivelly by the AT III dependent inactivation of factor $\mathrm{Xa}$. A mathematical model was used to analyze kinetic parameters of the formation of factor $\mathrm{Xa}$, and also of its velocity of inhibition. The curves of factor Xa generation obtained after the addition of TF/VII(a) to plasma were fitted to the model. The results indicated that some of the heparins studied impaired the generation of factor Xa in TF/VIIa activated plasma: Unfractionated heparin (UFH) and enoxaparin decrease the half-life of TF/VII(a). We demonstrated that this effect of UFH and enoxaparin on the half-life time of TF/VIIa his effect is due to a potentiation of the anti [TF/VIIa] activity of the Tissue Factor 
Pathway Inhibitor (TFPI). In contrast, the effect of the synthetic AT III binding pentasaccharide (PS) on factor Xa generation is limited to factor $X a$ scavenging. In agreement with the results of chapter two, the potency of the heparins to inhibit factor $\mathrm{Xa}$ generation does not vary significantly between the fractions when expressed in terms of ACLM. We also demonstrate that the feedback activation of factor VII by factor Xa is not inhibited. Because the pentasaccharide inhibits factor $\mathrm{Xa}$ generation exclusively by its anti-factor $\mathrm{Xa}$ activity, and possess no activity on the activator of factor $X$, we concluded that the major effect of heparins on factor $\mathrm{Xa}$ generation initiated by $\mathrm{TF}$ must therefore be attributed to the inactivation of factor $\mathrm{Xa}$.

In Chapter 4 we propose a way to determine the levels of active heparin species on the basis of their effect on the decay of thrombin and factor Xa. We define the Standard-Independent Unit of heparin as that amount that increases the decay constant of thrombin or factor Xa by one inverse minute. Heparin activity can be expressed in thrombin based SIUs or in factor Xa based SIUs. In the first case the SIU divided by the specific activity of the ACLM fraction will give the level of circulating ACLM. In the second case the activity level in anti-factor $\mathrm{Xa}$ units divided by the specific anti-factor Xa activity of the HAM fraction will give the level of HAM. The level of BCLM can be simply obtained by substraction. The feasibility of this approach is demonstrated in a preliminary studly carried out with three types of heparin, each administered once to one healthy volunteer.

In Chapter 5 we have applied the procedure proposed in the previous chapter to one dose of unfractionated heparin and two different doses of a LMWH administered subcutaneously to 12 volunteers. The material injected was a) classical unfractionated heparin $5000 \mathrm{U}$; b) enoxaparin 40 $\mathrm{mg}$, and c) enoxaparin $1 \mathrm{mg}$ per $\mathrm{kg}$ body weight.

Enoxaparin catalyzed more efficiently than UFH the ex vivo pseudo first order decay constant of both factor Xa and thrombin.

The HAM fraction of UFH disappears from circulation with a half life time of $3.04 \pm 0.41 \mathrm{~h}$; that of LMWH with $5.61 \pm 0.36 \mathrm{~h}$. The BCLM fraction did not appear in UFH; in LMWH its half life time was practically identical to that of total HAM. The ACLM of the two heparins was cleared from circulation with an apparent half-life of $2.24 \pm 0.18 \mathrm{~h}$. It was not dependent on the heparin preparation or dose.

Unfractionated heparin was less effective than enoxaparin with respect to the inhibition of thrombin, prothrombinase and factor $\mathrm{Xa}$ generation.

The inhibition of factor Xa generation, and the increase of the AT III dependent decay constant of factor Xa mediated by UFH persisted as long as the inhibition of thrombin. It must be attributed to the ACL 
heparin fraction. The effect of enoxaparin on factor $\mathrm{Xa}$ generation and factor Xa decay increased with increasing doses, and persisted somewhat longer in circulation than the effect on both thrombin generation and thrombin decay constant. The longer persistence of this activity compared to UFH was due to the circulating levels of BCLM, that was eliminated slower than ACLM.

There is a perfect linear correlation between inhibition of factor Xa generation and of thrombin generation. However, there is not a linear relationship between prothrombinase and factor $\mathrm{Xa}$ generation because the relation between inhibition of the factor $\mathrm{Xa}$ generation and the inhibition of prothrombin conversion is hyperbolical, as should be expected from experiments carried out in vitro.

We conclude that both $\mathrm{ACL}$ and $\mathrm{BCL}$ material of enoxaparin cooperate in the overall inhibition of factor IIa and factor Xa generation.

In Chapter 6, we demonstrate that ex vivo, unfractionated heparin and enoxaparin are able to delay the onset of thrombin generation in platelet rich plasma. In addition, enoxaparin inhibits, dose dependently, the amount of thrombin generated whereas UFH does not.

In serum obtained after clotting heparin-containing platelet rich plasma with thromboplastin, no increase of antithrombin activity can be found with either heparin or enoxaparin. The anti-factor Xa activity of UFH was also completely neutralized. In contrast, the antifactor Xa activity of enoxaparin was only partly neutralized. This indicates that platelet factor 4 (PF4), the main heparin neutralizing protein released by activated platelets, completely neutralizes ACLM but not BCLM. We conclude that the increase of the lag phase is mainly due to ACLM, while the inhibition of thrombin generation in platelet rich plasma must be attributed to BCLM, i.e.to an anti-factor Xa effect. 


\section{RESUMEN Y CONCLUSIONES}

El Capitulo 1 consta de una revisión bibliográfica sobre heparinas. Se comentan además los principales conceptos actuales sobre el mecanismo de la coagulación.

En el Capítulo 2 investigamos cómo se distribuye la actividad anticoagulante a lo largo de una serie de fracciones de una heparina de bajo peso molecular (HBPM, enoxaparina). Se observa que el contenido en material con alta afinidad (HAM) a la antitrombina III (AT III) de las fracciones de heparina aumenta con el PM. Gran parte de las variaciones en la actividad específica de fracciones de heparina descritas en la literatura se deben fundamentalmente a variaciones de su contenido en HAM. Dentro del HAM se distinguen basicamente dos clases: material superior a la longitud de cadena crítica de 18 monosacáridos (ó $5.400 \mathrm{D}$ ) (ACLM) y material inferior a la longitud de cadena crítica de 18 monosacáridos (BCLM). ACLM posee tanto actividad antitrombina como anti-factor Xa. BCLM posee exclusivamente actividad anti-factor Xa. Demostramos que las variaciones de la actividad específica de inactivación de trombina tienden a ser despreciables cuando dichas actividades específcas se expresan en términos de ACLM. La capacidad de las fracciones para inhibir la conversión de la protrombina varía minimamente cuando se expresa en términos de HAM. Se observa que in vitro, el ACLM es mucho más activo que el BCLM.

En el Capitulo 3, demostramos que en un sistema purificado constituído por factor tisular/factor VII(a) (FT/VIIa), AT III, heparina y factor X, la generación de factor Xa no es afectada por [AT III-heparina]. Esto significa que la serino-proteasa factor VIIa no es inhibida por el complejo [AT III-heparina]. La inhibición de la generación de factor Xa en tal sistema es debida exclusivamente al aumento de la constante de pseudo primer orden de decaimiento (AT III-dependiente) del factor Xa. En plasma humano, cuando se emplea un activador simple del factor Xa tal como es el veneno de Víbora Russel (VVR) también se observa que la inhibición de la generación del factor $\mathrm{Xa}$ se debe exclusivamente a la inactivación AT III dependiente del factor Xa. Utilizando simulaciones matemáticas hemos analizado parámetros cinéticos de la formación de factor Xa y de su velocidad de inactivación a partir de las curvas experimentales de generación de factor Xa. El modelo matématico mencionado fue utilizado para estudiar la generación de factor $\mathrm{Xa}$ en plasma activado por FT/VIIa. El análisis de las curvas de generación de 
factor Xa demostró que, a diferencia de lo observado en sistema purifícado o utilizando plasma activado por VVR, la heparina no fraccionada (HNF) y la enoxaparina disminuyen el tiempo de vida media del complejo FT/VIra. Se observó que esta propiedad de las heparinas está mediada por el inhibidor de la vía del factor tisular (IVFT). Por el contrario, este fenómeno no se manifestó cuando se estudió el efecto del pentasacárido sintético. Se constató que la actividad inhibitoria de tal pentasacárido se limita a la inhibición del factor Xa.

Acorde con los resultados del capítulo 2 , se observó que la potencia de las heparinas para inhibir la generación del factor $\mathrm{Xa}$ no varía significativamente cuando su actividad se expresa en términos de ACLM. Demostramos la alta eficiencia de la reacción de retroactivación positiva del factor Xa sobre la activación del factor VIla. Esta reacción de retroalimentación no es inhibida por AT III(heparina). Dado que el pentasacárido inhibe eficazmente la generación de factor Xa por medio de la inhibición directa del factor $\mathrm{Xa}$, y no afecta su activador, concluímos que durante la generación de factor Xa mediada por TF/VIIa, el efecto más importante de las heparinas es la inactivación del factor Xa.

En el capítulo 4 hemos propuesto un modo de determinación de los niveles circulantes de heparina activa, basado en la constante de decaimiento de la trombina y dell factor Xa. Definimos la Unidad Independiente de Standard (SIU) como aquella cantidad de heparina que aumenta la constante de pseudo primer orden de decaimiento de la trombina o del factor $\mathrm{Xa}$ en un $\mathrm{min}^{-1}$. Las actividades de heparina pueden entonces ser expresadas en SIU basadas en la inhibición de la trombina o en SIU basadas en la inhibición del factor Xa. En el primer caso, SIU dividido por la actividad específica de la fracción de ACLM permitirá la obtención de los niveles circulantes de ACLM. En el segundo caso, el nivel de unidades anti-factor Xa dividido por la actividad específica anti-Xa dará la concentración de HAM. La viabilidad de tal marcha analítica fue demostrada por medio de un estudio preliminar en el que se administraron tres heparinas a tres voluntarios sanos respectivamente.

En el capítulo 5 se aplicó el procedimiento previamente descrito al estudio de la farmacodinámica de una dosis de heparina no fraccionada (5.000 U), y dos dosis de la HBPM enoxaparina $(40 \mathrm{mg}$, y $1 \mathrm{mg} / \mathrm{kg}$ de peso corporal) inyectadas por vía subcutánea a 12 voluntarios. El estudio fue doble ciego, y los doce voluntarios recibieron ambas heparinas con un intervalo de siete días entre cada una de ellas. Se observó que ex vivo, enoxaparina cataliza más eficazmente que $\mathbb{H N F}$ a la constante de decaimiento de ambos, trombina y factor Xa. La fracción de HAM de la heparina no fraccionada desaparece de la circulación con un tiempo de vida media de $3,04 \pm 0,41$ hs. El HAM de la enoxaparina lo hace con un tiempo de vida media de $5,61 \pm 0,36$ hs. El BCLM de la HNF no apareció en circulación. En el caso de enoxaparina, el tiempo de vida media del BCLM fue cercano al del HAM total. El ACLM de ambas heparinas fue 
eliminado de la circulación con un tiempo de vida media aparente de 2,24 \pm 0.18 hs. El tiempo de vida media de eliminación fue independiente del tipo de heparina y de la dosis. Se observó que ex vivo la HNF es menos eficaz que la enoxaparina respecto de la inhibición de la generación de trombina, protrombinasa y factor Xa. La inhibición de la generación del factor $\mathrm{Xa}, \mathrm{y}$ el aumento de la constante de decaimiento del factor $\mathrm{Xa}$ mediado por HNF persistió tanto como la inhibición de la trombina. Se atribuye este efecto a la fracción ACLM. El efecto de enoxaparina sobre la generación del factor $\mathrm{Xa}$ y sobre el decaimiento del factor Xa aumentó al aumentar la dosis, y persistió algo más que el efecto sobre la generación de trombina y el decamiento de trombina. La mayor duración del efecto de enoxaparina respecto de $\mathrm{HNF}$ es debida a la presencia de estructuras de tipo BCLM (ausentes en HNF) que se eliminan más lentamente que las de tipo ACLM. Existe una perfecta correlación lineal entre la inhibición de la generación del factor Xa y de la generación de trombina. No obstante ello, no existe relación lineal entre la inhibición de la generación de factor Xa y de protrombinasa, sino hiperbólica, tal como se observa in vitro.

Concluímos que ambos, ACLM y BCLM de enoxaparina tienen efecto cooperativo en la inhibición ex vivo de la generación de trombina y de factor Xa.

En el Capitulo 6 demostramos que la HNF y la enoxaparina son capaces de prolongar ex vivo la fase de latencia que precede a la generación de trombina en plasma rico en plaquetas (PRP). Se observó que la enoxaparina tiene un efecto adicional, ya que inhibe la generación de trombina de un modo dosis-dependiente, mientras que HNF no. En suero obtenido luego de la adición de tromboplastina y iones $\mathrm{Ca}^{++}$al PRP, no se observa inhibición alguna de la actividad anti-trombina, ya sea luego de la inyección de HNF o de enoxaparina. Se observó también que la actividad anti-factor $\mathrm{Xa}$ de la HNF es neutralizada completamente. Por el contrario, el decaimiento de la actividad del factor $\mathrm{Xa}$ inducido luego de la inyección de enoxaparina se mostró solo parcialmente neutralizado. Esto demuestra que el ACLM es completamente neutralizado por el factor plaquetario 4 (PF4), principal proteína neutralizante de heparina liberada por las plaquetas activadas, mientras que el BCLM no lo es. Concluímos que la prolongación de la fase de latencia es debida al ACLM, o sea a las estructuras con actividad antitrombina $\mathrm{y}$ anti-factor $\mathrm{Xa}$, mientras que la inhibición del pico de generación de trombina en plasma rico en plaquetas es debida al BCLM, o sea a las estructuras de heparina que poseen exclusivamente actividad anti-factor Xa. 


\section{Samenvatting EN Conclusies}

Hoofdstuk 1 behandelt de eigenschappen van heparines en geeft een overzicht van onze huidige kennis omtrent het mechanisme van de bloedstolling.

Hoofdstuk 2 beschrijft ons onderzoek naar de verdeling van de antistollende activiteiten van een laag moleculair gewicht heparine (enoxaparine) over de fracties met verschillend molecuulgewicht waaruit het enoxaparine is samengesteld. We toonden aan dat het percentage materiaal met hoge affiniteit voor antithrombin III (HAM) toeneemt met het gemiddelde molecuulgewicht van zo'n fractie. De antistollende activiteit van de verschillende heparines wordt danook bepaald door het HAM-gehalte van het heparine preparaat. Binnen de zogenoemde HAM fractie konden twee subfracties geidentificeerd worden met verschillende antistollende eigenschappen: materiaal met zowel anti-thrombine als anti-factor $\mathrm{Xa}$ activiteit en materiaal met enkel anti-factor Xa activiteit. We konden bevestigen dat heparine-ketens met hoge affiniteit voor AT III en een molecuulgewicht hoger dan 5400 (ACLM) de inactivering van factor $\mathrm{Xa}$ en die van thrombine stimuleren, terwijl heparine ketens met een molecuulgewicht lager dan 5400 (BCLM) enkel een anti-factor Xa activiteit hebben. We lieten zien dat, mits berekend op basis van ACLM-gehalte, alle heparine(fracties) gelijke specifieke anti-thrombine activiteiten hebben. Ten aanzien van het remmende effect van een heparine op de activering van prothrombine kon vastgesteld worden dat de ACLM fractie een veel grotere bijdrage levert dan de BCLM fractie.

Hoofdstuk 3 behandelt de effecten van heparine op de factor $\mathrm{X}$ activering door een complex van thromboplastine en factor VIIla. In een buffer systeem met gezuiverde factoren werd geen effect gezien van antithrombine III en heparine op de factor $\mathrm{X}$ activering. De serine-protease factor VIIa wordt dus niet geinactiveerd door antithrombin III. Het gevormde factor Xa daarentegen wordt onder invloed van heparine versneld geinactiveerd door ATIII. Met een relatief eenvoudlig wiskundig model was het mogelijk de factor Xa generatiecurven te beschrijven. Via computersimulaties konden we zo de kinetische parameters van de factor $\mathrm{Xa}$ vorming en de snelheidsconstanten van de inactivering van factor $\mathrm{Xa}$ simultaan uit de factor Xa generatiecurven berekend worden. Het model werd vervolgens uitgebreid voor de situatie in plasma waar de thromboplastine-factor VIIa activiteit progresief geremd wordt door de plasma remmer Tissue Factor Pathway Inhibitor (TFPI). Analyse van plasma factor $\mathrm{Xa}$ generatiecurven in aanwezigheid van heparine toonde aan 
dat niet-gefractioneerd heparine (UFH) en een laag moleculairgewicht heparine, enoxaparine, de halfwaarde-tijd van de factor $\mathrm{X}$ activerende activiteit van het thromboplastine-factor VIIa complex dosis-afhankelijk verkortte. Het synthetische pentasaccharide heparine had geen effect. In plasma geactiveerd met de factor $X$ activator uit het gif van de Vipera Russelli, noch in aanwezigheid van antilichamen gericht tegen TFPI werd een dergelijke verkorting van de halfwaarde-tijd gevonden. De versnelling van de inactivering van het in plasma gevormde factor Xa door UFH en enoxaparine is echter van veel meer betekenis voor de regulatie van factor $X a$ generatie dan hun effect op de inactivering van het thromboplastine-factor VIIa complex.

In Hoofdstuk 4 stellen we voor het gehalte aan actief heparine materiaal in plasma vast te stellen op basis van hun effect op de inactivering van thrombine en factor Xa. Hiertoe definieerden we de "Standaard-Onafhankelijke Unit" (SIU): die gewichtshoeveelheid heparine die de pseudo eerste orde snelheidsconstante van inactivering van factor $\mathrm{Xa}$ of thrombine in plasma met 1 reciproke minuut doet toenemen. Heparine activiteit kan dus uitgedrukt worden in thrombine SIU's of in factor Xa SIU's. Door de thrombine SIU van een monster te delen door de specifieke activiteit van het ACLM kan de hoeveelheid ACLM in het monster gevonden worden. Op een zelfde manier kan uit de factor $\mathrm{Xa}$ SIU de hoeveelheid HAM in een monster berekend worden. De hoeveelheid BCLM kan dan berekend worden uit het verschil tussen HAM en ACLM. De toepasbaarheid van deze methode werd onderzocht in een kleine studie waarin een vrijwilleger drie verschillende heparine preparaten subcutaan kreeg toegediend.

In Hoofdstuk 5 beschrijven we de toepassing van de hierboven aangegeven methode in een studie met 12 vrijwilligers die allen afwisselend een eenmalige dosis UFH van 5000 units, $40 \mathrm{mg}$ enoxaparine en $1 \mathrm{mg}$ enoxaparine per $\mathrm{kg}$ lichaamsgewicht subcutaan kregen toegediend. In het laatste geval werden de hoogste ex vivo thrombine en factor Xa SIU activiteiten gemeten. De HAM fractie van het UFH verdween uit de circulatie met een halfwaarde-tijd van $3.04 \pm 0.41$ uur en die van enoxaparine met een $t \frac{1 / 2}{\text { van }} 5.61 \pm 0.36$ uur. De BCLM fractie van UFH werd niet aangetoond. De $t^{1 / 2}$ van het BCLM in enoxaparine was gelijk aan die van het HAM. De ACLM fracties van UFH en enoxaparin werden geklaard met een schijnbare halfwaarde-tijd van $2.24 \pm 0.18$ uur.

De op de verschillende tijden na toediening van heparine verkregen ex vivo monster werden ook onderzocht op de vorming van factor $\mathrm{Xa}$, prothrombinase en thrombine. UFH bleek minder effectief in de remming van thrombine-, factor Xa- en prothrombinase-vorming dan het enoxaparine.

De effecten van subcutaan toegediend UFH op de ex vivo factor Xa 
generatie, factor Xa- en thrombine inactivering hielden allen evenlang aan en zijn toe te kennen aan de ACLM fractie van UFH. De effecten van subcutaan toegediend enoxaparine op factor Xa generatie en inactivering namen toe met toenemende dosis en hielden langer aan dan het effect op thrombine vorming en inactivering. In vergelijking met UFH hield het effect op factor Xa vorming en inactivering langer aan. We nemen aan dat dit verschil tussen UFH en enoxaparine voortkomt uit de aanwezigheid van BCLM in laatst genoemde.

Ex vivo thrombine- en factor $\mathrm{Xa}$ generatie werden onder alle omstandigheden in gelijke mate geremd door het circulerende heparine. Echter, remming van de prothrombinase-vorming bleef ver achter bij die van de factor $\mathrm{Xa}$ vorming.

We concluderen dat het $\mathrm{ACL}$ en $\mathrm{BCL}$ materiaal van enoxaparine samenwerken in de remming van thrombine en factor Xa vorming.

In Hoofdstuk 6 laten we zien dat UFH en enoxaparin in staat zijn de ex vivo thrombinevorming in plaatjesrijk plasma te vertragen; daarnaast is enkel het enoxaparine in staat ook de thrombine-productie te beperken.

$\mathrm{Na}$ UFH toediening bevatte het serum verkregen uit gestold gehepariniseerd plaatjesrijk plasma noch anti-thrombine noch anti-factor $\mathrm{Xa}$ activiteit. Ook kon er geen anti-thrombine activiteit aangetoond worden in enoxaparine-bevattend serum, terwijl de anti-factor $\mathrm{Xa}$ activiteit gedeeltelijk teruggevonden werd. Deze resultaten geven aan dat plaatjes factor 4 (PF4), het belangrijkste heparine-neutraliserende eiwit dat vrijkomt tijdens de activering van bluedplaatjes, het ACLM maar niet het BCLM neutraliseert. Het effect van een heparine op het vertragen van het tijdstip van thrombinevorming in plaatiesrijk plasma is dus duidelijk het gevolg van de aanwezigheid van ACLM, terwijl het effect op de uiteindelijke thrombine-productie veroorzaakt wordt door het aanwezige BCLM en dus het gevolg is van het met BCLM geassocieerde anti-factor Xa activiteit. 



\section{ACKNOWLEDGMENTS}

The present investigation was carried out at the Laboratory of Biochemistry of the University of Limburg. Excellent facilities and working conditions were provided.

The author was granted a fellowship by Rhone-Poulenc Rorer for the preparation of this thesis. Without their financial support this work would have not been possible.

I wish to thank:

Prof. Dr. H. Coen Hemker, my promotor, for inviting me to prepare this thesis in his Department. For his advice and encouragement throughout these years of work I am indebted.

Prof. Dr. Michel Samama, for his encouragements and never failing belief in my research throughout the years. For his advice and friendship I am indebted.

Dr. Suzette Béguin, my co-promotor, for her daily direction and help during the preparation of this thesis. Her expertise in the field of blood coagulation was the inspiring source of our stimulating discussions.

Dr. Theo Lindhout, for his encouragement and enthusiastic support during struggling moments. Throughout our inspired discussions, he knew how to transmit his profound knowledge in the domain of biochemistry.

Dr. André Uzan, for his confidence in my research, his encouragement and support in the preparation of this thesis.

Dr. Jean Bouthier, for his believe in my research form its first steps. For his unconditional help and support I am thankful.

Mrs. Trees Camphuisen, Mariet Molenaar, and Gertie Wijckmans for their excellent secretarial work and assistance.

Han Kessels, for his help, stimulating discussions and friendship throughout these years.

Ron Blezer for his excellent and expert technical assistance.

Khaled Maroofi, Simone Wielders, Richard Knebel, Truus Jansen, Jo Fransen, and Paul Devilée for their sympathy and cooperation. 
My comrades from the Department of Biochemistry, for providing a friendly and positive scientific atmosphere.

My parents, for their invaluable support towards my decision to follow an academic degree.

My brothers, for their encouraging support.

My friends, for their positive advice and their support.

To my familly and friends: You all understood my frustration of neglecting you all during these years of hard work. May this work express how thankful I am for your support and understanding.

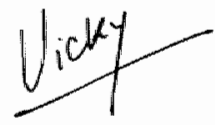




\section{CURRICULUM VITAE}

Vicky Bendetowicz was born in Córdoba, Argentina, the $7^{\text {th }}$ june 1961. In 1977 she obtained the highschool diploma at the Instituto Integral Israelita Gral. San Martín in Córdoba. In 1978 she was admitted to the Facultad de Ciencias Químicas, Universidad Nacional de Córdoba, Argentina. In 1984 she obtained the Acadlemic Title of Biochemist. In 1986 she received a fellowship from the Ministery of Health to study at the Facultad de Ciencias Exactas y Naturales, Universidad de Buenos Aires, under the supervision of Prof. Dr. Lucía Kordich. In 1987 she was admitted to prepare a Master's Degree in Life Sciences, specialization in Immunobiotechnology, Immunogenethics and Blood Transfusion at the Université Pierre et Marie Curie, Paris VT, France, under the supervision of Prof. Dr. Michel Samama, obtaining the M.Sc. in 1988. In 1989 she received a fellowship from Rhône-Poulenc Rorer to prepare the present $\mathrm{Ph} . \mathrm{D}$. thesis at the Departement of Biochemistry of the Rijksuniversiteit Limburg, under the supervision of Drs. Suzette Béguin and Theo Lindhout, and Prof. H.Coen Hemker. 